\title{
Use of Optical Fibers for Structural Health Monitoring of Aircraft Components
}

\author{
by \\ Prem Anand \\ A thesis submitted to
the Faculty of Graduate and Postdoctoral Affairs \\ in partial fulfilment of \\ the requirements for the degree of \\ Master of Applied Science \\ in \\ Aerospace Engineering \\ Ottawa-Carleton Institute for Mechanical and Aerospace Engineering \\ Department of Mechanical and Aerospace Engineering \\ Carleton University \\ Ottawa, Ontario, Canada \\ April 2017 \\ Copyright (C) \\ 2017 - Prem Anand
}


The undersigned recommend to

the Faculty of Graduate and Postdoctural Affairs

acceptance of the thesis

\title{
Use of Optical Fibers for Structural Health Monitoring of Aircraft Components
}

\author{
Submitted by Prem Anand \\ in partial fulfilment of the requirements for the degree of \\ Master of Applied Science
}

Professor Jeremy Laliberte, Supervisor

$\overline{\text { Professor Marcias Martinez, Co-Supervisor }}$

$\overline{\text { Dr. Ronald E. Miller, Department Chair }}$

Carleton University

2017 


\section{Abstract}

Structural Health Monitoring (SHM) systems for composites are being developed to improve the in-flight monitoring and safety of new aircraft structures. One of the emerging techniques for SHM which is becoming popular in the aircraft industry involves the use of optical fiber sensors due to their ease of integration, resistance to electromagnetic interference and low signal attenuation over long distances. This thesis describes a validated technique for optical fiber embedment and extraction of data from optical fiber data to measure strain.

In this research, a novel method to address ingress/egress points of optical fiber has been developed; a surface mounted component has been designed and manufactured using rapid prototyping for the protection of embedded optical fibers at the ingress/egress points. This single component can provide safety and integrity to optical fibers during manufacturing as well as cutting operation. The thesis also focuses on the study of mechanical strength of composites with embedded optical fibers. Composite panels were manufactured with integrated optical fibers using Vacuum Assisted Resin Transfer Molding. Tensile, flexural and impact tests were conducted on these coupons and their results were compared to identify any effects of the embedded fibers on the part performance. Finally, strain experienced by the material while it was in loading and unloading condition was calculated using integrated optical fiber sensors and the values were compared with extensometer data. 


\section{Acknowledgments}

I would like to thank my supervisor Professor Jeremy Laliberte for offering me this challenging and rewarding opportunity. His professionalism, guidance and support made it very easy for me to go through the process of graduate school. I would also like to thank my co-supervisor Professor Marcias Martinez for introducing me to the FBG based Structural Health Monitoring system.

My gratitude goes out to all the great people who helped me along the way. Especially I would like to thank Professor Jacques Albert for making his equipments and laboratory available to me for this research work. Many thanks are owed to Albane Laronche for her help in making Fiber Bragg Gratings. I am also grateful to Steve Truttman for assisting me with tensile tests. I am thankful to Alex Proctor, Ian Lloy and Kevin Sangster for helping me in the Machine Shop. Finally I would like to thank my family whose love and support has guided me throughout my life. 


\section{Table of Contents}

Abstract $\quad$ iii

Acknowledgments $\quad$ iv

Table of Contents $\quad$ v

List of Tables viii

List of Figures $\quad$ ix

List of Acronyms xiii

List of Symbols $\quad$ xiv

1 Introduction 1

1.1 Background ......................... . . . 2

1.1.1 Structural Health Monitoring . . . . . . . . . . . . . . 2

1.1.2 Importance of SHM . . . . . . . . . . . . . . . . 3

1.1.3 Non-Destructive Testing Methods ............. . 4

1.2 Optical Fiber Sensors for Structural Health Monitoring . . . . . . . . 4

1.3 Challenges Associated with Optical Fibers . . . . . . . . . . . 6

1.4 Motivation and Scope of Research . . . . . . . . . . . . . 7

1.5 Organization of the Thesis . . . . . . . . . . . . . 8 
1.6 Research Contributions . . . . . . . . . . . . . . . . . . . 9

2 Literature Review $\quad 10$

2.1 Integration of Optical Fiber Sensors in Composites . . . . . . . . . . 10

2.2 Types of Optical Fiber Sensors . . . . . . . . . . . . . . . . . 11

2.2.1 Bragg Gratings . . . . . . . . . . . . . . . . . 12

2.2.2 Rayleigh Fibers . . . . . . . . . . . . . . . . . . 14

2.2.3 Fabry-Perot Sensors . . . . . . . . . . . . . . . 15

2.3 Ingress and Egress Points: Challenges . . . . . . . . . . . . . . . 15

2.4 Mechanical Testing: with and without Integrated Optical Fibers . . . 20

2.5 SHM Applications . . . . . . . . . . . . . . . . . . . 22

3 Experimental Methodology 23

3.1 Composite Panels with Embedded Optical Fibers . . . . . . . . . . . 24

3.23 D Printed Fixture for Optical Fiber Ingress/Egress Points . . . . . . 30

3.2.1 First Design . . . . . . . . . . . . . . . . . . . 32

3.2.2 Second Design . . . . . . . . . . . . . . . . . . 33

3.2.3 Third Design . . . . . . . . . . . . . . . . 35

3.2.4 Fourth Design . . . . . . . . . . . . . . . . . . 36

3.2.5 Fifth Design . . . . . . . . . . . . . . . . 37

3.2.6 Production Testing Using VARTM . . . . . . . . . . . . . . . 39

3.3 Mechanical Testing . . . . . . . . . . . . . . . . . . . . . 47

3.3.1 Tensile Test Specimen Fabrication . . . . . . . . . . . . . . . 48

3.3.2 Tensile Test Procedure . . . . . . . . . . . . . . . . . . . . . 49

3.3.3 Compliance Calculation ............... 54

3.4 Impact Test . . . . . . . . . . . . . . . . . . . 56

3.4 .1 Specimen Fabrication . . . . . . . . . . . . 56

3.4 .2 Impact Test Procedure . . . . . . . . . . . . . . . . 58 
$3.5 \quad$ Flexural Test . . . . . . . . . . . . . . . . . . . . . . 62

3.5.1 Specimen Fabrication . . . . . . . . . . . . . . . 64

3.5.2 Flexural Test Procedure . . . . . . . . . . . . . . . . . 64

3.6 Measurement of the Strain Calibration Factor for Fiber Bragg Grating 67

4 Results and Discussion $\quad 72$

4.1 Tensile Test Results . . . . . . . . . . . . . . . . . . . . . . . . 72

4.2 Impact Test Results . . . . . . . . . . . . . . . . . . . . 74

4.3 Flexural Test Results . . . . . . . . . . . . . . . . . . . . . 80

4.4 Tensile Strain Measurement Using Embedded Optical Fibers . . . . . 83

5 Conclusions and Recommendations 106

5.1 Conclusions . . . . . . . . . . . . . . . . . . 106

5.2 Recommendations . . . . . . . . . . . . . . . . . . . . 108

$\begin{array}{ll}\text { References } & 110\end{array}$

Appendix A Model Parameters and Material Properties 116

A.1 Data sheet of optical fiber . . . . . . . . . . . 116

$\begin{array}{ll}\text { Appendix B Testing parameters } & 121\end{array}$

B.1 Calculation of Young's Modulus Using Compliance . . . . . . . . 121

B.2 Stress-strain curves . . . . . . . . . . . . . 123

$\begin{array}{lll}\text { Appendix C Data Sheet of Epoxy Resin } & 128\end{array}$ 


\section{List of Tables}

3.1 Summary of fixture design iterations . . . . . . . . . . . . . . 31

3.2 Machine's compliance measured using SS304 . . . . . . . . . . . 56

3.3 Dimensions of impact test specimens . . . . . . . . . . . . . 60

3.4 Dimensions of flexural test specimens . . . . . . . . . . . . 65

3.5 Strain calibration values from first optical fiber . . . . . . . . . . 69

3.6 Strain calibration values from second optical fiber . . . . . . . . . . . 69

4.1 Tensile test results from first panel . . . . . . . . . . . . 73

4.2 Tensile test results from second panel . . . . . . . . . . . . . . 74

4.3 Energy absorbed by the impact specimen . . . . . . . . . . . 76

4.4 Impact velocity of all the samples . . . . . . . . . . . . . 78

4.5 Codes for failure mode, area and location . . . . . . . . . . . . . . 80

4.6 Results of flexural test . . . . . . . . . . . . . . . . 81

4.7 Comparison of modulus of elasticity in AA6061 . . . . . . . . . . . 91

4.8 Modulus measured by all the gratings of AA6061 . . . . . . . . . 96

4.9 Modulus of Elasticity in fbg01 . . . . . . . . . . . . . . 96

4.10 Modulus of Elasticity in fbg02 . . . . . . . . . . . . . . . . 97

4.11 Modulus of Elasticity in fbg03 . . . . . . . . . . . . . . 100

4.12 Modulus of elasticity measured by all the gratings in fbg02 . . . . . . 102

4.13 Modulus of elasticity measured by all the gratings in fbg03 . . . . . . 104 


\section{List of Figures}

1.1 Size comparison of optical fiber and strain gage . . . . . . . . . 5

1.2 Right wing of Ikhana aIrcraft . . . . . . . . . . . . . . . . . 7

2.1 Microscopy of composite with and without optical fiber . . . . . . . 11

2.2 Production of sensing tape using sandwich technique . . . . . . . . 12

2.3 Reflected and transmitted light through a Bragg Grating . . . . . . . 13

2.4 (a) Extrinsic FPI sensor made by forming an external air cavity, and (b) intrinsic FPI sensor formed by two reflecting components, R1 and R2, along a fiber ...................... 15

2.5 Fiber sealing technique . . . . . . . . . . . . . . 16

2.6 Optical fiber connector . . . . . . . . . . . . . . . 17

2.7 Optical fiber reinforcement using tube. (a) using rubber tube and (b) using metal and plastic tube . . . . . . . . . . . . . . . 18

2.8 Protection of optical fibers against curing environment . . . . . . . . 18

2.9 connection using part fixture.(a)horizontal connection, (b) vertical con-

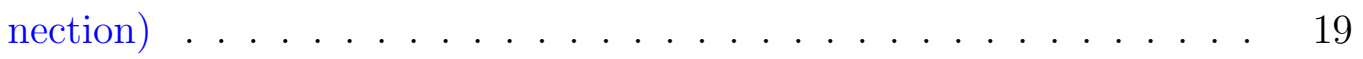

3.1 Fiberglass panel . . . . . . . . . . . . . . . . 24

3.2 Making guideway for optical fibers . . . . . . . . . . . . . 25

3.3 Sealant tape around fiberglass . . . . . . . . . . . . 25

3.4 Perforated film over fiberglass . . . . . . . . . . . . . . 26

3.5 Resin infusion mesh over fiberglass . . . . . . . . . . . . . 26 
3.6 T-connectors and spiral tubes on both ends of fiberglass . . . . . . . 27

3.7 VARTM setup . . . . . . . . . . . . . . . 27

3.8 Tube in clamped position . . . . . . . . . . . . . . . . . . 28

3.9 Mixing resin and hardener . . . . . . . . . . . . . . . . . . 28

3.10 Resin flow path under vacuum . . . . . . . . . . . . . . . . . 29

3.11 Fiberglass panel after curing . . . . . . . . . . . . . . . . 30

3.12 Parts of the first design . . . . . . . . . . . . . . . . . 32

3.13 Assembly of the first design . . . . . . . . . . . . . . . 33

3.14 Parts of the second design . . . . . . . . . . . . . . . 34

3.15 Assembly of second design in vacuum . . . . . . . . . . . . . 35

3.16 Parts of third design . . . . . . . . . . . . . . . . 35

3.17 Assembly of third design in vacuum . . . . . . . . . . . . 36

3.18 Side part design . . . . . . . . . . . . . . . . 37

3.19 Assembly of Fourth design . . . . . . . . . . . . . . . 37

3.20 Assembly of the fourth design in vacuum . . . . . . . . . . . . 38

3.21 Side part of the fifth design . . . . . . . . . . . . . . . 38

3.22 Fifth design in vacuum . . . . . . . . . . . . . . . . . . . 39

3.23 Applying PVA over fixture . . . . . . . . . . . . . . . . . . 40

3.24 Optical fiber entering the fixture . . . . . . . . . . . . . . . 40

3.25 Use of wax to fill the gaps . . . . . . . . . . . . . . . 41

3.26 Layout of four tensile specimens . . . . . . . . . . . . . . . . . . 42

3.27 Optical fibers in the fixture . . . . . . . . . . . . . . . . 42

3.28 Coiling optical fiber in the fixture . . . . . . . . . . . . . . 43

3.29 Complete assembly of the fixture with optical fiber coiled inside . . . 43

3.30 Resin infusion mesh over the fixtures . . . . . . . . . . . . . . . . . 44

3.31 VARTM setup with fixtures . . . . . . . . . . . . . . 44

3.32 Resin flow direction . . . . . . . . . . . . . . . . . 45 
3.33 Cured fiberglass . . . . . . . . . . . . . . . . . 46

3.34 Disassembling of fixture . . . . . . . . . . . . . . . 46

3.35 Optical fiber taken out from the fixture . . . . . . . . . . 47

3.36 Checking the integrity of embedded optical fiber . . . . . . . . 48

3.37 Schematic of ply orientation in tensile test coupons . . . . . . . 49

3.38 AA6061 with optical fiber bonded on the surface . . . . . . . . 50

3.39 Tensile test . . . . . . . . . . . . . . . . . 50

3.40 Stress-strain curve of fiberglass with and without embedded optical fiber 52

3.41 Splicing of optical fiber . . . . . . . . . . . . . . 53

3.42 Tensile testing of composite with embedded optical fiber $\ldots \ldots . .53$

3.43 Load vs displacement for SS304 sample1 . . . . . . . . . . . 55

3.44 Schematic of ply orientation in impact test specimen $\ldots . . . .55$

3.45 Manufactured panel for impact test specimen . . . . . . . . 58

3.46 Cutting layout schematic of impact and flexural test specimen . . . 59

3.47 Fiberglass impact specimen without (left) and with embedded optical fiber (right) . . . . . . . . . . . . . . . . . . 59

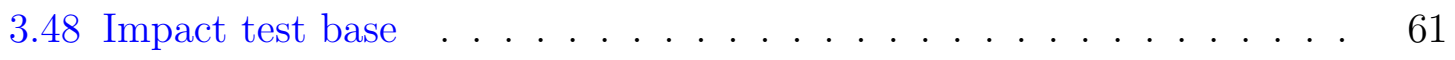

3.49 Impact test setup . . . . . . . . . . . . . . . . . . . . 62

3.50 Aluminium sample after impact test . . . . . . . . . . . . . 63

3.51 Fiberglass sample after impact test $\ldots \ldots \ldots \ldots . \ldots \ldots$

3.52 Flexural test specimen with embedded optical fiber . . . . . . . . 64

3.53 Schematic of three point bend test $\ldots \ldots \ldots \ldots \ldots \ldots$

3.54 Three point bend test . . . . . . . . . . . . . . 66

3.55 Wavelength shift in optical fiber during strained condition . . . . 70

3.56 Measurement of the strain calibration factor of optical fiber . . . . . 71

4.1 Young's Modulus of specimens from the first panel . . . . . . . 75

4.2 Young's Modulus of specimens from the second panel . . . . . . . 75 
4.3 Energy vs time for all the impact specimens . . . . . . . . . . . 77

4.4 Energy absorbed by impact specimens . . . . . . . . . . . . . . 78

4.5 Velocity vs time for all the impact specimens . . . . . . . . . . . . 79

4.6 Stress-strain curve for flexural test . . . . . . . . . . . . . . . . . . 82

4.7 Strain in AA6061 during loading cycle . . . . . . . . . . . . 85

4.8 Strain in AA6061 during unloading cycle . . . . . . . . . . . . 86

4.9 Strain in fbg01 during loading cycle . . . . . . . . . . . . . . 87

4.10 Strain in fbg01 during unloading cycle . . . . . . . . . . . . . . 88

4.11 Strain in fbg02 during loading cycle . . . . . . . . . . . . . . 89

4.12 Strain in fbg02 during unloading cycle . . . . . . . . . . . . . 90

4.13 Strain in fbg03 during loading cycle . . . . . . . . . . . . . . . . 92

4.14 Strain in fbg03 during unloading cycle . . . . . . . . . . . . . . 93

4.15 Strain in AA6061 : full cycle . . . . . . . . . . . . . . . 94

4.16 Strain in fbg02: full cycle . . . . . . . . . . . . . . 95

4.17 Modulus measured by all the gratings in AA6061 . . . . . . . . . . . 97

4.18 Comparison of modulus (GPa) of fbg02 during loading and unloading

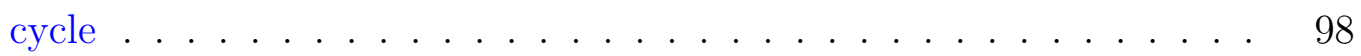

4.19 Comparison of modulus (GPa) of fbg03 during loading and unloading

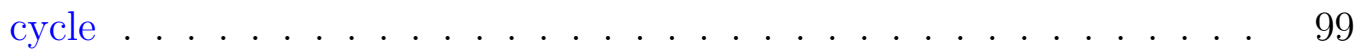

4.20 Modulus measured by all the gratings in fbg02 . . . . . . . . . . . 102

4.21 Strain measured by all the gratings in fbg02 . . . . . . . . . . 103

4.22 Modulus measured by all the gratings in fbg03 . . . . . . . . . . . . . 104

4.23 Strain measured by all the gratings in fbg03 . . . . . . . . . . . 105 


\section{List of Acronyms}

\begin{tabular}{ll} 
Acronyms & Definition \\
\hline \hline VARTM & Vacuum Assisted Resin Transfer Molding \\
SHM & Structural Health Monitoring \\
FBG & Fiber Bragg Grating \\
OF & Optical Fiber \\
NDT & Non Destructive Testing \\
FBG & Fiber Bragg Grating \\
OFDR & Optical Frequency Domain Reflectometry \\
FPI & Fabry-Perot Interferometer \\
PVA & Polyvinyl Alcohol \\
ABS & Acrylonitrile Butadiene Styrene \\
& \\
& American Society for Testing and Materials \\
&
\end{tabular}




\section{List of Symbols}

\begin{tabular}{ll} 
Symbols & Definition \\
\hline \hline$n$ & Refractive index \\
$\lambda_{B}$ & Bragg wavelength \\
$\Lambda$ & Grating period \\
$\epsilon$ & Strain \\
$\lambda$ & Wavelength \\
$\xi$ & Thermal optic coefficient \\
$\Delta T$ & Change in temperature \\
$E$ & Young's Modulus \\
$A$ & Cross sectional area \\
$L$ & Gage length \\
$E_{p}$ & Potential Energy \\
$E_{k}$ & Kinetic Energy \\
$m$ & Mass
\end{tabular}




$\begin{array}{ll}g & \text { Acceleration due to gravity } \\ h & \text { Height } \\ C_{m} & \text { Machine's compliance } \\ C_{m a t} & \text { Material's compliance } \\ C_{T} & \text { Total compliance }\end{array}$




\section{Chapter 1}

\section{Introduction}

Composite materials are widely used in military as well as transport aircraft. They were initially restricted to secondary structures such as fairings, doors and control surfaces. With advancements of technology, their application in primary structures such as wings and fuselages has increased $[1,2]$.

At present, carbon fiber and fiberglass reinforced polymers are being used in almost all modern aerospace structures as a primary structural material. However, it is still difficult to precisely manufacture large complex composite structures and ensure their structural integrity during operation. Hence, development of innovative techniques to monitor the internal behavior of composites is required. Novel methods to utilize these data to improve the structural design and maintenance methods are also

needed. As of now various sensors (Strain Gauges/Crack Gauges, Surface Mountable Crack Sensors (SMC), piezoceramic, optical fiber sensors and Internal Strain Gauge Sensors (ISG)) are being used to locate and assess the damage inside composite structures. Among the existing systems, optical fiber sensors have attracted considerable attention since they are small, lightweight, immune to electromagnetic interference, environmentally stable and have very little signal attenuation over long distances. Also, they possess sufficient flexibility to be embedded into composite 
laminates [3,4]. Optical fiber sensors such as Fiber Bragg Gratings (FBG), are being used for stress analysis and health monitoring of structures [5-7]. Optical fibers can be integrated within composite structures as they are small in size and fibrous in nature. However these fibers are vulnerable at ingress and egress points of the composite structure. This poses challenges in the manufacturing process [5]. Since the composite materials are usually applied in the form of plies or sheets, sensors have to be embedded within the structure during the manufacturing process. As a consequence of embedding the sensors, there may be a significant decrease in the mechanical properties of the composite material [8]. The most common type of optical fiber sensors are Intrinsic Fabry-Perot Intereferometers, Extrinsic Fabry-Perot Intereferometers and Fiber Bragg Gratings. The most advantageous sensor is the Bragg Grating sensor because its simple construction leaves the continuous fiber intact and strain levels can be deduced from optical wavelength shifts [9]. It is possible to write a series of identical Bragg gratings on a long section of optical fiber and read them individually $[6,9,10]$.

This thesis presents a novel approach to embed optical fibers within composite structures and to identify a crack/defect on the surface as well as within the structure.

\subsection{Background}

\subsubsection{Structural Health Monitoring}

Structural Health Monitoring (SHM) can be defined as the process by which on-board sensors are utilized to identify and quantify structural damage through a continuous in-service monitoring [4]. It is possible that damage can initiate in composites during their life cycle. Hence, there is a need to develop a system which can 
detect internal damage as early as possible [11]. Composites, being multiphase materials, have distinct anisotropic properties. The initiation of flaws within or on the composite's surface and the propagation of the flaw through the composite volume, leading to an ultimate failure is complicated. Describing a damage evolution and fracture behavior in composites remains a challenging task $[12,13]$. On impact, matrix cracks can appear, grow and interact, leading to delamination. It is also possible that fiber breakage appears on the opposite side to the impact and is thus, difficult to detect. Damage can be induced in composites during fabrication as well. It may be due to incorrect operations during manufacturing or assembly, aging or service condition [12]. Hence, it becomes important to devise a method to assess the structural integrity of composite aircraft structures.

\subsubsection{Importance of SHM}

Often impact damage in composite structures such as de-bonding of core and skins, delamination of carbon fiber or epoxy laminate skins and deformation of honeycomb core in sandwich structures are barely visible externally $[14,15]$. Although the initial defect may be small, it can grow with time and cause catastrophic structural failure [16]. This will eventually require either repair of the structure or replacement with a new part. Structural repairs increase the cost of transportation in two ways. First, repair or replacement implies direct costs. Second, as the particular part is being repaired, the aircraft remains out of service for a considerable period of time. This will incur cost due to loss of operation time or as a result of leasing a substitute system. Hence structural health monitoring becomes an issue of cost savings as well [17]. Although SHM methods costs money, it provides real time data. Availability of real time data requires the aircraft to be taken out of service only when the defect is above a well-defined threshold level. Thus, it obviates the need for a part's inspection after every flight. 


\subsubsection{Non-Destructive Testing Methods}

During manufacturing of composite structures, random porosities may appear inside the part. In their life cycle, an impact may result in delamination or debonding, affecting the mechanical properties of the material. These defects are revealed using Non-Destructive Testing (NDT) methods $[18,19]$. Common NDT methods are

ultrasonic, X-ray, thermography and eddy current methods [20,21]. Structural Health Monitoring (SHM), an emerging technique developed from NDT, uses sensors with intelligent algorithms to investigate the structural health condition. Unlike NDT, a real-time and online damage detection can be achieved in SHM. The advantages of SHM include improving reliability and safety, reducing inspection time and improvising designs of composite materials [12]. These methods are carried out using complicated, heavy equipments and are labor-extensive and time-consuming especially for large-scale structures. Moreover, the structure to be tested may need to be disassembled to make the inspection area accessible, which increases maintenance costs.

\subsection{Optical Fiber Sensors for Structural Health Monitoring}

While the conventional methods have their own advantages and disadvantages, optical fibers have been shown to be an efficient tool for SHM [6,17,22]. Optical fibers are extremely light and are about the diameter of a human hair. In the aerospace industry, where weight is extremely crucial to the mission, this feature provides an attractive advantage [17]. For example, Figure 1.1 shows a size comparison between a strain gage and an analogous optical fiber sensor. As seen in the picture, the strain gage sensor itself is larger and its installations requires copper wires which connect 


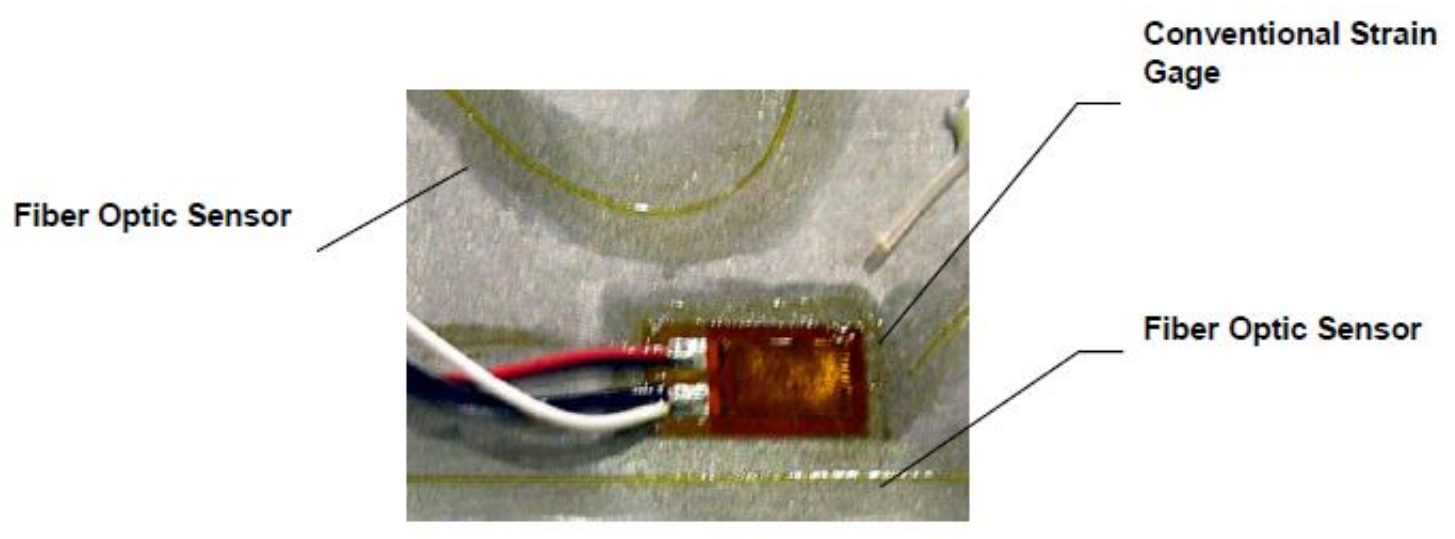

Figure 1.1: Size comparison of optical fiber and strain gage [17]

to the data acquisition system. As far as optical fibers are concerned, hundreds of sensors can be placed on a single optical fiber. Therefore, significant weight savings can be gained by using these sensors instead of strain gages. Optical fibers can be embedded within carbon fiber or fiberglass reinforced polymer composites without affecting their mechanical properties [23]. This feature allows strain measurement in the material during the manufacturing process or loading condition. One of the unique features of fiber optic strain sensing technology is that a single fiber can have thousands of Fiber Bragg Gratings (FBG) along its length using Optical Frequency Domain Reflectometry (OFDR) multiplexing scheme. Multiplexing dramatically reduces sizes of cables and thus eliminates the complexity of integrating and testing of large-scale structural components. A flight test program at NASA Dryden conducted on a Predator-B (General Atomics Aeronautical Systems, Incorporated, San Diego, California) successfully flew with optical fibers, each containing 480 optical fiber sensors [17]. Each of these sensors produced a strain measurement at 0.5 inch intervals that was analogous to the discrete measurements provided by strain gages [17, 24]. Optical fibers are chemically inert and are not susceptible to corrosion. They are also not prone to causing or suffering from electro-magnetic interference with other electronic systems. Moreover, they do not have the potential for ground loops, electrical 
faults, arcing or Joule heating [17].

\subsection{Challenges Associated with Optical Fibers}

According to the Federal Aviation Administration (FAA) advisory circular AC20-10-107B for aircraft composites, the discrepancies during manufacturing and fabrication of composites should be substantiated by mechanical testing of coupons [25]. In order to meet this requirement, the composite panels manufactured with integrated optical fibers were tested to study the effect of embedment on the mechanical strength of the host material.

The locations where the optical fiber exits the composite structure are critical as they are susceptible to the environment, vibration and/or severe work conditions. For SHM applications of optical fiber sensors, practical approaches such as sensor installation, mechanical properties of sensors, connection of ingress/egress to an exterior system etc. should be studied [26].

Optical fibers are embedded within the plies during the manufacturing of composite panels. These are then brought in contact with resins in vacuum. The readings of optical fibers might be affected if they come in contact with resin. For the purpose of conducting tensile tests, these panels are to be cut into standard sized coupons as per ASTM 3039 standard [27]. The cutting operation might damage or break the fiber as they are protruding out from the composite panels. Moreover, during tensile testing, the specimen is held tightly in between the grips of the testing machine which might damage the fiber as well.

Considering the above mentioned problems, there is a need for development of a novel system which can protect the fiber from resin during cure, maintain its integrity 
during cutting operation and ensure its safety during mechanical tests.

\subsection{Motivation and Scope of Research}

An existing example of optical fiber sensors for Structural Health Monitoring is NASA's Ikhana aircraft. It has approximately 3,000 Fiber Bragg Gratings installed on its wings (Figure 1.2). The FBGs are being used to sense the shape and monitor the stress of Ikhana wings in real time. The technology was also helpful in accomplishing structural health and load monitoring during the experiment. Research tasks were performed in the areas of algorithm and system development, environmental qualification testing, system/vehicle integration, sensor installation, ground test validation and experiment integration [17,24]. The experiment presented a unique approach
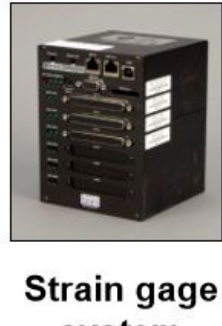
system

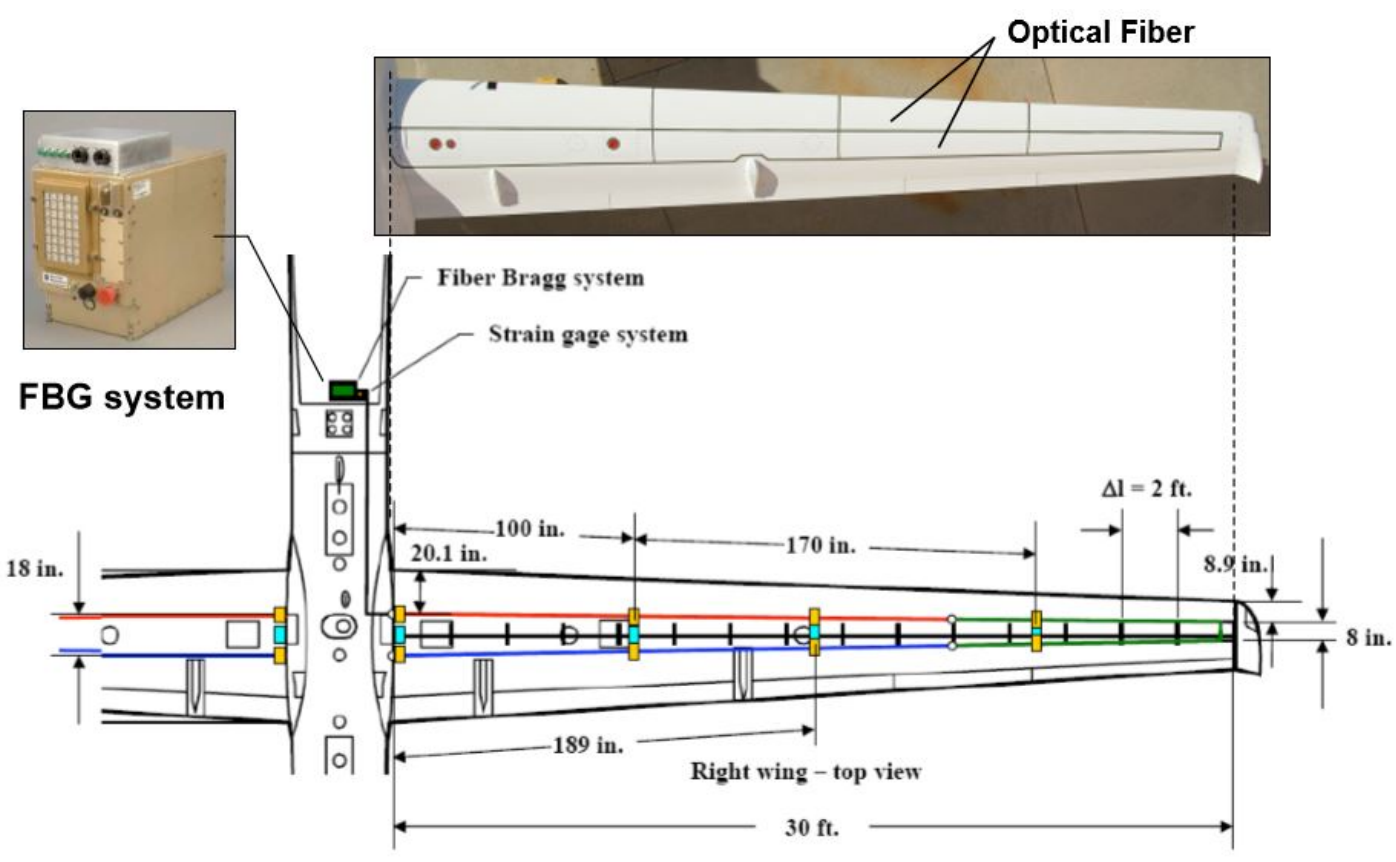

Figure 1.2: Right wing of Ikhana aircraft [17]

of measuring real time strain using embedded optical fiber sensors, which was the motivation for this thesis. The objective of this thesis was not to conduct a flight 
test to obtain real time data but it was to develop the process of embedding optical fibers within composites during the manufacturing processes. The goal was to aid in improving the methods of manufacturing composite panels with integrated optical fibers and to protect the ingress/egress points of embedded optical fibers during cutting and post-processing. Finally, data from the embedded optical fibers were used to measure strain while the material was in loading condition.

\subsection{Organization of the Thesis}

This thesis presents the method of embedding optical fiber sensors inside the composite material, design of fixture to protect ingress and egress points of optical fibers, a study of the mechanical properties of composite material after embedding, extraction of data from embedded sensors and correlation of the obtained data to strain value within the material.

Chapter 2 contains a literature review on embedding optical fibers in composite materials, their effect on mechanical properties of materials and process of extraction of data from optical fiber sensors. In Chapter 3, the method of embedding optical fibers within fiberglass composite, fabrication of specimen for tensile, impact and flexural testing is explained. The chapter also provides the evolution and design of a fixture to protect ingress/egress points of embedded optical fibers. Chapter 4 contains the test results of tensile, impact and flexural tests of the fiberglass reinforced epoxy and fiberglass reinforced epoxy with embedded optical fibers and their comparisons. It also demonstrates the method of extracting data from embedded optical fiber sensors

during loading and unloading conditions. Lastly, Chapter 5 summarizes the results of this research and provides recommendations for future work that can be carried out from the information provided in this thesis. 


\subsection{Research Contributions}

The following are contributions made through this thesis towards the advancement of SHM based on embedded optical fiber sensors:

1. Methods of embedding optical fiber sensors were explored and used to embed optical fibers in between the plies of fiberglass composites. Structural integrity of the embedded fibers were evaluated by passing Red Laser Light of wavelength $630 \mathrm{~nm}$. It was observed that optical fibers remained undamaged during manufacturing and cutting.

2. A unique 3D printed fixture was designed to protect the ingress/egress points of embedded optical fibers during manufacturing and cutting operation.

3. Tensile, impact and flexural tests were carried out on fiberglass specimens with and without embedded optical fibers and the results were compared to study the effect of embedment on the host material.

4. Data from embedded optical fiber sensors were used to calculate the strain in fiberglass materials during loading and unloading cycles and were compared with the strain values of the extensometer.

The information provided in this research can be put to practice in optical fiber sensor based SHM system. The data generated form the embedded optical fibers can be used to calculate the strain values and modulus of the material. This method can also be used to obtain real time data in flight. 


\section{Chapter 2}

\section{Literature Review}

Available literature shows that various attempts have been made to integrate optical fibers to composite structures during manufacturing processes. One of the most important factors of integration is the orientation of optical fibers with respect to composite ply layup. Points at which these fibers enters and exit the composite structure are vulnerable to damage during fabrication and machining. Researchers have conducted mechanical tests to study the effect of embedding optical fiber on the parent material. Once integrated successfully, optical fibers are used for strain analysis using a reflectometer.

\subsection{Integration of Optical Fiber Sensors in Com- posites}

Brown et al. embedded optical fibers in unidirectional epoxy and PETI-5 composites and performed microscopic analysis to study the void content of the fiber/composite interface [28] (Figure 2.1). They also performed $0^{\circ}$ and $90^{\circ}$ flex tests on coupons with and without embedded fibers to analyze the effect on stresses and the modulus of the composite [28]. Liu et al. embedded two optical fibers in a 16 ply composite layup. The sensors were embedded in between plies 2 and 3 as 
well as 8 and 9 in a cross ply $\left[0 / 90_{2} / 0_{2} / 90 / 0 / 90\right]_{s}$ carbon fibre reinforced prepreg system [29]. Shyprykevich et al. manufactured two different laminate geometries using AS4/3501-6 graphite epoxy material. The ply orientations were $\left[ \pm 45 / 90 / 0_{2} / \pm 45 / 0\right]_{s}$ and $\left[ \pm 45 / 90 / 15_{2} / \pm 45 / 15\right]_{s}$. Since the optical fiber was placed in the plane of symmetry to the load direction, they were at an angle of $15^{\circ}$ with respect to graphite fiber in the second configuration [30]. Another novel method of integrating optical fiber was
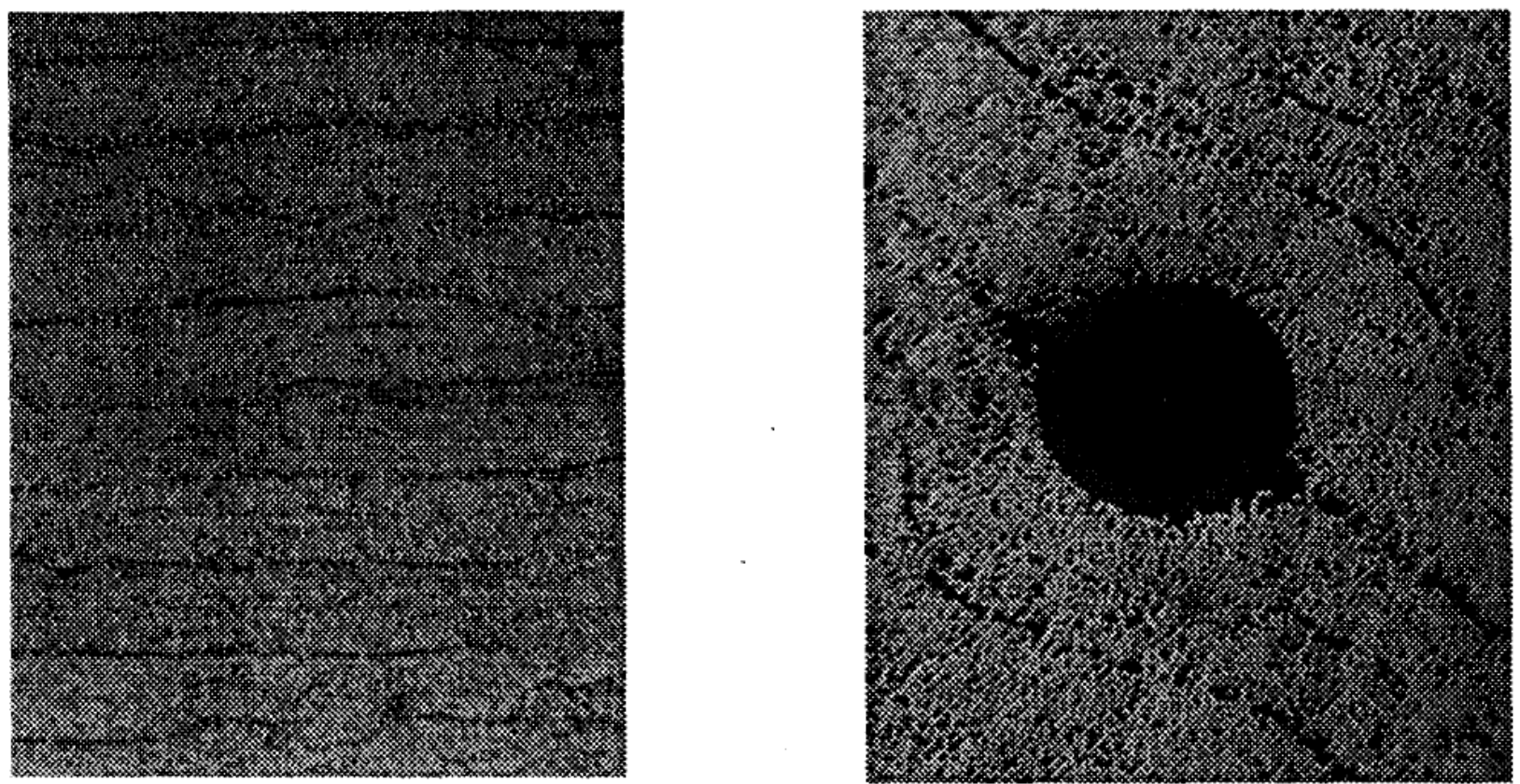

Figure 2.1: Microscopy of composite with and without optical fiber [28]

demonstrated by Glisic et al. They used the sandwich technique to embed optical fibers between unidirectional glass fibers reinforced plastic tape [31]. Two tapes of half thickness $(0.1 \mathrm{~mm})$ and optical fiber were assembled as seen in Figure 2.2.

\subsection{Types of Optical Fiber Sensors}

Among the readily available optical fiber sensors, the most commonly used sensors are Fiber Bragg Gratings, Rayleigh and Fabry Perot sensors. 


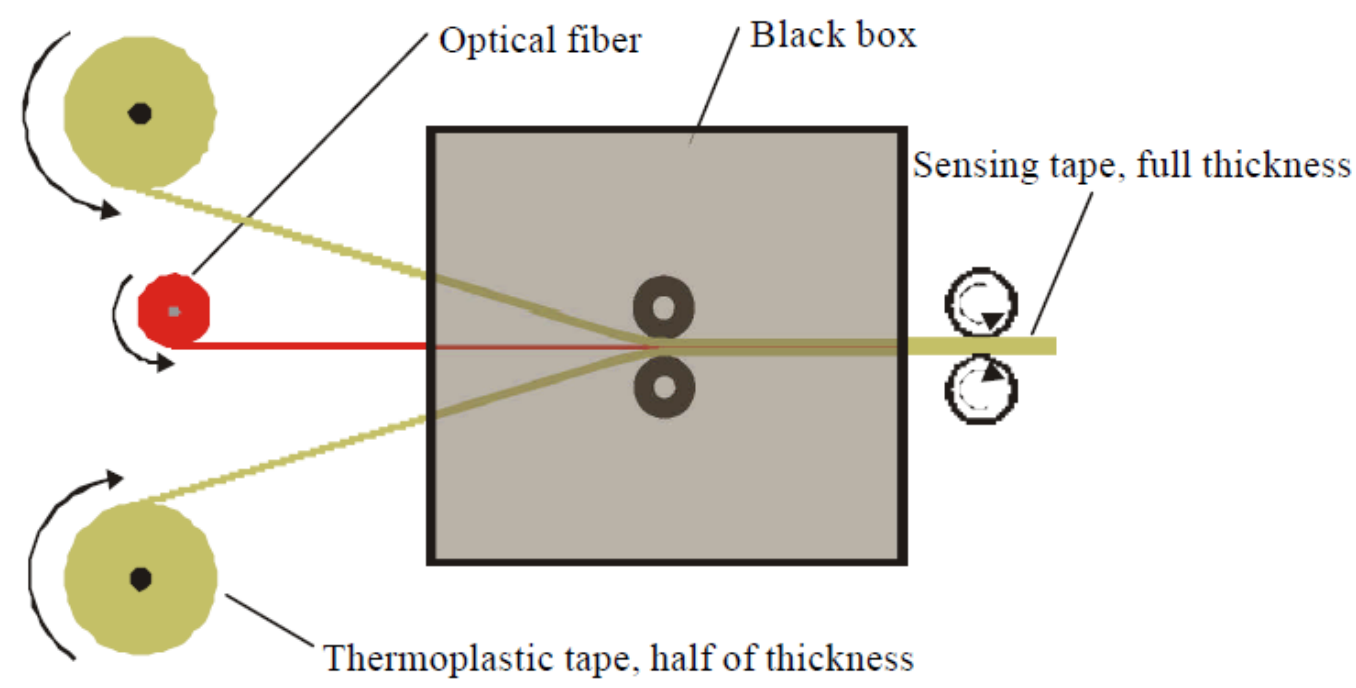

Figure 2.2: Production of sensing tape using sandwich technique [31]

\subsubsection{Bragg Gratings}

Fiber Bragg Gratings (FBG) are close parallel lines typically between $1 \mathrm{~mm}$ to $25 \mathrm{~mm}$ long, consisting of alternating regions of high and low refractive indices on the core of an optical fiber (Figure 2.3). Broadband light passing through the grating is partially reflected from the grating at particular wavelength [32-34]. This wavelength is known as Bragg wavelength, $\lambda_{B}$, and is given by [35]

$$
\lambda_{B}=2 n \Lambda
$$

where $n$ is average refractive index in the grating region and $\Lambda$ is the grating period. When a load is applied to the structure, the grating is strained and thus, there is a change in the peak reflected wavelength. The new wavelength becomes $\lambda$. The change in wavelength can be related to the strain experienced by the fiber, which can 
be defined as [9]

$$
\epsilon=\frac{\lambda-\lambda_{B}}{\lambda_{B}}
$$

Considering material properties, the above equation becomes

$$
\epsilon=K\left(\frac{\lambda-\lambda_{B}}{\lambda_{B}}-\xi \Delta T\right)
$$

where constant $K$ is a function of the refractive index, Poisson's ratio and strainoptic constants of the fiber, $\xi$ is the thermal-optic coefficient, and $\Delta T$ is change in temperature.

Fiber Bragg Grating strain sensors were used in the present research to perform Structural Health Monitoring of composite materials because they were readily available from the Optics Laboratory, Department of Electronics at Carleton University.
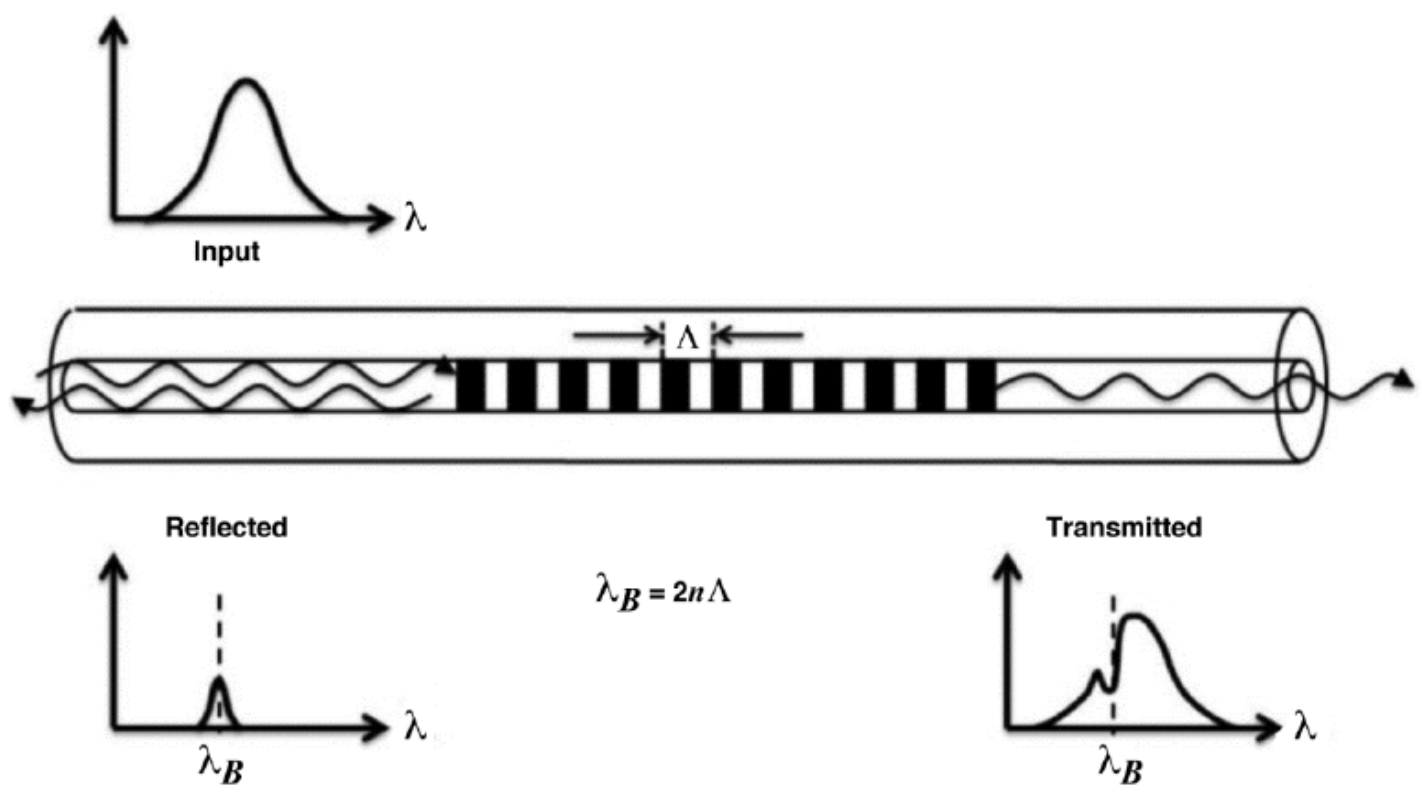

Figure 2.3: Reflected and Transmitted light through a Bragg Grating [17] 


\subsubsection{Rayleigh Fibers}

In a non-excited state, each fiber has a specific local geometry and distribution of impurities or irregularities within it. When the optical fiber experiences strain and/or temperature changes, those features also change. As a result of these variations, the optical backscattering changes as well. Taking the non-excited state as reference and comparing with its later states, the difference can be used for strain or temperature measurements. Within the distributed sensing systems there are three measurement methods: Raman, Brillouin and Rayleigh. They differ from each other in terms of the wavelength of backscattering. Different interactions within the fiber produces different wavelengths. The Raman method obtains scattering due to interaction between light photons and thermal vibration of silica molecules of the material. The Brillouin method employs photon-photon interaction due to local geometry variations of the fiber core. Raman and Brillouin methods can provide good global strain and temperature measurements over lengths in the range of kilometers [36]. The spatial resolution of Raman and Brillouin backscatter signals are limited to 1 m. The Rayleigh method produces intensity reflections greater compared with the other methods with its spatial resolution being in the range of millimeters [37]. Using Rayleigh scattering technique allows the entire length of optical fiber to act as a sensor. Rayleigh scattering is based on Optical Frequency Domain Reflectometry (OFDR) which measures the scattering amplitude and phase of the scattered signal produced by optical fiber. The reflected spectrum is in the form of random pattern from inherent variations of the optical fiber. An application of strain or temperature causes the spectrum to shift at the location where they are applied. The new spectrum is compared with the reference reading at nominal strain and temperature to calculate the strain experienced by the optical fiber [38,39]. 


\subsubsection{Fabry-Perot Sensors}

A Fabry-Perot interferometer (FPI) consists of two parallel reflecting surfaces separated by a certain distance. Multiple superpositions of both reflected and transmitted beams at two parallel surfaces result in interference. In optical fibers, the FPI can be formed by building up reflectors inside or outside of fibers. Fabry-Perot sensors are of two types: extrinsic and intrinsic. The extrinsic FPI sensor uses the reflections from an external cavity formed outside the fiber. Figure 2.4 (a) shows an extrinsic FPI sensor, in which the air cavity is formed by a supporting structure. With high reflecting mirrors, the extrinsic structure can obtain a high resolution interference signal [40]. Intrinsic FPI fiber sensors contains reflecting surfaces within the fiber itself (Figure 2.4 (b)). An application of longitudinal strain in the FPI sensor causes the physical length or/and the refractive index of the cavity material to change, resulting in phase variation. Strain experienced by the optical fiber can be calculated by measuring the shift of the wavelength spectrum of a FPI and comparing it with the initial value.

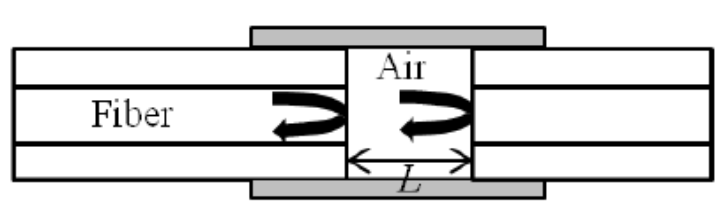

(a)

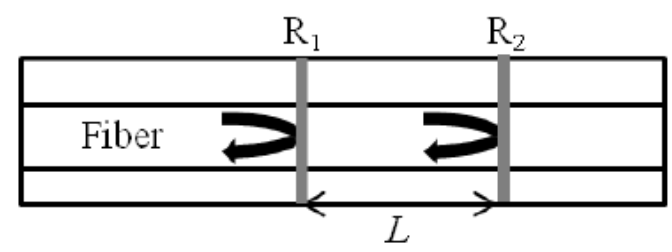

(b)

Figure 2.4: (a) Extrinsic FPI sensor made by forming an external air cavity, and (b) intrinsic FPI sensor formed by two reflecting components, R1 and R2, along a fiber [40]

\subsection{Ingress and Egress Points: Challenges}

During integration and manufacturing, the optical fibers emerging at ingress/egress on the surface are vulnerable to damage. Also, these protruding fibers 
can easily be damaged while performing cutting operations on the manufactured composite panels. As data extraction from optical fibers requires connecting their ends to the reflectometer, there is a need for development of a system which can provide a protective environment to optical fibers at the ingress/egress points. Several authors have suggested and published the development of certain connectors which serves the above mentioned purpose. Keulen et al. introduced a thin steel tube around the fiber which housed the fiber and protected it from breaking as well as reinforced it at the ingress/egress points after the manufactured part was removed from the mold. The tube passed through a silicone stopper and was sealed, as the stopper was held in the mold using a custom fitting [41] (Figure 2.5).

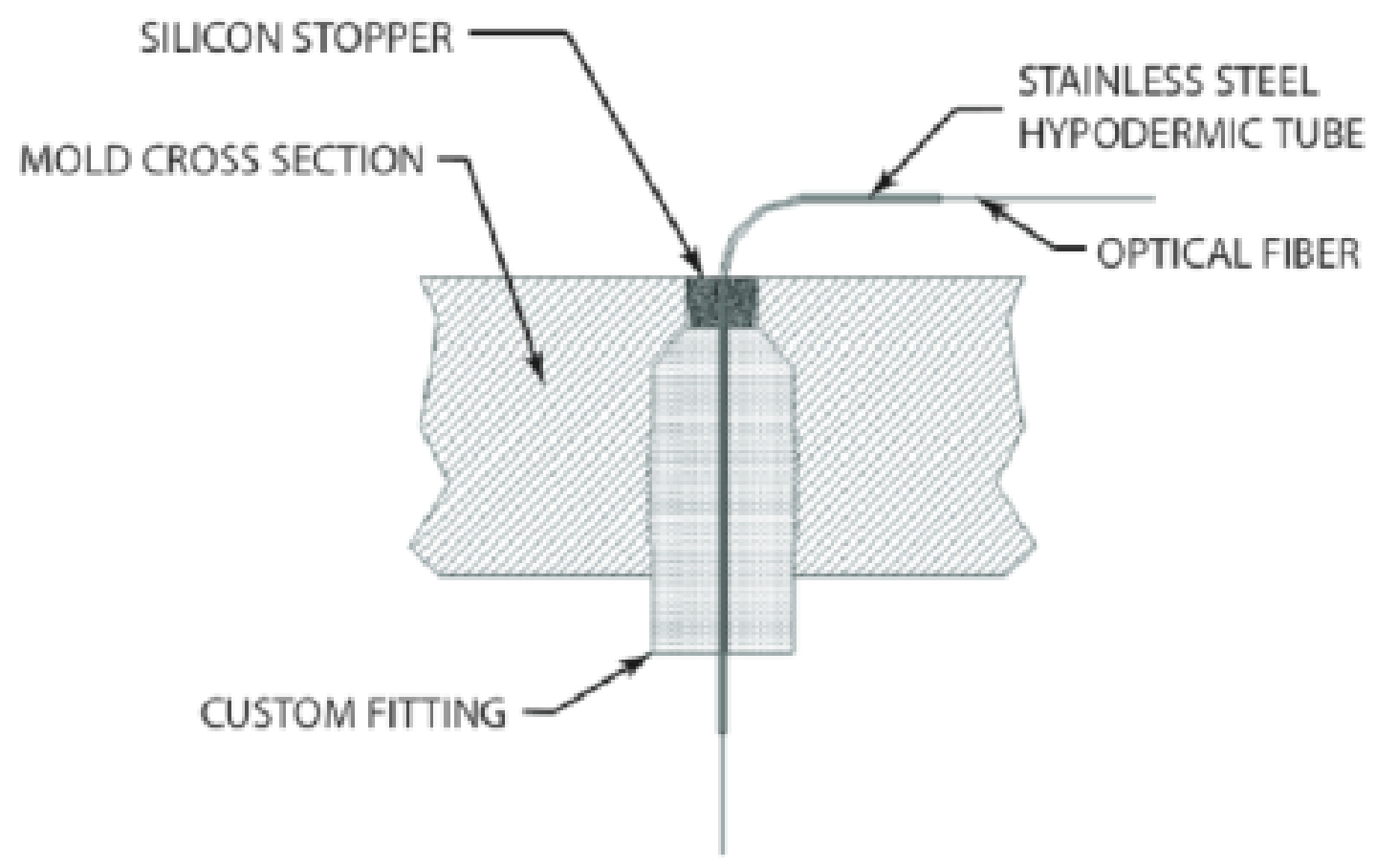

Figure 2.5: Fiber sealing technique [41]

One possible approach to protect the optical fiber is to manufacture custom designed connectors with ingress/egress optical fiber ends. An example of such a 
connector is shown in Figure 2.6. However, such a design makes it impossible to carry out machining or trimming on the edge of the composite [42,43]. Hong et al. used a rubber tube as well as a combination of metal and plastic tubes for the reinforcement of the optical fiber at the ingress/egress point [26,44] as seen in Figure 2.7 .

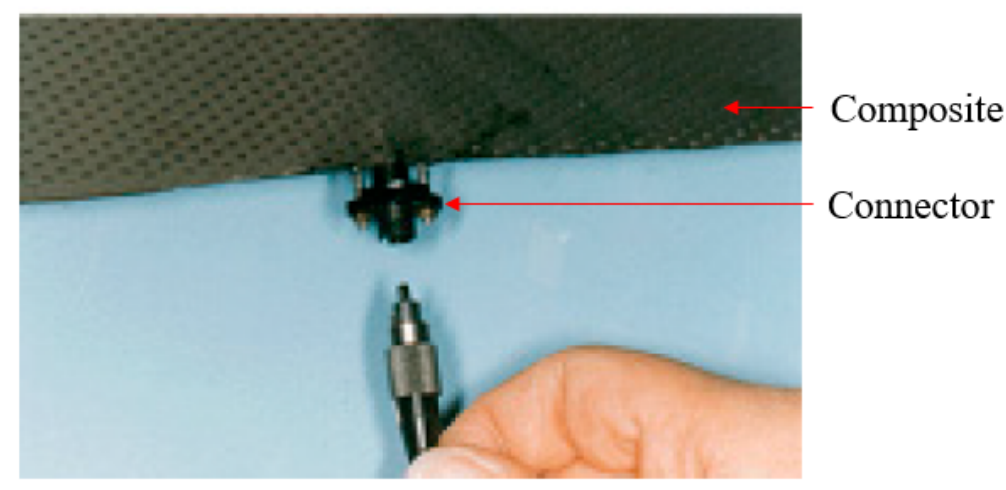

Figure 2.6: Optical fiber connector [42]

In order to protect the optical cable from high temperatures and pressures during curing in an autoclave, Kang et al. developed a fiber protector made of aluminium. This component was bonded to composite using an adhesive film. They wrapped the optical cable with breather fabric and covered it with metal elements as seen in Figure 2.8. These composite laminates were cured in an autoclave. They also developed optical connection fixtures to fasten the connecting element on the smart structure element. These fixtures can be designed in various shapes according to the purpose and the connecting direction of optical fibers. They were attached by FM73M adhesive film (Cynamid). These systems were utilized in horizontal connections as well as in vertical connections, as shown in Figure 2.9.

As seen in above examples, the presence of the connectors make it difficult to machine the sides of composites. This thesis presents a unique design to protect the 


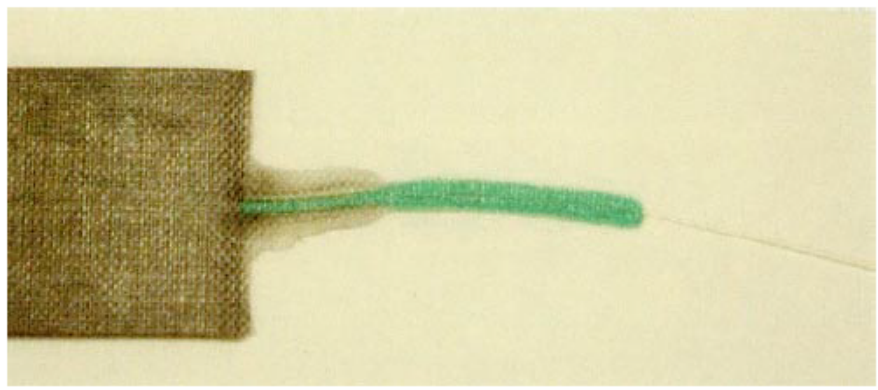

(a)

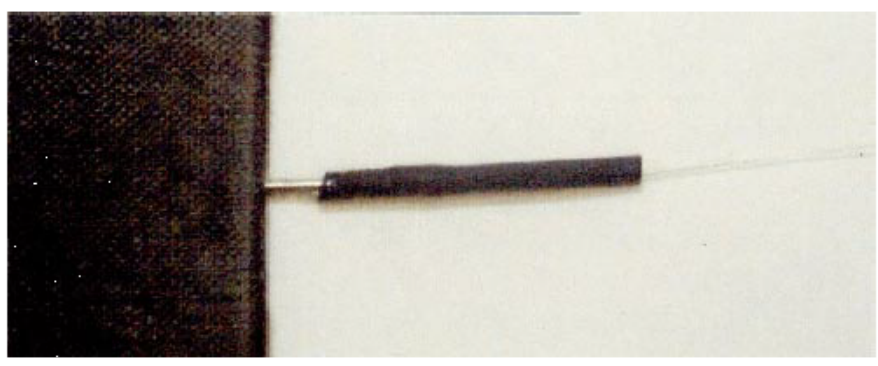

(b)

Figure 2.7: Optical fiber reinforcement using tube. (a) using rubber tube and (b) using metal and plastic tube [26]

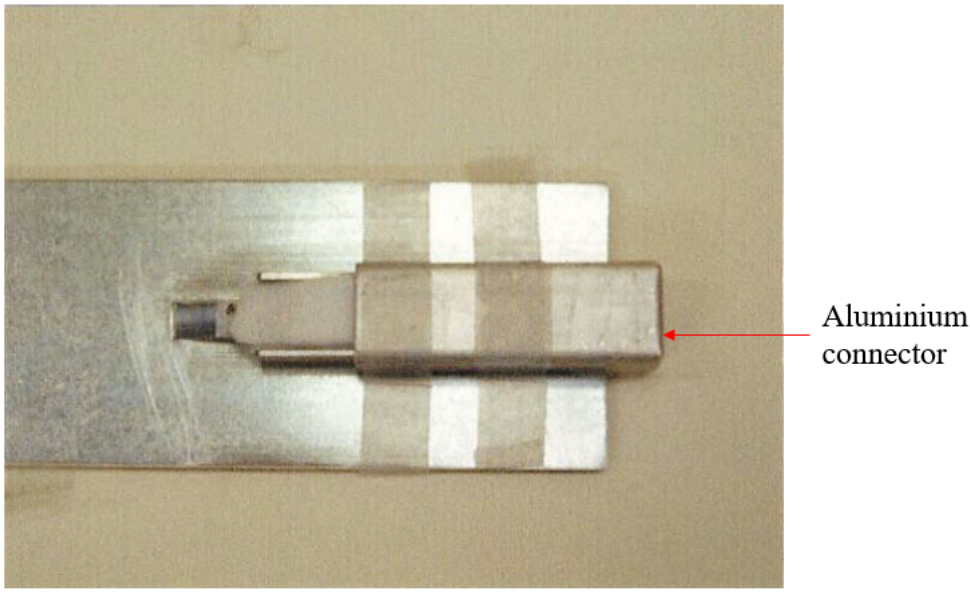

Figure 2.8: Protection of optical fibers against curing environment [26] 


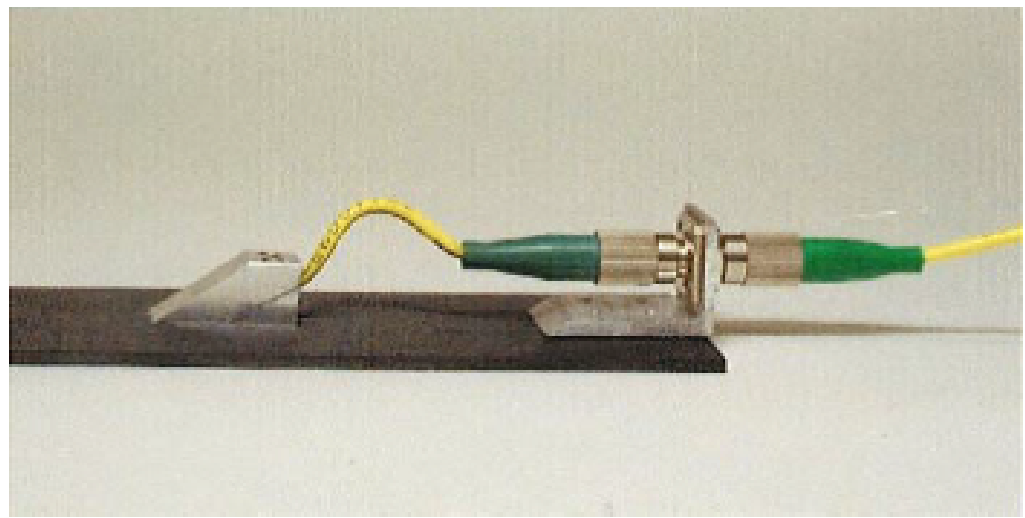

(a)

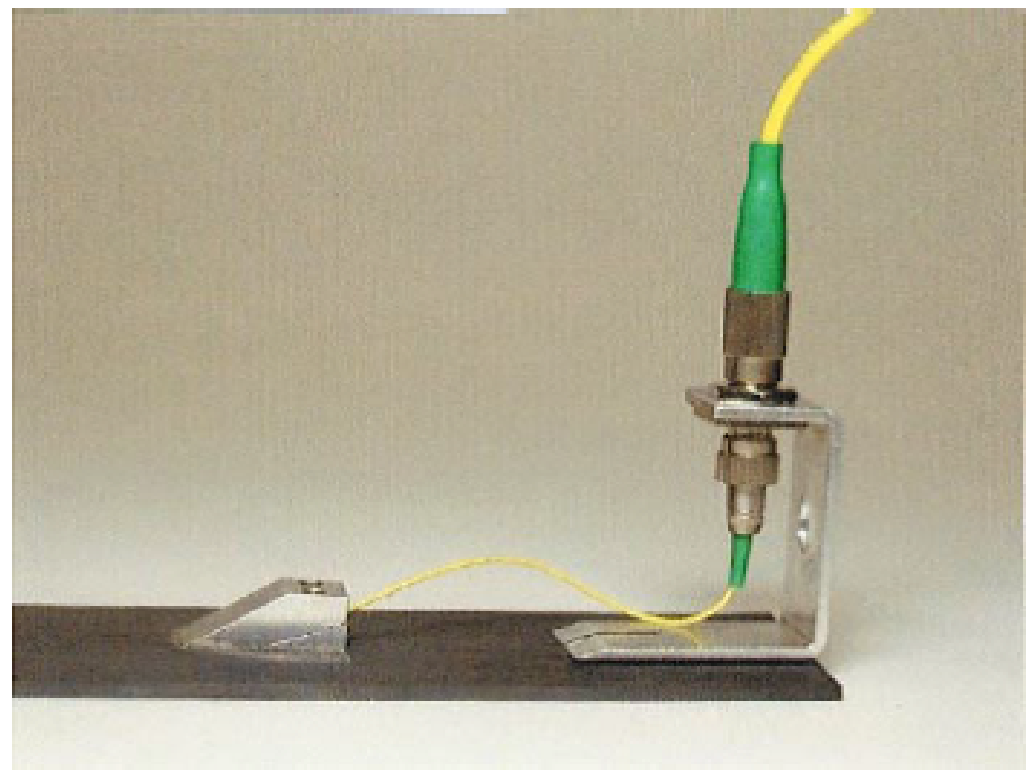

(b)

Figure 2.9: connection using part fixture.(a)horizontal connection, (b) vertical connection) [26] 
ingress and egress points of optical fibers during manufacturing as well as cutting operation.

\subsection{Mechanical Testing: with and without Inte- grated Optical Fibers}

Optical fibers are made up of glass inscribed within a different coating material. These are very distinct and separate from the composites they are embedded in. Embedding can only be justified if the system can measure the strain values in the local environment without affecting the structural integrity and strength of the parent material. Hence, it is important to study the mechanical behavior of the composites with embedded optical fibers and compare it with that of host material without embedded fibers. Hadzic et al. manufactured composite laminates from commercial AS4/3501-6 (carbon-epoxy) tape [45]. The pre-preg stacks were laminated as eight ply $\left[90_{4} / 0_{4}\right]_{s}$ and 16 ply $\left[90_{8} / 0_{8}\right]_{s}$ panels. Optical fibers were embedded in the midplane or near the surface of the laminate. They also made a laminate from Fibredux 914 unidirectional carbon pre-preg. Optical fibers were embedded below the surface and near the bottom of the laminate. Laminates contained $0.24 \%$ optical fibers. In all the cases, the optical fibers were aligned with the carbon fibres and placed between two plies of same orientation. The samples were cured in an autoclave. Tensile tests and compression tests were conducted in accordance with ASTM-D3039M-93 and ASTM-D3410-87 respectively.

For tensile tests, specimens were subjected to continuously increasing tensile loads. The obtained results indicated that the presence of optical fibers did not seriously degrade the mechanical properties of the host material. However, on the Fibredux panels, the failure load of composite laminates with comparatively more densely 
embedded OF decreased by approximately 33\% [45]. Lee et al. fabricated tensile specimens from HFG GU-300 pre-preg and fatigue specimens from Sunkyung Industry Co. UGN-150 prepreg [46]. Two types of stacking sequences: unidirectional $\left[0_{6}\right]_{T}$ and crossply $\left[0 / 90_{2}\right]_{s}$ for static tests and unidirectional $\left[0_{10}\right]_{T}$ and crossply $\left[0 / 90_{4}\right]_{s}$ for fatigue tests, were chosen. The effects of embedding optical fiber parallel and perpendicular to adjacent reinforcing fibers on the mechanical properties of laminates were investigated. The acrylate coating of embedded optical fiber was removed to increase the sensitivity to damage. The deviation of stiffness, strength and Poisson's ratio was found to be less than $5 \%$ of their mean value. It was thus concluded that optical fibers embedded at low volume fractions did not have significant effects on the tensile properties of composite laminates [46].

Jensen et al. manufactured tensile and compressive specimens from unidirectional Gr/BMI pre-preg tape with embedded optical fibers [47]. They reported that the effect of embedded optical fiber orientation on the laminate tensile mechanical properties was of the order of $10 \%$ or less. The results indicated that optical fibers embedded perpendicular to the loading direction in composite laminates induce the largest degradation in their mechanical performance. They concluded that optical fibers should be embedded parallel to both the loading direction and adjacent reinforcing fibers for minimal intrusion, when possible [47]. They also reported a $70 \%$ reduction in the compressive strength of composites in the presence of optical fibers. Another observation was that the largest compressive strength reductions occured in composite laminates with optical fibers embedded perpendicular to both the loading direction and the adjacent graphite fibers [48]. 
Based on the recommendations provided above, all the specimens manufactured for this research work had optical fibres embedded parallel to the reinforcing laminates. Also the configuration was chosen in such a way that they remained parallel to the loading direction in the case of tensile testing.

\subsection{SHM Applications}

Embedded optical fibers have been used for real time strain measurements as described in available literatures. Pedrazzani et al. used Rayleigh scattering based fiber optic strain sensing to monitor the distributed strain during fatigue testing of a 9-meter CX-100 wind turbine blade with intentionally introduced defects [49]. Amplitude and phase of the light reflected from the fibers were measured using a commercial Optical Frequency Domain Reflectometer (OFDR). Changes in these parameters were used to determine strain along the entire length of fiber. Fatigue testing was carried out on the wing blade and optical fiber data was taken with the blade under no load, -375 lbs and $\pm 500 \mathrm{lbs}$ load. The strain values were found to be comparable with the resistance strain gage data. They concluded that embedded optical fibers have the potential to measure strain throughout the life cycle of composite components [49]. Torres et al. used embedded FBG-based optical fiber to measure strain within composite samples. The sensors were placed on the surface of material and they were subjected to uniform tension, compression and bending. The readings of the FBG sensors were found comparable to those of the strain gauges, with a maximum difference of only $3 \%[50]$.

This thesis contains the results of the strain values as measured by the embedded optical fibers in fiberglass reinforced epoxy samples. The values have been compared with the extensometer readings during tensile loading of the specimens. 


\section{Chapter 3}

\section{Experimental Methodology}

The first step of embedding optical fibers was to choose a suitable manufacturing method. Since the optical fibers were to be embedded manually, the best option was to work with dry fabric instead of pre-preg. Pre-pregs are the composite fibres pre-impregnated by resin [51]. The presence of resin might bond the optical fibers to pre-preg's surface during manual embedment and make it difficult to move and position them at the desired location. Readings of optical fibers can be affected by the application of heat. Since the study of thermal effect on the optical fibers was not a part of this thesis, a room temperature manufacturing method was required. Vacuum Assisted Resin Transfer Molding (VARTM) met all of these criteria and all the apparatus required for VARTM was available in Composites Laboratory at Carleton University. Hence, VARTM was chosen for the manufacturing of the composite panels with embedded optical fibers. Optical fibers were embedded in the fiberglass fabric during the layup process. The ingress and egress points were protected using a custom 3D printed structure. After the sample was cured, test samples were cut from the panels using a diamond saw. Coupons with and without embedded optical fibers were fabricated. For final tests, optical fibers with six inscribed Bragg Gratings were provided by the Optics Laboratory, Department of Electronics at Carleton University. 


\subsection{Composite Panels with Embedded Optical Fibers}

Unidirectional non-crimp fiberglass fabric was used to make all the samples. A glass sheet was used as the tooling plate. The steps involved in the manufacturing of composites using VARTM are as follows:

Step 1: Fiberglass was cut, weighed and placed on the tooling plate in the desired orientation (Figure 3.1).

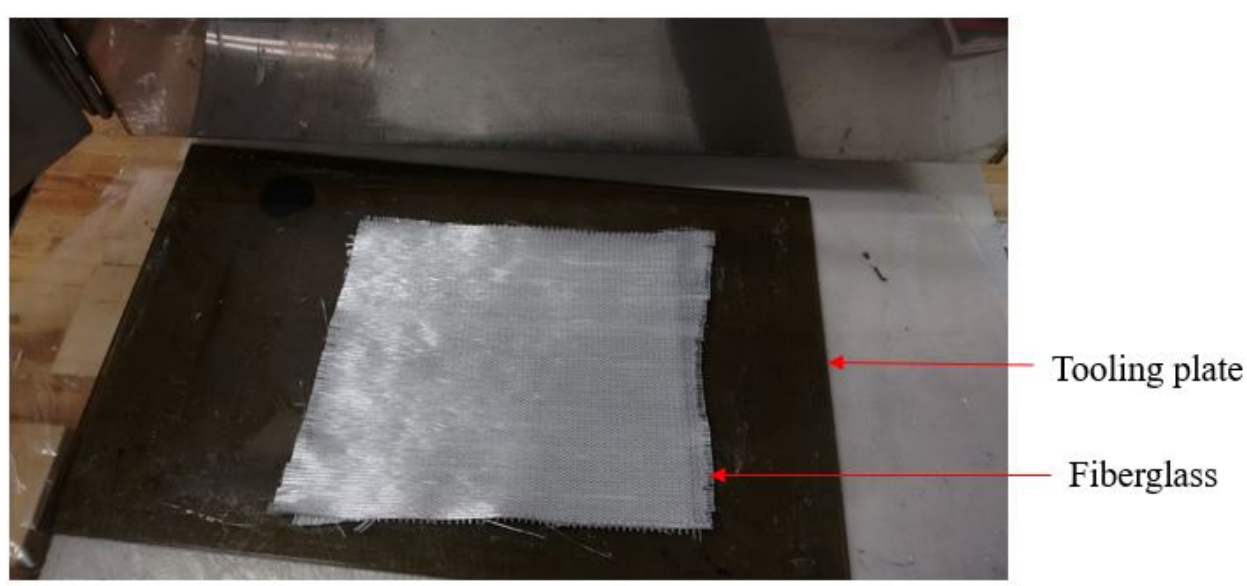

Figure 3.1: Fiberglass panel

Step 2: Optical fibers were embedded in between the center plies. To place the optical fiber in between fiberglass material, a guideway was made using a sewing needle (Figure 3.2). Optical fibers were inserted in the guideway and remained embedded in between the plies. Initial fabrications were done with optical fibers remaining loose without any retaining fixture.

Step 3: Sealant tape was fixed around the fiberglass material leaving a gap on all sides as shown in Figure 3.3. A layer of vacuum bagging film was placed below the fiberglass to prevent its bonding with the tooling plate after curing.

Step 4: A layer of perforated film was placed over fiberglass as seen in Figure 3.4. 


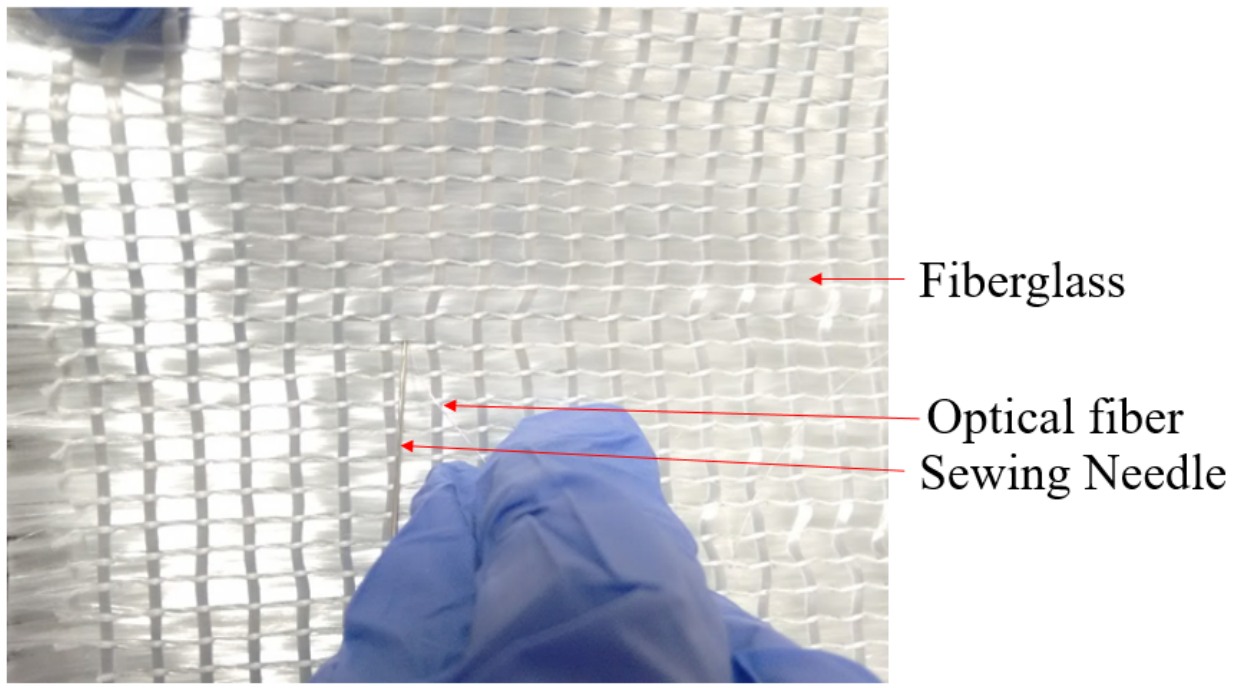

Figure 3.2: Making guideway for optical fibers

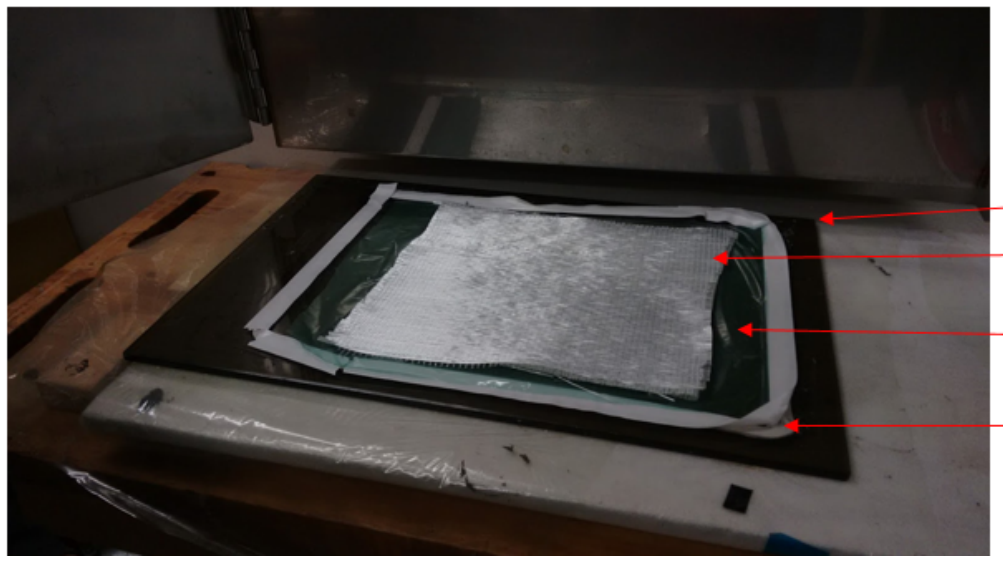

Base plate

Fiberglass

Vacuum bagging

film

Sealant tape

Figure 3.3: Sealant tape around fiberglass 
Perforated films have small pores on their surface, which allows resin to seep through the surface of fiberglass during infusion.

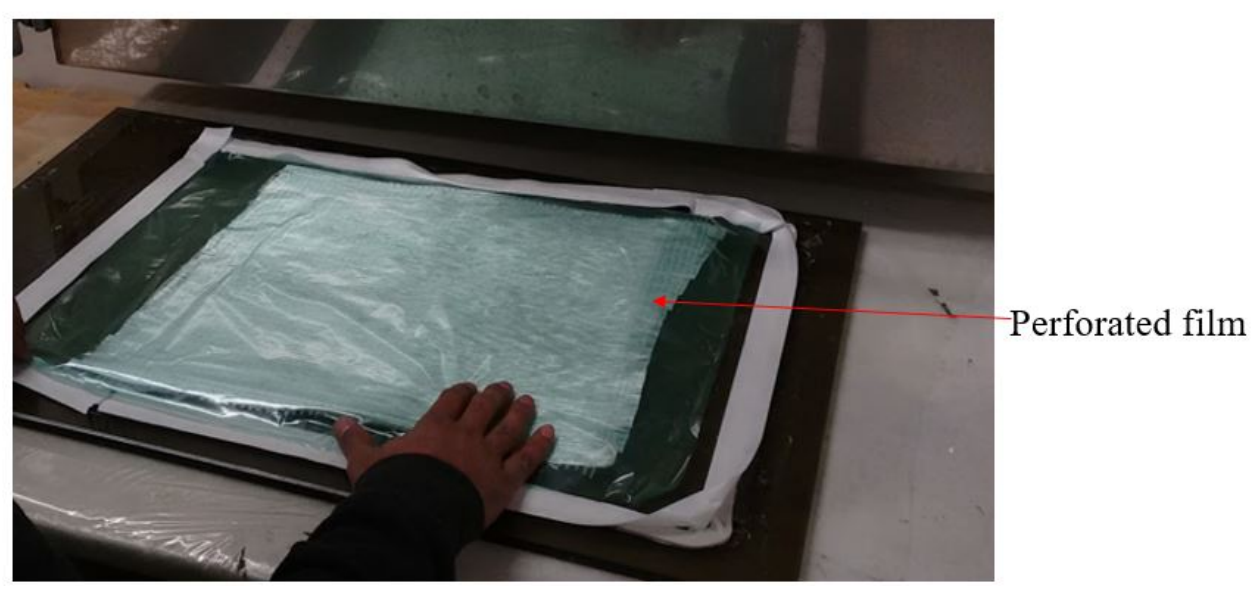

Figure 3.4: Perforated film over fiberglass

Step 5: Resin infusion mesh was placed on top to help resin to spread throughout the surface area of the fiberglass during infusion process as shown in Figure 3.5.

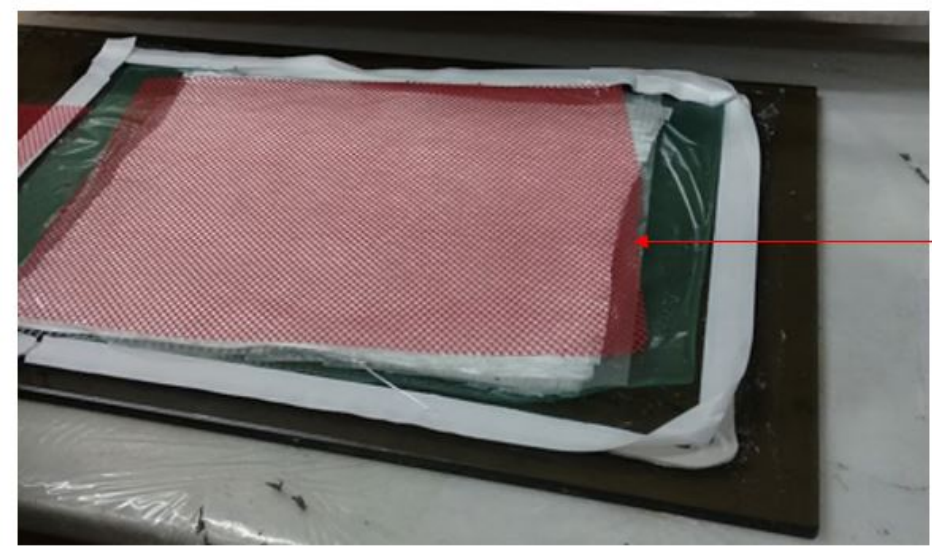

Resin infusion mesh

Figure 3.5: Resin infusion mesh over fiberglass

Step 6: T-connectors were placed on both ends of the fiberglass. They were placed in between spiral tubes to enforce the resin to flow throughout the width of the fiberglass during infusion process as shown in Figure 3.6.

Step 7: Vacuum bagging film, covering the entire area, was placed on top and it 


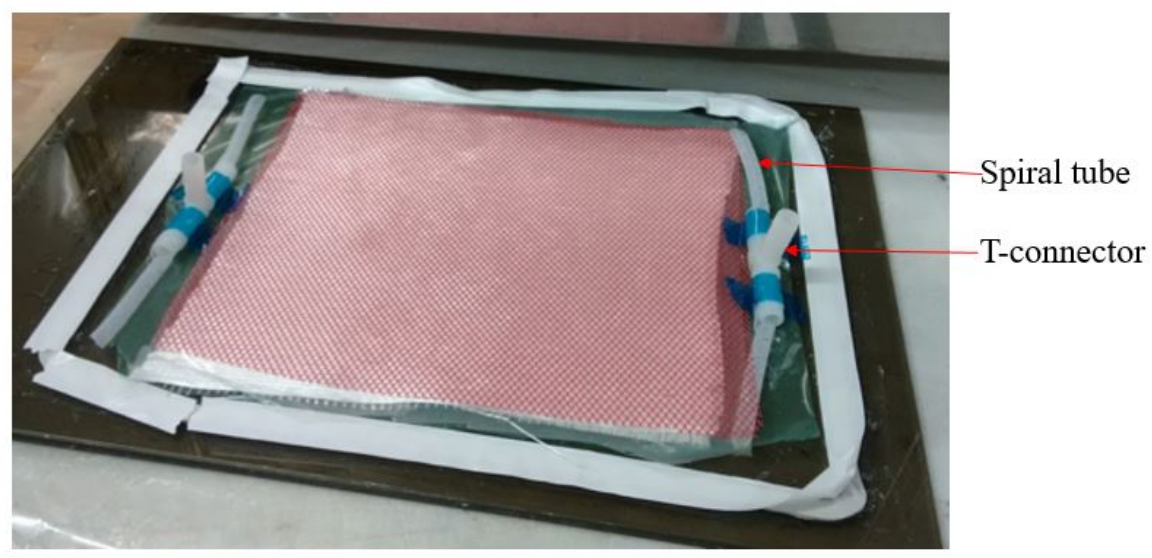

Figure 3.6: T-connectors and spiral tubes on both ends of fiberglass

was bonded to the sealant tape. Holes were made in the bagging film allowing the top part of T-connector to come out. This region was sealed using sealant tape to prevent air entry. Tubes were inserted in the T-connectors from top. The tube on one end was clamped using a C-clamp and the tube on the other end was connected to the vacuum pump. The pump was turned on to create vacuum inside the setup. The setup is shown in Figure 3.7 and Figure 3.8.

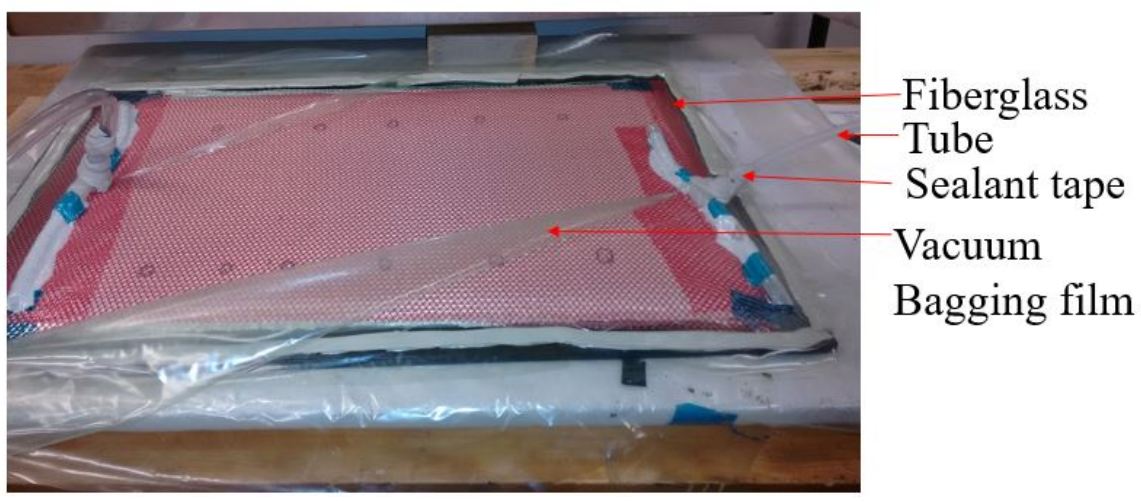

Figure 3.7: VARTM setup

Step 8: Epoxy resin (PT 2712) and hardener were mixed in a mixing cup as shown in Figure 3.9. A ratio of 22 grams of hardener per 100 grams of resin was added as per the supplier's direction. 


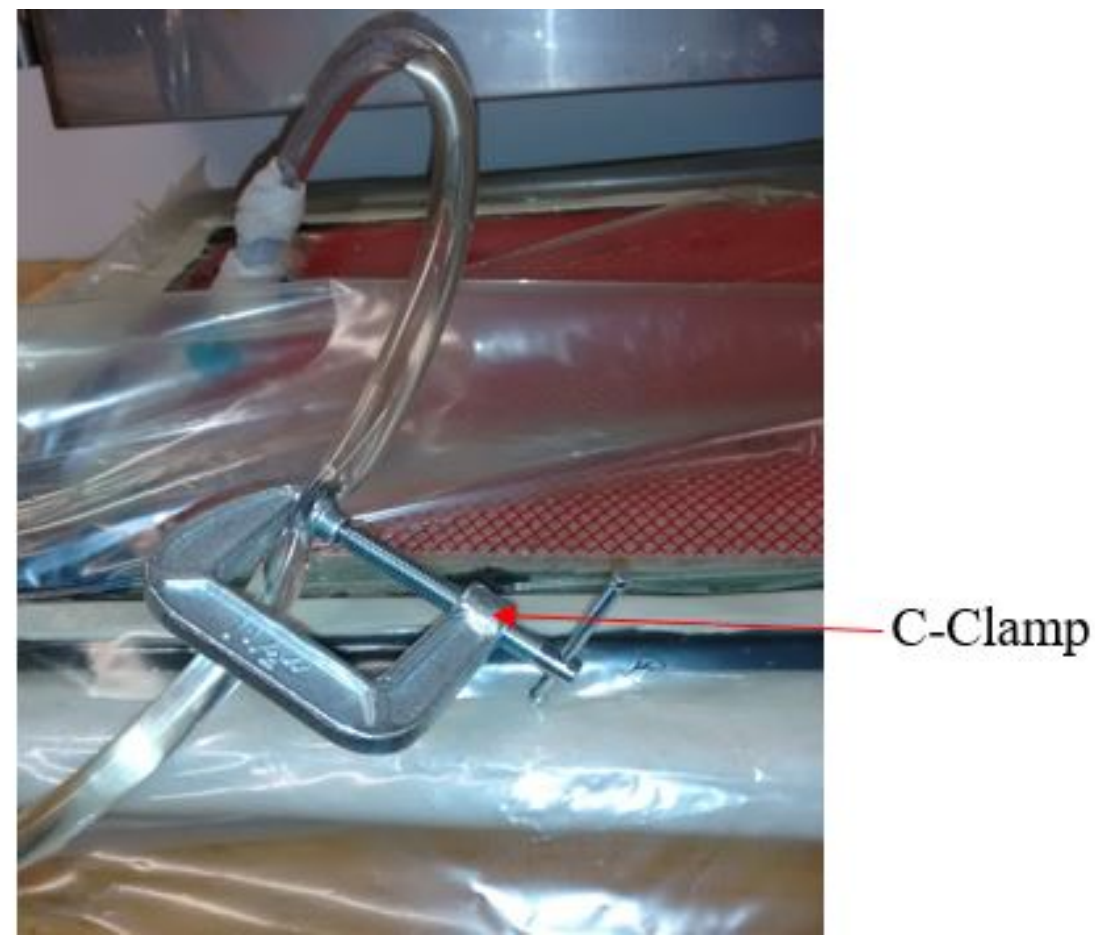

Figure 3.8: Tube in clamped position

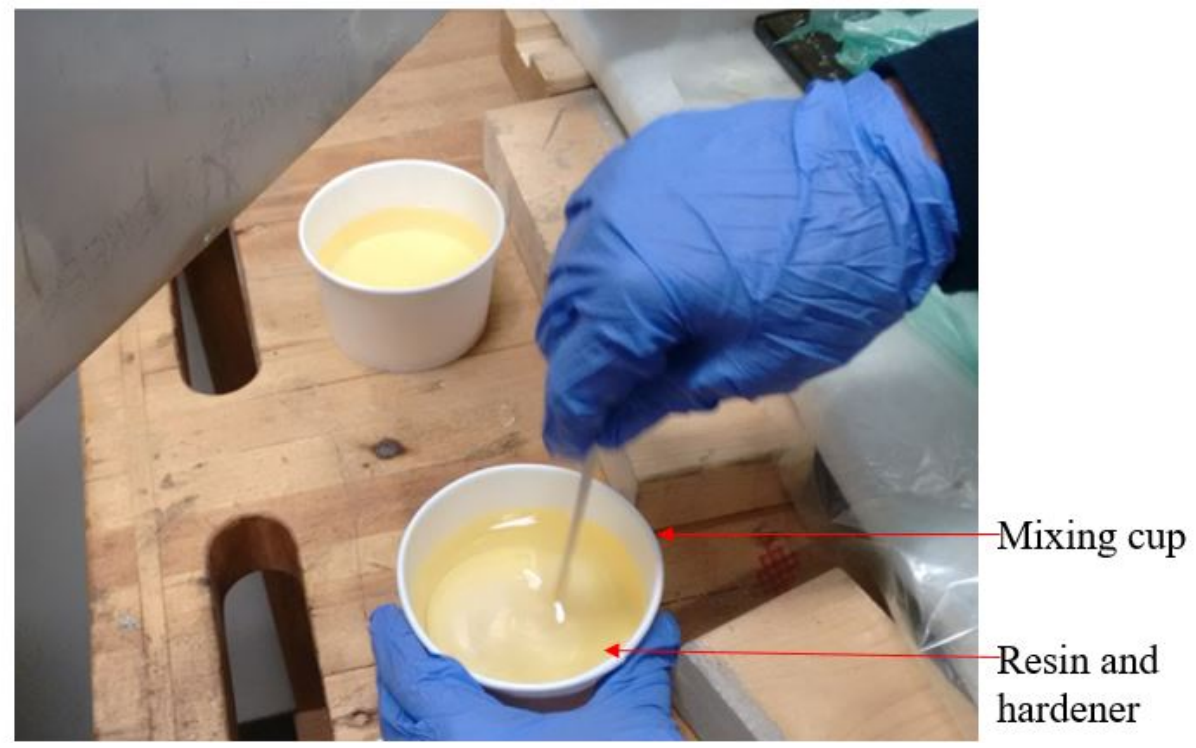

Figure 3.9: Mixing resin and hardener 
Step 9: One end of the tube was immersed in resin and hardener's solution and it was unclamped. As air was being pulled from the other end of the tube, resin started to flow from the cup to the tube and was distributed over the fiberglass via the T-connector. Resin flow path is shown in Figure 3.10.

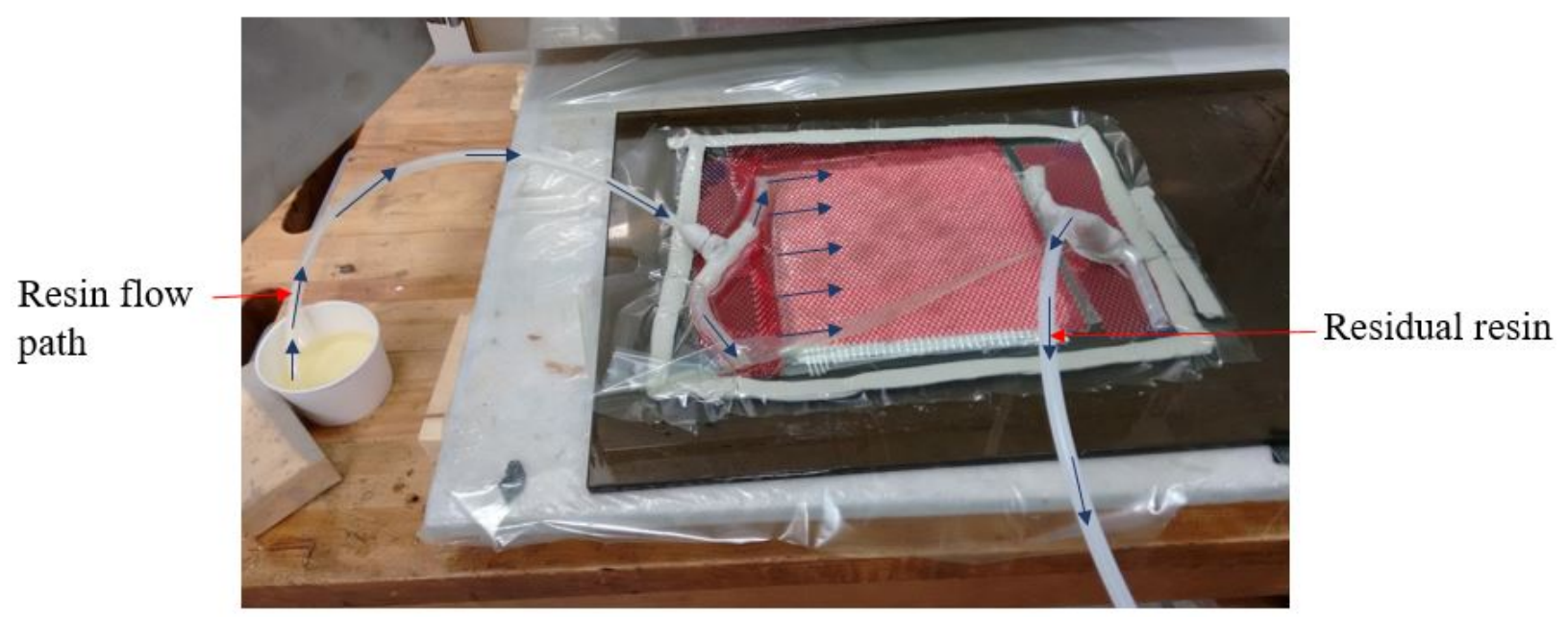

Figure 3.10: Resin flow path under vacuum

Before all the resin was pulled, the loose end of the tube was clamped using the C- clamp in order to avoid any air entry. After all the resin infused the fabric, the vacuum pump was turned off. The system was allowed to cure for 24 hours. After the panel was cured, the sealant tape, vacuum bagging film, perforated film and resin infusion mesh were removed and the fiberglass panel was taken out. Since it had sharp edges, the sides were covered using tape for safety. A typical fiberglass panel after curing is shown in Figure 3.11.

Subsequently, the test samples were cut from the panel using a diamond saw (UKAM Smart Cut 6001 GP Sectioning Saw). Tensile test specimens were made from four ply panel with $[90 / 0]_{s}$ configuration. Impact and flexural test specimens were made from six ply panel with $[0 / 90 / 0]_{s}$ configuration. Details on the specimens are 


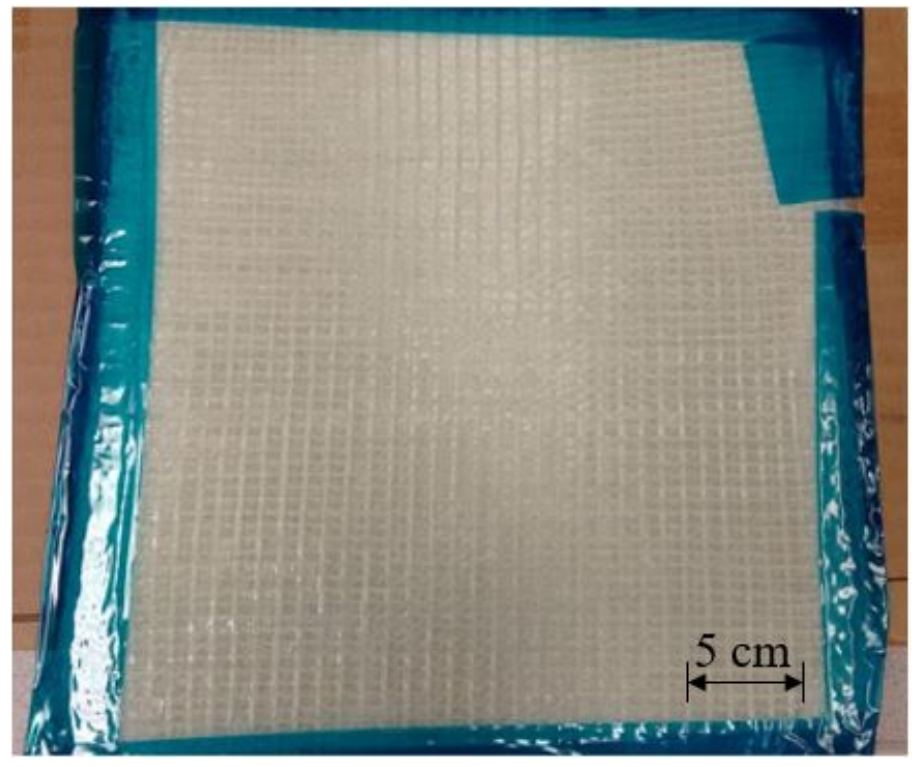

Figure 3.11: Fiberglass panel after curing

provided in Chapter 4.

\subsection{D Printed Fixture for Optical Fiber Ingress/Egress Points}

The points where optical fibers enter and exit the composite panel are vulnerable to damage during manufacturing and cutting operations. In order to protect the optical fibers, a 3D printed structure was made. Three considerations were made during its design:

1. Optical fibers should be fully placed inside the structure and remain undamaged during VARTM processing.

2. The design should be compatible with VARTM without negatively affecting the process in any way.

3. After curing, the fixture should be easy to remove.

The objective was to keep the optical fiber coiled inside this fixture during the 
VARTM process. Various designs were developed for this purpose and were tested under vacuum. All the proposed designs were able to accommodate coiled optical fibers within them fulfilling the first requirement. Applying mold release wax and PolyVinyl Alcohol (PVA) release film before placing them over fiberglass for VARTM would allow them to be removed after the curing process. Thus, the third requirement was also met. The challenge was to come up with a design which would satisfy the second requirement. All the designs were printed using rapid prototyping and were observed in VARTM setup. It was observed that the structure made the vacuum bagging film follow their profile and in this process, created a gap between the bagging film and fiberglass. This gap could allow resin to collect during infusion process. Therefore, modifications were made in the structure to allow the bagging film to sit on it while the vacuum was created. These changes led to the design and manufacturing of the final design which consisted of 5 parts. It was easy to assemble and disassemble and did not create any gap between bagging film and fiberglass, thus, fulfilling the second requirement. Table 3.1 summarizes all the designs and their corresponding requirement fulfillments.

Table 3.1: Summary of fixture design iterations

\begin{tabular}{|l|l|l|l|l|}
\hline Design & Description & Requirement $\mathbf{1}$ & Requirement $\mathbf{2}$ & Requirement $\mathbf{3}$ \\
\hline $\mathbf{1}$ & 2 part plug & Yes & No & Yes \\
\hline $\mathbf{2}$ & Sloped 3 parts & Yes & No & Yes \\
\hline $\mathbf{3}$ & Curved 3 parts & Yes & No & Yes \\
\hline $\mathbf{4}$ & Curved with side parts & Yes & No & Yes \\
\hline $\mathbf{5}$ & $\begin{array}{l}\text { Curved with modified } \\
\text { side parts }\end{array}$ & Yes & Yes & Yes \\
\hline
\end{tabular}

The design and evolution of the fixture is described in the following sections. 


\subsubsection{First Design}

The fixture had a small hole at the bottom through which optical fiber would enter and remain safely coiled. The initial design had 2 parts- a cylindrical shaped top part and a bottom part in the shape of a cap (Figure 3.12). This structure's

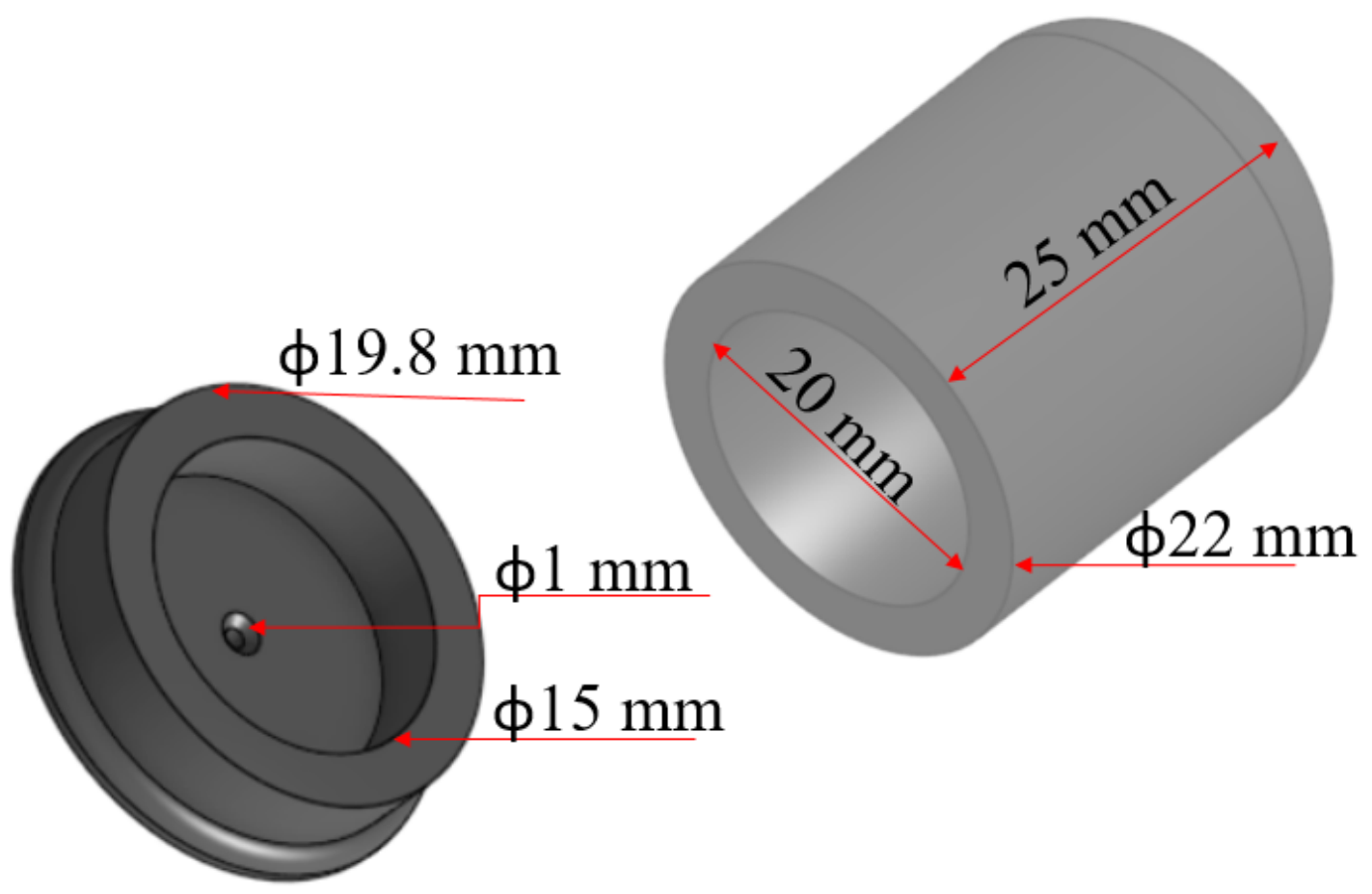

Figure 3.12: Parts of the first design

assembly is shown in the Figure 3.13. The objective was to make the optical fiber enter this fixture from the bottom hole (1 mm diameter) and to keep it coiled in the top cylindrical space. Upon further observation, it was noticed that the removal of the fixture to retrieve the optical fibers might break/ damage the fibers as the fixture would have to be pulled with a force. Hence, this design was changed and not printed. A better approach was to make the main body with 2 pieces which could fit face to face and could still be easily detached. This improvement was incorporated in the following designs. 


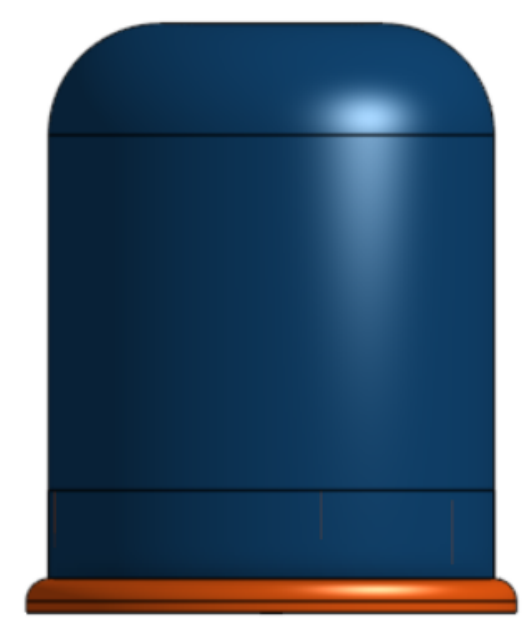

Figure 3.13: Assembly of the first design

\subsubsection{Second Design}

The fixture design was modified from the first design. In this attempt, a male and a female part were designed which could be easily opened and closed. These parts could be easily disassembled after curing. Both of these parts had semi-circular holes at the bottom which allowed optical fiber to enter and remain coiled inside the cylindrical space between them. A separate cylindrical cover would sit on top of these structures to complete the assembly. The parts are shown in Figure 3.14. For the removal of this assembly, the top cap would be removed first which would uncoil the optical fiber and make it emerge out of the structure with its end in between the bottom hole. Then the male and female part would be separated and removed. This would leave the optical fiber exiting from the ingress/egress point. The parts for this and all the subsequent designs were printed with Acrylonitrile Butadiene Styrene (ABS) plastic using Fortus 250MC 3D printer at Carleton University.

In order to check the compatibility of the second design during VARTM, the assembly was placed on top of a cured fiberglass sample. It was fixed on the composite 


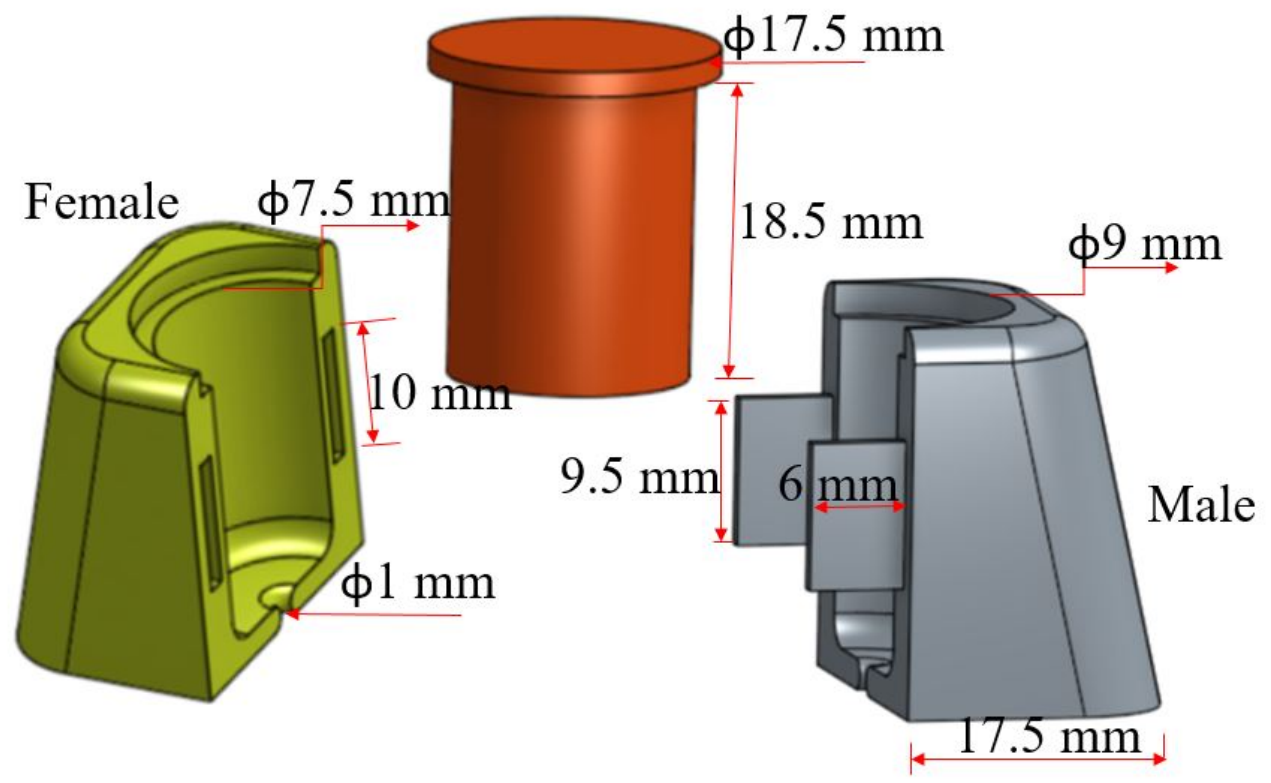

Figure 3.14: Parts of the second design

using a spray adhesive. Sealant tape was applied on the sides and the system was covered using a vacuum bagging film. The setup was sealed using sealant tape as mentioned in Section 3.1 and the vacuum pump was switched on in order to suck all the air and create vacuum (-30 $\mathrm{mm}$ of $\mathrm{Hg}$ ). The bagging film spread and covered the complete structure (Figure 3.15). As seen in Figure 3.15, the vacuum bagging film did not follow the complete profile of the fixture and there was a gap on the sides of the structure. This could allow the resin to accumulate in that gap during the infusion process. After curing, it would be extremely difficult to remove the cured resin from that space. These observations led to further modification of the fixture.

Based on the observation of the second design in vacuum, the third fixture design focused on a structure which would allow the bagging film to spread along the profile of the structure. As observed in Figure 3.15, vacuum bagging film spreads in the shape of a parabola on both sides. Hence, male and female parts were extended on the sides with the extended profile being the same as seen in Figure 3.15. 


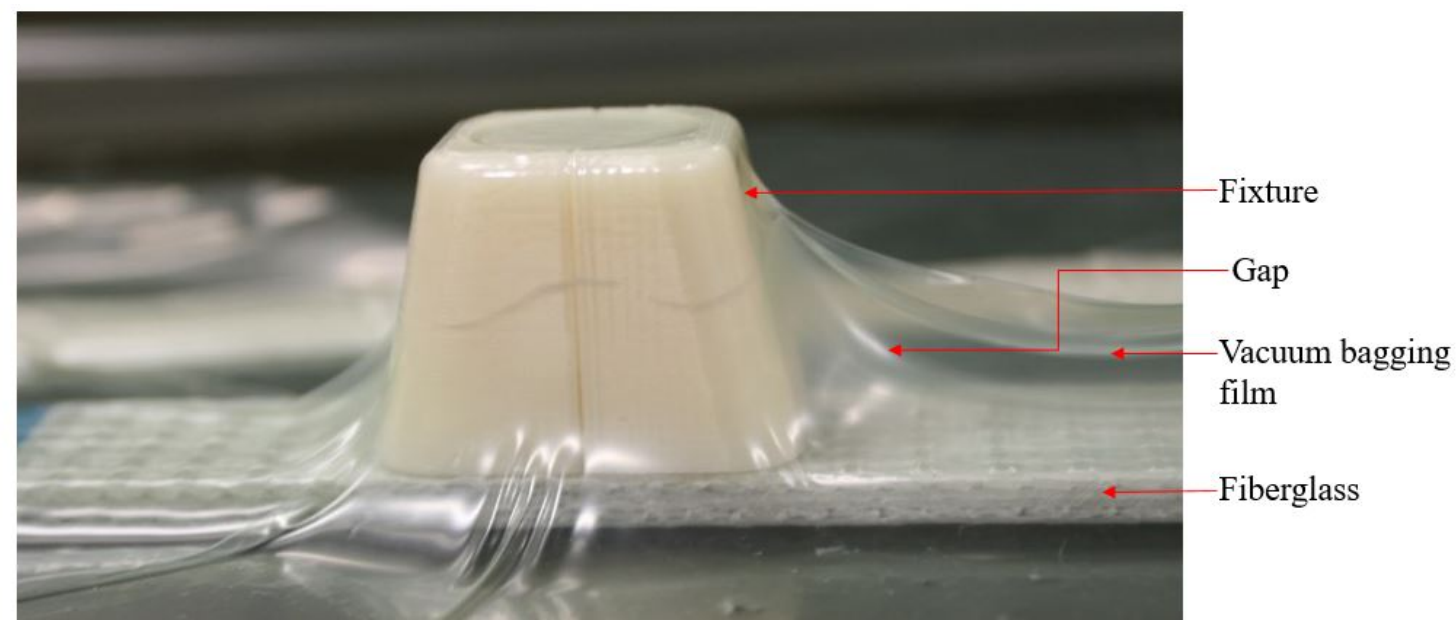

Figure 3.15: Assembly of second design in vacuum

\subsubsection{Third Design}

The third part consisted of male end, female end and a cap at the top. The sides were extended to match the profile of vacuum bagging film as observed in the last experiment. Fiber optics would enter from the bottom and remain coiled inside the fixture similar to last design. The parts of this design have been shown in Figure 3.16.

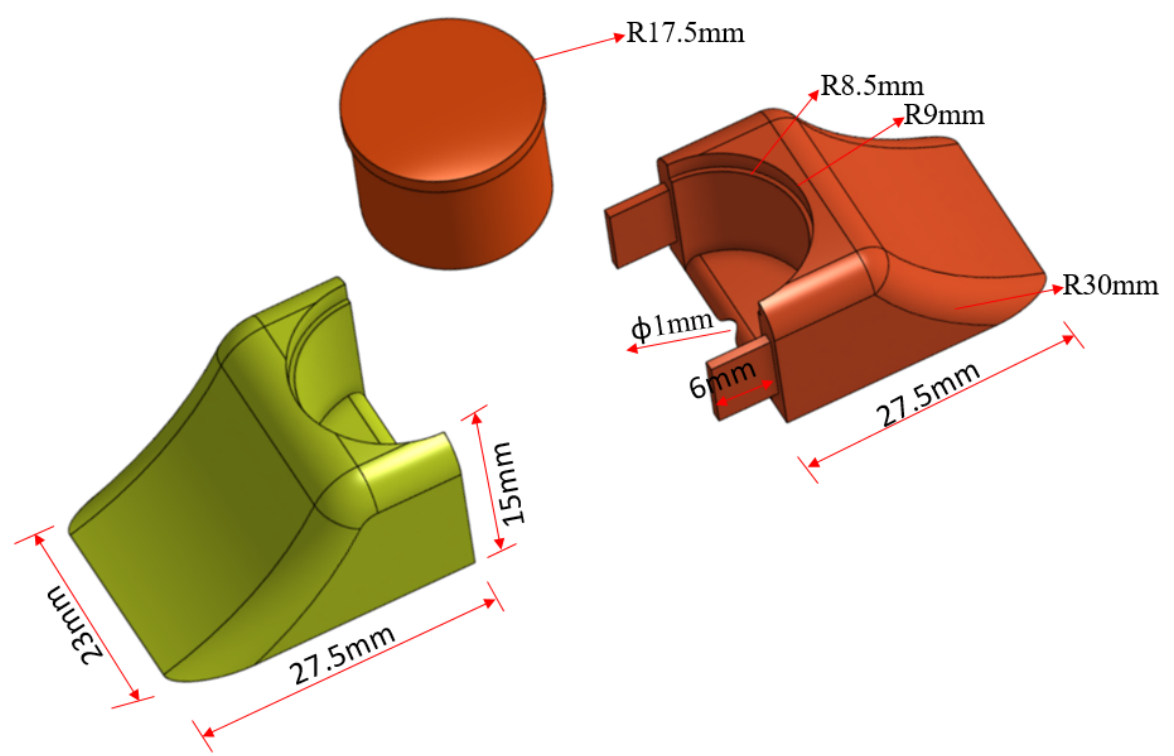

Figure 3.16: Parts of third design 
The parts were 3D printed and were inspected under vacuum to investigate if the new modification met the requirements. The parts were attached to a composite panel using a spray adhesive and the assembly was inspected under vacuum as seen in Figure 3.17. This time, the vacuum bagging film followed the fixture's profile on both ends. The design had been optimized to meet its requirements. Resin would not be collected at any undesired location and hence manufacturing would be normal. However, it was observed that there was still a gap present on left and right sides of

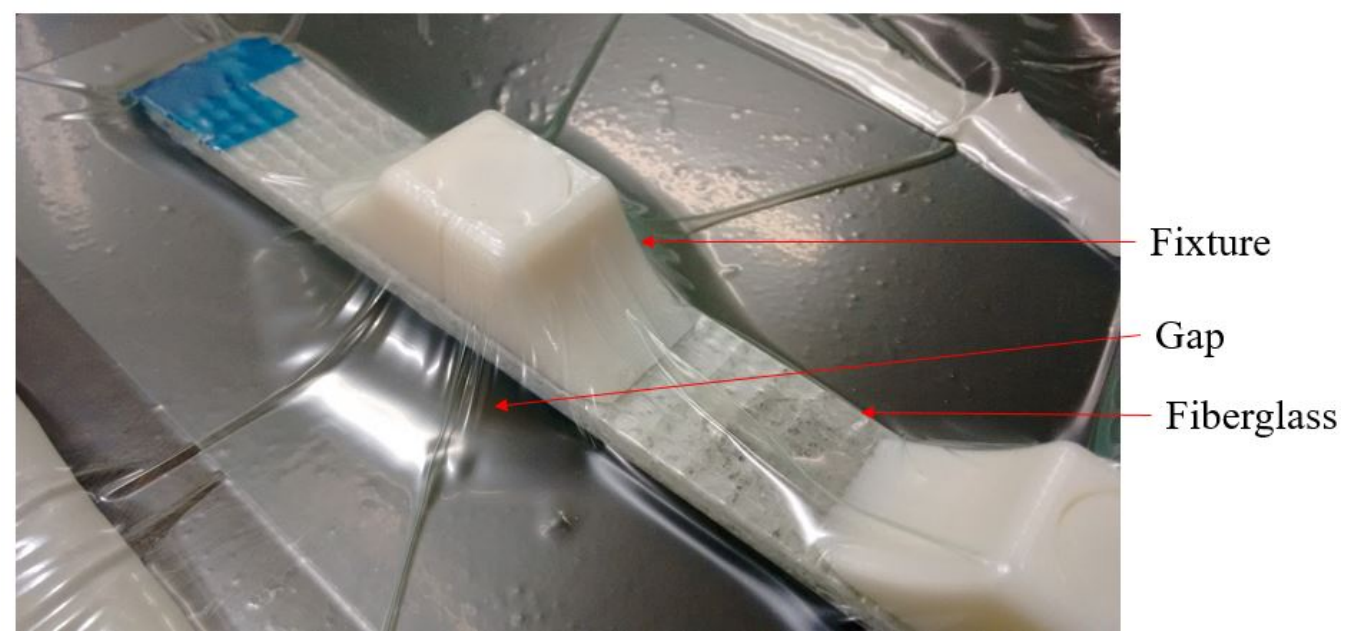

Figure 3.17: Assembly of third design in vacuum

the fixture. One possible solution to cover this gap would be to use wax to seal this space. It would be practical while manufacturing a panel with a few ingress/egress points. Since the panels to be manufactured for this research were meant to have four to six tensile specimen cut out of them, a more efficient method than using wax was explored.

\subsubsection{Fourth Design}

The deformation profile of the vacuum bagging film located on the sides of fixture was observed to be the same as earlier. In order to address this issue, two side 
parts were made which would go on the left and right of the structure respectively (Figure 3.18). The complete assembly drawing of the fixture is shown in Figure 3.19.

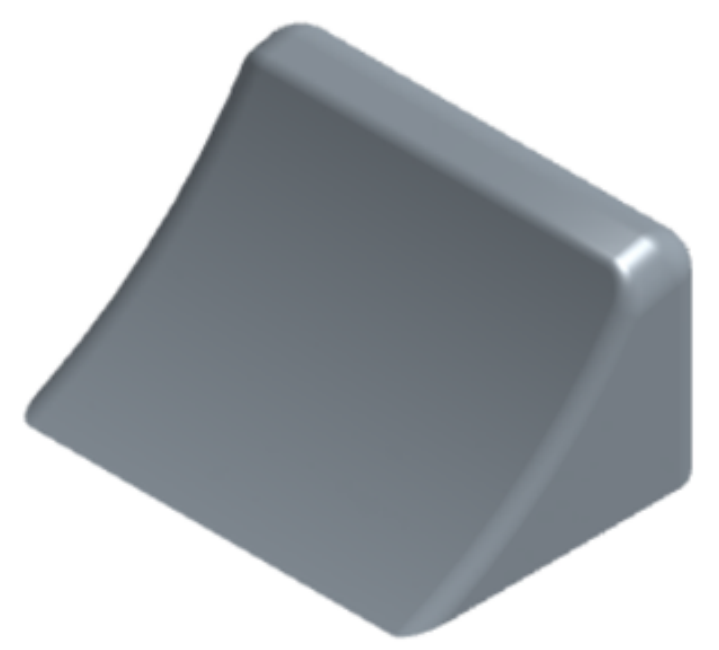

Figure 3.18: Side part design

Figure 3.19: Assembly of Fourth design

After the parts were printed, they were assembled over the fiberglass fabric and placed in vacuum. Stretchlon film was used as the vacuum bagging material in this experiment. As expected, this design performed better than the third design. The bagging film followed the complete profile of the fixture as shown in Figure 3.20. There was however, a very small noticeable gap in the corners as seen in Figure 3.20. This demonstrated that there was still a need for improvement in the existing design.

\subsubsection{Fifth Design}

In order to cover the small gap observed in Design 4, a curvature was added to the side part (Figure 3.21). This made the ends run smoother and allowed the bagging film to follow the complete profile of the fixture under vacuum. 


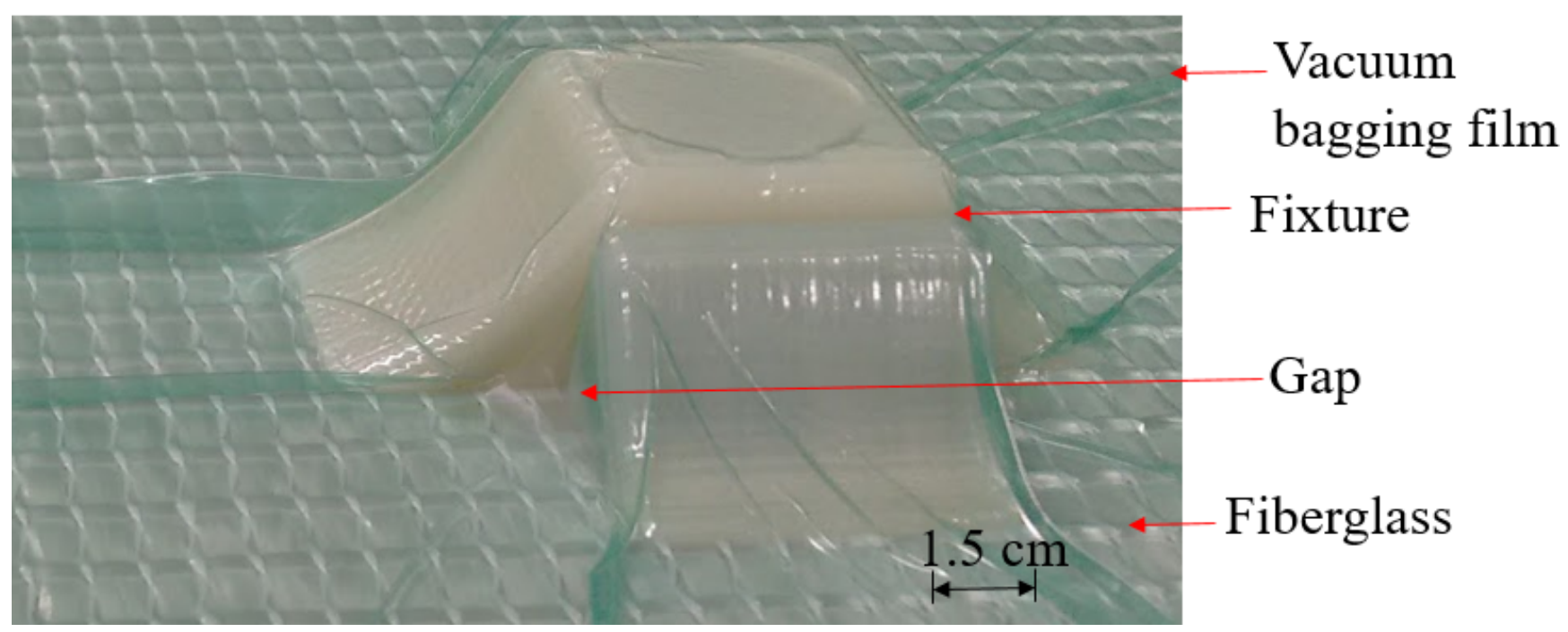

Figure 3.20: Assembly of the fourth design in vacuum

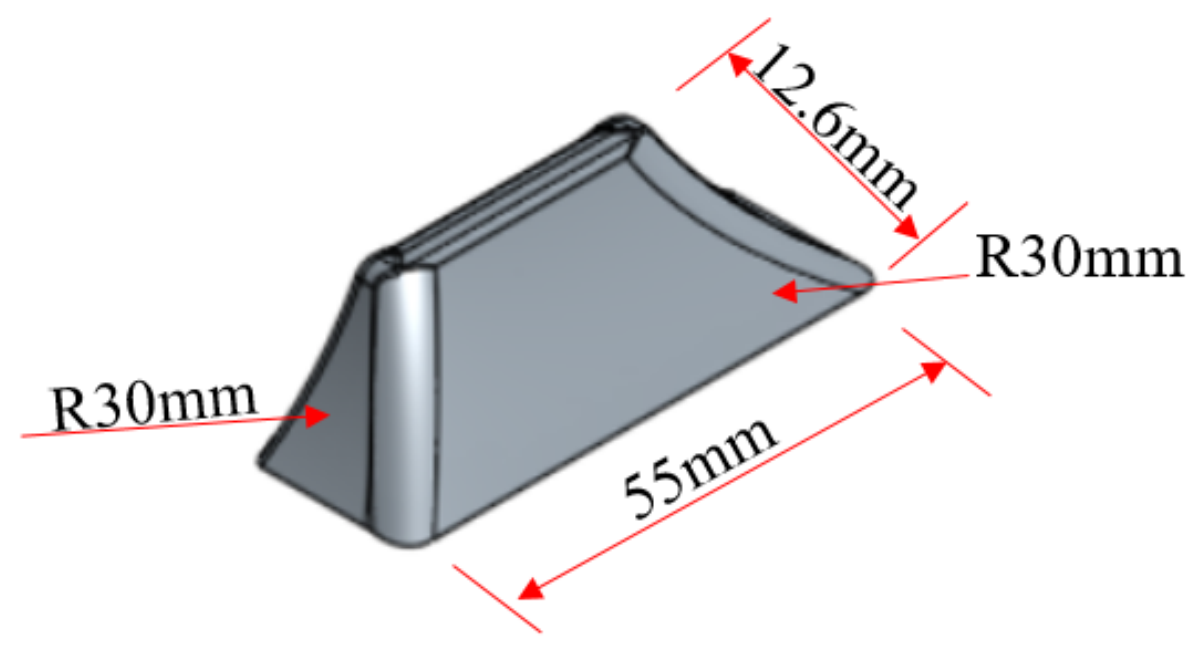

Figure 3.21: Side part of the fifth design 
All the parts of the fifth design were assembled and inspected under vacuum (Figure 3.22). It was observed that vacuum bagging film spread over the fixture without leaving any gap. This design was therefore finalized and was used as the fixture for protecting optical fibers during the VARTM process.

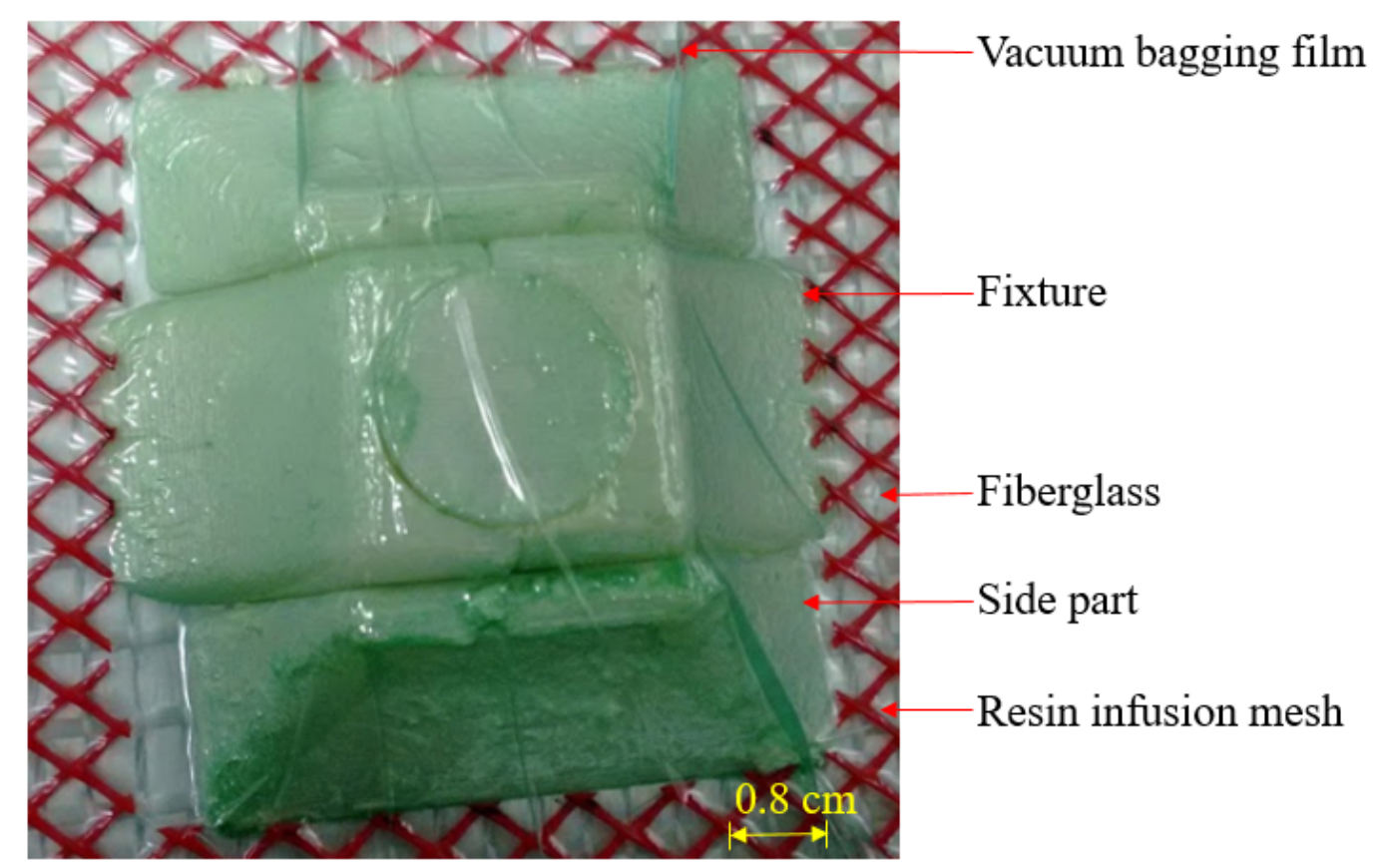

Figure 3.22: Fifth design in vacuum

\subsubsection{Production Testing Using VARTM}

The fixture was used to protect optical fiber during VARTM. It was important to remove the fixture after the composite was cured. PolyVinyl Alcohol release agent and mold release wax were used for this purpose. PolyVinly Alcohol release agent was applied to the parts using a painting brush after they were coated with wax. After the parts dried up, they were fixed over fiberglass using spray adhesive. The parts were placed over fiberglass, which had perforated film on top. The optical fiber entered through the bottom hole as shown in Figure 3.24. 


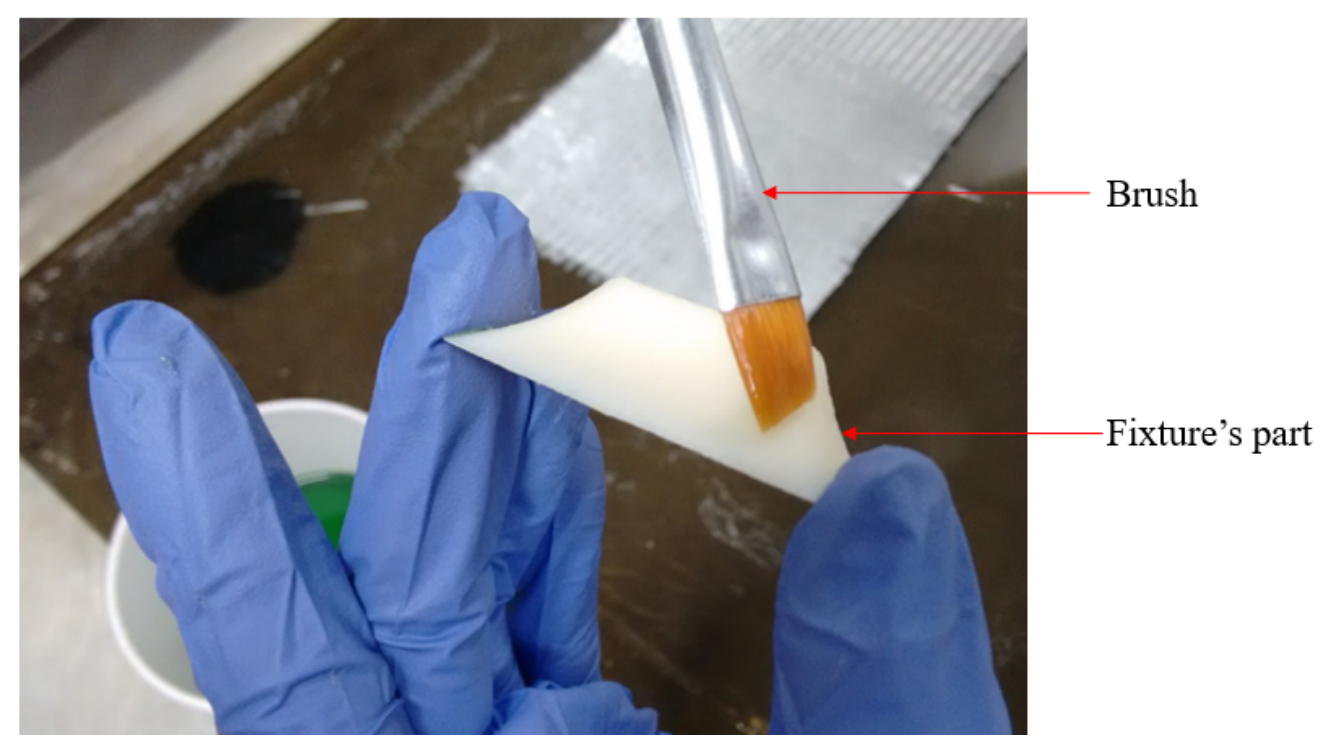

Figure 3.23: Applying PVA over fixture

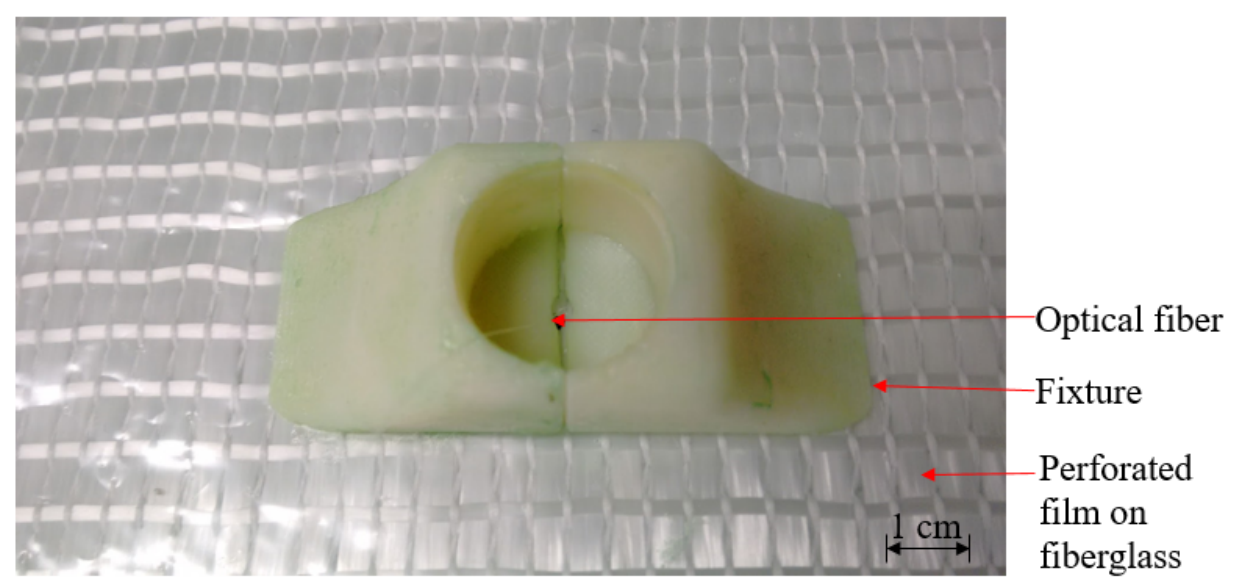

Figure 3.24: Optical fiber entering the fixture 
In order to fill the gaps between the parts of the fixtures, wax was used as seen in Figure 3.25. This was done to make sure that resin did not enter inside the fixture during the infusion process.

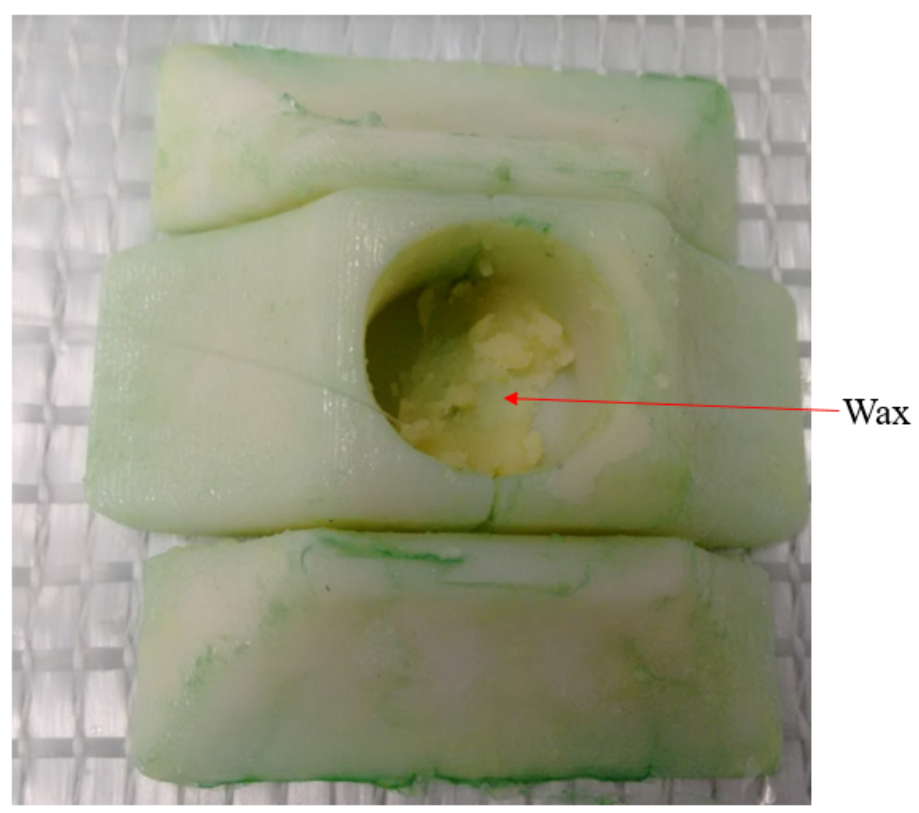

Figure 3.25: Use of wax to fill the gaps

Four pairs of fixtures were used at eight locations with two of them being on the same line. These were the ingress and egress points of optical fibers spaced $80 \mathrm{~mm}$ apart. These number of fixtures were good enough to make four tensile specimens as shown in Figure 3.26. The fixture's base and side parts were assembled as seen in Figure 3.27. Optical fibers were coiled and placed in the cylindrical space of the fixture. The top cap was placed to complete the assembly as seen in Figure 3.29. Resin infusion mesh was placed on top. The region around fixtures were cut to make the infusion mesh sit on the fiberglass (Figure 3.30).

Complete VARTM setup was made as mentioned in Section 3.1. The setup and resin flow direction can be seen in Figure 3.31 and Figure 3.32 respectively.

The setup was disassembled after 48 hours to check the integrity of fixtures and the optical fibers. It was noted that the rear part of the panel was not fully infused 


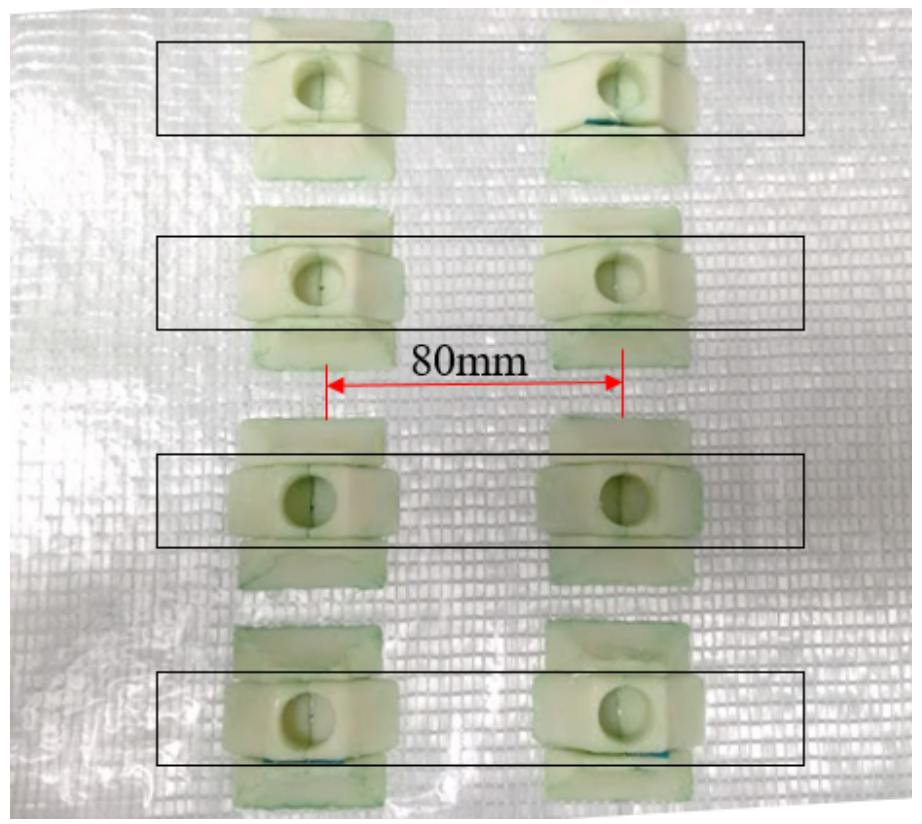

Figure 3.26: Layout of four tensile specimens

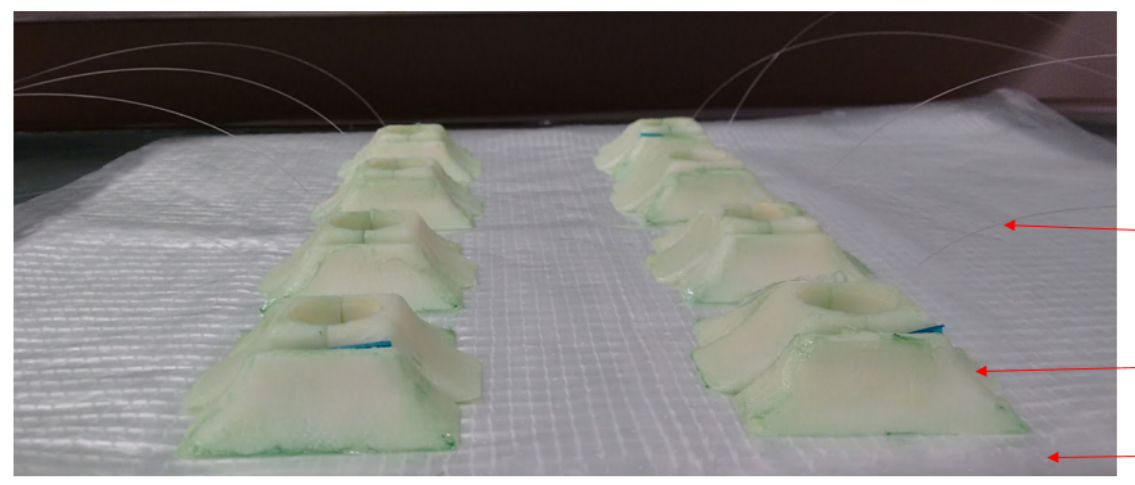

Optical Fiber

Figure 3.27: Optical fibers in the fixture

-Fixture

Perforated film on fiberglass 


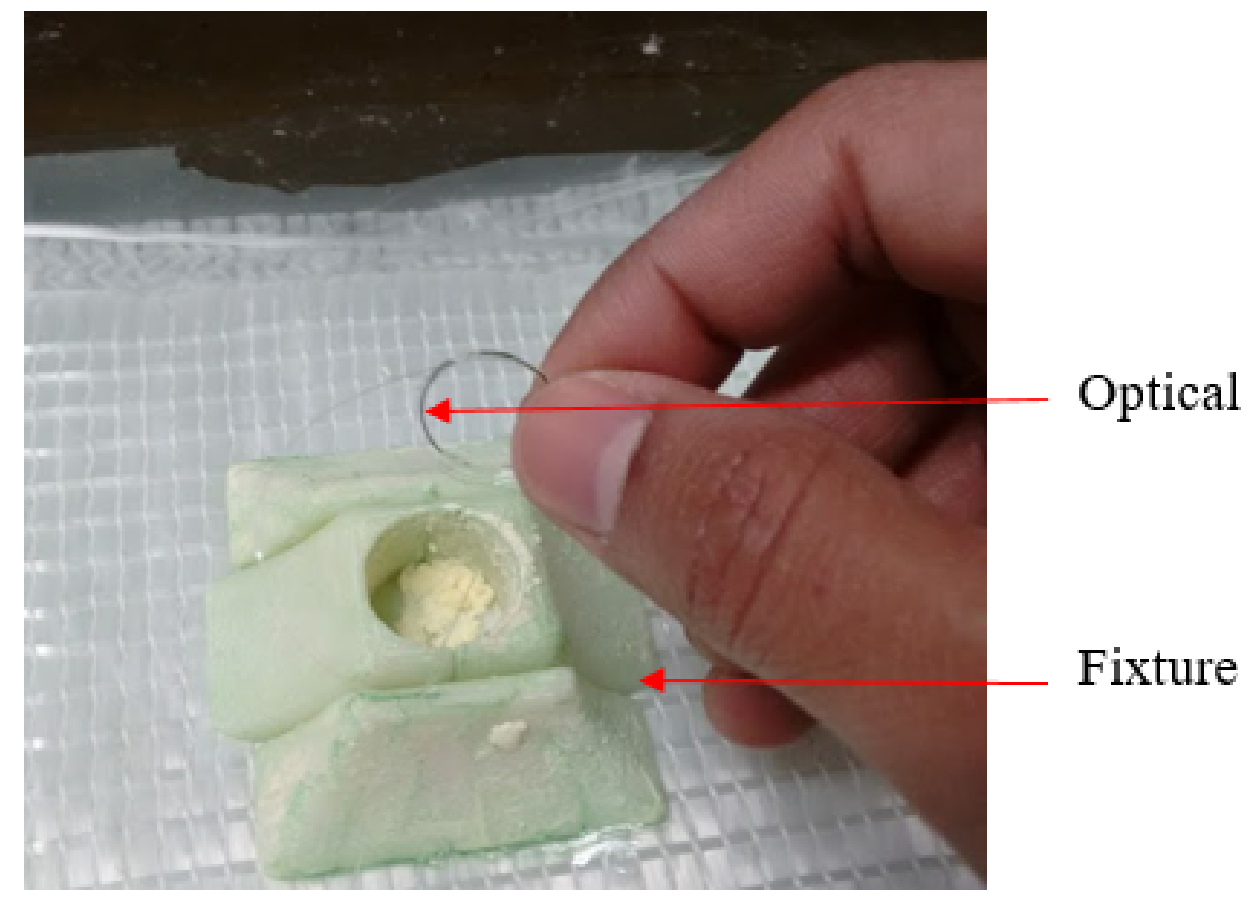

Figure 3.28: Coiling optical fiber in the fixture

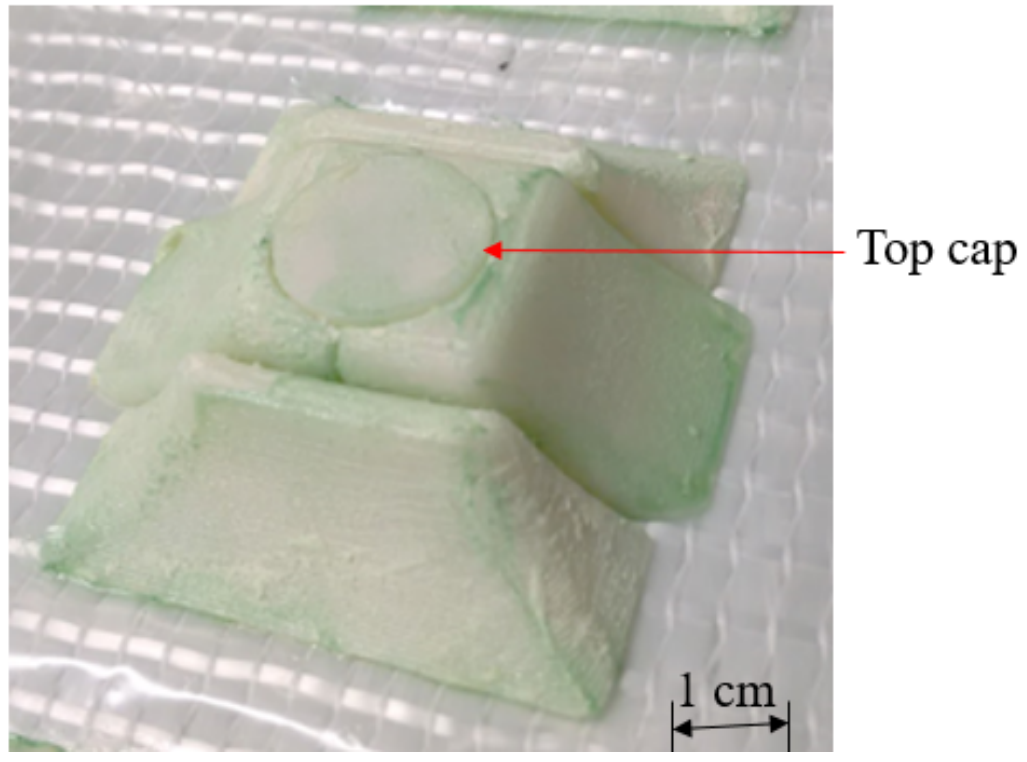

Figure 3.29: Complete assembly of the fixture with optical fiber coiled inside 


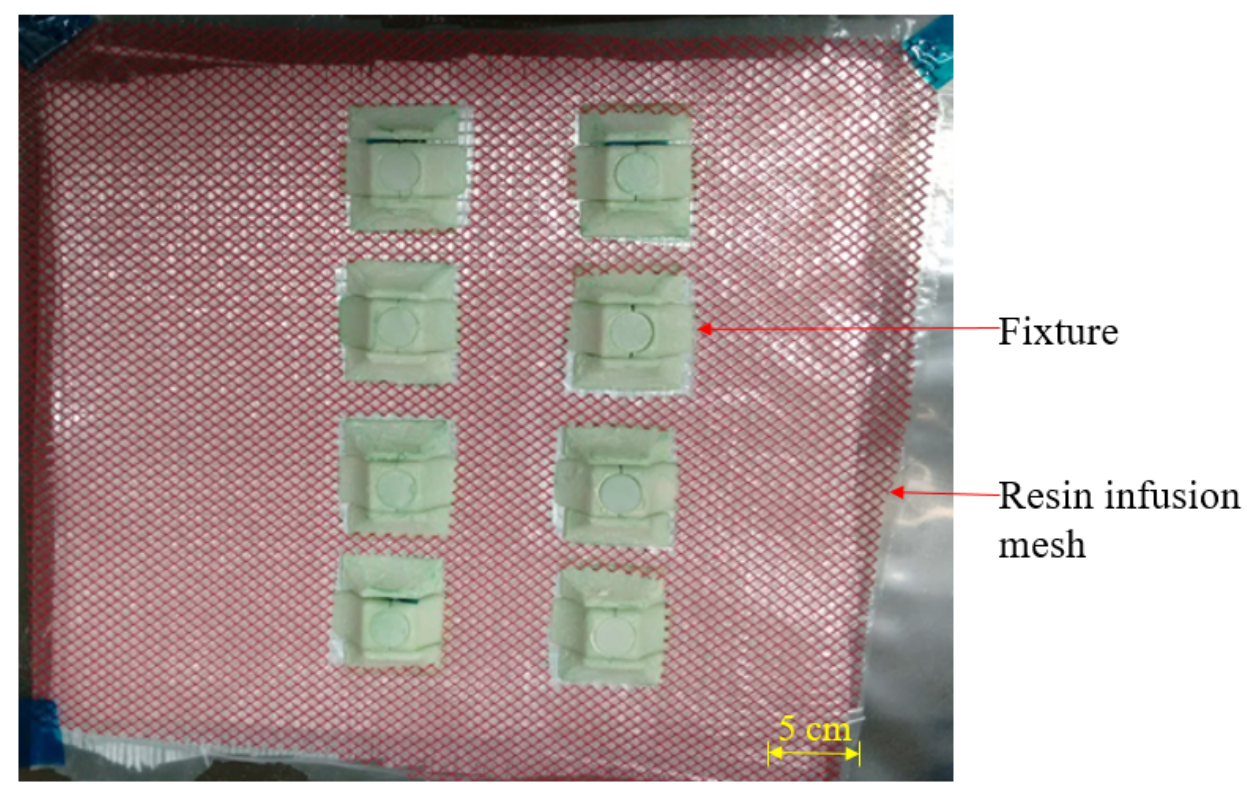

Figure 3.30: Resin infusion mesh over the fixtures

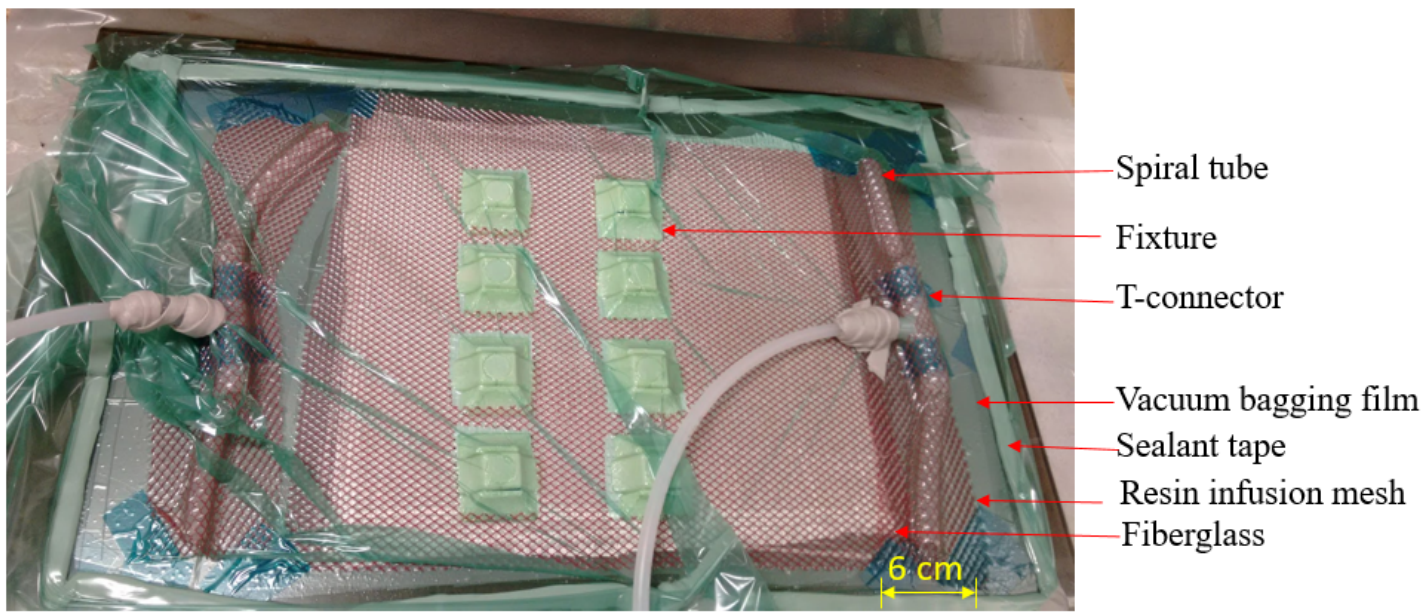

Figure 3.31: VARTM setup with fixtures 


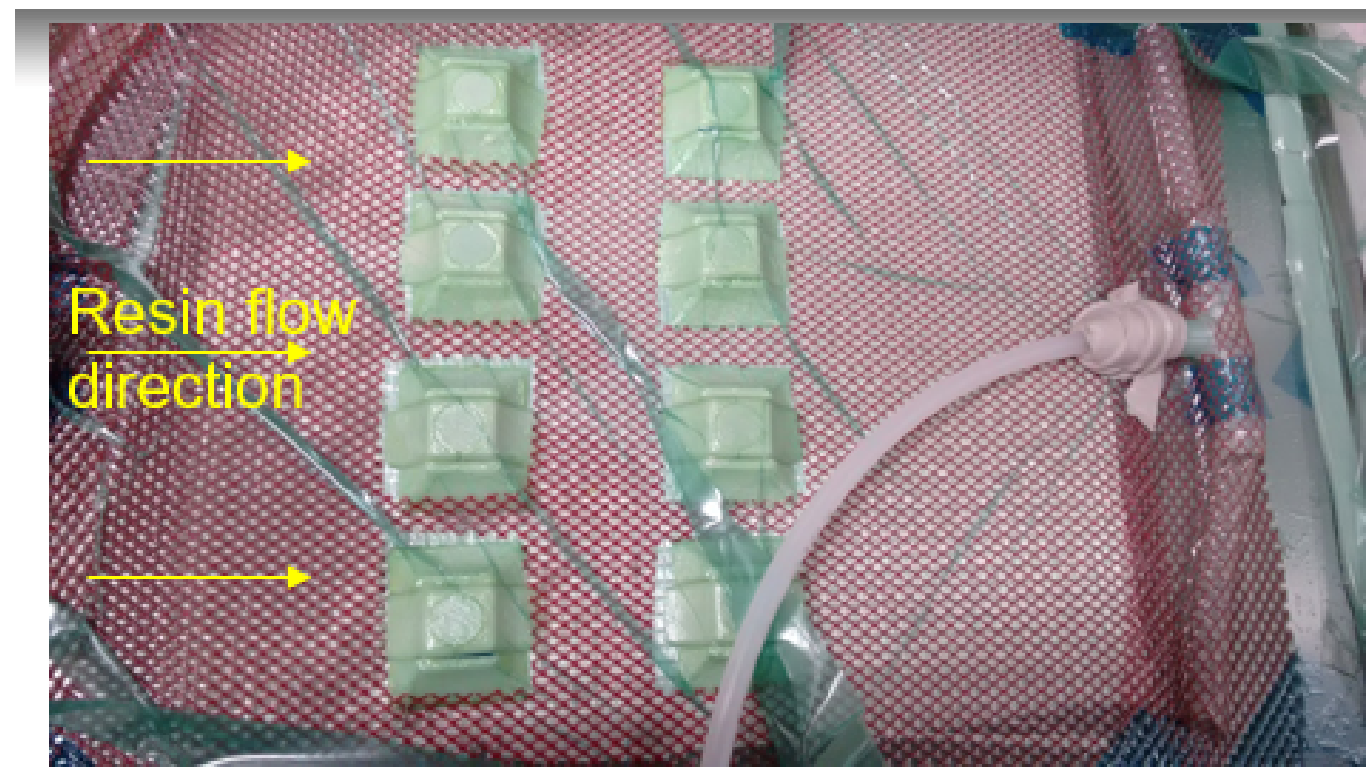

Figure 3.32: Resin flow direction

(Figure 3.33). This could be due to slowing down of the resin infusion process by the presence of fixtures. Hence, the resin gelled before reaching the end. However, the uncured part was away from the fixtures and there was still enough cured fiberglass to cut 4 tensile specimens. One of the fixtures was disassembled to check the condition of optical fiber inside. The side parts were removed and the main parts were separated as shown in Figure 3.34.

The coiled optical fiber was removed from the top cap. This was done very carefully as the optical fiber could very easily be broken . It was found that the optical fiber remained undamaged after the fixture was completely disassembled (Figure 3.35). Hence, the goal of protecting the ingress/egress point using the fixture was accomplished.

The side parts from all the fixtures were removed and tensile coupons were cut from the panel using a diamond saw. The fixtures were disassembled and optical fibers were taken out from them. In one of the samples, the optical fiber broke during the process of fixture disassembly. Hence, a total of three tensile coupons were available 


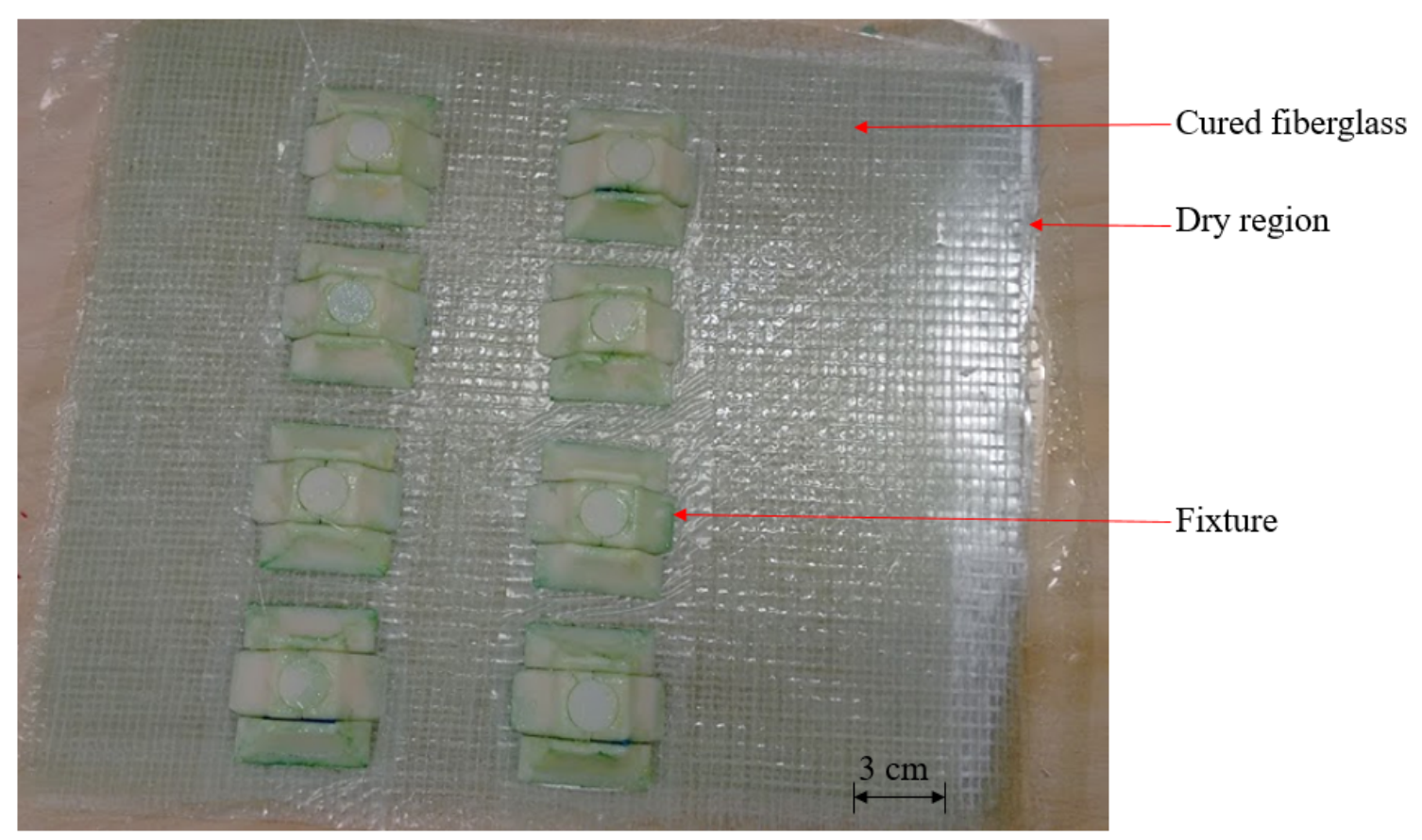

Figure 3.33: Cured fiberglass

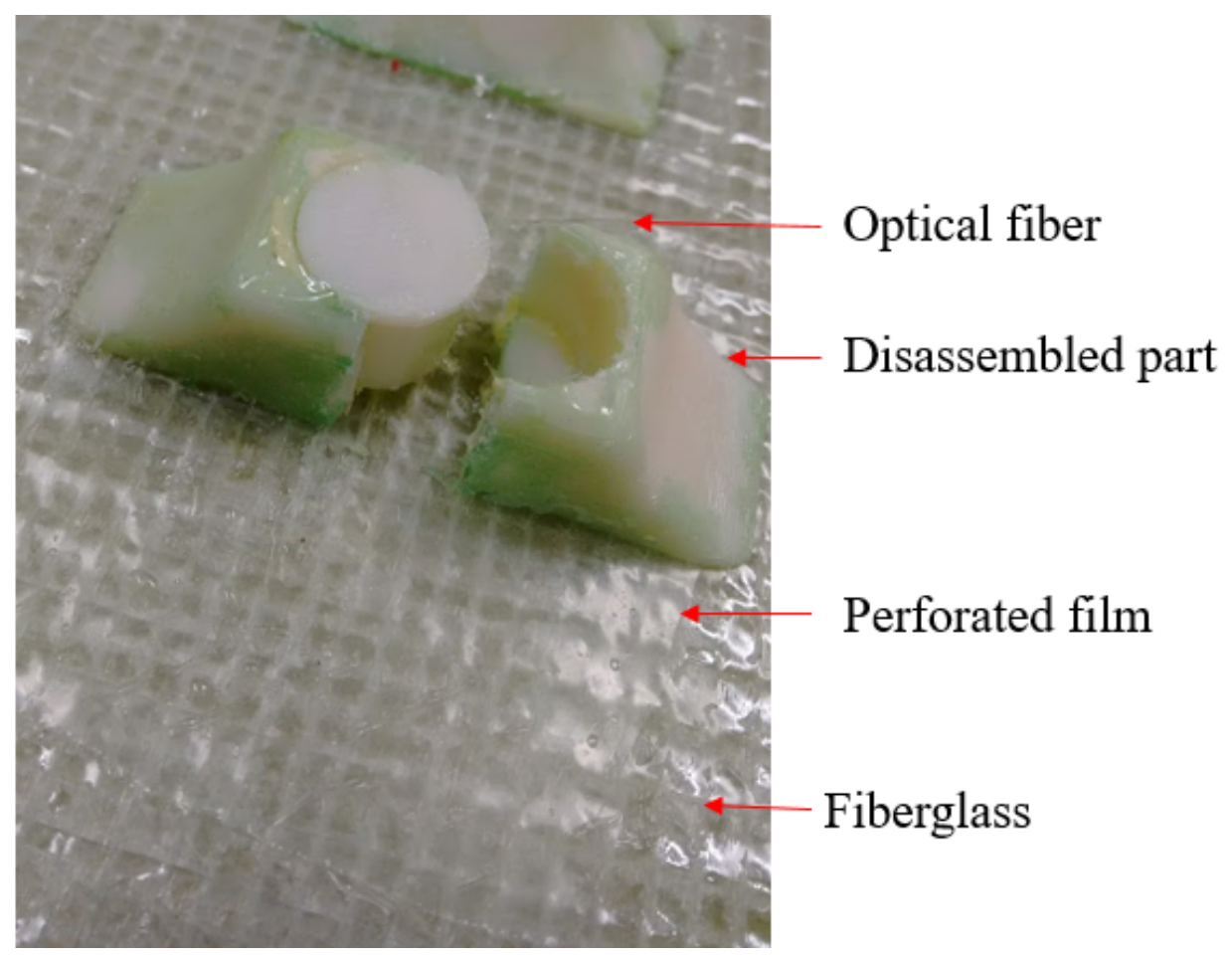

Figure 3.34: Disassembling of fixture 


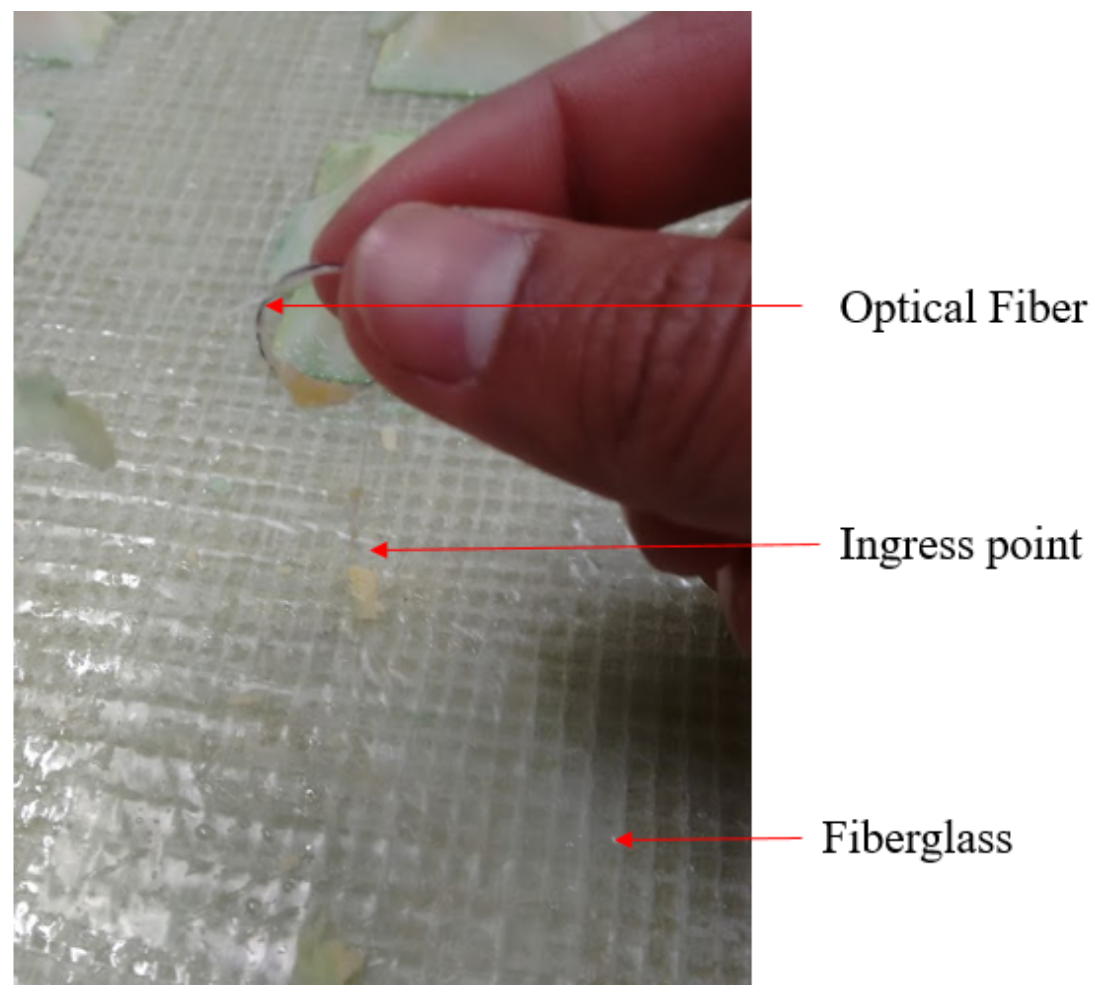

Figure 3.35: Optical fiber taken out from the fixture

to extract data from the embedded optical fibers during tensile testing. In order to check if the optical fibers were undamaged inside the composite, a laser light source was connected to one end. Red Laser light $(\lambda=630 \mathrm{~nm})$ was passed from that end and its transmission was observed on the other end (Figure 3.36). This showed that the embedded optical fibers remained undamaged during manufacturing and cutting operation. Tensile tests were performed on the coupons and the results were recorded. The method of testing and results are mentioned in Section 3.3 and Chapter 4 respectively.

\subsection{Mechanical Testing}

It is important to know the change in mechanical properties of the materials after they have been damaged. To study the effect of embedded optical fibers in 


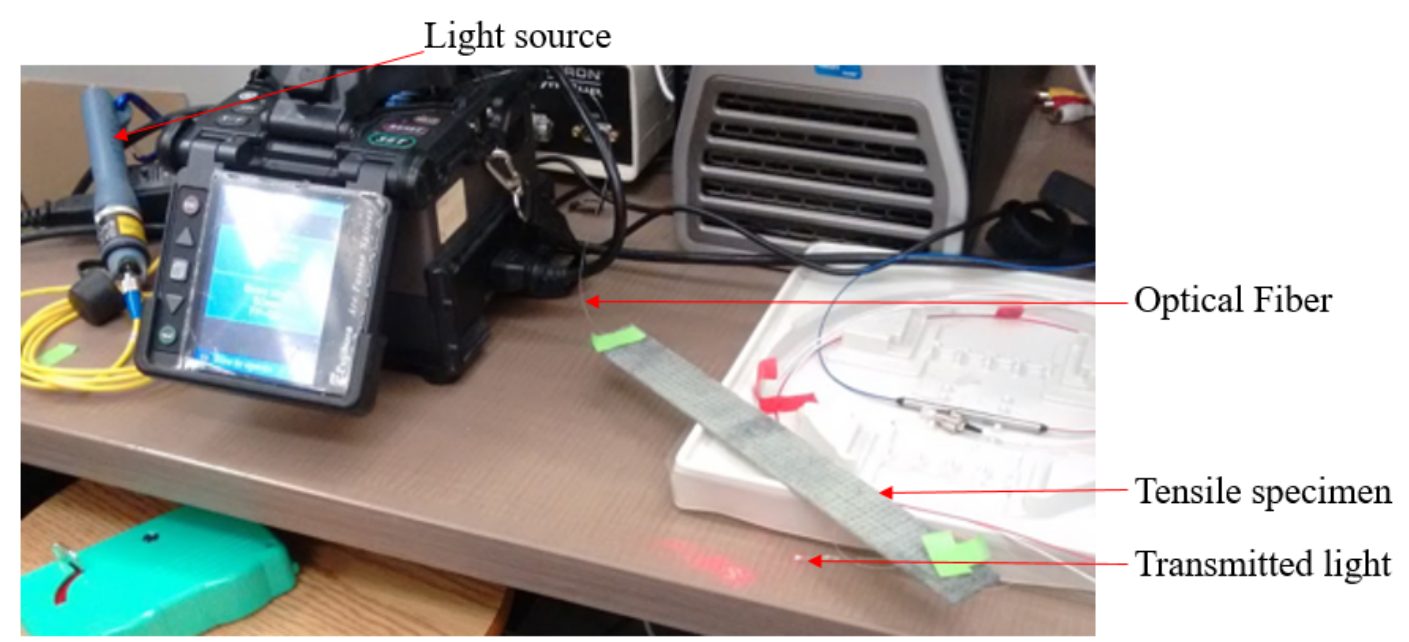

Figure 3.36: Checking the integrity of embedded optical fiber

fiberglass, tensile, impact and three point bend tests were carried out on the cured samples. After the composite panels were cured, two types of test coupons were cut : parent material (fiberglass) and fiberglass with embedded optical fibers. This was done to make sure that the samples with embedded optical fibers were from the same manufacturing batch as that of parent material without optical fibers.

\subsubsection{Tensile Test Specimen Fabrication}

Composite panels were manufactured using VARTM as explained in Section 3.1. Two panels were manufactured separately. Ply orientation in both samples were $[90 / 0]_{s}$. Optical fibers were embedded in the middle parallel to the ply direction as seen in Figure 3.37. As the ends of tensile coupons remains gripped during testing, ingress and egress points were located in the central region to make sure they stayed away from the grips. Both the panels had one embedded optical fiber. After the material was cured, tensile specimens were cut out of them using a diamond saw. Dimensions of the tensile coupons were measured after they were made. 


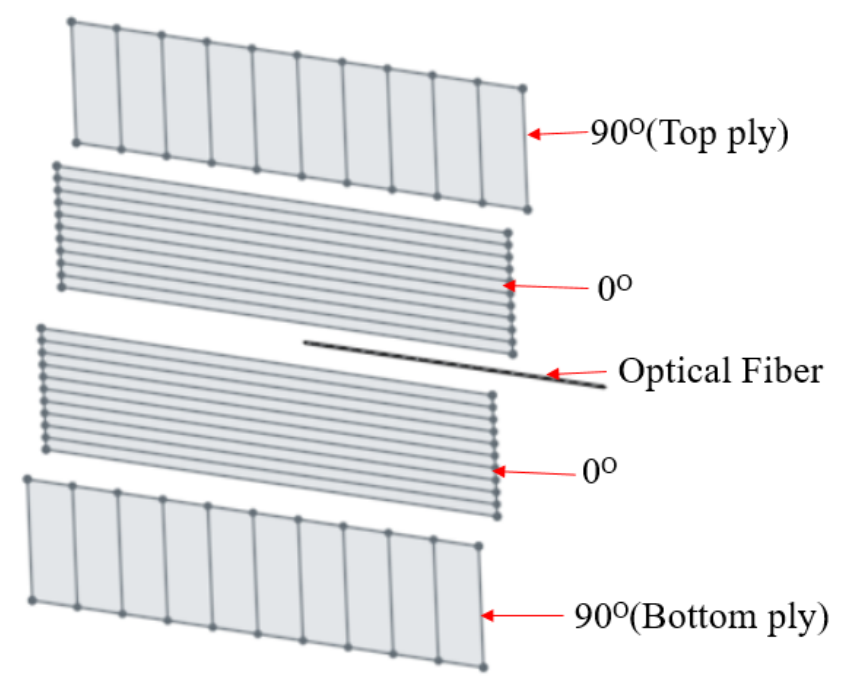

Figure 3.37: Schematic of ply orientation in tensile test coupons

One optical fiber sensor was also bonded on an AA6061 rectangular coupon. The sample was $31.77 \mathrm{~mm}$ wide, $3.186 \mathrm{~mm}$ thick and had a gage length of 137.34 mm. Resin and hardener (PT 2712) used for bonding was the same as used for the fiberglass during VARTM. The center line of the specimen was drawn using a pencil and optical fiber was bonded at center (Figure 3.38). The specimen was allowed to cure for 24 hours. Tensile testing was carried out as described in Section 3.3.2 and the data recorded by extensometer and optical fiber sensor were compared. The results of this test are reported in Chapter 4.

\subsubsection{Tensile Test Procedure}

Tensile tests were carried out to measure Young's Modulus of the material. Specimens were fabricated and tested as per ASTM D3039 [27]. Tensile tests were performed using a $100 \mathrm{kN}$ MTS machine (model number: 647.10A-01). The center line of all the specimens were marked using a pencil in order to align them with machine's grip. The specimens were loaded under a constant displacement rate of $2 \mathrm{~mm} /$ minute. An MTS axial extensometer (gage length=1 inch \pm 0.002 inch, model 


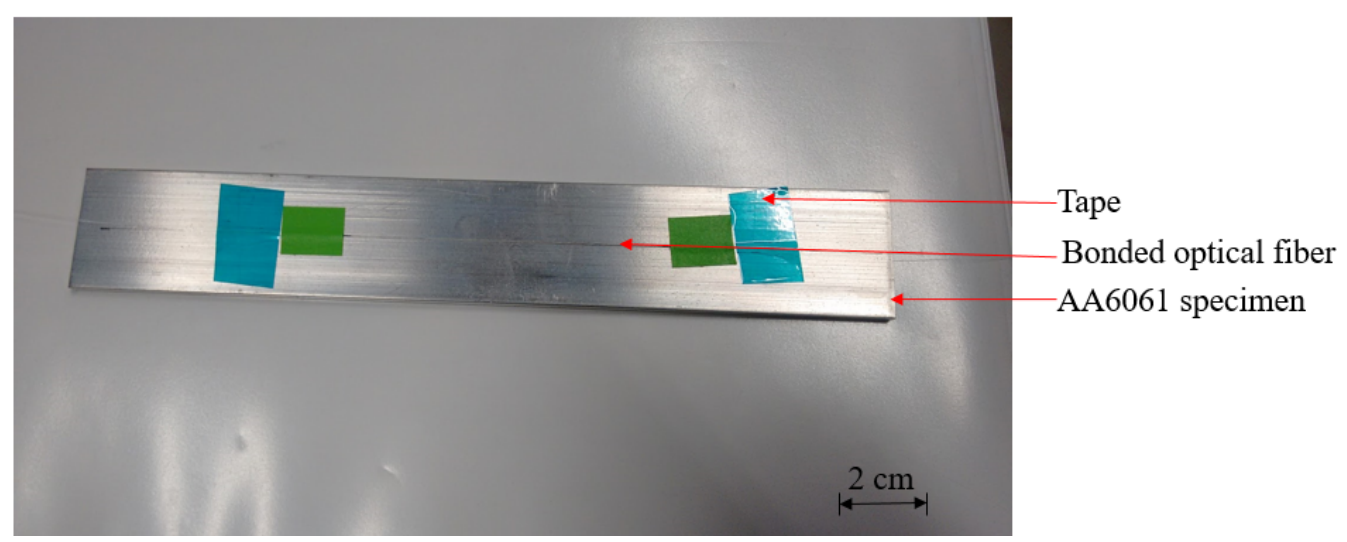

Figure 3.38: AA6061 with optical fiber bonded on the surface

number: 634.12E-24) was mounted on the specimen in order to measure axial strain values. Load, axial displacement, strain and time values were recorded automatically by the data acquisition system. Data were recorded at a frequency of $4 \mathrm{~Hz}$. Stress versus strain values were plotted and the Young's Modulus was calculated by measuring the slope of curve. The results for specimens with and without embedded optical fibers were compared to study the effect of optical fibers on mechanical strength of the host material.

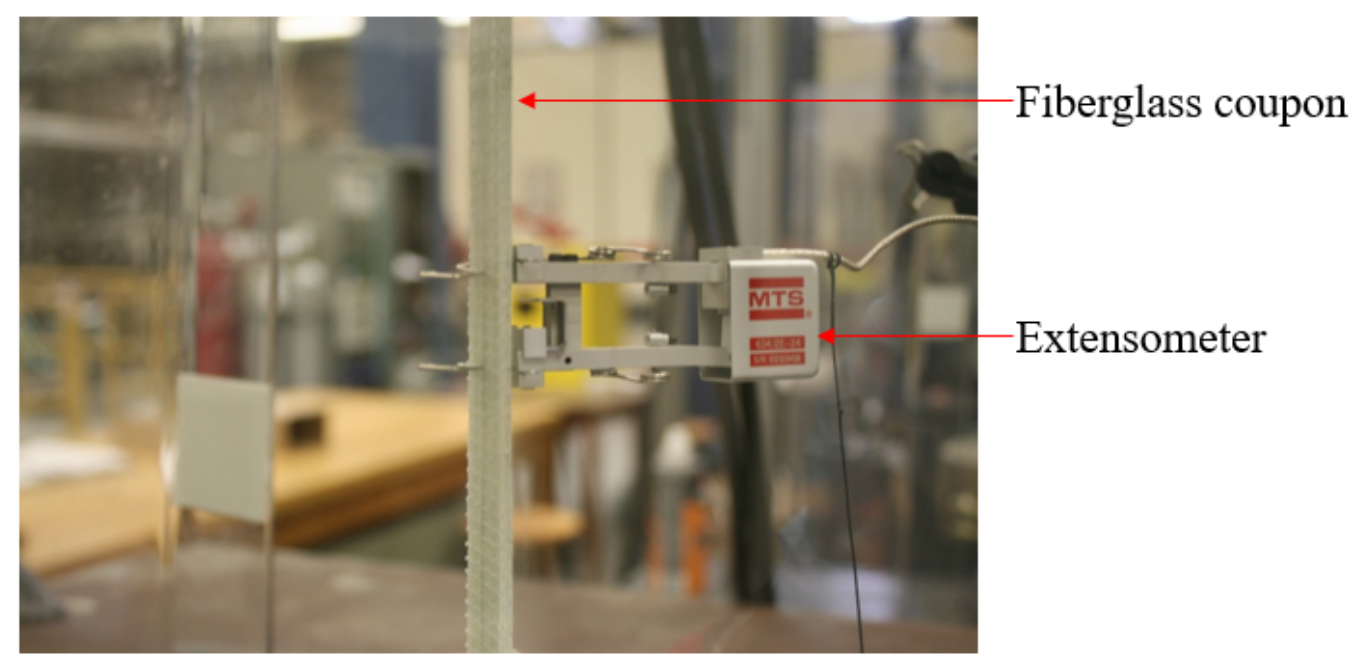

Figure 3.39: Tensile test

Stress-strain curves for fiberglass with and without embedded optical fiber can be 
seen in Figure 3.40. The plot shows an overlap between the data points of both the samples.

As per ASTM 3039, the slope of the linear region between the strain values of 0.001 and 0.003 were used to calculate the Young's Modulus of the material [27]. The relationship between stress, strain and Young's Modulus is given by [27]:

$$
E=\frac{\Delta \sigma}{\Delta \varepsilon}
$$

The results obtained from tensile tests are presented in Chapter 4.

Tensile coupons with embedded optical fibers were tested in $100 \mathrm{kN}$ MTS machine. Before testing, one end of optical fiber was connected to a patch cord using a splicer. The stripped end was cleaned using isopropyl alcohol before splicing. The ends of the patch cord and optical fibers were brought close and were spliced as shown in Figure 3.41 .

To test these coupons, the specimen was mounted in the tensile testing machine. As one end was enough to record the optical fiber's data, the other end was detached in order to avoid scattering of the optical fiber pieces which might result due to any breakage of the loose end during testing. In order to prevent breaking, the optical fibers were placed away from the grip of the machine during testing. The procedure for tensile test described above was repeated. After the specimen was gripped, the optical fiber was connected to the reflectometer using a patch cord as shown in Figure 3.42. The coupons were loaded from 0 to $5 \mathrm{kN}$ in multiple loading and unloading cycles to collect as much linear elastic data as possible.

Strain was measured by the extensometer using the data aquisition system and the wavelength of embedded optical fiber was measured using the reflectometer (Micron Optics Si720). Strain calculated from both the sources were recorded, compared 


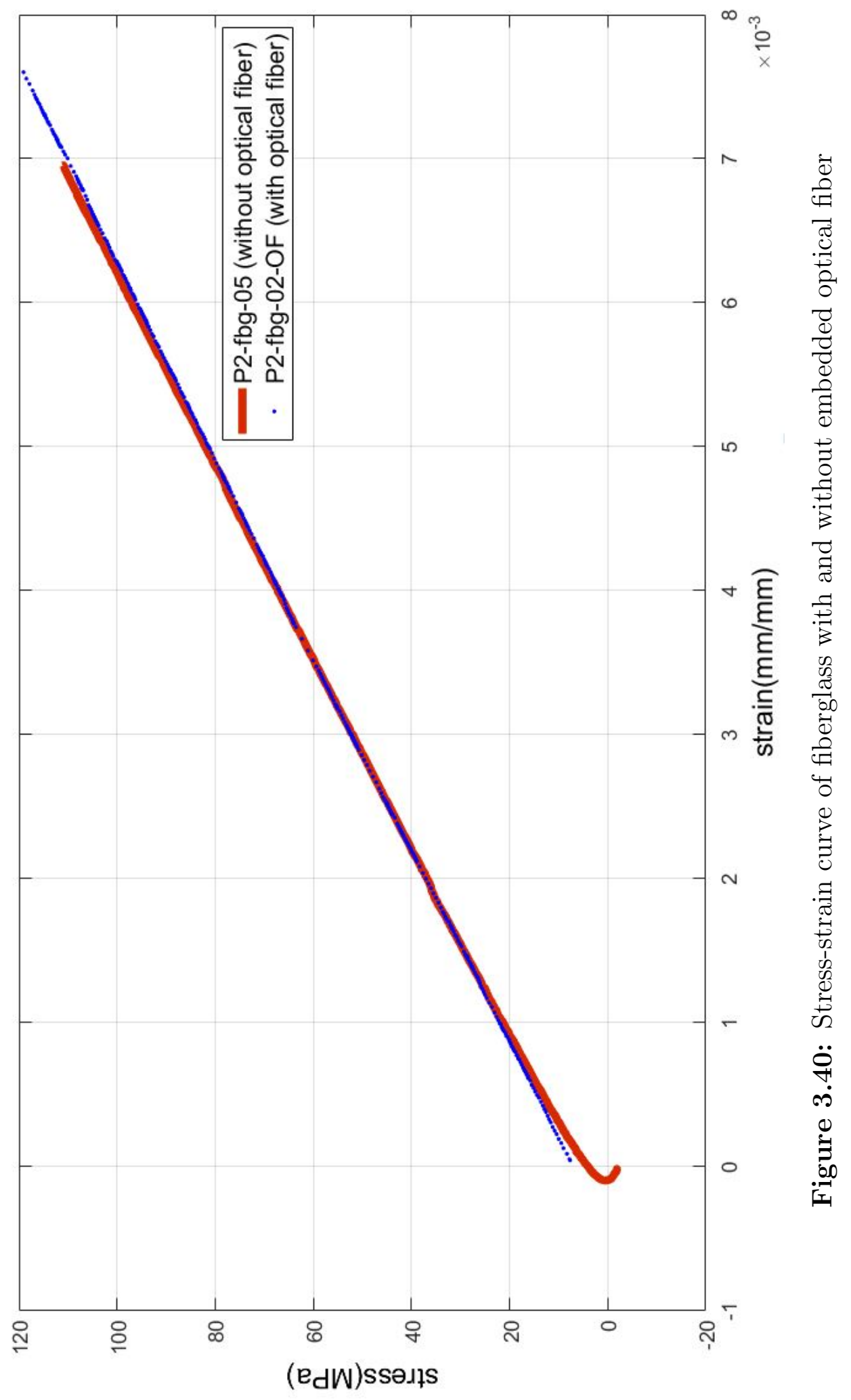




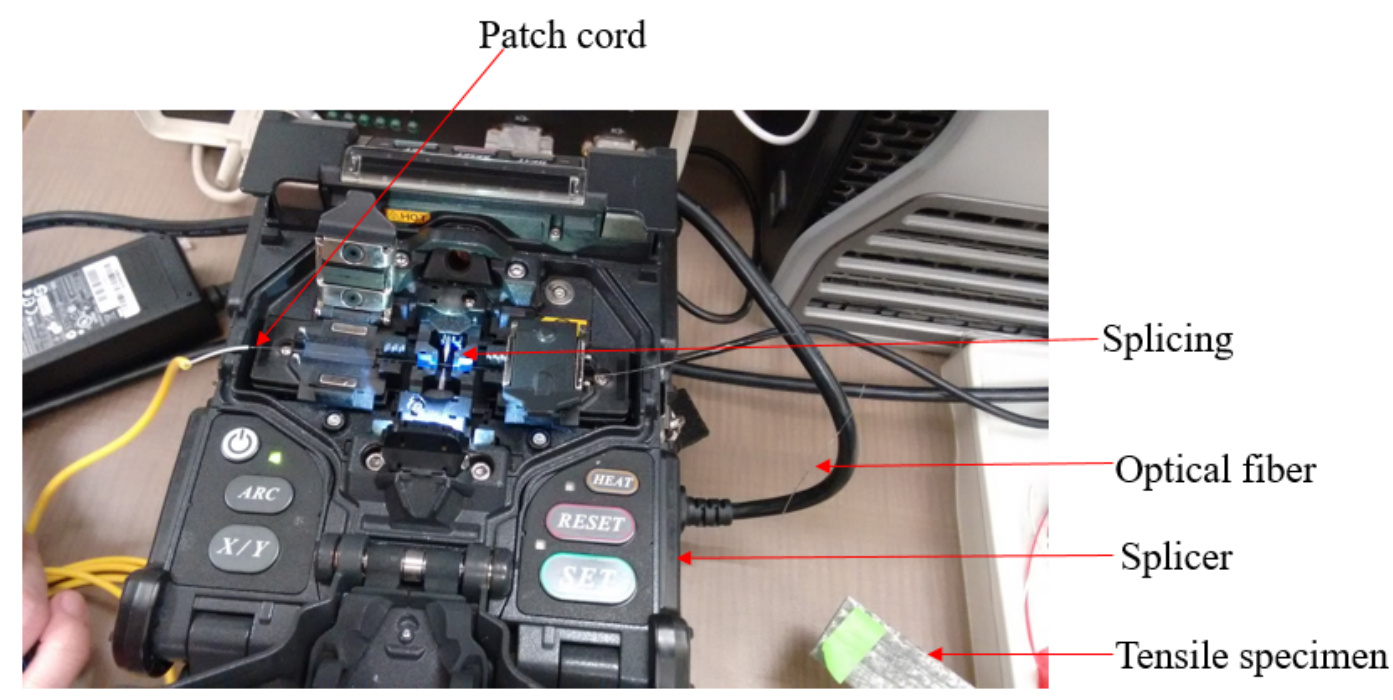

Figure 3.41: Splicing of optical fiber

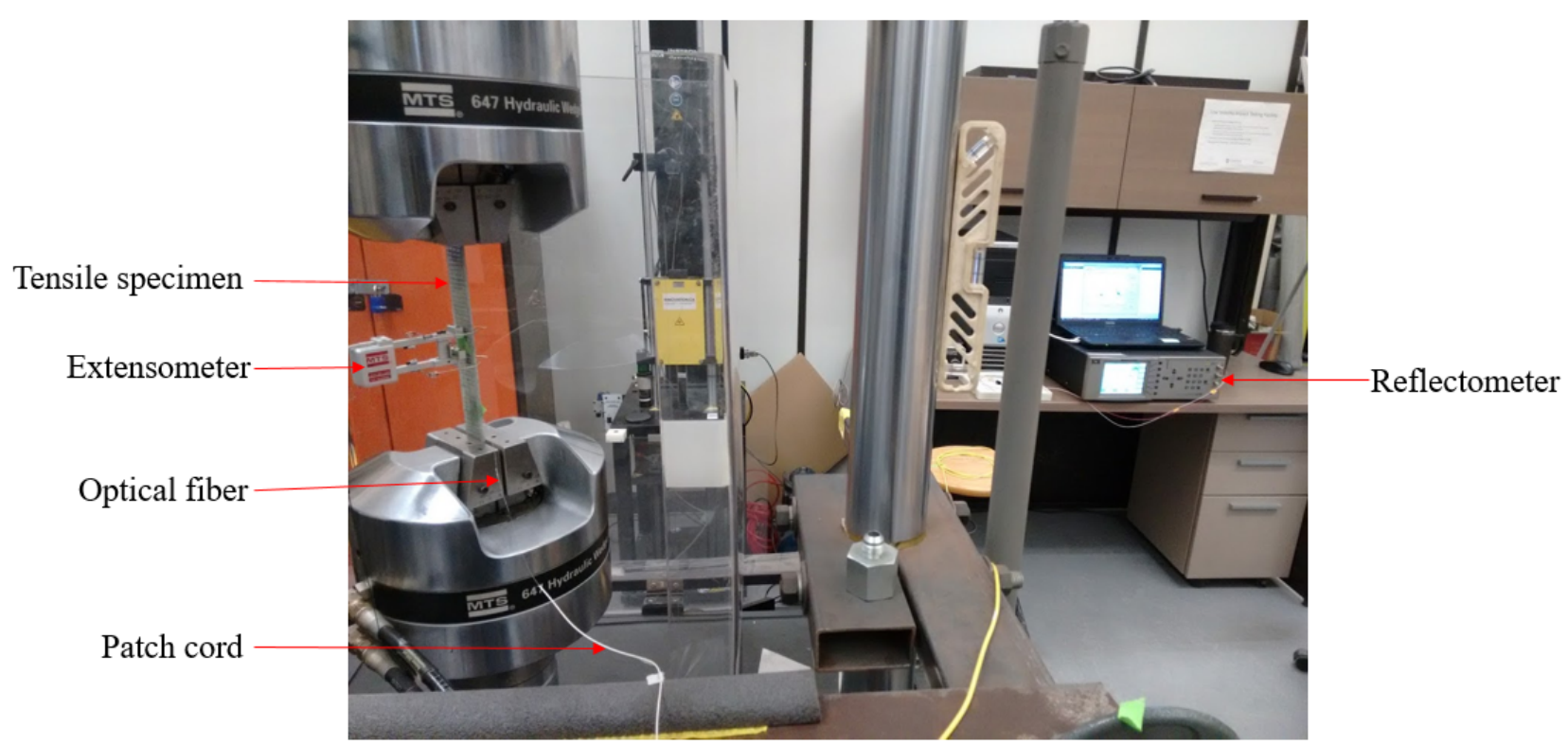

Figure 3.42: Tensile testing of composite with embedded optical fiber 
and are explained in Chapter 4.

\subsubsection{Compliance Calculation}

Tensile tests on the coupons manufactured from first panel were done without an extensometer due to its non-availability. In the absence of an extensometer, axial strain values were not recorded by the data acquisition system. In order to calculate the material's Young's Modulus of Elasticity (E), the compliance of the tensile testing machine was calculated and reported. Using the compliance value, E was generated for all the coupons.

Compliance was obtained through tensile testing of rectangular SS304 stainless steel specimens with $130 \mathrm{~mm}$ gage length, $31 \mathrm{~mm}$ width and $3 \mathrm{~mm}$ thickness. The test was started in displacement control mode at a rate of $2 \mathrm{~mm} /$ minute with the loading of 0 to $35 \mathrm{kN}$. The upper limit of load was reached within 33 seconds. In order to keep the test running for a longer duration and record more data points, the mode was changed to load control with a rate of $20 \mathrm{kN} /$ minute. An MTS extensometer (gage length $=1$ inch) mounted on the mid-section of test coupon measured strain in the material during the loading condition. The crosshead displacement was recorded by the data aquisition system. The compliance measured by the crosshead displacement $\left(C_{T}\right)$ is the sum of the material's compliance $\left(C_{m a t}\right)$ and the machine's compliance $\left(C_{m}\right)$. This relation can be represented by the following equation [52]:

$$
C_{m a t}+C_{m}=C_{T}
$$

Compliance is calculated by taking the inverse of the load-displacement curve and it has a unit of $\mathrm{mm} / \mathrm{kN}$. $C_{m a t}$ is calculated using the load value recorded by the data aquisition system and the displacement value obtained from the strain data 
recorded by the extensometer. The data points are plotted (Load in Y-axis and displacemnt in X-axis) and the inverse of their slope is calculated to get the material's compliance. $C_{T}$ is calculated using the load value recorded by the data aquisition system and the displacement value obtained from the crosshead displacement data of the tensile testing machine. The data points are plotted (Load in Y-axis and displacement in X-axis) and inverse of their slope is calculated to find total compliance $[52,53]$. Load versus displacement plot for crosshead and extensometer is shown in Figure 3.43.

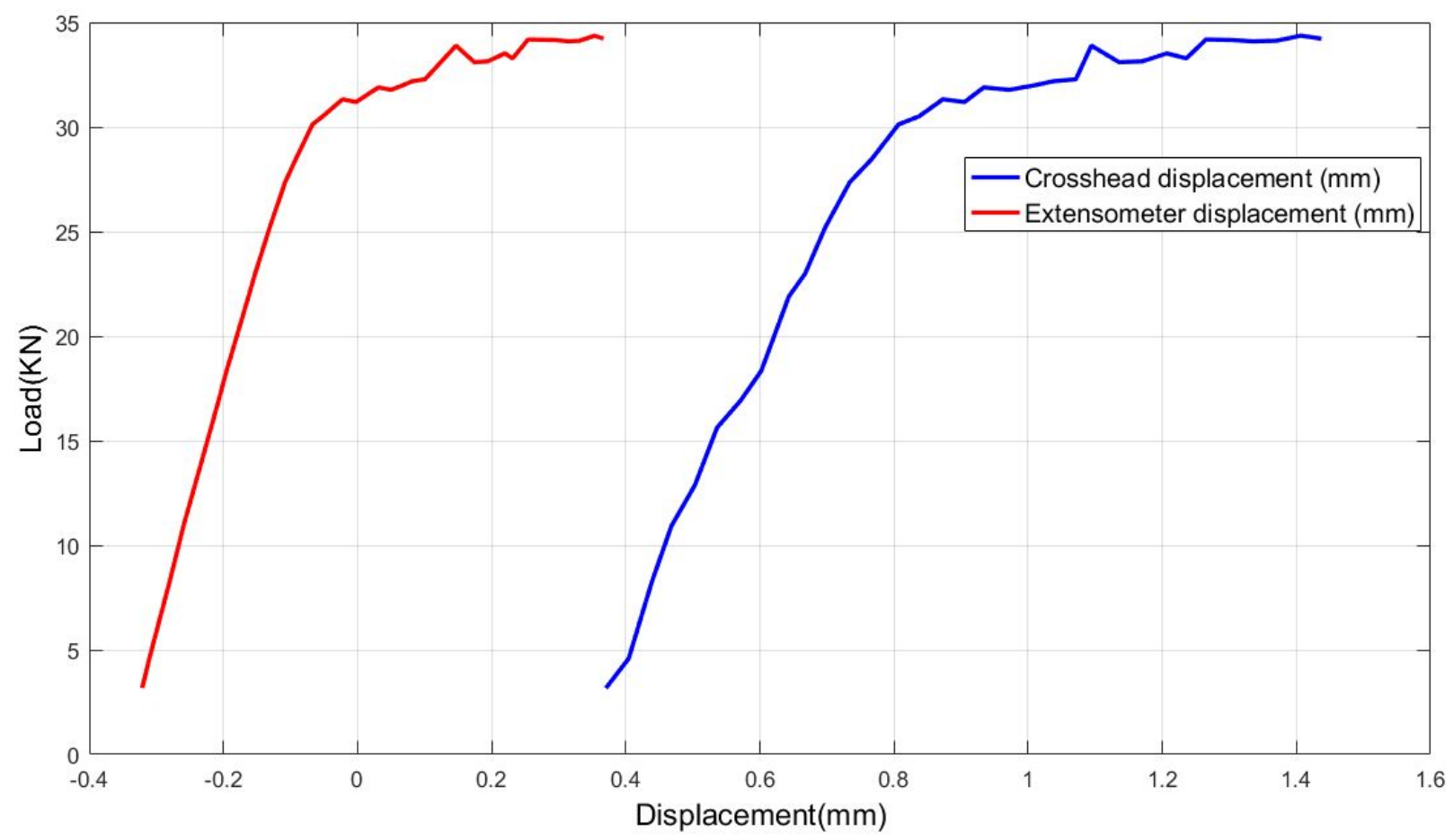

Figure 3.43: Load vs displacement for SS304 sample1

After the calculation of these values, $C_{m}$ was obtained using equation 3.2. Four different SS304 specimens were tested and their average value was taken as machine's compliance. The values are displayed in Table 3.2.

The average value of the machine's compliance $\left(\mathrm{C}_{m}\right)$ was used to calculate Young's 
Table 3.2: Machine's compliance measured using SS304

\begin{tabular}{|l|l|}
\hline Sample Number & Machine Compliance, Cm $(\mathbf{m m} / \mathbf{k N})$ \\
\hline 1 & 0.0075 \\
\hline 2 & 0.0083 \\
\hline 3 & 0.0078 \\
\hline 4 & 0.0071 \\
\hline
\end{tabular}

\begin{tabular}{|l|l|}
\hline Average & $0.0077 \pm 0.0005$ \\
\hline
\end{tabular}

Modulus (E) of the fiberglass using Equation 3.3 [52]

$$
E=\frac{E_{T}}{1-\frac{C_{m} E_{T} A}{L}}
$$

where, $E_{T}$ is the elastic modulus calculated with the machine's crosshead displacement, $A$ is the cross-sectional area and $L$ is the gage length of the test specimen. Derivation of the above equation is included in Appendix 1.

\subsection{Impact Test}

Impact tests were conducted to determine the damage resistance of composite materials subjected to drop-weight impact. Fabrication and testing of the materials were carried out according to ASTM7136 [54].

\subsubsection{Specimen Fabrication}

The test samples were $150 \mathrm{~mm}$ long, $100 \mathrm{~mm}$ wide and $6 \mathrm{~mm}$ thick. A total of six plies $[0 / 90 / 0]_{s}$ were used to achieve this thickness. Optical fibers were embedded between the center plies and were parallel to the resin flow direction. A total of six impact test specimens were fabricated from the same panel. Three of them had 
optical fiber embedded inside while the other three had no embedded optical fiber. The Layout of the panel is shown in Figure 3.44 and Figure 3.45.

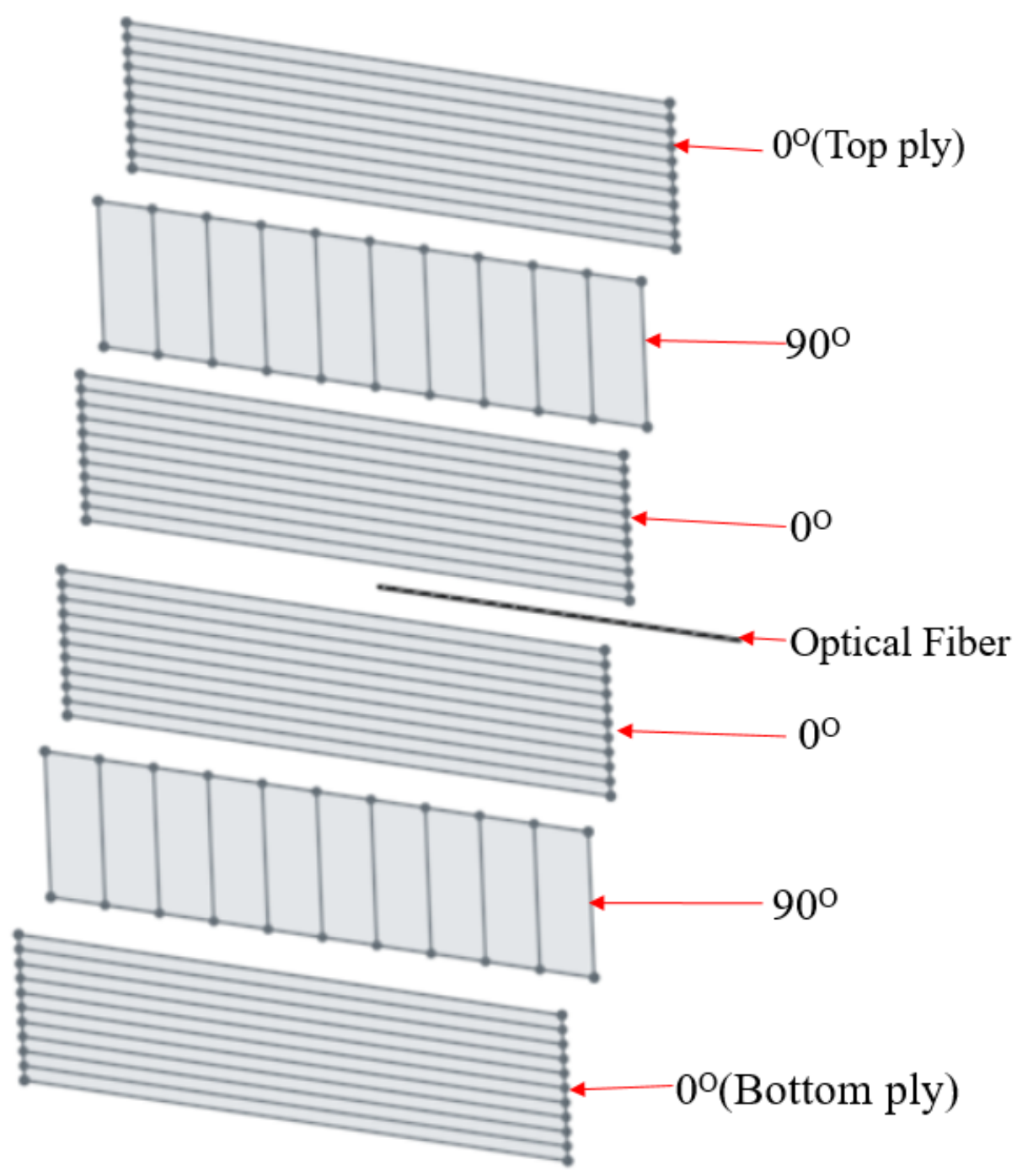

Figure 3.44: Schematic of ply orientation in impact test specimen

Impact test and flexural test samples were made from the same larger rectangular composite panel. A total of six samples (3 impact and 3 flexural coupons) with embedded optical fibers and six samples of parent material (3 impact and 3 flexural) were cut from this panel. During the manufacturing and cutting operations, some optical fibers broke at the ingress/egress points while still remaining embedded inside 


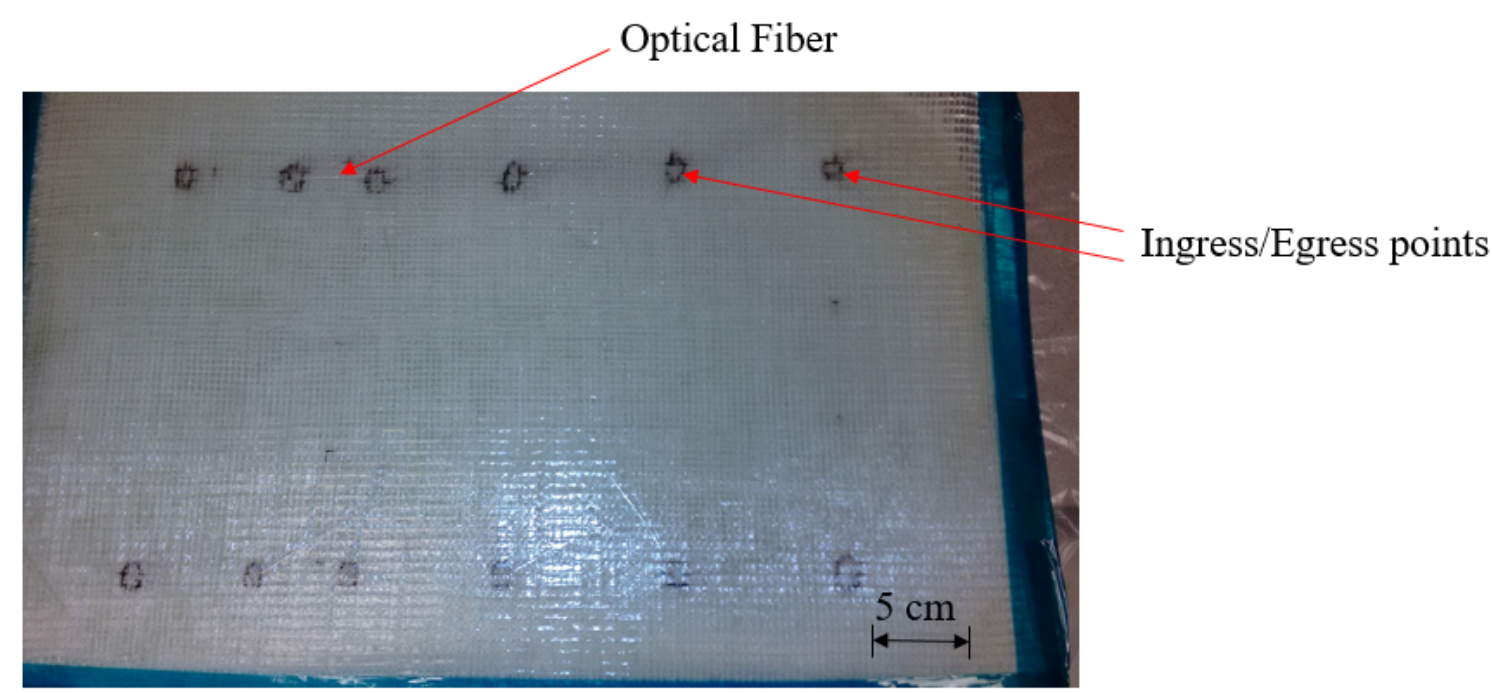

Figure 3.45: Manufactured panel for impact test specimen

the fiberglass. The cutting layout and resin flow direction is shown in Figure 3.46. The top three samples show the impact test specimens with embedded optical fiber. The three coupons in the second row show the impact test specimens without optical fiber. Three coupons in the last row show flexural test specimens with embedded optical fiber and the row above them are the fiberglass' flexural test specimens without optical fiber. At the end, two more flexural samples were cut from the remaining material between the second and third row. The dimensions of the flexural test specimens are mentioned in Section 3.5.

The specimen dimensions were measured using a Vernier Caliper and are mentioned in the Table 3.3.

\subsubsection{Impact Test Procedure}

Impact tests were performed using an Instron Dynatup drop tower machine (model number: 7800-056). During the drop tower impact tests, a hemispherical impactor was set at a known height from the test specimen. The mass of the impactor was provided by the supplier. At this position, the impactor possesses potential energy 


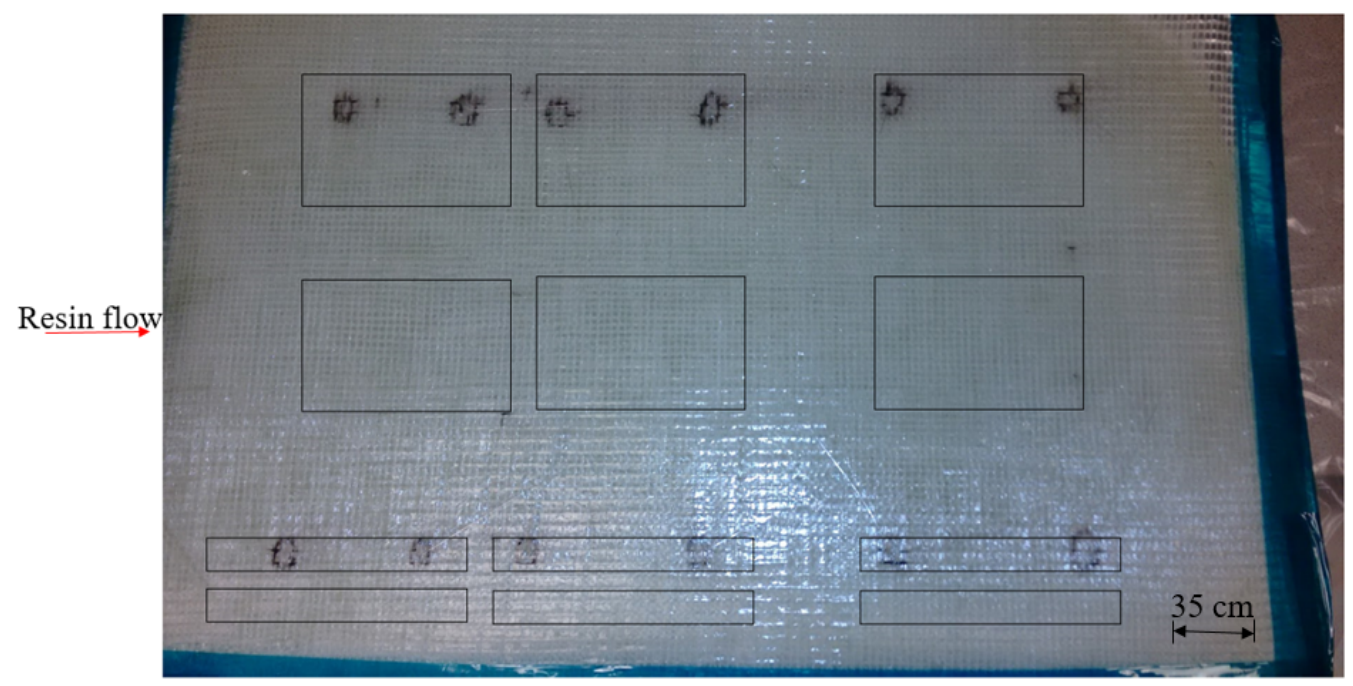

Figure 3.46: Cutting layout schematic of impact and flexural test specimen
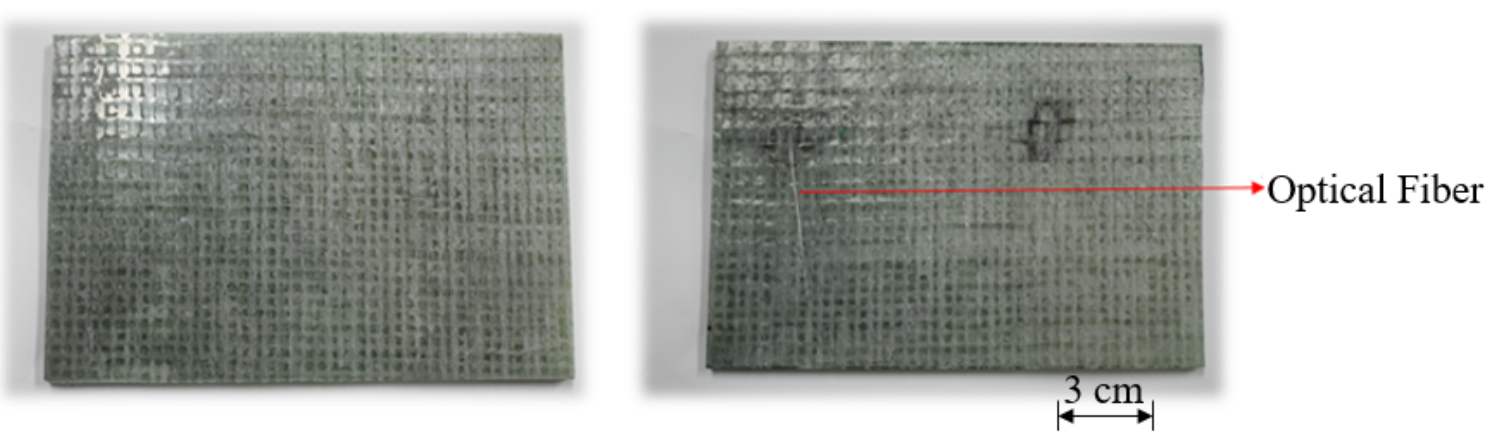

Figure 3.47: Fiberglass impact specimen without (left) and with embedded optical fiber (right) 
Table 3.3: Dimensions of impact test specimens

\begin{tabular}{|l|l|l|l|}
\hline Specimen & Length $(\mathbf{m m})$ & Width $(\mathbf{m m})$ & Thickness $(\mathbf{m m})$ \\
\hline $1-\mathrm{OF}$ & $149.22 \pm 0.32$ & $99.79 \pm 0.17$ & $6.23 \pm 0.24$ \\
\hline $2-\mathrm{OF}$ & $148.46 \pm 0.65$ & $98.78 \pm 0.50$ & $6.17 \pm 0.17$ \\
\hline $3-\mathrm{OF}$ & $148.38 \pm 0.31$ & $99.93 \pm 0.39$ & $5.98 \pm 0.15$ \\
\hline 4 & $149.46 \pm 1.50$ & $98.23 \pm 0.55$ & $5.89 \pm 0.67$ \\
\hline 5 & $146.51 \pm 0.12$ & $99.89 \pm 1.33$ & $5.87 \pm 0.06$ \\
\hline 6 & $149.04 \pm 1.26$ & $99.74 \pm 0.59$ & $5.97 \pm 0.15$ \\
\hline
\end{tabular}

$\left(\mathrm{E}_{p}\right)$, which is given by

$$
E_{p}=m g h
$$

where, $m$ is mass of the impactor, $g$ is acceleration due to gravity and $h$ is height of the impactor from test specimen.

The specimen was placed and gripped on the base (Figure 3.49). As the impactor was released, it hit the specimen at its center. Optical fibers were embedded away from the center line in order to protect them during the test. After the impactor was released, it fell under gravity. Potential energy converted into kinetic energy by virtue of its motion and can be given by

$$
E_{k}=\frac{1}{2} m v^{2}
$$

where, $m$ is mass of the impactor and $v$ is its velocity.

Time $(t)$, load $(F)$, displacement $(\delta)$ and velocity $\left(v_{i}\right)$ were recorded using the data acquisition system. Impactor velocity $\left(v_{t}\right)$ at any time, $t$ is given by [54]

$$
v_{t}=v_{i}+g t-\int_{0}^{t} \frac{F(t)}{m} d t
$$


Impact energy, $E_{i}$ can be calculated by Equation 3.5

$$
E_{i}=\frac{1}{2} m v_{i}^{2}
$$

where $v_{i}$ is the impact velocity.

Energy absorbed, $\left(E_{a}\right)$ can be given by the difference between initial and final kinetic energy of the impactor

$$
E_{a}=\frac{m\left(v_{i}^{2}-v_{t}^{2}\right)}{2}+m g \delta(t)
$$

Energy absorbed by the samples with and without embedded optical fibers were compared to analyze if the embedment had any effect on the absorbed energy. The test setup is shown in Figure 3.49.

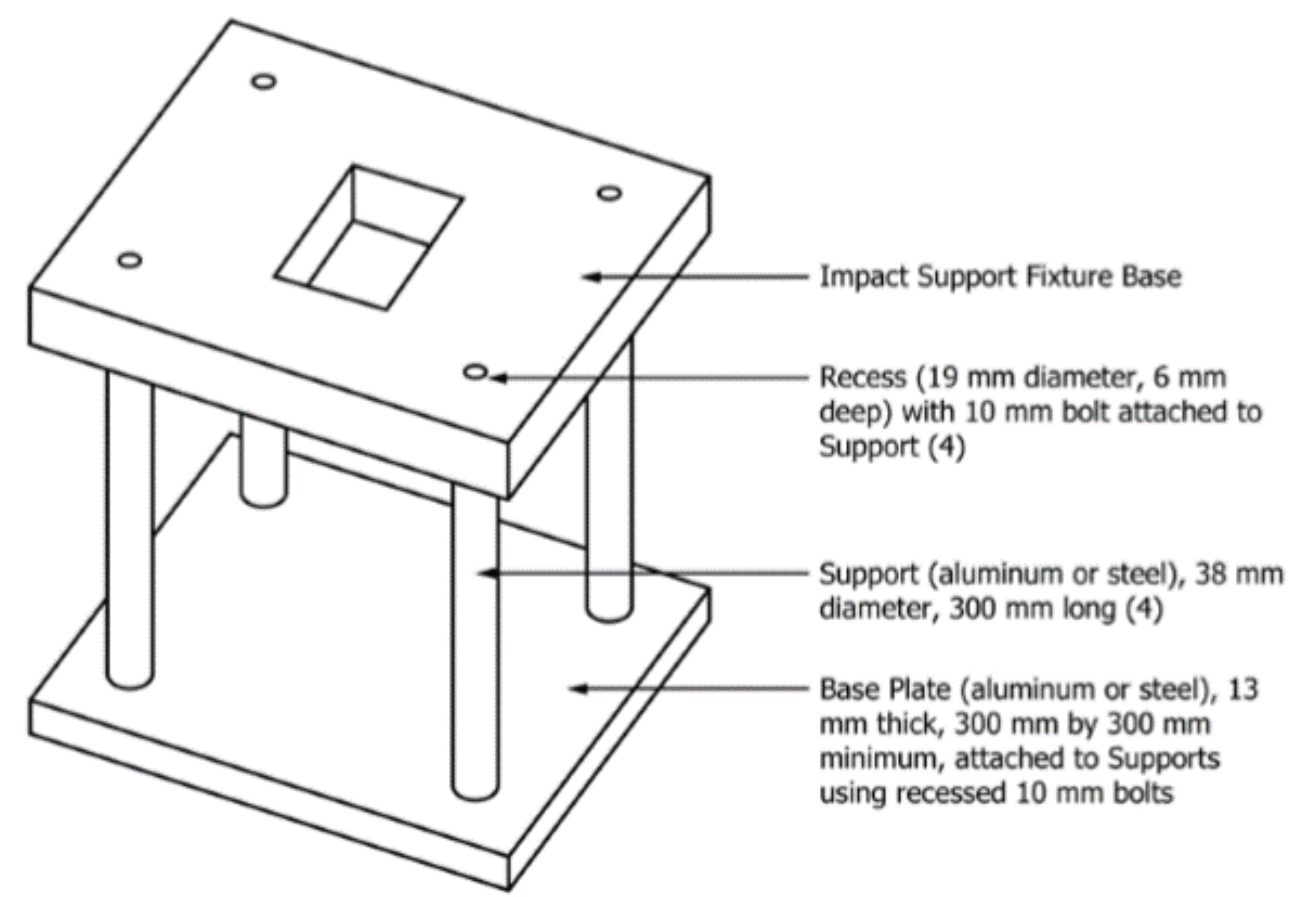

Figure 3.48: Impact test base [54]

The testing started with an AA6061 aluminium specimens as an exercise to get 


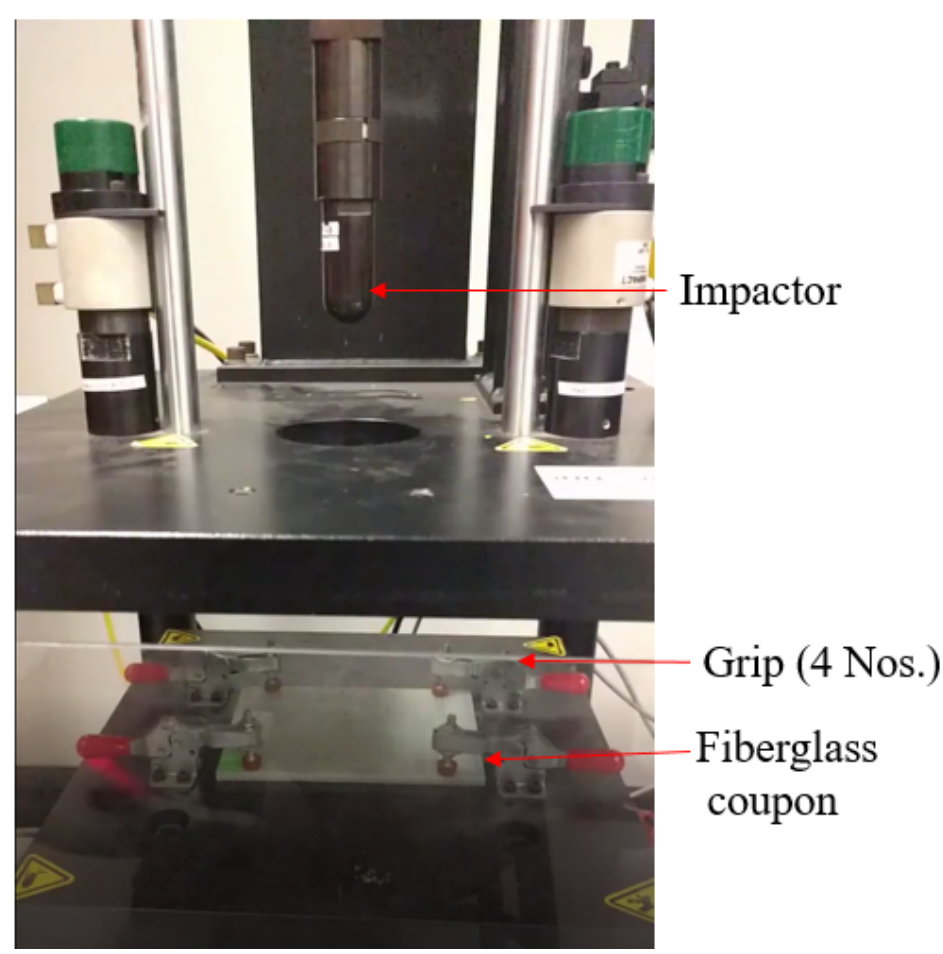

Figure 3.49: Impact test setup

familiarization with the drop tower impact test machine. A picture of an impact tested aluminium specimen is shown in Figure 3.50.

A fiberglass specimen after the impact test is shown in Figure 3.51. Due to the presence of voids, the samples were infiltrated with water and dirt during the cutting operation. As optical fibers are brittle and break easily, the samples were not cleaned in order to avoid their breakage.

\subsection{Flexural Test}

Flexural tests were conducted to determine the flexural stiffness and strength of the material. Fabrication and testing were carried out according to ASTM7264 [55]. 


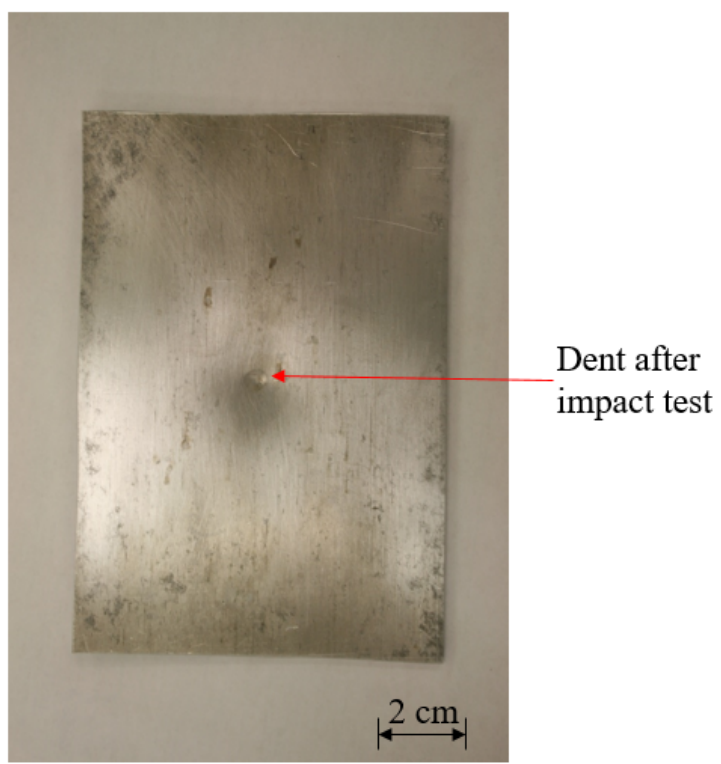

Figure 3.50: Aluminium sample after impact test

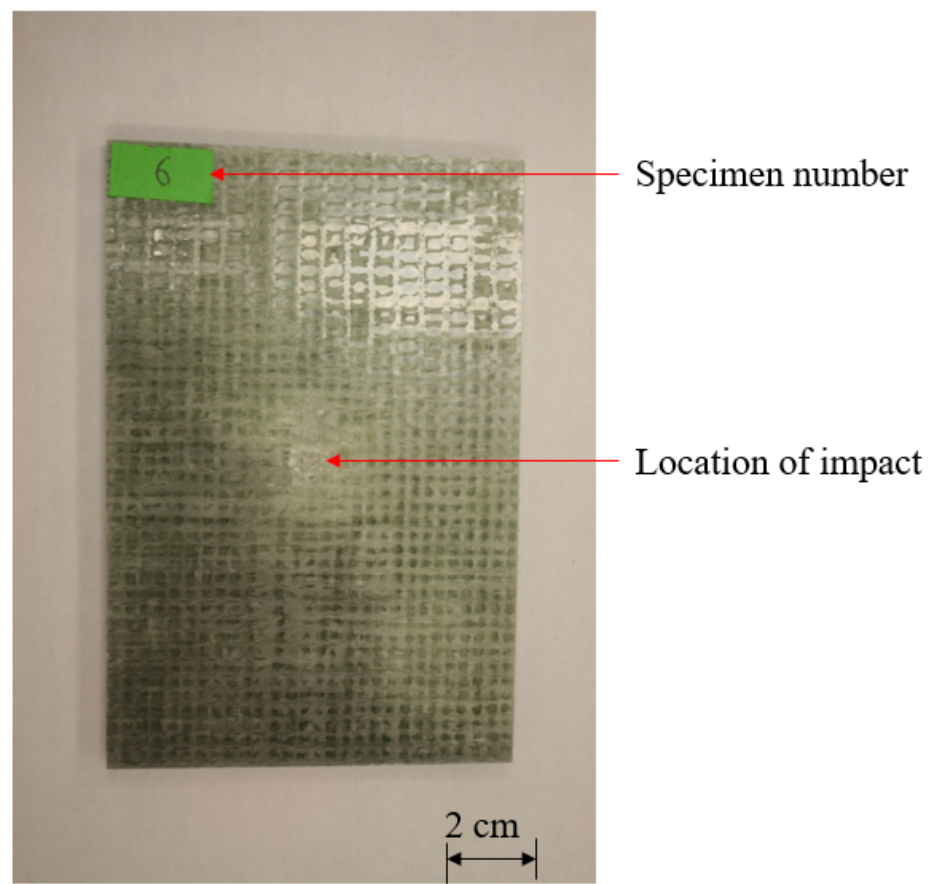

Figure 3.51: Fiberglass sample after impact test 


\subsubsection{Specimen Fabrication}

Three point bend test specimens were cut out of the same panel. Eight specimens (3 with embedded optical fibers and 5 host material) were fabricated. Optical fiber was embedded in the central plane of the specimens. The span to thickness ratio

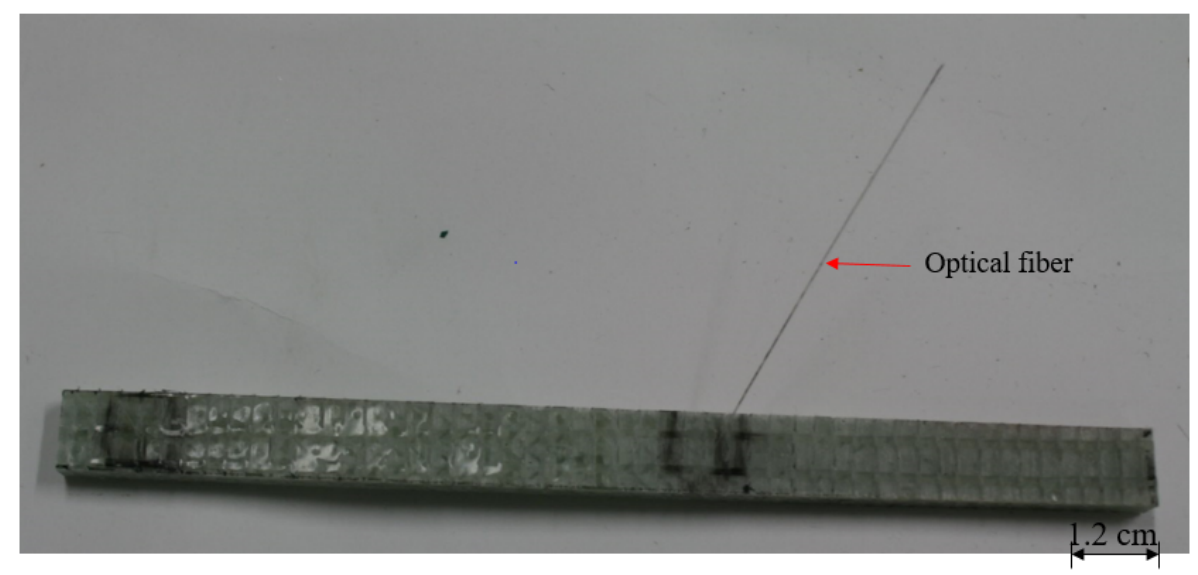

Figure 3.52: Flexural test specimen with embedded optical fiber

of the coupons was kept 32:1. This was to ensure that failure occurred at the outer surface of the specimen due to bending moment. The dimensions of the samples are mentioned in the Table 3.4. All the dimensions were taken as the average of three readings measured using a Vernier Caliper.

\subsubsection{Flexural Test Procedure}

Flexural tests were performed using a $25 \mathrm{kN}$ MTS machine (model number: 661.20E-01). In three point loading configuration, the test sample rests on two support rollers and is loaded at the midway point using a loading nose (Figure 3.53). The maximum flexural stress is located directly under the loading nose [55].

Testing was performed under displacement control at $1 \mathrm{~mm} / \mathrm{minute}$. The loading nose and the supporting rollers were aligned such that their cylindrical axes were parallel. The loading nose was kept midway between the supports. Specimens were 
Table 3.4: Dimensions of flexural test specimens

\begin{tabular}{|l|l|l|l|}
\hline S.No. & Length(mm) & Width(mm) & Thickness(mm) \\
\hline 1 & $178.2 \pm 0.63$ & $12.03 \pm 0.72$ & $6.67 \pm 0.15$ \\
\hline 2 & $178.7 \pm 0.45$ & $11.52 \pm 0.49$ & $6.72 \pm 0.17$ \\
\hline 3 & $169.8 \pm 0.32$ & $11.50 \pm 0.70$ & $6.58 \pm 0.14$ \\
\hline 4 & $179.6 \pm 0.10$ & $12.37 \pm 0.53$ & $6.26 \pm 0.39$ \\
\hline 5 & $171.5 \pm 0.37$ & $12.95 \pm 0.55$ & $6.52 \pm 0.90$ \\
\hline 6 & $171.4 \pm 0.59$ & $14.54 \pm 0.16$ & $5.99 \pm 0.19$ \\
\hline 7 & $179.1 \pm 0.65$ & $13.48 \pm 0.36$ & $6.22 \pm 0.36$ \\
\hline 8 & $177.5 \pm 0.14$ & $13.12 \pm 1.32$ & $6.40 \pm 0.46$ \\
\hline
\end{tabular}

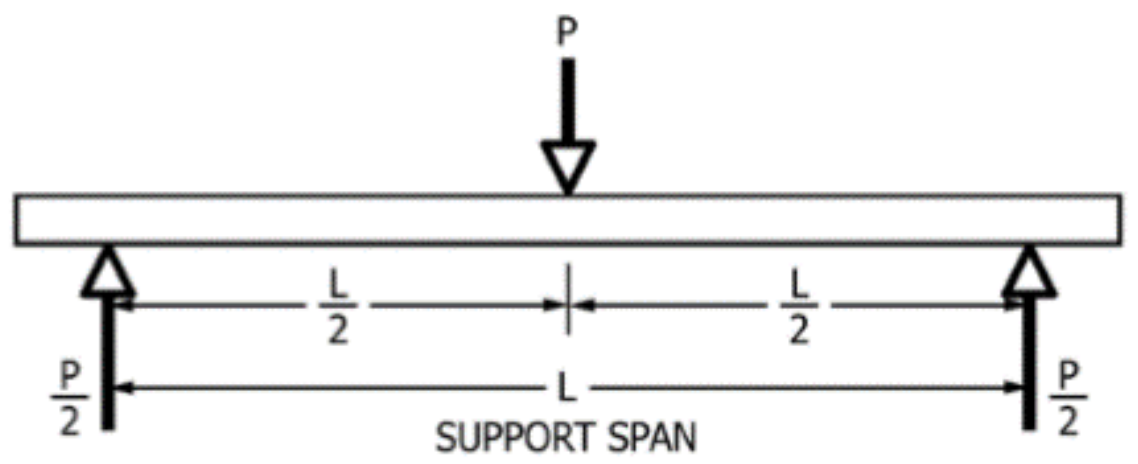

Figure 3.53: Schematic of three point bend test [55]

positioned on two side rollers and the central roller was aligned in the middle of the specimen. An extensometer was mounted to monitor the strain values during the test. Load, deflection and time values were recorded using the data aquisition system. The tests continued until the specimens failed. The nature of failure, maximum flexural strength, maximum strain and flexural modulus of elasticity were calculated and recorded for each test. The test setup can be seen in Figure 3.54.

Maximum flexural stress and maximum strain was calculated using the expressions below [55]:

$$
\sigma=\frac{3 P L}{2 b h^{2}}
$$




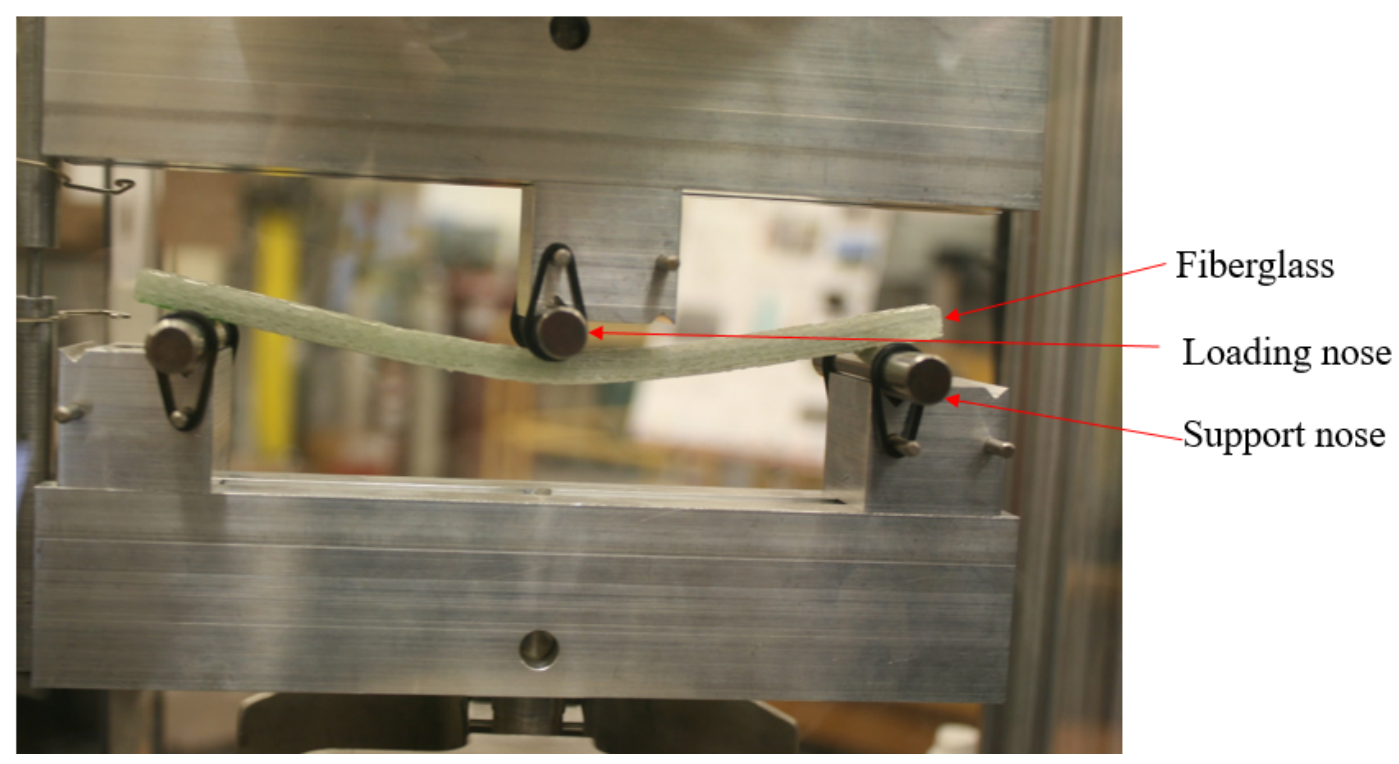

Figure 3.54: Three point bend test

where, $\sigma$ is flexural stress, $P$ is applied Load, $L$ is support span's length, $b$ is width and $h$ is thickness of the specimen.

$$
\varepsilon=\frac{6 \delta h}{L^{2}}
$$

where, $\varepsilon$ is maximum strain, $\delta$ is deflection of mid-span, $L$ is support span's length and $h$ is thickness of the specimen.

Since the length of smallest specimen was $169.8 \mathrm{~mm}$ (Sample 3), the fixture was adjusted such that sample 3 could fit in. The same configuration was maintained for all the samples without changing the distance between the anvils. The overall length of the available fixture was $150 \mathrm{~mm}$ and the diameter of the loading roller was $10 \mathrm{~mm}$. The overall length of the sample accounts for $20 \%$ more than its span [55]. From Figure $3.53,1.2 \mathrm{~L}=169.8 \mathrm{~mm}$. Solving for $\mathrm{L}$ gives the distance between the support rollers as $141.5 \mathrm{~mm}$. Hence, length of support span used in the calculation was $141.5 \mathrm{~mm}$.

The slope of the stress-strain curve gives the flexural chord modulus of elasticity. 
Maximum value of stress prior to failure gives the flexural strength of the material. The results of flexural tests are presented in Chapter 4.

\subsection{Measurement of the Strain Calibration Factor for Fiber Bragg Grating}

The strain value obtained by observing the shift in wavelength of Bragg Gratings was correlated to the strain experienced by the optical fiber. A single optical fiber with six Bragg Gratings was wrapped between two rollers in 100 N MTS LF Plus loading machine (Figure 3.56). An initial wavelength reading of the gratings was recorded using Micron Optics Si720. As there were six Bragg Gratings, six peaks were recorded in the graph (Figure 3.55). The fiber was stretched in the loading machine, which caused the wavelength patterns to shift from their original position. Optical fiber was given extensions in increments of $0.2 \mathrm{~mm}$. For every increment, the force value was recorded. Young's Modulus and the cross sectional area of optical fiber was provided by the manufacturer. The wavelength readings were recorded using the reflectometer for every extension. Actual strain was calculated using Young's Modulus of the fiber, their cross sectional area and applied force values. The following set of equations shows the method of calculating strain using this method:

$$
E=\frac{\sigma}{\epsilon}
$$

Using the definition of stress

$$
\sigma=\frac{F}{A}
$$


Substituting this term in the first line

$$
E=\frac{F}{A \epsilon}
$$

Solving for strain,

$$
\epsilon=\frac{F}{A E}
$$

Strain can also be measured using wavelength shift of Bragg Grating. The wavelength of the first peak was used to calculate strain. Strain was calculated by its initial and displaced position using Equation 2.2.

$$
\epsilon_{\text {grating }}=\frac{\lambda-\lambda_{B}}{\lambda_{B}}
$$

Strain calilbration factor, $\mathrm{K}$ is the ratio of both the measured value of strain.

$$
K=\frac{\epsilon_{\text {grating }}}{\epsilon}
$$

This test was performed on two optical fibers. Seven set of readings were taken on both the optical fibers and the average value of strain calibration factor, $K$ was used for calculations. The results of these experiments are reported in Table 3.5. The initial wavelength of the first peak in both the optical fibers was $1543.01 \mathrm{~nm}$.

The average value of the strain calibration factors from both the fibers was 0.771 . This value of $\mathrm{K}$ was considered for final calculations. 
Table 3.5: Strain calibration values from first optical fiber

\begin{tabular}{|l|l|l|l|l|l|}
\hline $\begin{array}{l}\text { Extension } \\
(\mathbf{m m})\end{array}$ & $\begin{array}{l}\text { Force, } \mathbf{F} \\
(\mathbf{N})\end{array}$ & $\begin{array}{l}\text { Strain, } \epsilon \\
(\mathbf{m m} / \mathbf{m m})\end{array}$ & $\begin{array}{l}\text { Wavelength, } \lambda \\
(\mathbf{n m})\end{array}$ & $\begin{array}{l}\text { Strain, } \epsilon_{\text {grating }} \\
(\mathbf{n m} / \mathbf{n m})\end{array}$ & $\mathbf{K}$ \\
\hline 0.2 & 0.031 & 0.000036105 & 1543.055 & 0.000029163 & 0.808 \\
\hline 0.4 & 0.229 & 0.000266715 & 1543.355 & 0.000223589 & 0.838 \\
\hline 0.6 & 0.515 & 0.000599818 & 1543.753 & 0.000481526 & 0.803 \\
\hline 0.8 & 0.755 & 0.000879345 & 1544.062 & 0.000681784 & 0.775 \\
\hline 1 & 1.156 & 0.001346388 & 1544.648 & 0.001061561 & 0.788 \\
\hline 1.2 & 1.488 & 0.001733066 & 1545.067 & 0.001333109 & 0.770 \\
\hline 1.4 & 1.842 & 0.002145369 & 1545.567 & 0.001657151 & 0.772 \\
\hline
\end{tabular}

Table 3.6: Strain calibration values from second optical fiber

\begin{tabular}{|l|l|l|l|l|l|}
\hline $\begin{array}{l}\text { Extension } \\
(\mathbf{m m})\end{array}$ & $\begin{array}{l}\text { Force, } \mathbf{F} \\
(\mathbf{N})\end{array}$ & $\begin{array}{l}\text { strain, } \epsilon \\
(\mathbf{m m} / \mathbf{m m})\end{array}$ & $\begin{array}{l}\text { wavelength, } \lambda \\
(\mathbf{n m})\end{array}$ & $\begin{array}{l}\text { strain, } \epsilon_{\text {grating }} \\
(\mathbf{n m} / \mathbf{n m})\end{array}$ & $\mathbf{K}$ \\
\hline 0.1 & 0.095 & 0.0001106 & 1545.162 & 0.00009385 & 0.848 \\
\hline 0.2 & 0.271 & 0.0003156 & 1545.365 & 0.00022524 & 0.713 \\
\hline 0.3 & 0.443 & 0.0005159 & 1545.630 & 0.00039675 & 0.769 \\
\hline 0.4 & 0.271 & 0.0007686 & 1545.880 & 0.00055857 & 0.726 \\
\hline 0.5 & 0.854 & 0.0009946 & 1546.140 & 0.00072685 & 0.731 \\
\hline 0.6 & 1.049 & 0.0012217 & 1546.402 & 0.00089643 & 0.734 \\
\hline 0.8 & 1.488 & 0.0017330 & 1546.940 & 0.00124464 & 0.718 \\
\hline
\end{tabular}




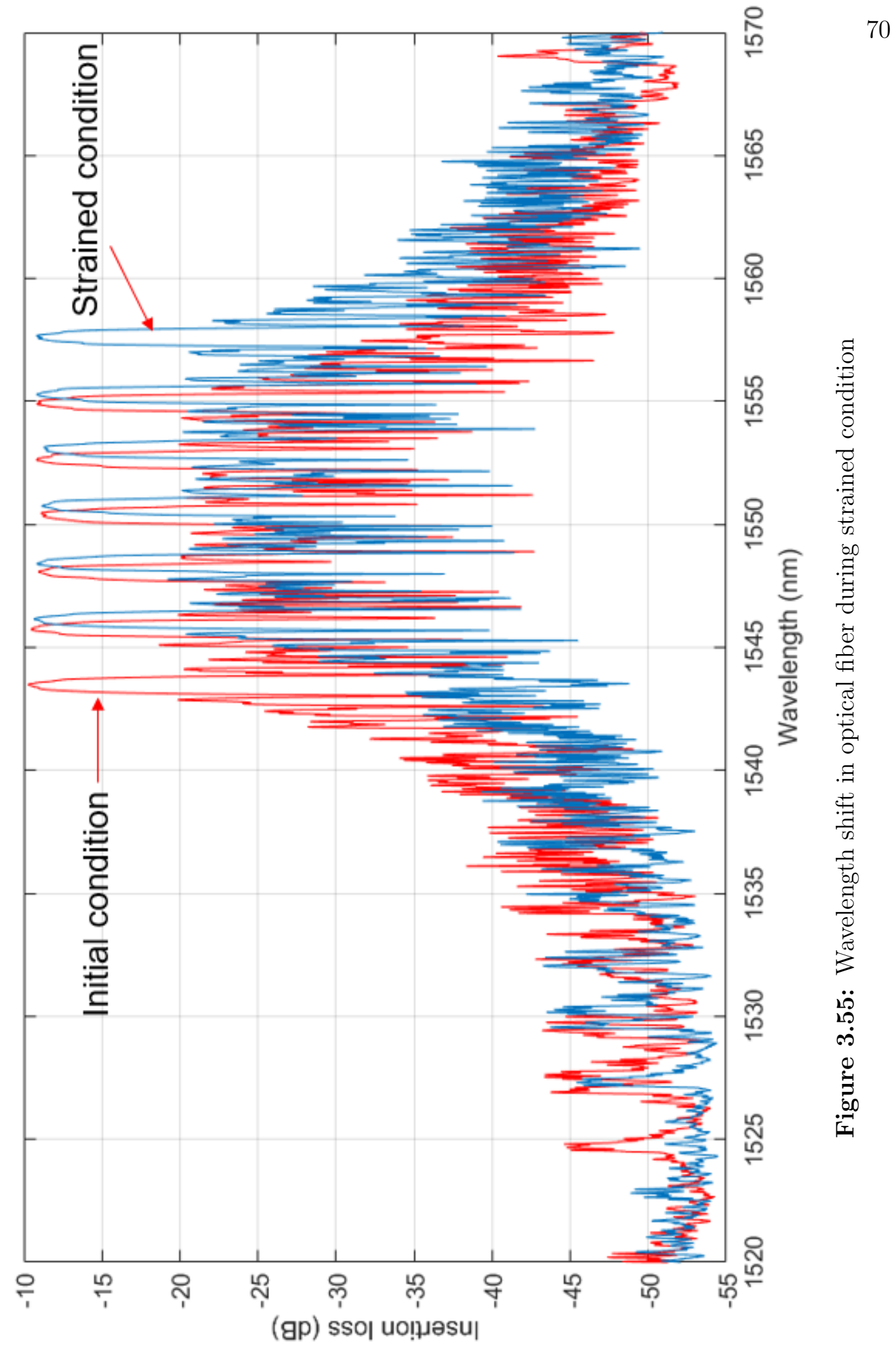




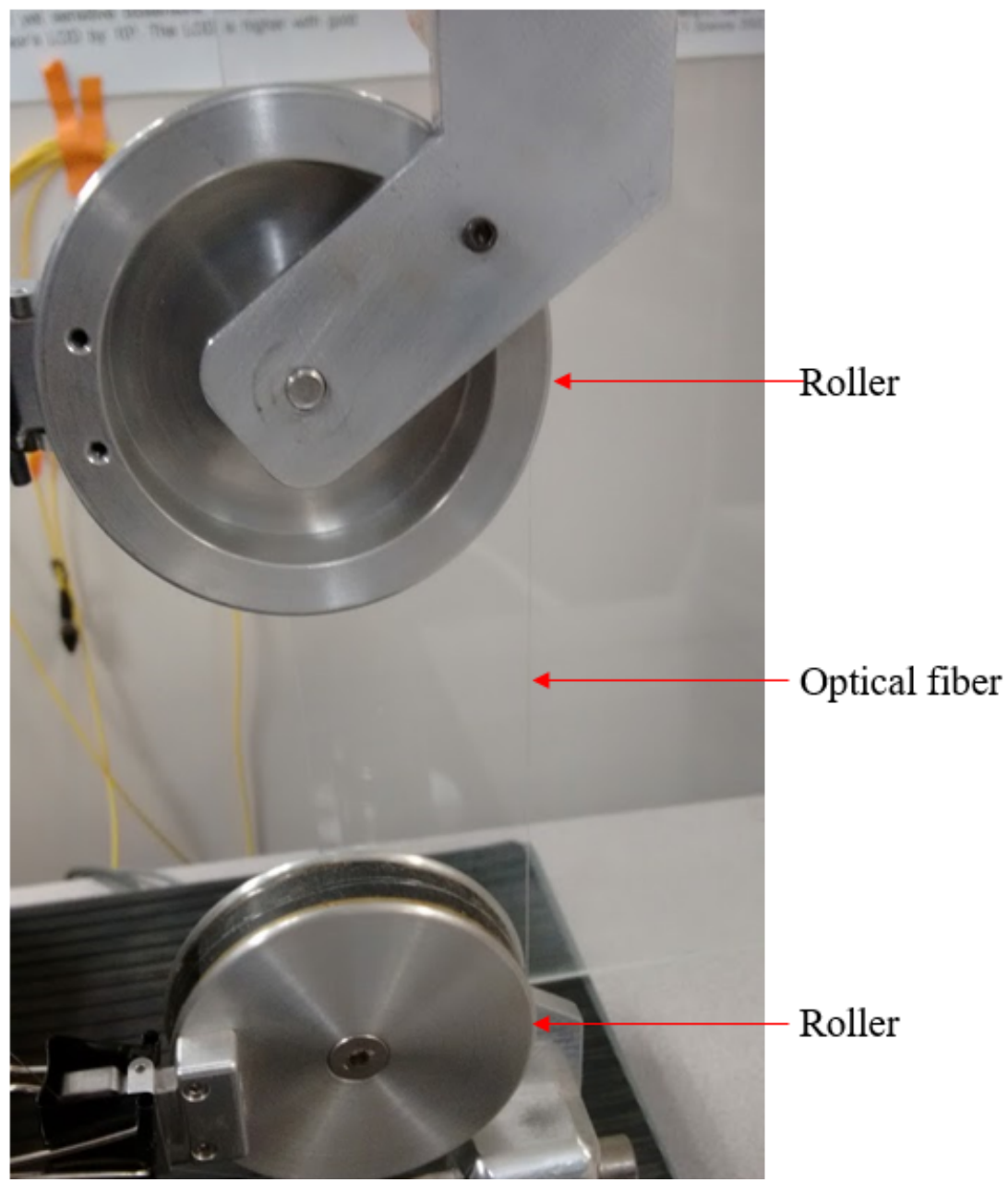

Figure 3.56: Measurement of the strain calibration factor of optical fiber 


\section{Chapter 4}

\section{Results and Discussion}

This thesis includes two stages of tests:

1. Mechanical testing (Tensile, Flexural and Impact) to study the effect of embeding optical fiber on composite.

2. Extraction of data from embedded optical fiber sensors using a reflectometer to measure strain.

Finally the strain values obtained by extensometer during tensile test were compared with the strain measured using embedded optical fiber sensors. The results of these tests are described in the following sections.

\subsection{Tensile Test Results}

The specimens starting with P1 were made from the first panel and the ones starting with P2 were from the second panel. The specimens with embedded optical fibers have been named with OF. All the results have been reported up to three decimal places. As the specimens made from the first panel were tested without an extensometer, their Young's Modulus were calculated using the machine's compliance value as described in Section 3.3.3. 
Table 4.1: Tensile test results from first panel

\begin{tabular}{|l|l|}
\hline Specimen Id. & Young's Modulus, E (GPa) \\
\hline P1-fbg01 & 10.217 \\
\hline P1-fbg02 & 12.362 \\
\hline P1-fbg04 & 11.973 \\
\hline P1-fbg05-OF & 10.159 \\
\hline
\end{tabular}

\begin{tabular}{|l|l|}
\hline Mean & 11.177 \\
\hline Variance & 1.331 \\
\hline Standard Deviation & 1.1540 \\
\hline Coefficient of Variation (\%) & 10.324 \\
\hline
\end{tabular}

Since the specimens were from the same panel, possible reasons for the difference in their values can be local manufacturing defects such as the presence of voids in the composite material.

The coupons made from the second panel were tested separately and the results were recorded. Specimens with non-straight edges were discarded. Table 4.2 shows their Young's Modulus, average values and standard deviations. Figure 4.1 and Figure 4.2 show the bar graph representing the Young's Modulus of the tensile samples from both the panels.

As evident from both the tables, Young's Modulus of the specimens with embedded optical fibers (P1-fbg05-OF and P2-fbg02-OF) did not show any decrease in their values. Young's Modulus of Elasticity (E) was not affected by the presence of optical fiber inside the tensile coupon. Hence, it can be concluded that fiberglass with a ply configuration of $[90 / 0]_{s}$ with embedded optical fiber in between center plies can take as much longitudinal load as the parent material. The minor deviation in between the modulus calculated by embedded optical fibers and fiberglass material 
Table 4.2: Tensile test results from second panel

\begin{tabular}{|l|l|}
\hline $\begin{array}{l}\text { Specimen } \\
\text { Id. }\end{array}$ & Young's Modulus, E(GPa) \\
\hline P2-fbg01 & 13.945 \\
\hline P2-fbg02-OF & 15.234 \\
\hline P2-fbg05 & 15.222 \\
\hline
\end{tabular}

\begin{tabular}{|l|l|}
\hline Mean & 14.800 \\
\hline Variance & 0.548 \\
\hline SD & 0.740 \\
\hline Coefficient of Variation(\%) & 5.00 \\
\hline
\end{tabular}

can be due to the fact that the coating on the optical fiber was of polyacrylate, which is a soft material. Hence, the strain measured using optical fibers did not match the exact readings of extensometer.

\subsection{Impact Test Results}

The first specimen to be tested was sample number 6 . The impactor was set at a height of $21 \mathrm{~cm}$. Mass of the impactor was $5.785 \mathrm{~kg}$. At this position, the potential energy was $12 \mathrm{~J}$. During the impact and rebound process, it appeared that the impactor hit the sample twice in the recorded video. Hence, mass of the impactor was reduced to $5.403 \mathrm{~kg}$ and it was raised to a height of $23.6 \mathrm{~cm}$. The potential energy was changed to 12.5 J. However, upon further analysis of the test's video, it was confirmed that the impactor did not come in contact with the specimen more than once. Thus, results of the first test were not discarded and are presented with all the other impact test results. 


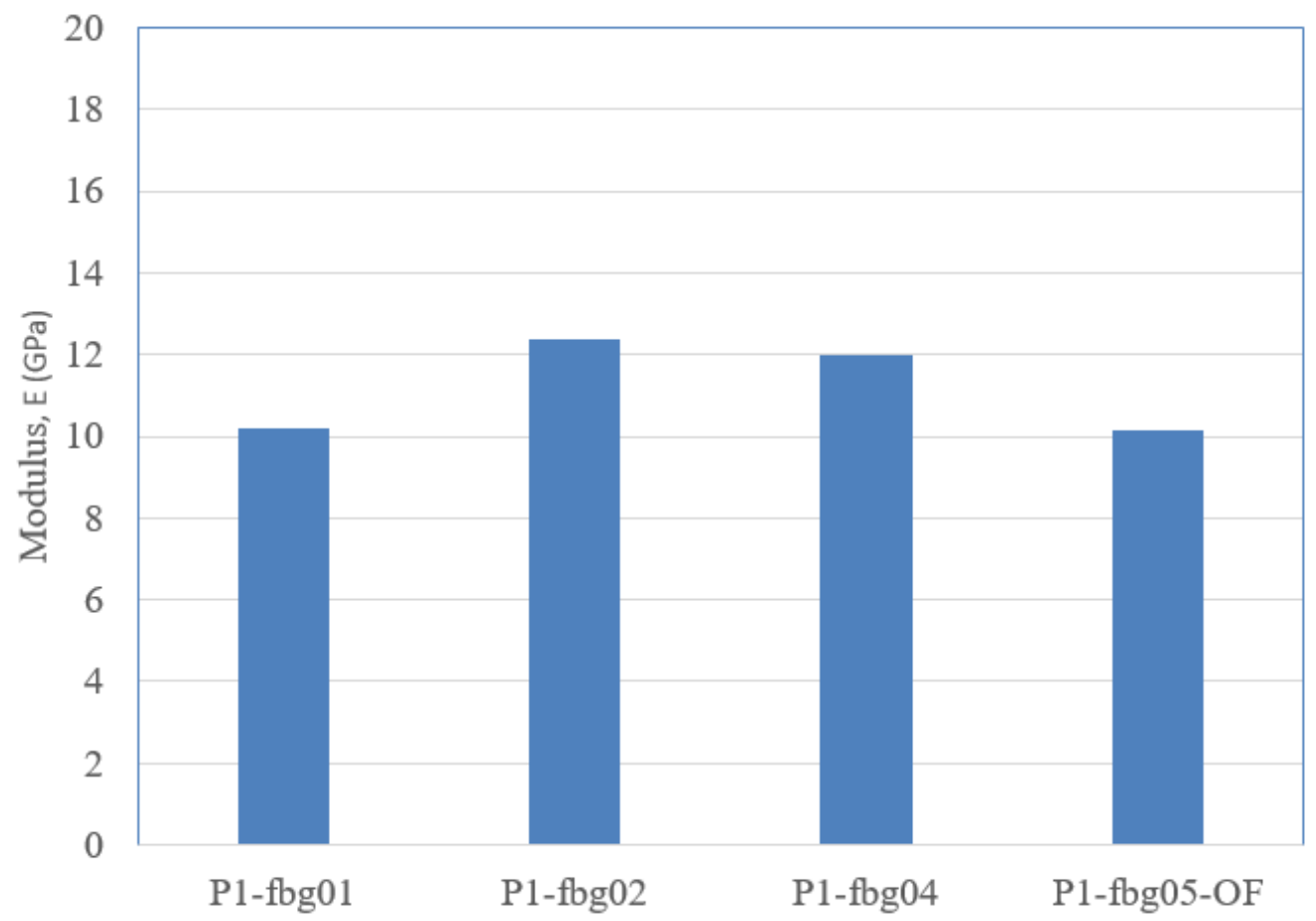

Figure 4.1: Young's Modulus of specimens from the first panel

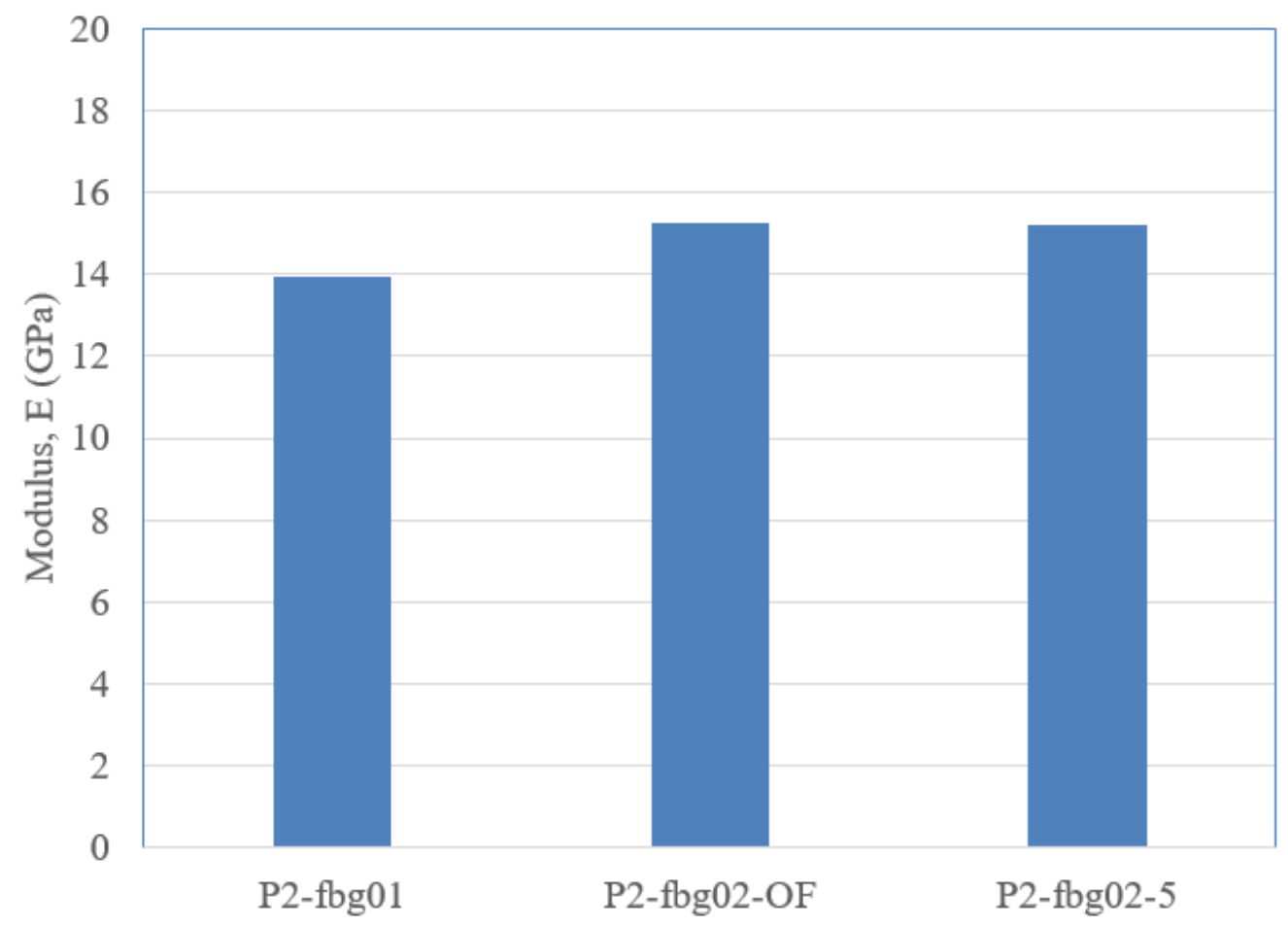

Figure 4.2: Young's Modulus of specimens from the second panel 
The energy absorbed by each specimen was recorded and plotted versus time. Figure 4.3 shows the energy absorbed versus time plot for all the samples and Figure 4.4 shows the bar graph representing the energy absorbed by impact specimens. Samples 1, 2 and 3 had optical fiber embedded while samples 4, 5 and 6 were host material (fiberglass with no optical fiber).

Energy absorbed by each sample were obtained from the graph and are presented in Table 4.3. Energy absorbed is the difference between the peak value of energy and the stagnant value at the end. As seen in the table, there is no significant difference between the energy absorbed by the sample with embedded optical fiber and that of fiberglass without embedded optical fiber. Their average values match to one decimal place. Thus, the impact energy required to just fracture the specimen is not affected when optical fibers are embedded in the center plane of fiberglass laminate.

Table 4.3: Energy absorbed by the impact specimen

\begin{tabular}{|l|l|l|l|}
\hline Specimen No. & Energy absorbed (J) & Average (J) & $\begin{array}{l}\text { Standard } \\
\text { Deviation (J) }\end{array}$ \\
\cline { 1 - 2 } $\mathbf{1}$ (OF embedded) & 3.537 & \multirow{2}{*}{3.472} & \multirow{2}{*}{0.201} \\
\cline { 1 - 2 } $\mathbf{2}$ (OF embedded) & 3.634 & & \\
\cline { 1 - 2 } $\mathbf{3}$ (OF embedded) & 3.247 & \multirow{2}{*}{3.423} & \multirow{2}{*}{0.066} \\
\cline { 1 - 2 } $\mathbf{4}$ (parent material) & 3.392 & & \\
\hline
\end{tabular}

The velocity of the impactor was recorded with respect to time and has been plotted in Figure 4.5. Positive value of velocity represents the movement of the impactor towards the direction of gravity, i.e downwards. After the impact, it rebounds 


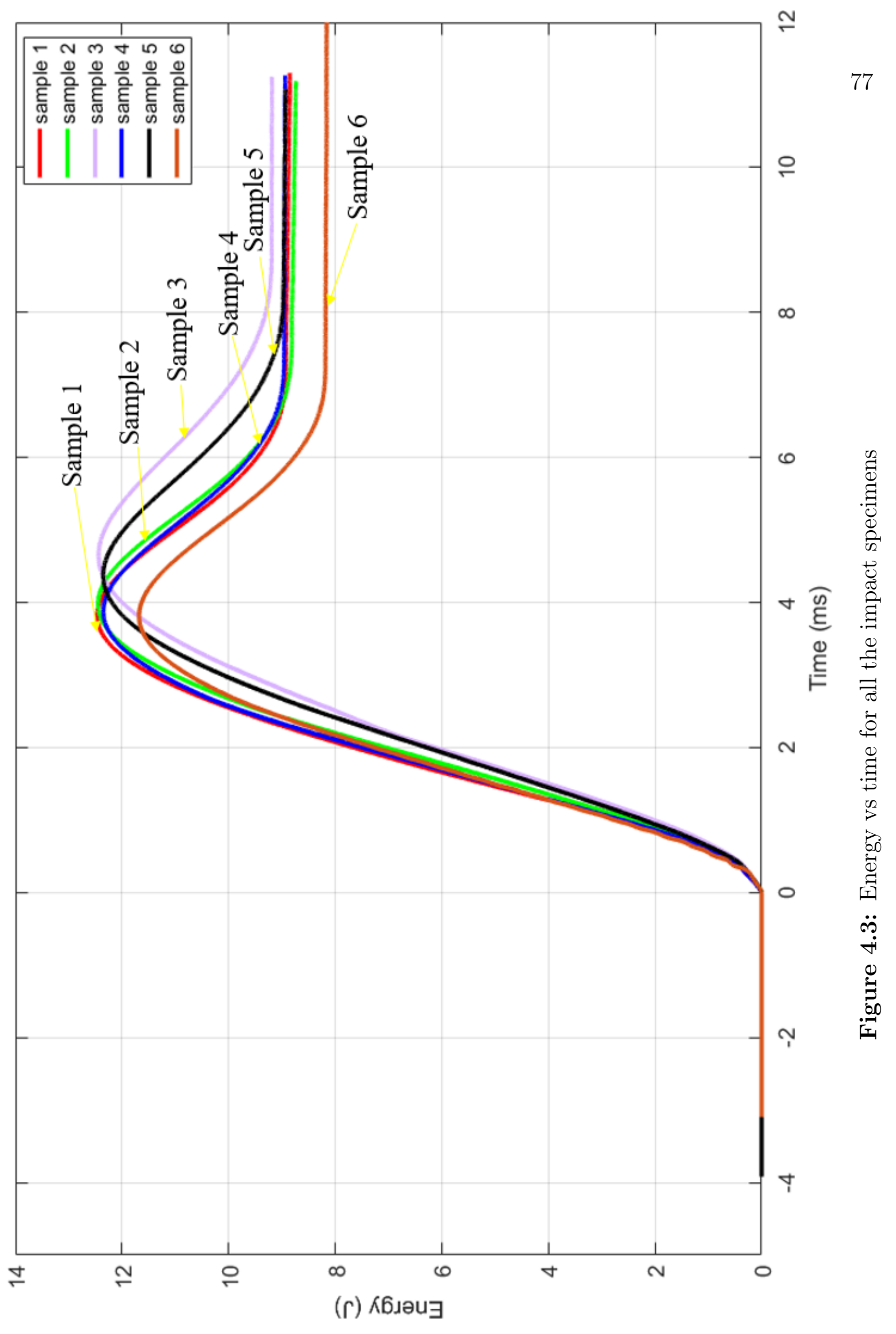




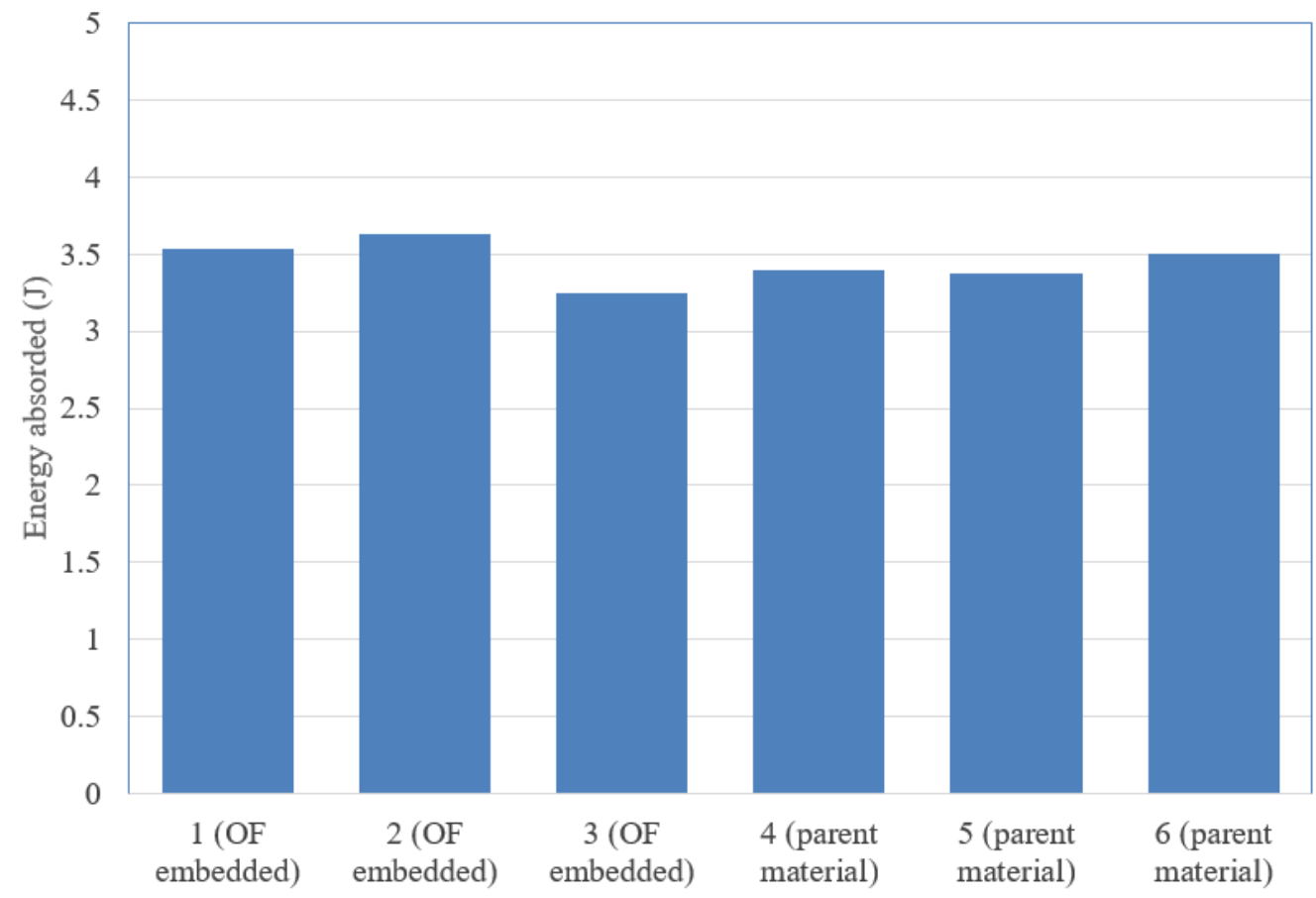

Figure 4.4: Energy absorbed by impact specimens

and this upward movement is represented by negative values. Impact velocity was calculated using Equations 3.4 and 3.5.

Table 4.4: Impact velocity of all the samples

\begin{tabular}{|l|l|l|l|}
\hline Specimen No. & Impact velocity (m/s) & Average (J) & $\begin{array}{l}\text { Standard } \\
\text { Deviation (J) }\end{array}$ \\
\cline { 1 - 2 } $\mathbf{1}$ (OF embedded) & 2.125 & \multirow{2}{*}{2.122} & \multirow{2}{*}{0.003} \\
\cline { 1 - 2 } $\mathbf{2}$ (OF embedded) & 2.123 & & \multirow{2}{*}{2.069} \\
\cline { 1 - 2 } $\mathbf{3}$ (OF embedded) & 2.119 & & \multirow{2}{*}{0.078} \\
\cline { 1 - 2 } $\mathbf{5}$ (parent material) & 2.115 & \\
\cline { 1 - 2 } $\mathbf{6}$ (parent material) & 2.113 & & \\
\hline
\end{tabular}

The calculated value of impact velocity for sample 6 was $2.028 \mathrm{~m} / \mathrm{s}$ and for samples 1 to 5 , it was $2.151 \mathrm{~m} / \mathrm{s}$. The measured values showed good agreement with the calculated values. A possible reason for this difference can be attributed to the energy 


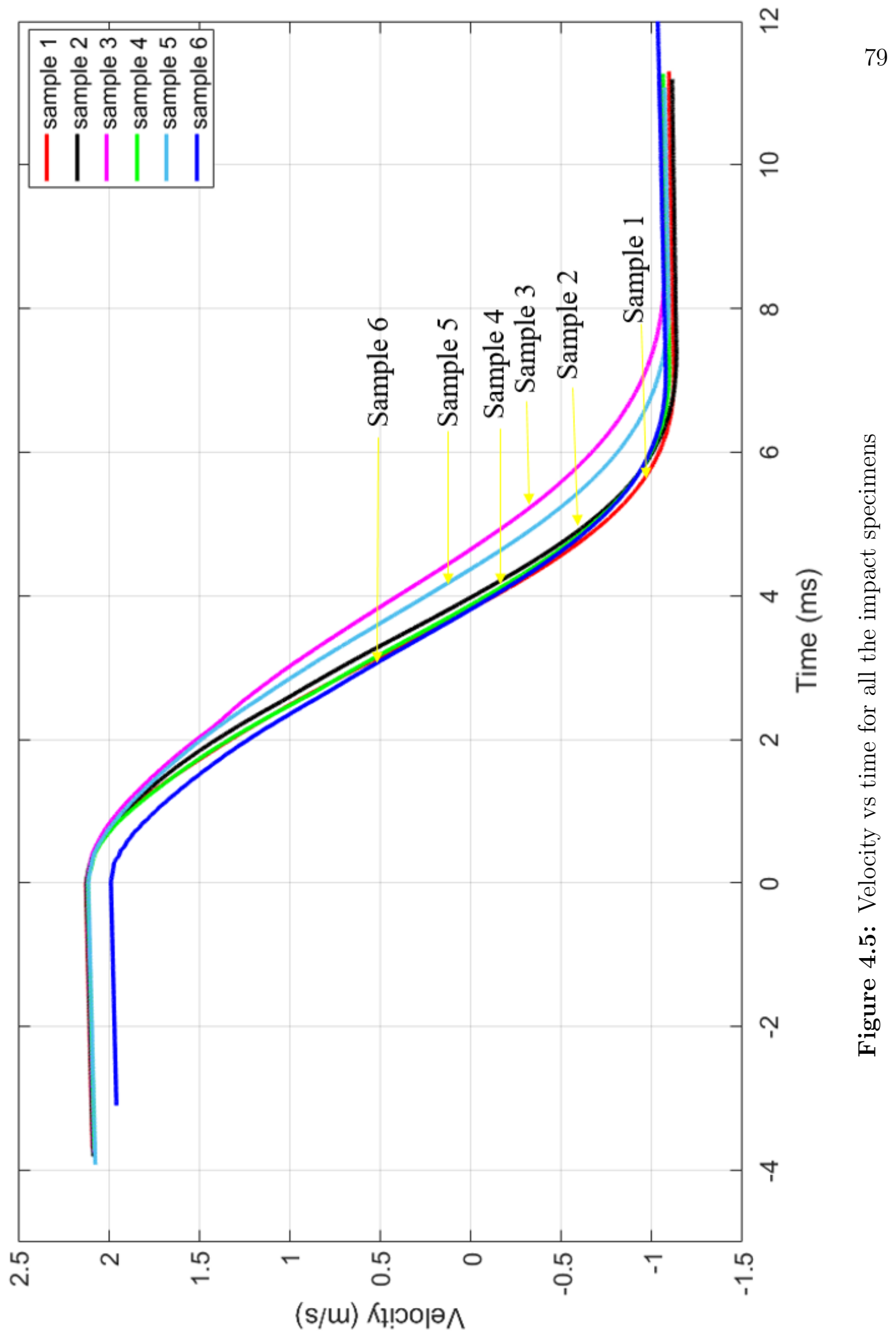


lost due to friction during drop [54].

\subsection{Flexural Test Results}

It was observed that sample number 1 had a crack on the top surface so it was not tested. Flexural modulus, flexural strength, failure mode, failure area and failure location were noted and have been reported as per ASTM 7264's guideline. Table 4.5 shows the meaning of codes for mode, area and location of failure [55]. Flexural results of the samples are shown in Table 4.6.

Table 4.5: Codes for failure mode, area and location

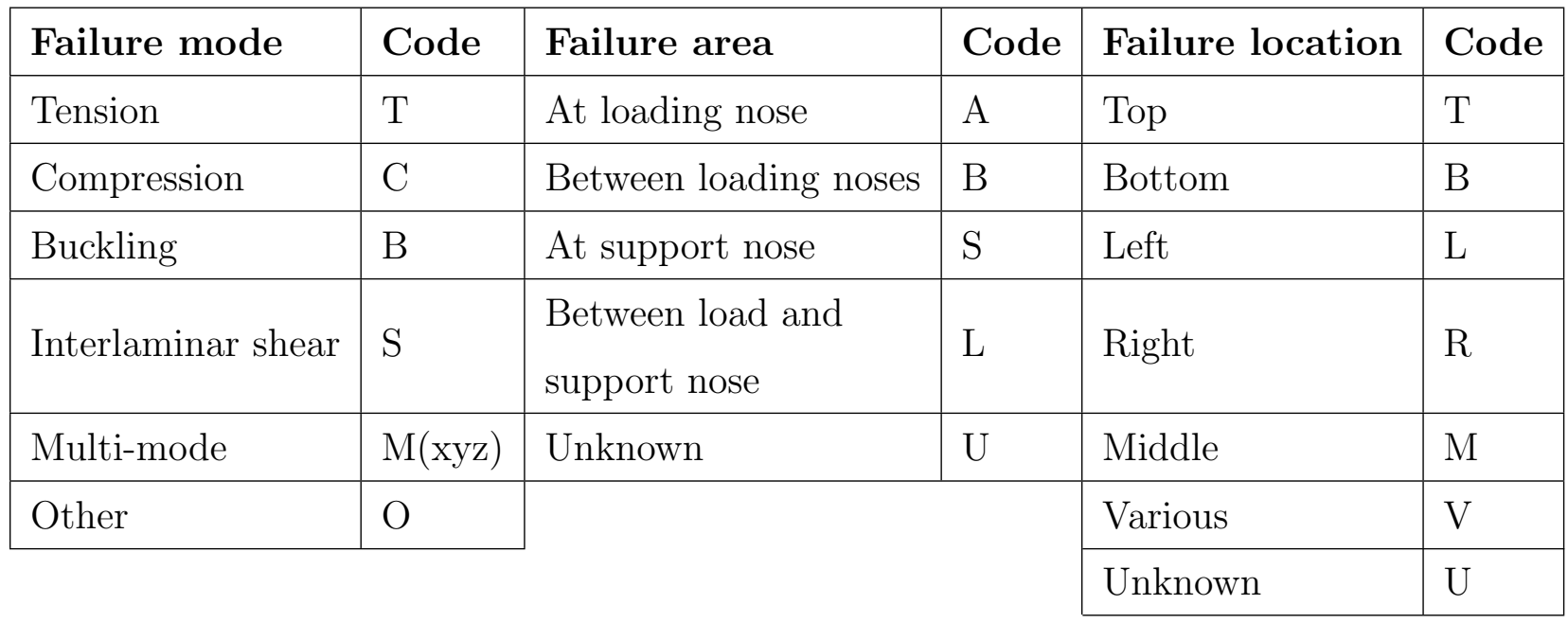

The stress strain curves for all the specimens are shown in Figure 4.6. The slope of the linear region before failure was used to calculate flexural modulus. The region of the curve from 0 to the point of first load drop was taken for this purpose.

Specimens ending with OF have optical fiber embedded between the center plies. As evident from the results, the flexural modulus of the specimens was between $73 \mathrm{GPa}$ to $115 \mathrm{GPa}$. The lowest value of flexural modulus of specimen with embedded optical fiber was 83.222 GPa, which was still more than the lowest value of fiberglass 


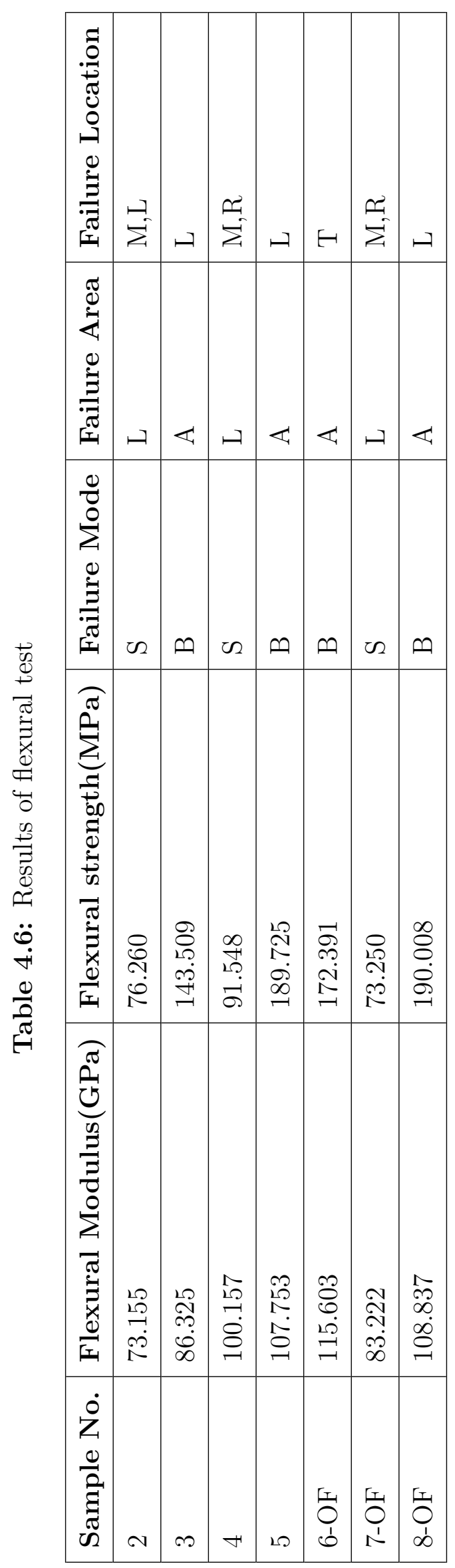




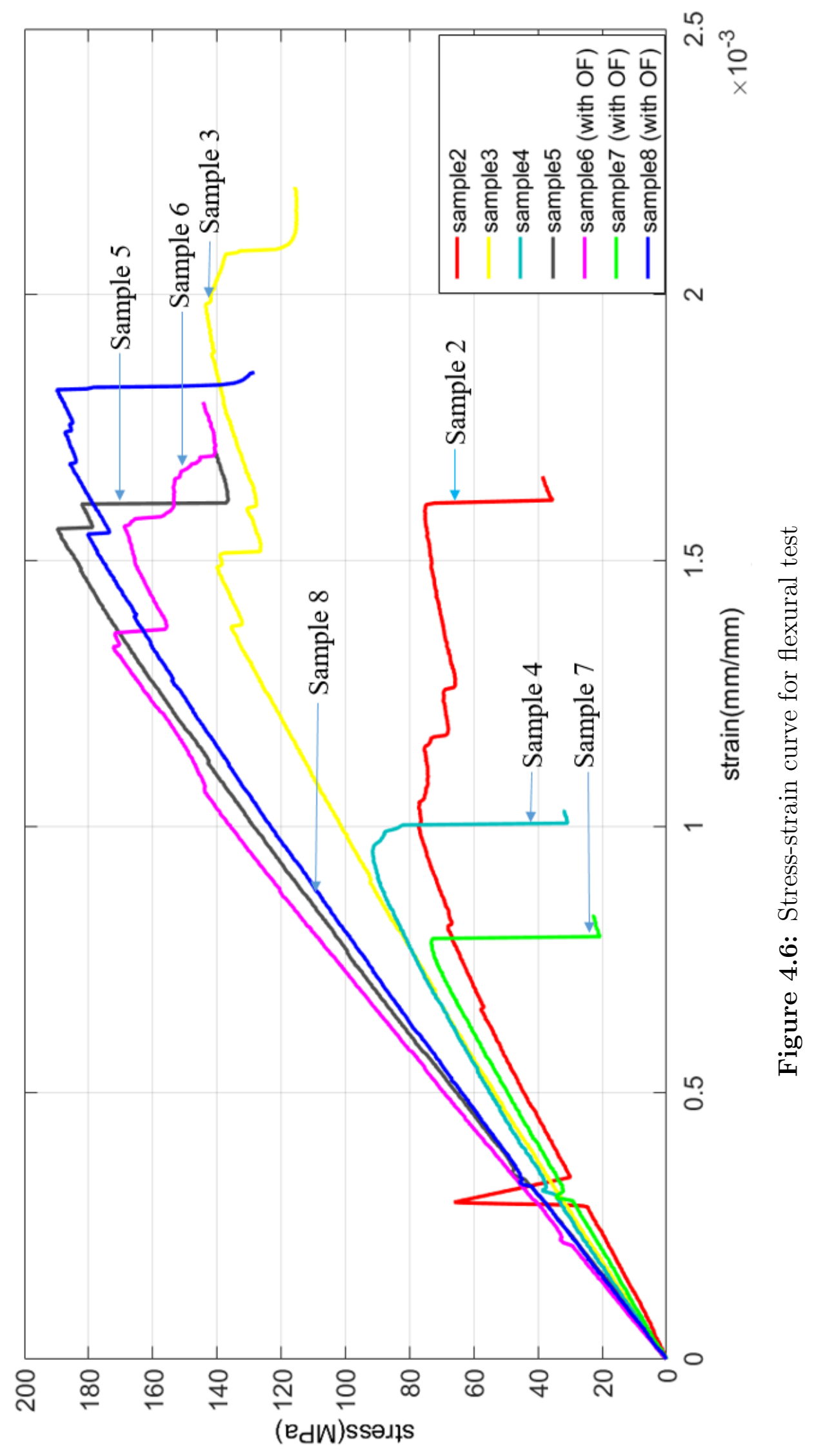


specimen without embedded optical fiber (73.155 GPa for sample 2). Specimen 6-OF, which was embedded with optical fiber had the highest flexural modulus among all the samples tested. The values obtained were not consistent for all the samples. However, it can be observed that embedding optical fiber in fiberglass did not deteriorate the flexural modulus of the host material.

Flexural strength of all the specimen except sample 3 lie between 24.33 MPa and 44.29 MPa. As observed in Figure 4.6, specimen 3 did not experience failure until 131.181 MPa. The specimen with the lowest value of flexural strength was Sample 2 (without embedded optical fiber). Two of the samples with optical fiber (6 and 7) have close values of flexural strength while the third sample (sample 8) has a higher value. The results lead to the conclusion that embedding optical fiber in between center plies of fiberglass has no significant effect on their flexural strengths.

The failure modes of all the samples was either buckling or interlaminar shear. The reason for interlaminar shear could be due the presence of voids in the sample as a result of manufacturing defects. Four specimens failed at the loading nose and three of them failed between the loading nose and support nose. Failure locations varied between the samples. Three specimens were observed to have failed at two locations (samples 2, 4 and 7).

\subsection{Tensile Strain Measurement Using Embedded Optical Fibers}

Strain during tensile tests were measured by an extensometer. Optical fiber data was recorded using the reflectometer during loading and unloading conditions. Coordinates of the peak values combined with strain calibration factor were used 
to measure strain using Equation 2.2. The testing was started with an aluminium AA6061 coupon with an optical fiber bonded on its surface. The specimen was loaded in displacement mode with increments of $0.05 \mathrm{~mm}$ until $0.6 \mathrm{~mm}$ and then unloaded in the same increments. Strain and modulus of elasticity were calculated from both curves. The stress-strain curve for loading and unloading condition can be seen in Figure 4.7 and Figure 4.8. The slope of these curves were calculated to find the modulus of elasticity, which were compared for loading and unloading cycle.

The stress-strain curves of fiberglass reinforced epoxy with embedded optical fiber was plotted using the values obtained by extensometer and optical fiber (Figure 4.9 and Figure 4.10). The data points corresponding to the extensometer and that of optical fibers did not seem to match in the curve. Possible reason for this mismatch could be that the optical fiber was not bonded well within fiberglass. Modulus of elasticity for all the loading and unloading cycles was calculated for both the readings. The values did not seem to match, giving an evidence of poor bonding between optical fiber and the host material. One way to confirm the nature of bonding between the embedded optical fiber and the fiberglass material can be cutting the specimen at various locations and observing the cross section under a microscope. However, this exercise was not carried out for this thesis.

The plot of the second specimen with embedded optical fiber showed good correlation between the strain values of the extensometer and that of optical fiber as shown in Figure 4.11 and Figure 4.12. Data were recorded during four loading and four unloading cycles and compared to examine the agreement of strain values and modulus of elasticity. Unlike the first sample, the values showed good correlation. It also proved that embedded optical fiber was well bonded within the fiberglass composite. 


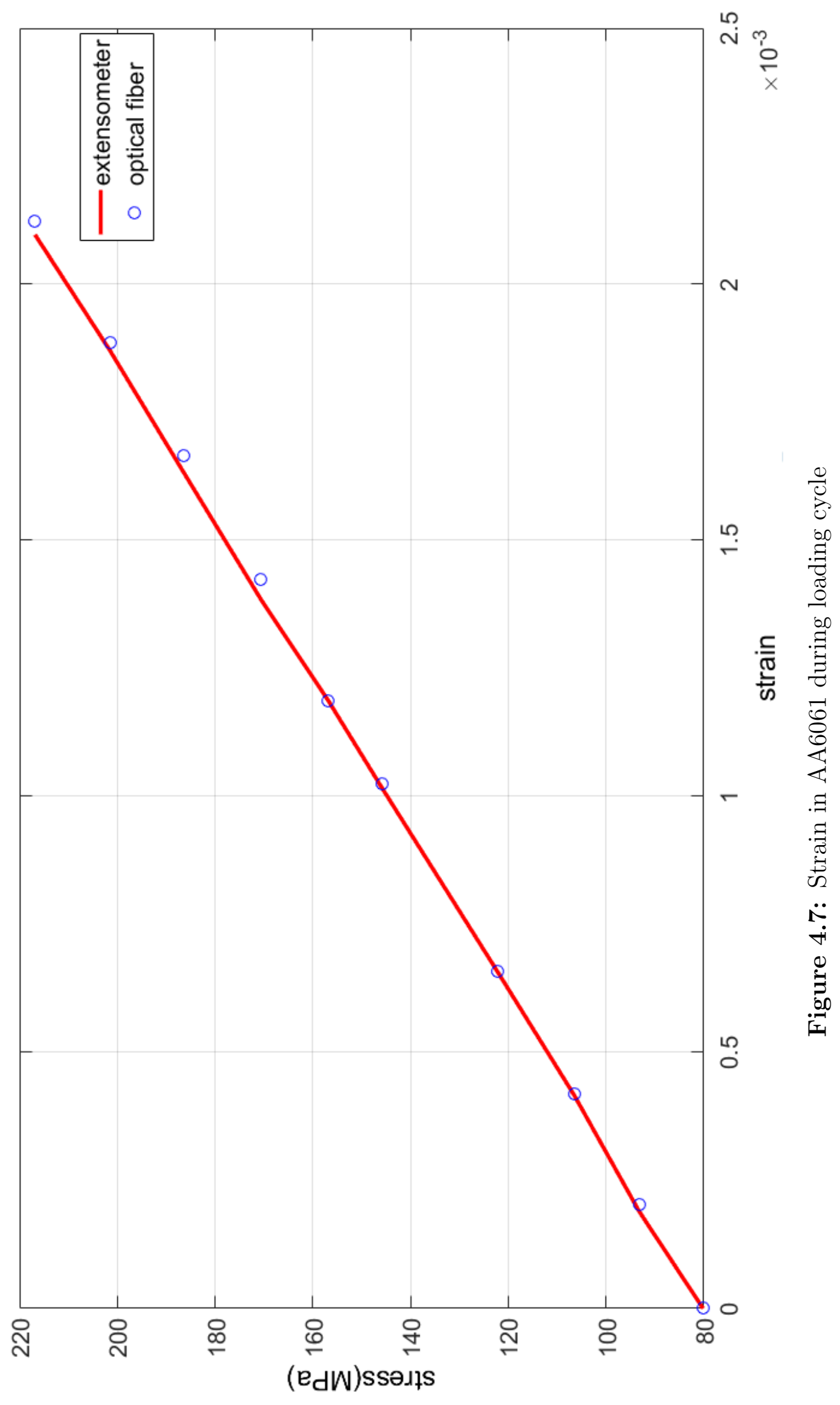




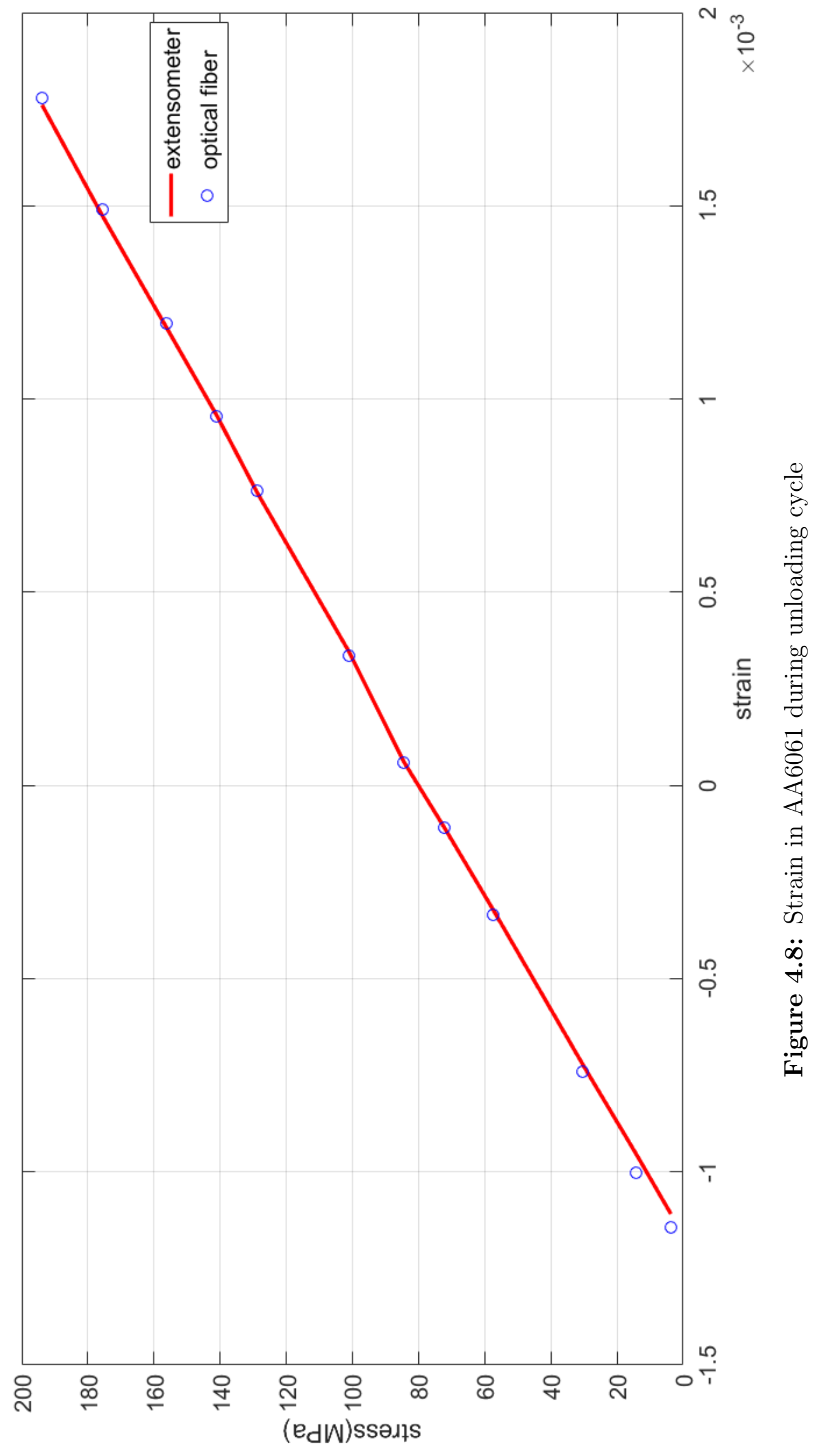




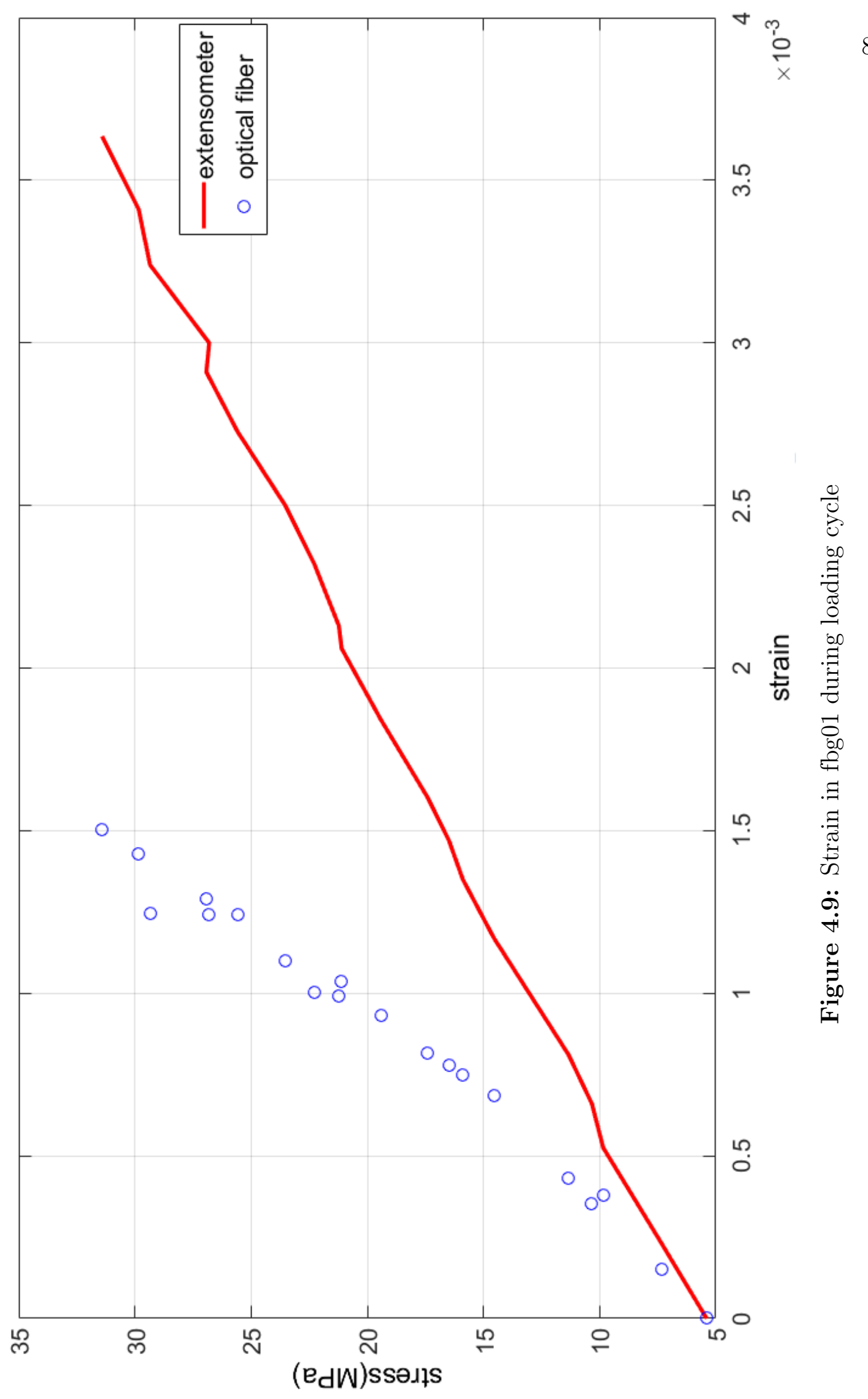




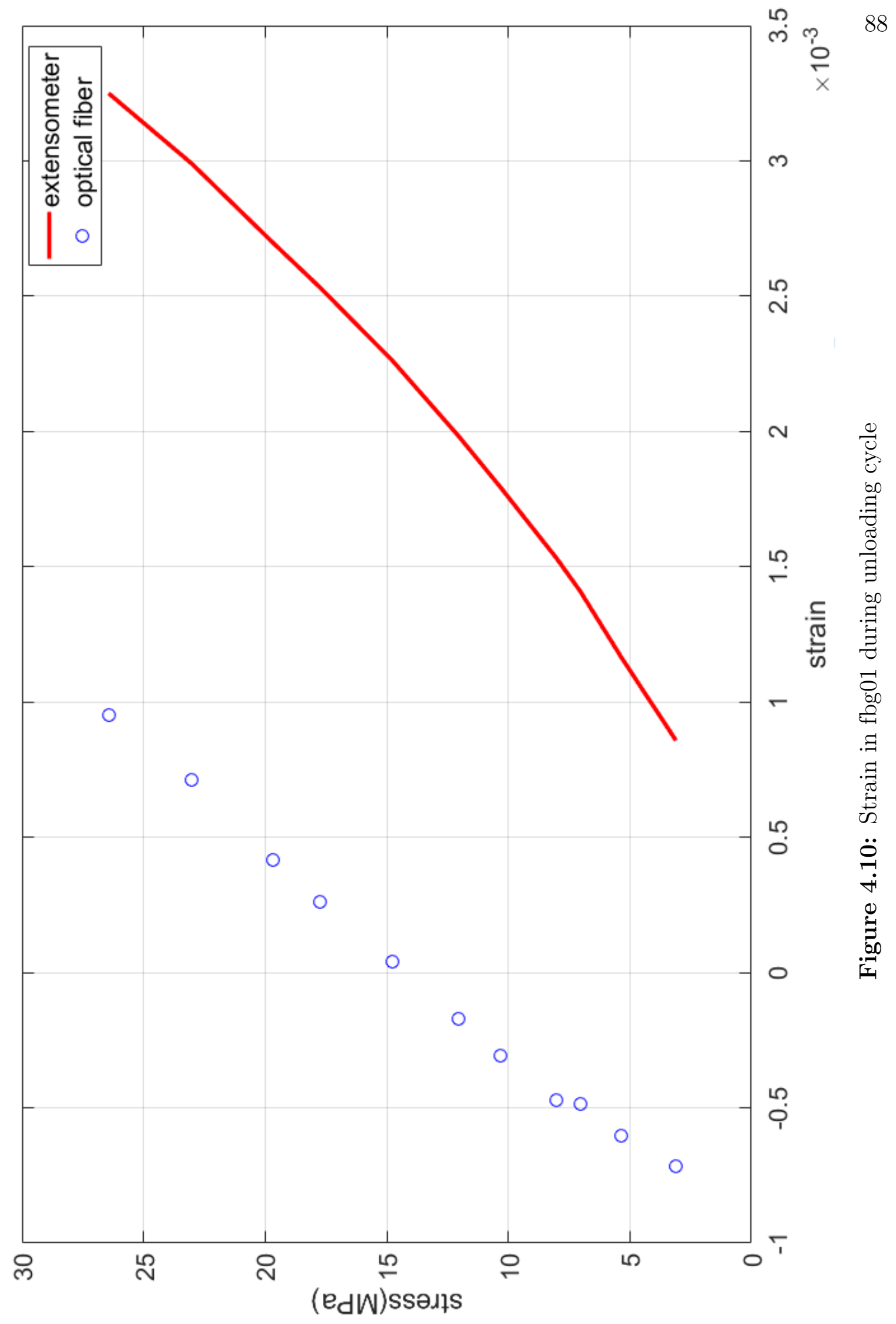




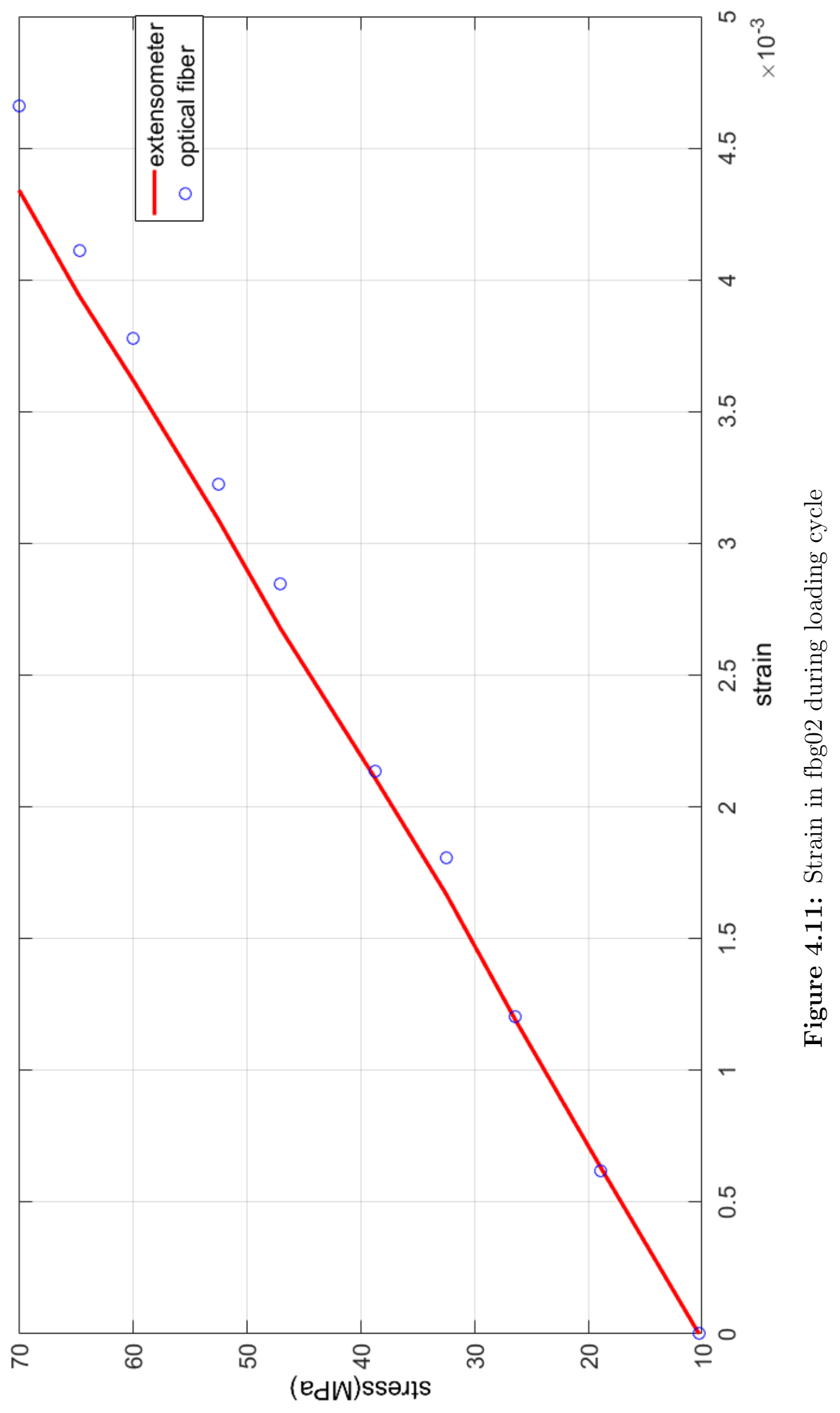




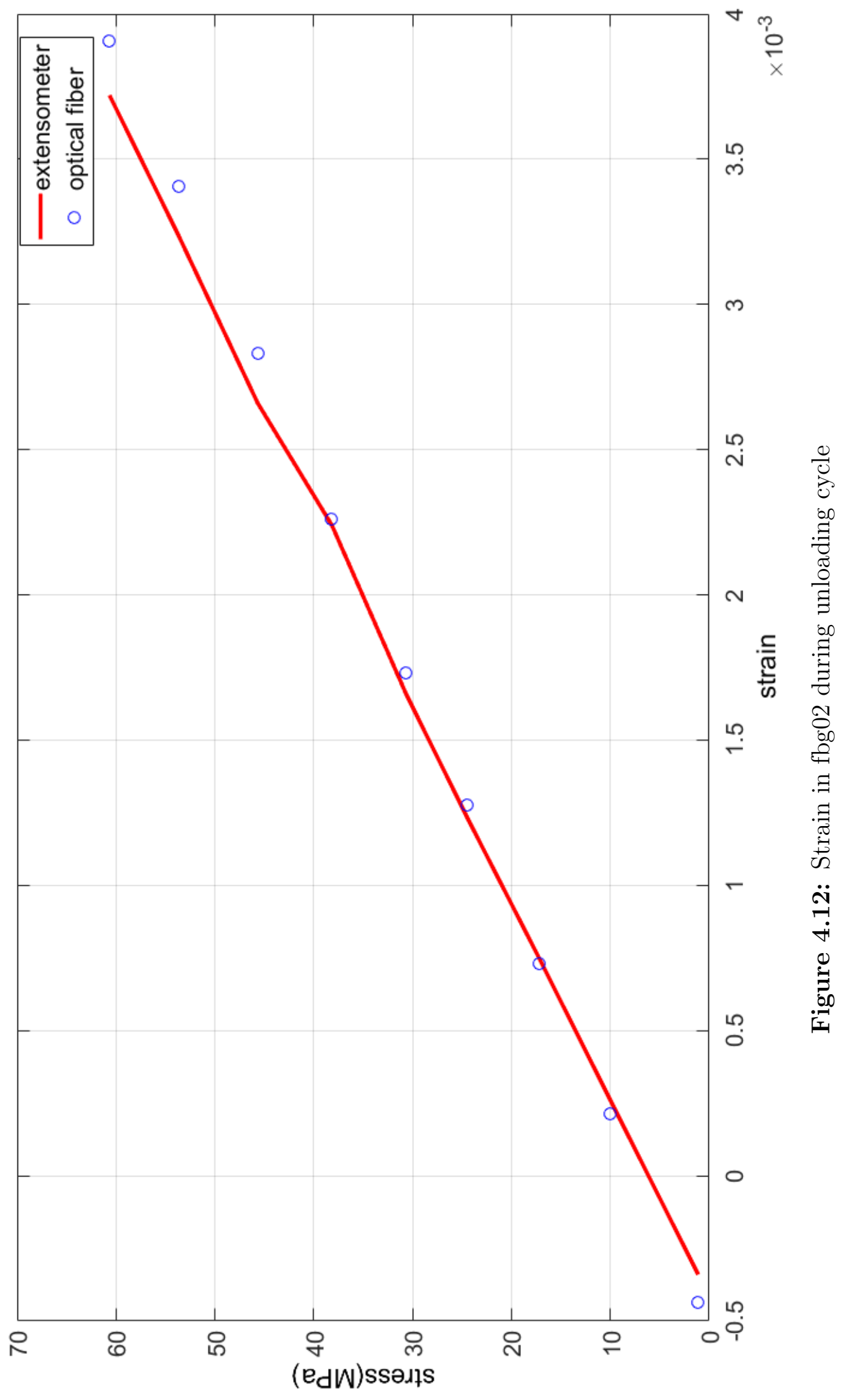


The stress-strain curve of the third sample with embedded optical fiber also showed good agreement between the strain values obtained by extensometer and that of the optical fiber. Plots are shown in Figure 4.13 and Figure 4.14.

The stress comparison for the full cycle in AA6061 aluminium is shown in Figure 4.15 and that of fiberglass with embedded optical fiber is shown in Figure 4.16. The strain values measured from both methods seem to follow the same pattern with some minor deviations with the exception being the first fiberglass coupon whose optical fiber was not properly bonded with the parent material. However, the conclusion on the nature of bonding can only be confirmed by cutting the sample and observing the cross sectional area under a microscope.

The calculated data prove that the optical fibers recorded the correct strain measurement during loading and unloading cycles while they were bonded on the surface (in case of AA6061) as well as when they were embedded within the fiberglass.

Modulus of elasticity was calculated for each loading and unloading cycle from the stress-strain curve. The values obtained for AA6061 using an extensometer and embedded optical fiber are shown in Table 4.7. Modulus of Elasticity for fiberglass coupons are displayed in Table 4.9, Table 4.10 and Table 4.11. Modulus calculated from all the grating of the optical fiber were close with a standard deviation of 0.340 GPa as seen in Table 4.8 .

Table 4.7: Comparison of modulus of elasticity in AA6061

\begin{tabular}{|l|l|l|l|}
\hline Specimen & Cycle & E extensometer (GPa) & E optical fiber (GPa) \\
\hline \multirow{2}{*}{ Al01 } & Loading & 65.096 & 64.246 \\
\cline { 2 - 4 } & Unloading & 66.122 & 64.970 \\
\hline \\
\cline { 2 - 4 } & Average & 65.609 & 64.608 \\
\cline { 2 - 4 }
\end{tabular}




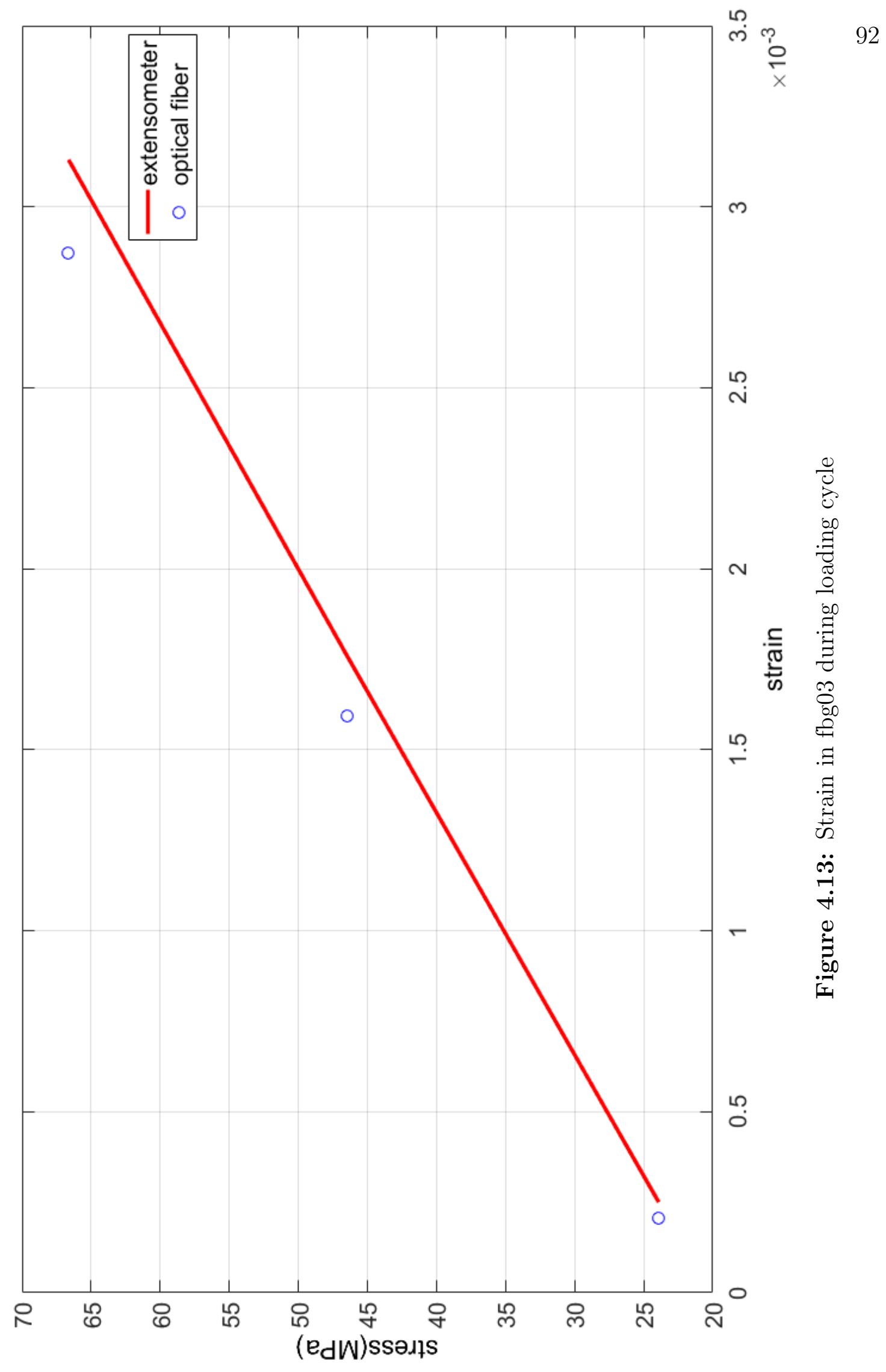




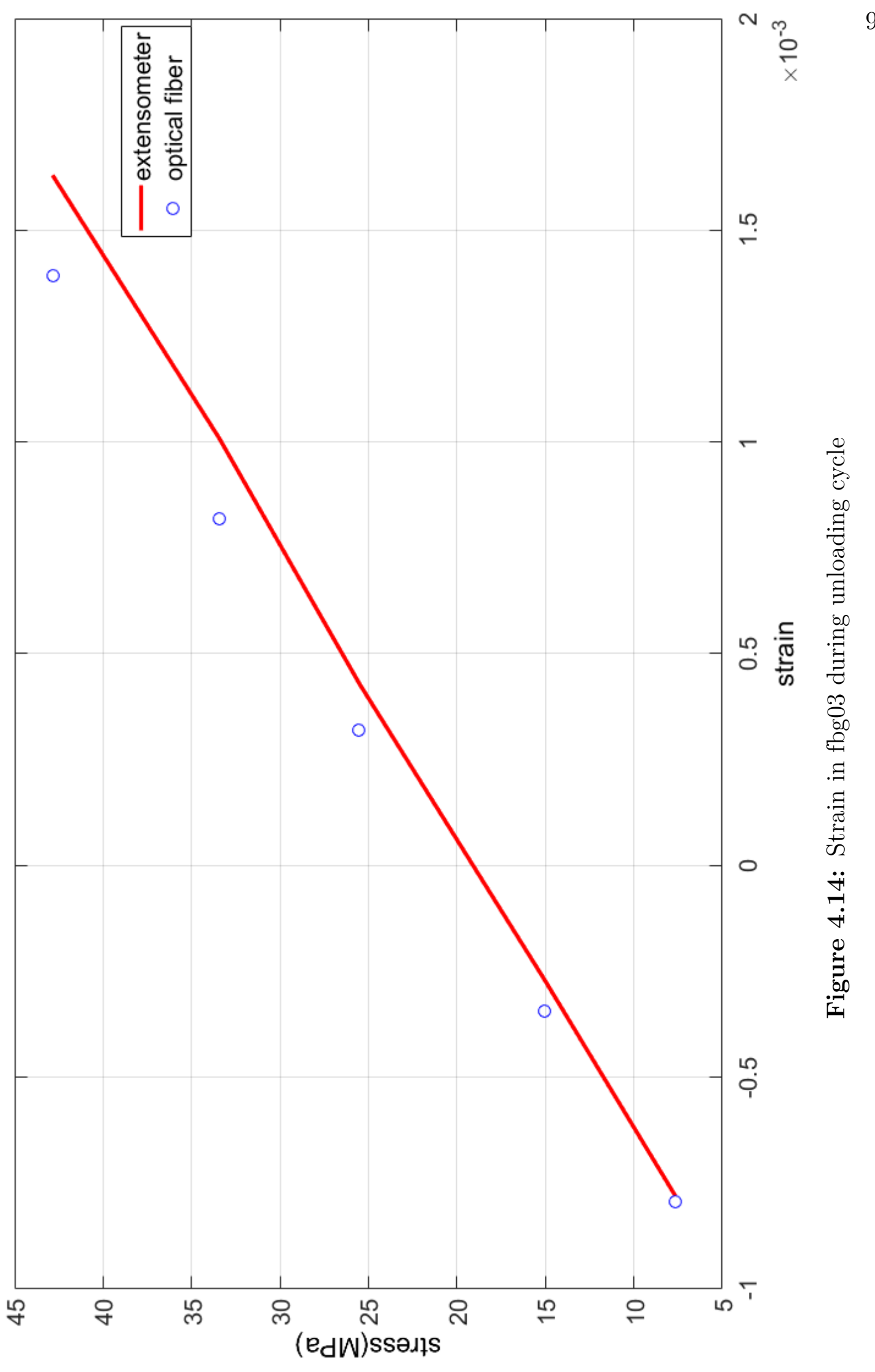




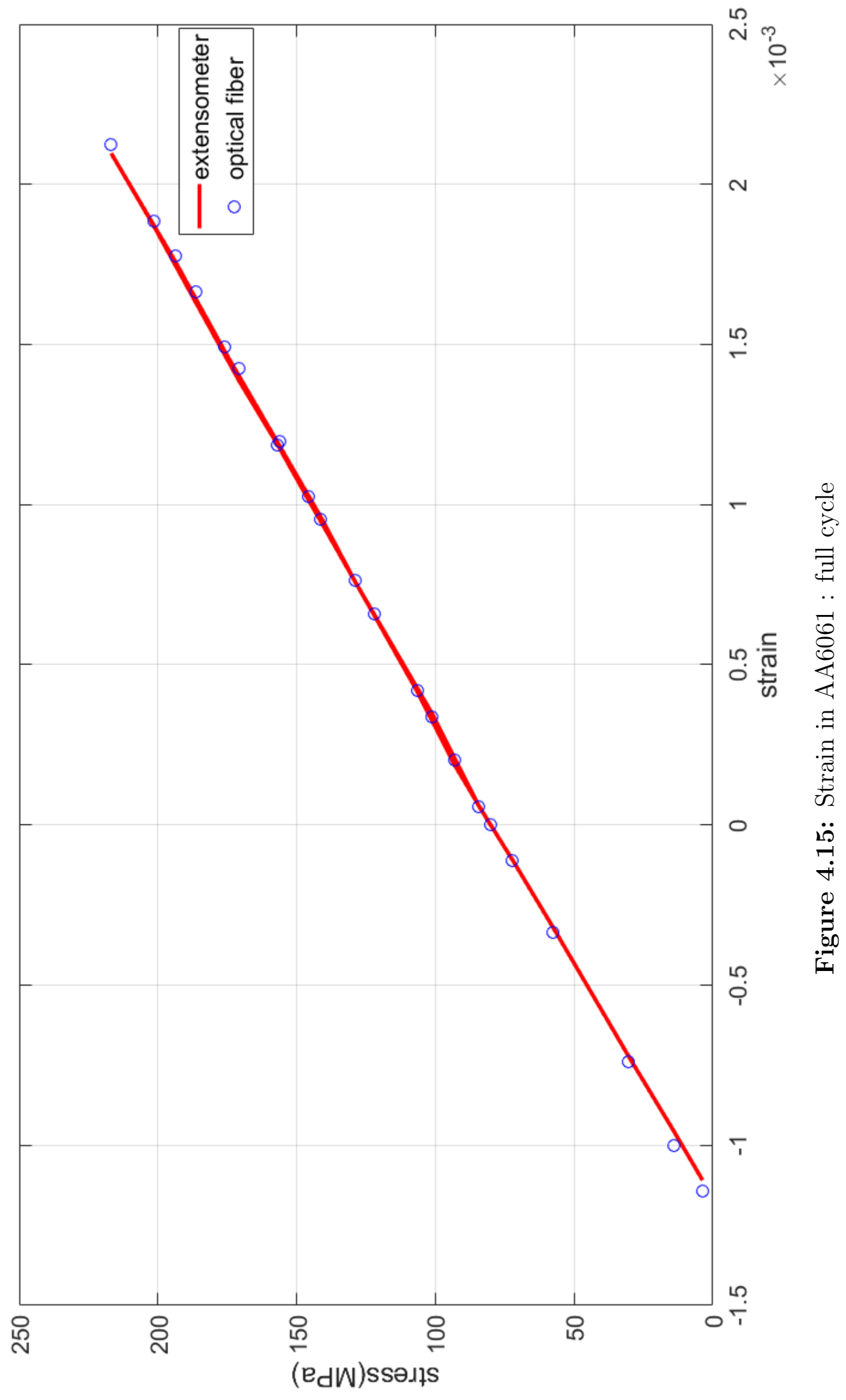




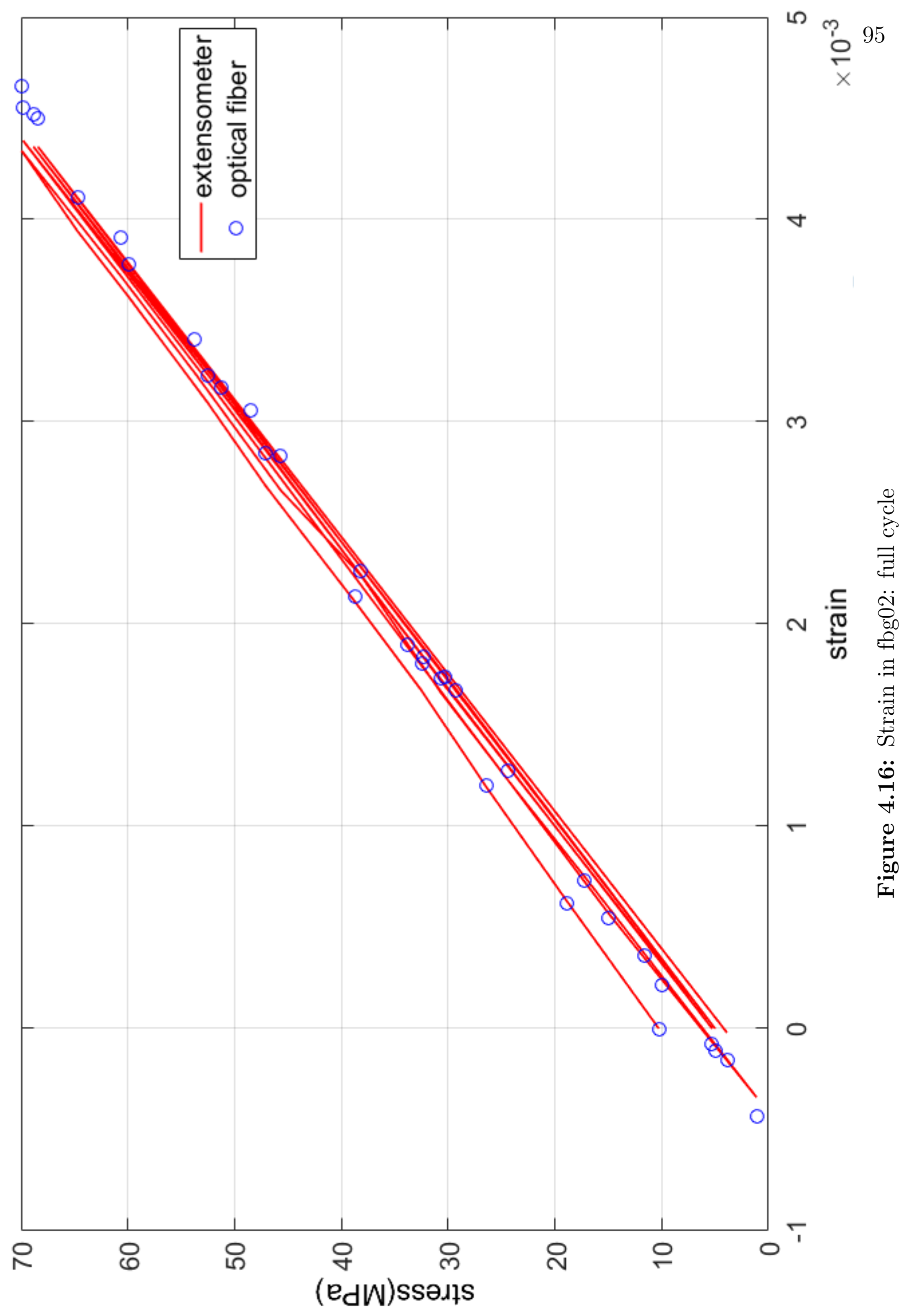


Table 4.8: Modulus measured by all the gratings of AA6061

\begin{tabular}{|l|l|l|l|}
\hline Source & E (GPa) & Average (GPa) & Standard Deviation (GPa) \\
\hline Grating 1 & 64.353 & & \\
\cline { 1 - 2 } Grating 2 & 63.941 & & \\
\cline { 1 - 2 } Grating 3 & 64.583 & \multirow{2}{*}{64.459} & 0.340 \\
\cline { 1 - 2 } Grating 4 & 64.842 & & \\
\cline { 1 - 2 } Grating 5 & 64.2624 & & \\
\cline { 1 - 2 } Grating 6 & 64.772 & & \\
\cline { 1 - 2 } Extensometer & 65.609 & &
\end{tabular}

Table 4.9: Modulus of Elasticity in fbg01

\begin{tabular}{|l|l|l|l|}
\hline Specimen & Cycle & E extensometer (GPa) & E optical fiber (GPa) \\
\hline \multirow{4}{*}{ fbg01 } & Loading1 & 7.142 & 18.116 \\
\cline { 2 - 4 } & Unloading1 & 9.755 & 13.569 \\
\cline { 2 - 4 } & Loading2 & 9.664 & 14.14 \\
\cline { 2 - 4 } & Unoading2 & 10.131 & 11.337 \\
\cline { 2 - 4 } & Loading3 & 10.484 & 14.457 \\
\cline { 2 - 4 } & Unloading3 & 11.556 & -1.184 \\
\hline
\end{tabular}

As seen in Table 4.7, the average value of Modulus of Elasticity shows good agreement with extensometer and optical fiber. In the case of fbg01, all the values do not match with each other. This was expected as the stress-strain plot showed that the strain values were not in coordination with each other. A possible reason for this behaviour was that the embedded optical fiber was not properly bonded with the host material. Also, E calculated by optical fiber was negative in the third unloading cycle. The negative value of $\mathrm{E}$ in third unloading cycle affected the standard deviation 


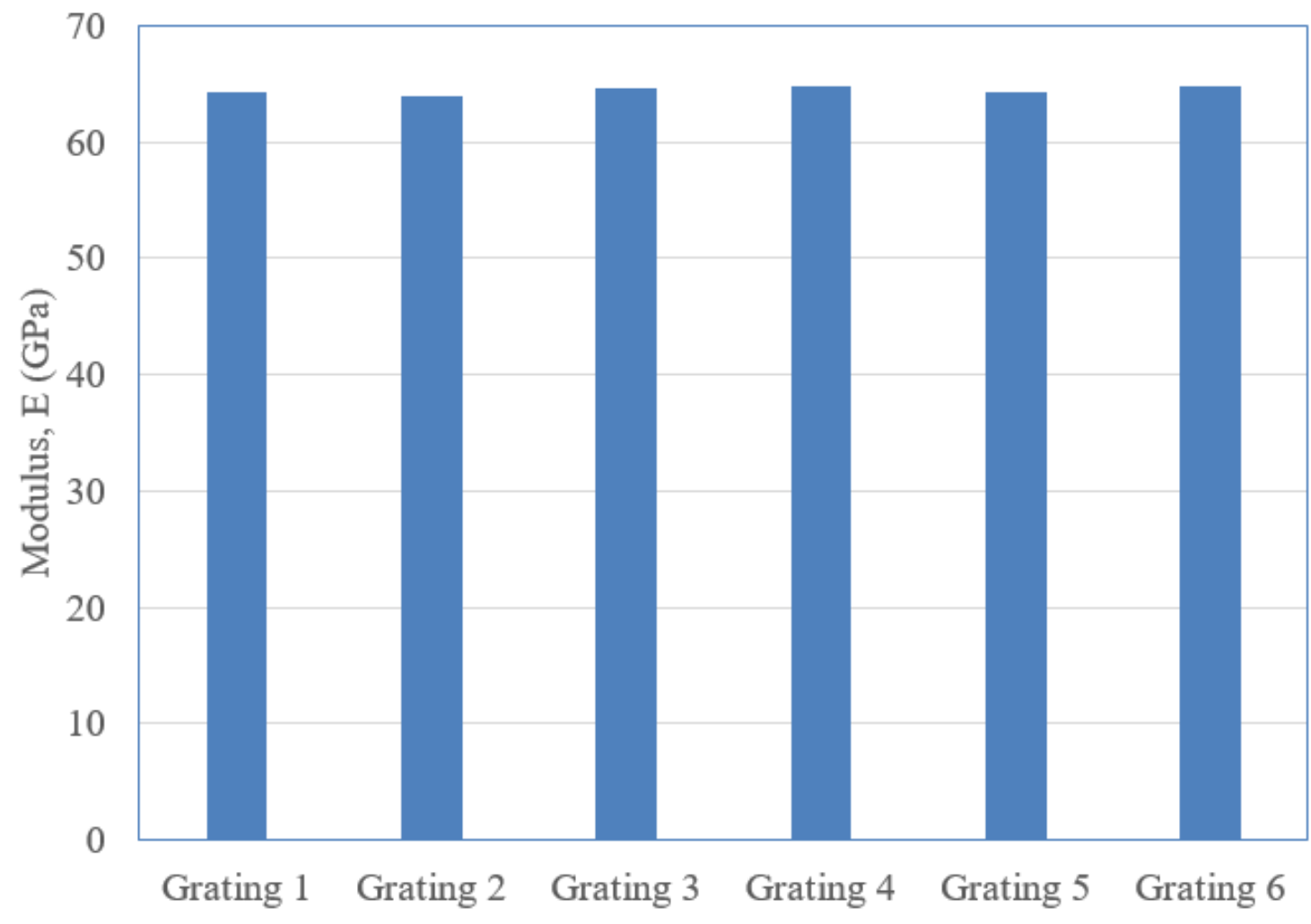

Figure 4.17: Modulus measured by all the gratings in AA6061

Table 4.10: Modulus of Elasticity in fbg02

\begin{tabular}{|l|l|l|l|l|}
\hline Specimen & Cycle & Extensometer & Optical fiber & $\begin{array}{l}\text { Data points } \\
\text { measured }\end{array}$ \\
\hline \multirow{5}{*}{ fbg02 } & Loading 1 & 13.805 & 12.979 & 10 \\
\cline { 2 - 5 } & Unloading 1 & 14.658 & 13.69 & 9 \\
\cline { 2 - 5 } & Loading 2 & 14.339 & 13.677 & 4 \\
\cline { 2 - 5 } & Unloading 2 & 14.614 & 13.722 & 4 \\
\cline { 2 - 5 } & Loading 3 & 14.485 & 13.605 & 2 \\
\cline { 2 - 5 } & Unloading 3 & 14.458 & 13.641 & 2 \\
\cline { 2 - 5 } & Loading 4 & 14.548 & 13.749 & 2 \\
\cline { 2 - 5 } & Unloading 4 & 14.735 & 13.848 & 2 \\
\hline
\end{tabular}

\begin{tabular}{|l|l|l|}
\hline Average & $14.455 \pm 0.29$ & $13.614 \pm 0.27$ \\
\hline
\end{tabular}




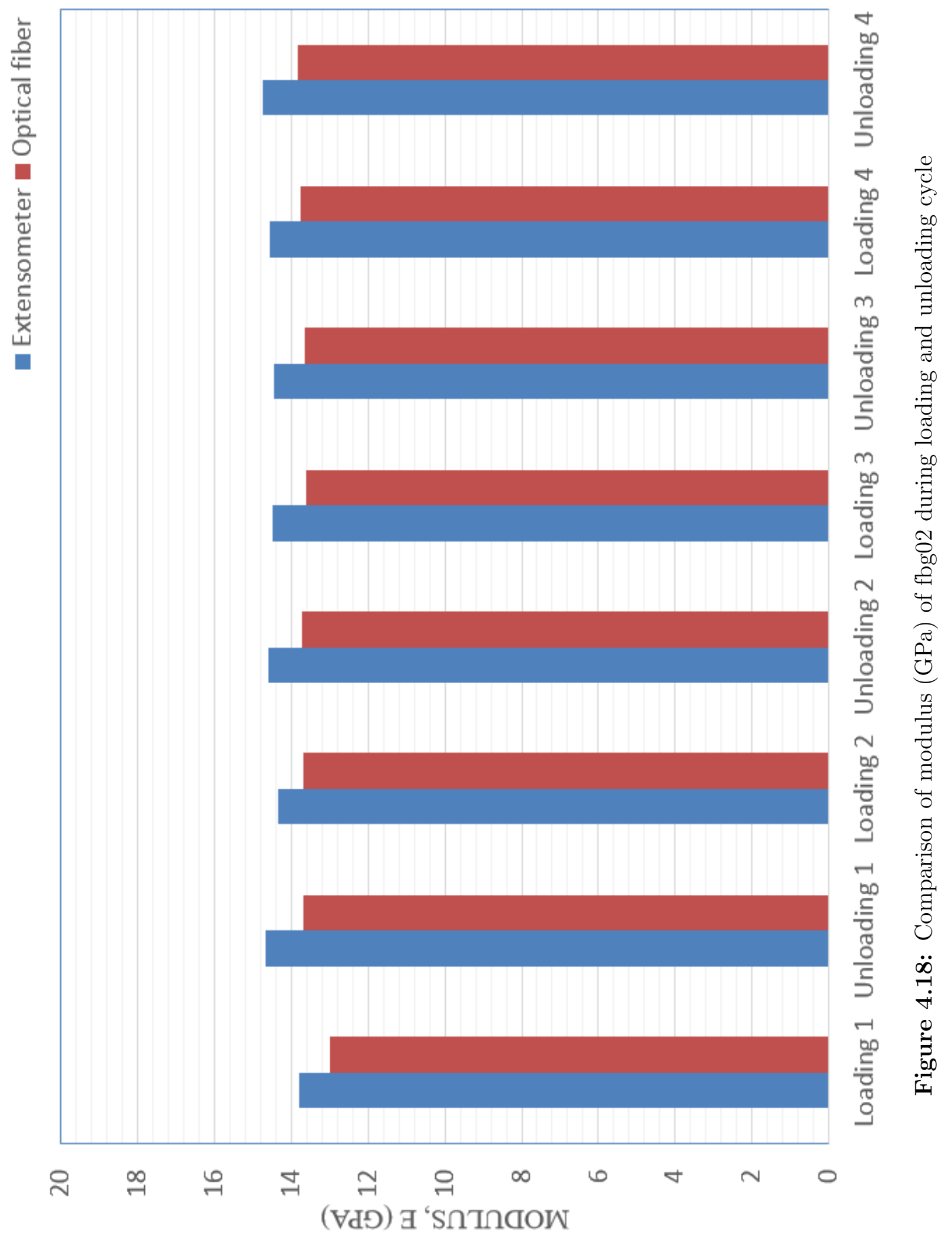




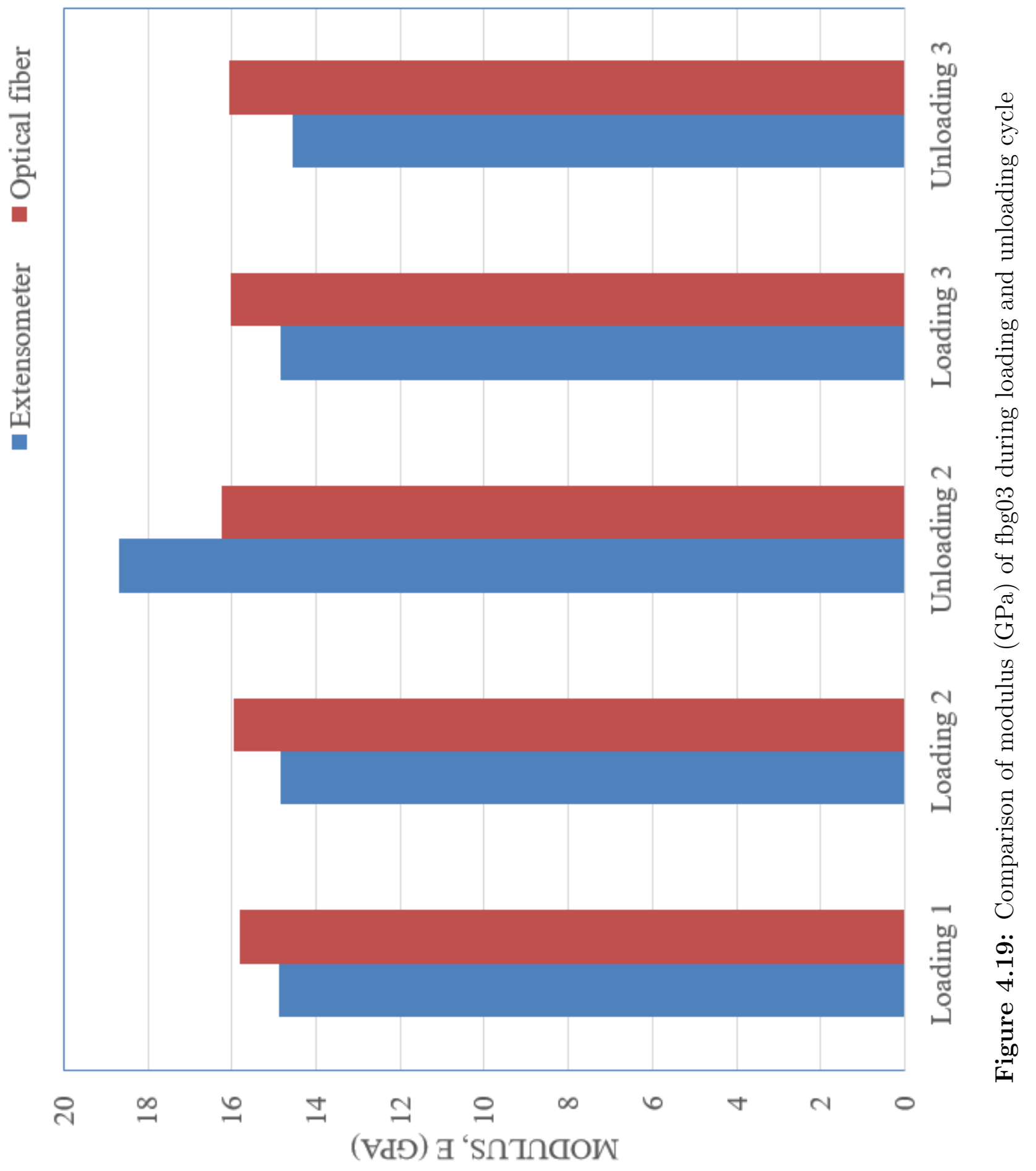


Table 4.11: Modulus of Elasticity in fbg03

\begin{tabular}{|l|l|l|l|l|}
\hline Specimen & Cycle & Extensometer & Optical fiber & $\begin{array}{l}\text { Data points } \\
\text { measured }\end{array}$ \\
\hline \multirow{4}{*}{ fbg03 } & Loading 1 & 14.866 & 15.830 & 5 \\
\cline { 2 - 5 } & Loading 2 & 14.839 & 15.972 & 3 \\
\cline { 2 - 5 } & Unloading 2 & 18.688 & 16.249 & 3 \\
\cline { 2 - 5 } & Loading 3 & 14.835 & 16.025 & 3 \\
\cline { 2 - 5 } & Unloading 3 & 14.560 & 16.047 & 5 \\
\hline \multicolumn{4}{|l|}{} \\
\cline { 2 - 4 } \\
\cline { 2 - 4 } & Average & $15.557 \pm 1.75$ & $16.024 \pm 0.15$ &
\end{tabular}

value, which was calculated to be $6.69 \mathrm{GPa}$. It can be safely concluded from these observations that in the absence of proper bonding between the embedded optical fiber sensor and parent material, the measured value of strain will not be the exact representation of the strain experienced by the host material.

Specimens fbg02 and fg03 showed close agreement between their modulus values during both loading and unloading cycles. The difference in their modulus could be due to the presence of voids resulting due to manufacturing defects. The average value of $\mathrm{E}$ for fbg02 was $14.455 \mathrm{GPa}$ while the average measured by optical fiber sensor was $13.614 \mathrm{GPa}$. Both the data sets have comparable standard deviations (0.29 GPa for extensometer and 0.27 GPa for optical fiber). Bar graph showing the comparison of modulus of elasticity measured by extensometer and optical fibers is shown in Figure 4.18. Specimen fbg03 had an outlier in unloading 1 cycle, which affected its average modulus in first unloading cycle $(0.286 \mathrm{GPa})$, which in turn affected its average modulus of elasticity. Hence, this value was excluded from Table 4.11. All the other values measured by optical fiber sensors were close to extensometer values. Modulus calculated by embedded optical fiber was consistent with a standard 
deviation of 0.15 GPa. Figure 4.19 shows the bar graph comparing the modulus values as observed by extensometer and optical fiber. All these data points and their comparisons proved that the strain experienced by the material was interpreted successfully by the gratings inscribed in optical fibers. Hence, integration of optical fiber to measure strain during loading condition of material is feasible.

As there were six gratings on the embedded optical fibers, one set of loading cycle of specimen fbg02 was analyzed using all the gratings and the values were compared to the extensometer data. The stress strain curve showing the readings from all the gratings and extensometer for loading cycle is seen in Figure 4.21. The values obtained by the gratings seem to coincide, which is indicative of the fact that one optical fiber with distributed Bragg Gratings can be used for strain measurement at multiple locations within the structure. Modulus of elasticity was calculated for all the gratings and are reported in Table 4.12. The value of E measured by all the gratings are close to each other with standard deviation of $0.077 \mathrm{GPa}$. This shows that all the gratings experienced the same amount of strain during the loading condition. It also proves that the reason for their values being in agreement with that of the extensometer is good bonding between the fiberglass and embedded optical fiber.

Modulus of elasticity measured by all the gratings of embedded optical fiber sensor in specimen fbg03 were calculated and are mentioned in Table 4.13. The average value of modulus of elasticity recorded by the gratings was $16.100 \mathrm{GPa}$ with a standard deviation of $0.273 \mathrm{GPa}$. The strain values measured by the gratings were close to each other as seen in Figure 4.23. The modulus recorded by extensometer was 14.867 GPa. 
Table 4.12: Modulus of elasticity measured by all the gratings in fbg02

\begin{tabular}{|l|l|l|l|}
\hline Source & $\begin{array}{l}\text { Modulus of } \\
\text { Elasticy, E (GPa) }\end{array}$ & Average E (GPa) & $\begin{array}{l}\text { Standard } \\
\text { Deviation (GPa) }\end{array}$ \\
\cline { 1 - 2 } Grating 1 & 12.979 & \multirow{2}{*}{13.061} & \\
\cline { 1 - 2 } Grating 2 & 13.074 & \multirow{2}{*}{0.077} \\
\cline { 1 - 2 } Grating 3 & 13.033 & & \\
\cline { 1 - 2 } Grating 4 & 13.098 & & \\
\cline { 1 - 2 } Grating 5 & 13.188 & & \\
\cline { 1 - 2 } Grating 6 & 12.994 & & \\
\cline { 1 - 2 } Extensometer & 13.805 & &
\end{tabular}

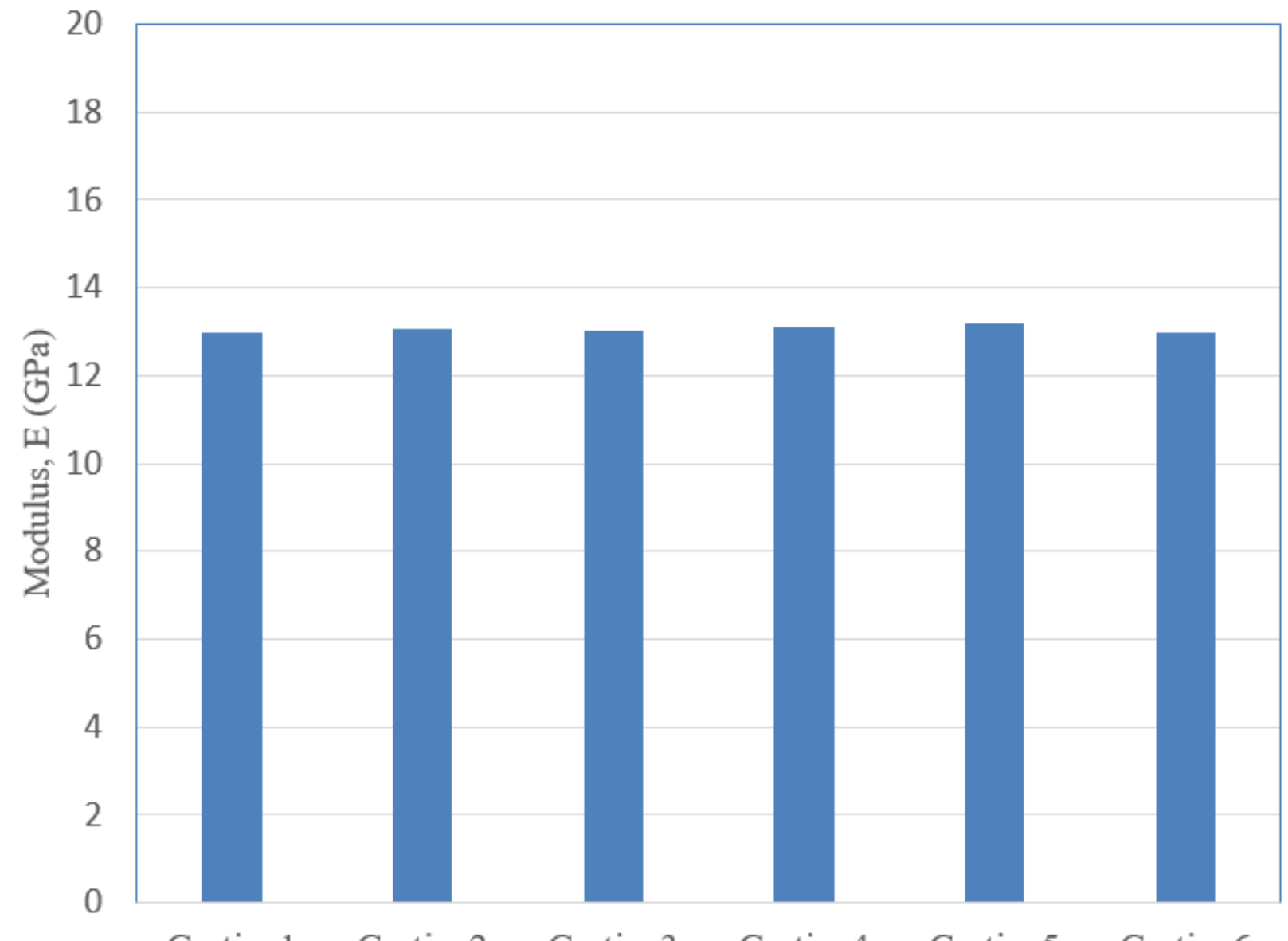

Grating1 Grating2 Grating3 Grating4 Grating5 Grating6

Figure 4.20: Modulus measured by all the gratings in fbg02 


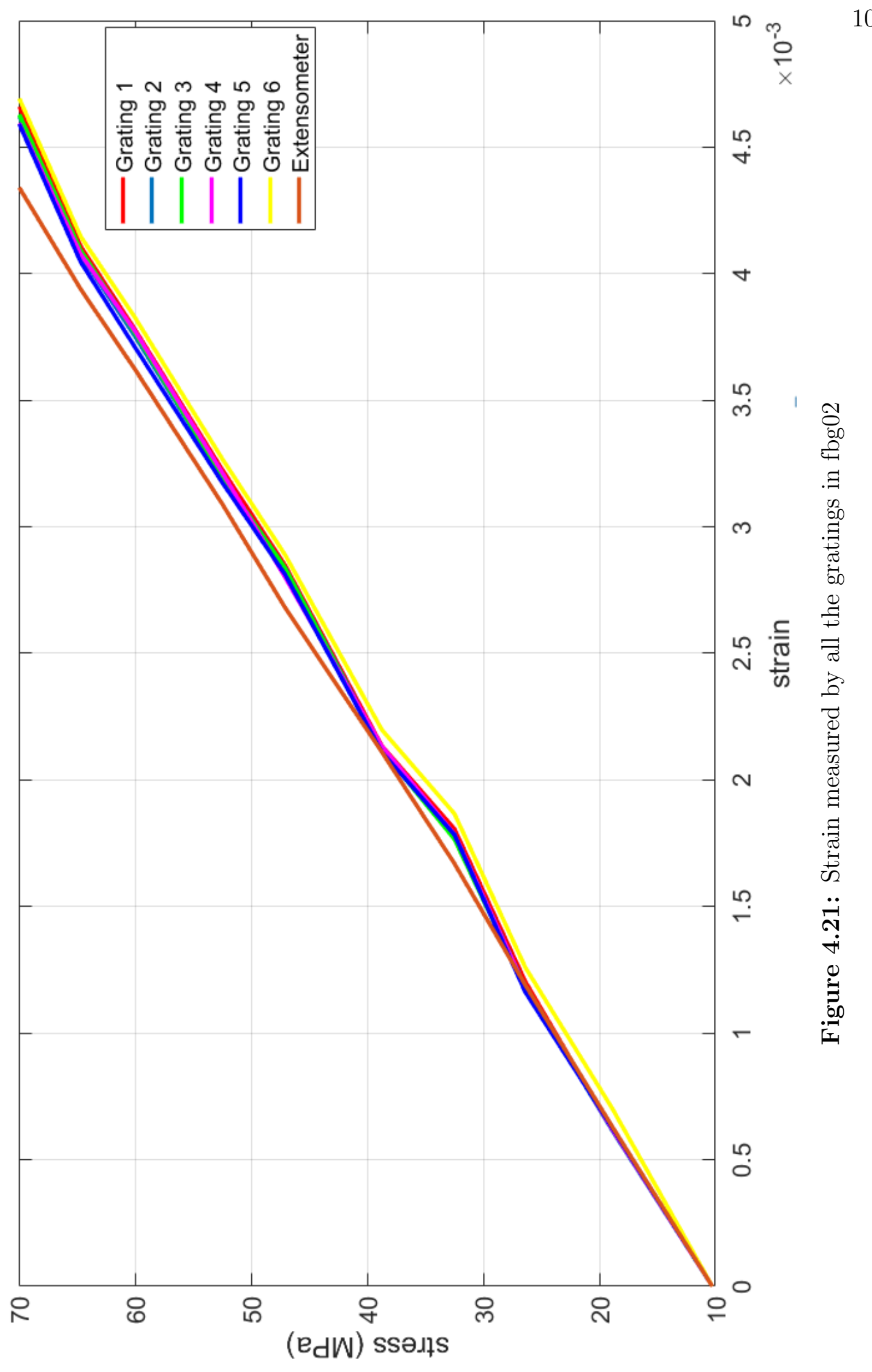


Table 4.13: Modulus of elasticity measured by all the gratings in fbg03

\begin{tabular}{|l|l|l|l|}
\hline Source & $\begin{array}{l}\text { Modulus of } \\
\text { elasticity, E (GPa) }\end{array}$ & Average E (GPa) & $\begin{array}{l}\text { Standard } \\
\text { Deviation (GPa) }\end{array}$ \\
\cline { 1 - 2 } Grating 1 & 15.830 & \multirow{2}{*}{16.100} & \\
\cline { 1 - 2 } Grating 2 & 15.884 & & \multirow{2}{*}{0.273} \\
\cline { 1 - 2 } Grating 3 & 16.245 & & \\
\cline { 1 - 2 } Grating 4 & 15.889 & & \\
\cline { 1 - 2 } Grating 5 & 16.246 & & \\
\cline { 1 - 2 } Grating 6 & 16.507 & &
\end{tabular}

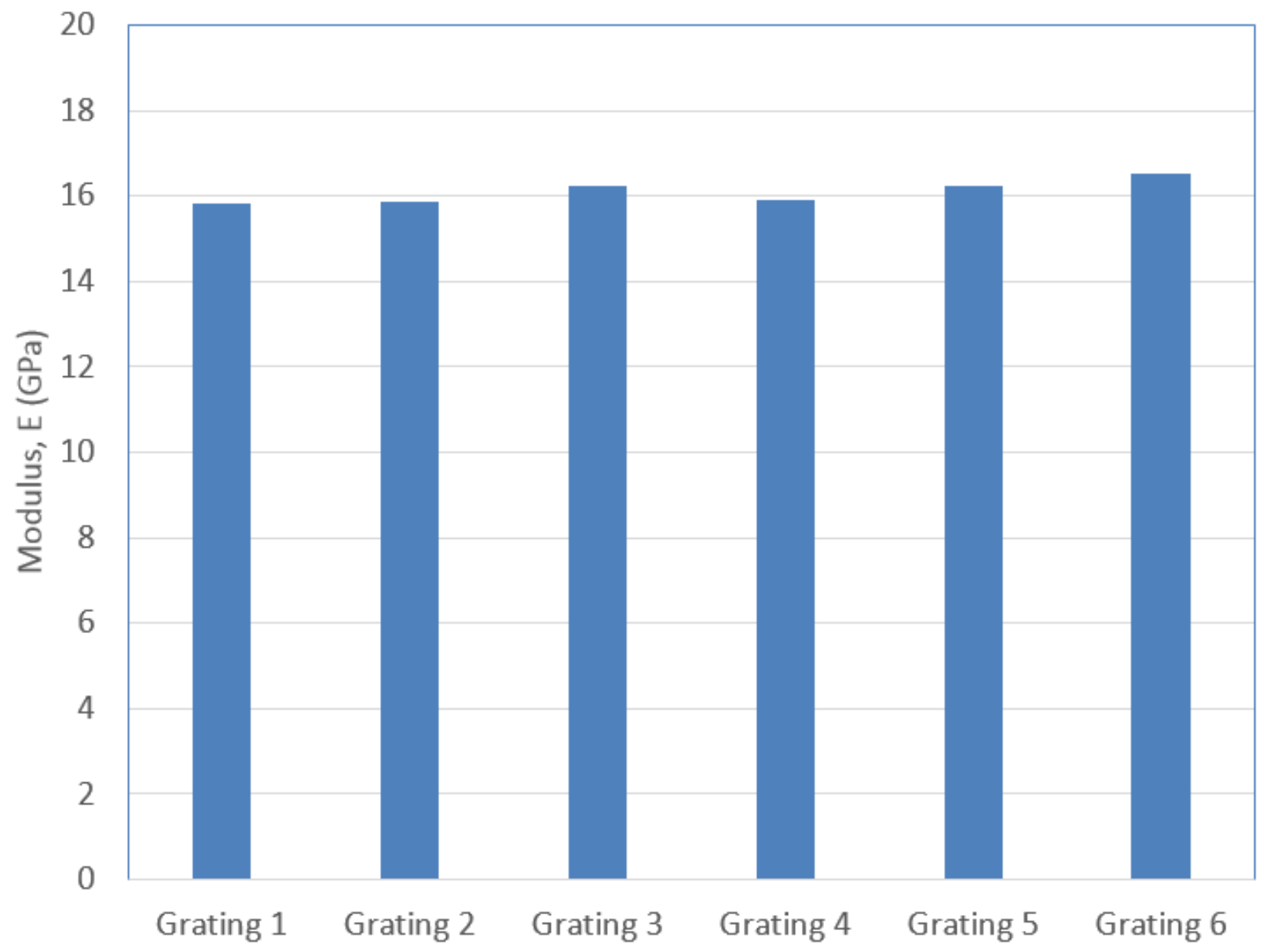

Figure 4.22: Modulus measured by all the gratings in fbg03 


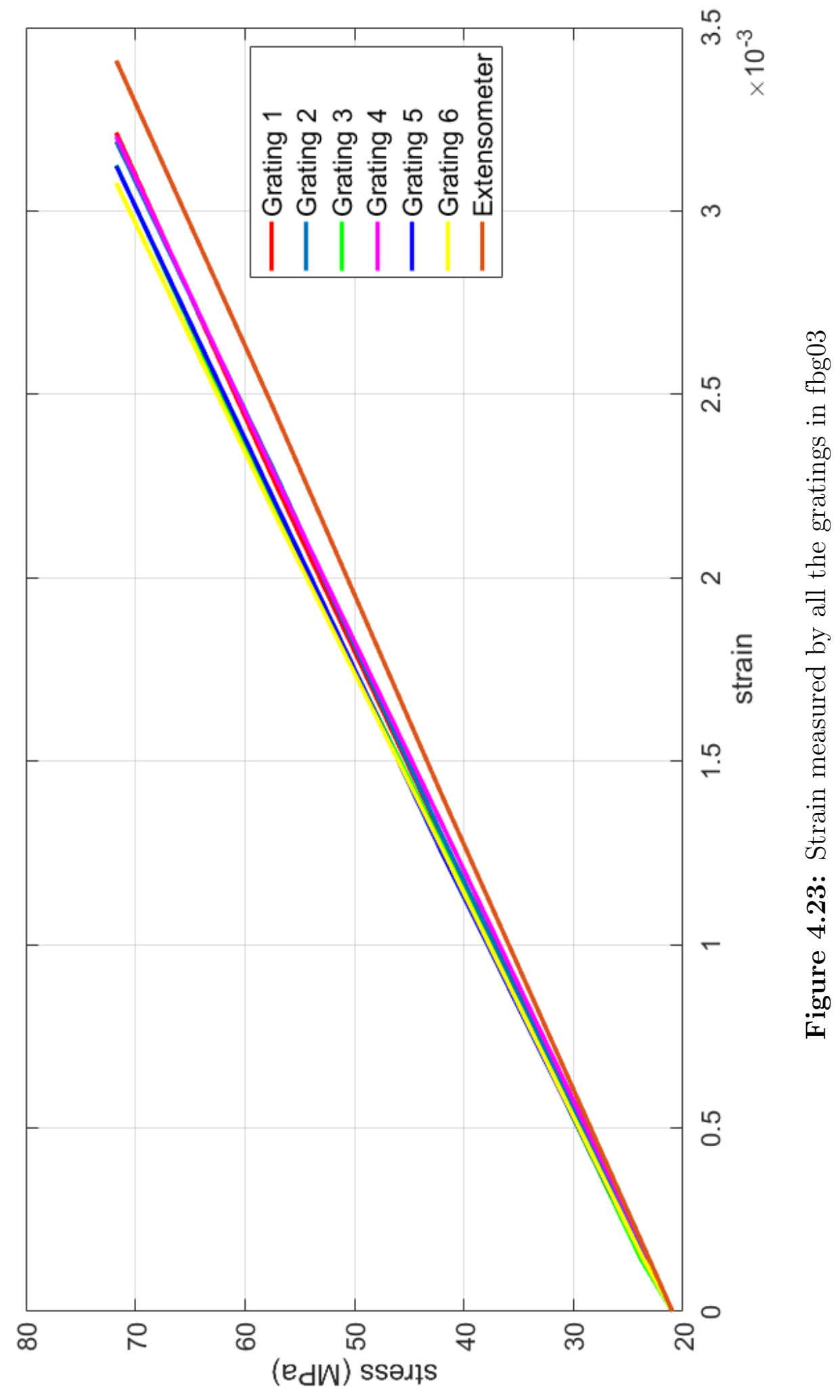




\section{Chapter 5}

\section{Conclusions and Recommendations}

The conclusions drawn from this thesis and the recommendations for future work are discussed in this chapter.

\subsection{Conclusions}

1. Based on available literature, optical fiber was embedded parallel to the ply orientation. This was done because optical fiber embedded in other orientations has an adverse effects on the mechanical properties of the host material.

2. In order to insert optical fiber within the fibers of fiberglass, a sewing needle was used to make a guideway. Embedded optical fibers had ingress and egress points at the ends of this guideway.

3. Optical fibers were placed in between the center plies of fiberglass, which were oriented in the longitudinal direction. As the literature review suggested that there was a deterioration in the tensile values when the optical fibers were not embedded parallel to the fiberglass fabric, the optical fibers were placed in between the plies of $0^{\circ}$ orientation.

4. A unique fixture consisting of five parts was designed to protect ingress and egress points of embedded optical fibers. The parts can be easily assembled and 
disassembled before and after the fabrication process. The optical fiber remained coiled within the fixture during the manufacturing and cutting operation. It was found that the ingress and egress points were safe during the entire process. As the ingress/egress points were used to extract data from the embedded optical fibers to measure the strain experienced by the material, protection of those points was important during manufacturing and cutting process. The design proposed was unique for this research and it successfully served its purpose of protecting the ingress and egress points.

5. Red laser light was used to check the structural integrity of the embedded optical fibers after the specimens were made. Light was sent through one end and its transmission was observed on the other end. This confirmed that the embedded optical fibers remained undamaged during the manufacturing and cutting operation.

6. Tensile tests were conducted on fiberglass with and without embedded optical fibers. The results showed that there was no adverse effect of embedding optical fibers within fiberglass. It was found that modulus of elasticity of both types of specimens were comparable within $10.324 \%$ coefficient of variation.

7. The results of the impact tests showed that the impact energy required to initiate fracture of the specimen was not affected when the specimen had embedded optical fiber in their central plane.

8. The results of the flexural test showed that there was no deterioration in flexural strength and flexural modulus of fiberglass when they had optical fibers embedded within them.

9. The strain values recorded by embedded optical fiber sensors were found to be in good agreement with extensometer data. Modulus of elasticity measured by the optical fibers were comparable to the values measured using an extensometer during loading and unloading cycles. The results showed that embedded optical fiber sensors can be used to measure strain within the material as long as there is strong bonding 
between the sensor and host material.

10. The strain and modulus values shown by all the gratings within the same optical fiber were in agreement with each other, which proved that a single optical fiber sensor can be used to detect strain at various locations in the material.

11. The design of the support fixture successfully protected the ingress and egress points of embedded optical fibers. The strain experienced by the material was recorded by embedded optical fibers. The objective of this research work was met as both the aforementioned goals were achieved. In conclusion, it was shown that optical fibers are a viable option for Structural Health Monitoring of out-of-autoclave composite materials.

\subsection{Recommendations}

The following recommendations were made based on the performed research work:

1. The work involved mechanical testing at room temperature. It would be useful to examine the response of embedded optical fiber sensors at higher and lower temperatures as an aircraft experiences both high and low temperatures during its flight.

2. The fixture designed to protect ingress/egress points can be made from a different material in order to serve its purpose at higher or cryogenic temperatures.

3. Data from embedded optical fibers were extracted using reflectometer, which is a big and heavy instrument. It would be beneficial to use a smaller data acquisition system, which could be easily carried on the aircraft and operated in flights to get real time data.

4. It would be worthwhile to study fatigue tests of composite material with embedded optical fibers to see if the embedment has any effect on the life of material. 
5. The reason for mismatch between the strain values of optical fiber and extensometer should be explored by cutting the fiberglass specimen at various cross sections and observing them under a microscope to inspect the nature of bonding between fiberglass and embedded optical fiber.

6. More mechanical testing on composites with embedded optical fibers should be done to build a statistical database. 


\section{References}

[1] Deo R. B., Starnes Jr J. H., and Holzwarth R. C. Low-cost composite materials and structures for aircraft applications. 2003.

[2] Botelho E. C., Silva R.A., Pardini L.C., and M.C.Rezend. A review on the development and properties of continuous fiber/epoxy/aluminum hybrid composites for aircraft structures. Materials Research, 9(3):247-256, 2006.

[3] Minakuchi S. and Takeda N. Recent advancement in optical fiber sensing for aerospace composite structures. Photonic Sensors, 3(4):345-354, 2013.

[4] Habib F., Martinez M., Artemev A., and Brothers M. Structural health monitoring of bonded composite repairs-a critical comparison between ultrasonic lamb wave approach and surface mounted crack sensor approach. Composites Part B: Engineering, 47:26-34, 2013.

[5] Beukema R.P. Embedding technologies of fbg sensors in composites: Technologies, applications and practical use. In Proceedings of the 6th European Workshop on Structural Health Monitoring, Dresden, Germany, volume 3, 2012.

[6] Wu M.C, Winfree W.P, and Moore J.P. Fiber optic thermal health monitoring of composites. In Proc. SPIE, volume 7648, page 764808, 2010.

[7] Furlong P.A.C. Strain Measurement of Composite Materials Using Fibre Optic Sensors. PhD thesis, Carleton University, Ottawa, 2007.

[8] Glisic B. and Inaudi D. Integration of long-gage fiber optic sensor into a fiberreinforced composite sensing tape. In Smart Structures and Materials, pages 179-186. International Society for Optics and Photonics, 2003.

[9] Anastasi R. F and Lopatin C. Application of a fiber optic distributed strain sensor system to woven e-glass composite. 2001. 
[10] Giurgiutiu V. Structural Health Monitoring of Aerospace Composites. Academic Press, 2015.

[11] Lissenden C. J and Rose J. L. Structural health monitoring of composite laminates through ultrasonic guided wave beam forming. In NATO Applied Vehilce Technology Symp. on Military Platform Ensured Availability Proc, 2008.

[12] Cai J., Liang D., Qiu L., Shi L., Liu P., and Yuan S. Structural Health Monitoring for Composite Materials. INTECH Open Access Publisher, 2012.

[13] Rouchon J. Fatigue and damage tolerance evaluation of structures: the composite materials response, 22nd plantema memorial lecture. In 25th Symposium of the International Committee on Aeronautical Fatigue, volume 27, 2009.

[14] Kalhori H., Ye L., and Mustapha S. Inverse estimation of impact force on a composite panel using a single piezoelectric sensor. Journal of Intelligent Material Systems and Structures.

[15] Boller C. Next generation structural health monitoring and its integration into aircraft design. International Journal of Systems Science, 31(11):1333-1349, 2000.

[16] Ko J.M. and Ni Y.Q. Technology developments in structural health monitoring of large-scale bridges. Engineering structures, 27(12):1715-1725, 2005.

[17] Richards W.L, Parker Jr A. R, Ko W. L, Piazza A., and Chan P. Application of fiber optic instrumentation. 2012.

[18] Fahr A. Aeronautical applications of non-destructive testing. DEStech Publications, Inc, 2013.

[19] Garnier C., Pastor M.L., Eyma F., and Lorrain B. The detection of aeronautical defects in situ on composite structures using non destructive testing. Composite structures, 93(5):1328-1336, 2011.

[20] Cawley P. The rapid non-destructive inspection of large composite structures. Composites, 25(5):351-357, 1994.

[21] Bates D., Smith G., Lu D., and Hewitt J. Rapid thermal non-destructive testing of aircraft components. Composites Part B: Engineering, 31(3):175-185, 2000.

[22] Prosser W.H, Allison S.G, Woodard S.E, Wincheski R.A, Cooper E.G, Price D.C, Hedley M., Prokopenko M., Scott D.A, and Tessler A. Structural health management for future aerospace vehicles. 2004. 
[23] Satori K., Fukuchi K., Kurosawa Y., Hongo A., and Takeda N. Polyimidecoated small-diameter optical fiber sensors for embedding in composite laminate structures. In SPIE's 8th Annual International Symposium on Smart Structures and Materials, pages 285-294. International Society for Optics and Photonics, 2001.

[24] Richards L., Parker A.R, Ko W. L, and Piazza A. Fiber optic wing shape sensing on nasa's ikhana uav. 2008.

[25] Advisory Circular. Circular 20-107b. composite aircraft structure. Federal Aviation Administration, 2009.

[26] Kang H.K, Park J.W, Ryu C.Y, Hong C.S, and Kim C.G. Development of fibre optic ingress/egress methods for smart composite structures. Smart materials and structures, 9(2):149, 2000.

[27] ASTM Standard et al. Standard test method for tensile properties of polymer matrix composite materials. ASTM D3039/D 3039M, 2008.

[28] Brown T.L, Wood K. H, Childers B.A, Cano R.J, Jensen B.J, and Rogowski R.S. Fiber optic sensors for health monitoring of morphing aircraft. In 1999 Symposium on Smart Structures and Materials, pages 60-71. International Society for Optics and Photonics, 1999.

[29] Liu T., Wu M., Rao Y., Jackson D. A, and Fernando G. F. A multiplexed optical fibre-based extrinsic fabry-perot sensor system for in-situ strain monitoring in composites. Smart materials and structures, 7(4):550, 1998.

[30] Shyprykevich P., Fogg B.R, Murphy K.A, and Claus R.O. Performance of extrinsic fabry-perot optical fiber strain sensors in the presence of cyclic loads. In 1993 North American Conference on Smart Structures and Materials, pages 388-399. International Society for Optics and Photonics, 1993.

[31] Glisic B. and Inaudi D. Integration of long-gage fiber optic sensor into a fiberreinforced composite sensing tape. In Smart Structures and Materials, pages 179-186. International Society for Optics and Photonics, 2003.

[32] Pant S. Lamb Wave Propagation and Material Characterization of Metallic and Composite Aerospace Structures for Improved Structural Health Monitoring (SHM). PhD thesis, Carleton University, Ottawa, 2014. 
[33] Panopoulou A., Loutas T., Roulias D., Fransen S., and Kostopoulos V. Dynamic fiber bragg gratings based health monitoring system of composite aerospace structures. Acta Astronautica, 69(7):445-457, 2011.

[34] Kreuzer M. Strain measurement with fiber bragg grating sensors. HBM, Darmstadt, S2338-1.0 e, 2006.

[35] Tennyson R.C, Mufti A.A, Rizkalla S., Tadros G., and Benmokrane B. Structural health monitoring of innovative bridges in canada with fiber optic sensors. Smart materials and Structures, 10(3):560, 2001.

[36] Bueno P. M. Structural Design,FEM Analysis and Manufacturing of a Composite Optic Fibre Instrumented UAV Wing. Masters thesis, TU Delft, 2014.

[37] Samiec D. Distributed fibre-optic temperature and strain measurement with extremely high spatial resolution. Photonik international, 1:10-13, 2012.

[38] Soller B., Peairs D., Sang A., and Fernandez A. Monitoring carbon composite structures with optical fiber sensors. National Aeronautics and Space Administration (NASA) Tech Briefs, 2010.

[39] Zhou D.P, Li W., L.Chen, and Bao X. Distributed temperature and strain discrimination with stimulated brillouin scattering and rayleigh backscatter in an optical fiber. Sensors, 13(2):1836-1845, 2013.

[40] Lee B.H., Kim Y.H, Park K.S, Eom J.B., Kim M.J., Rho B.S., and Choi H.Y. Interferometric fiber optic sensors. Sensors, 12(3):2467-2486, 2012.

[41] Keulen C., Rocha B., Yildiz M., and Suleman A. Embedded fiber optic sensors for monitoring processing, quality and structural health of resin transfer molded components. In Journal of Physics: Conference Series, volume 305, page 012135. IOP Publishing, 2011.

[42] Ramakrishnan M., Rajan G., Semenova Y., and Farrell G. Overview of fiber optic sensor technologies for strain/temperature sensing applications in composite materials. Sensors, 16(1):99, 2016.

[43] Green A.K, Darvish S., and Shafir E. Practical terminations for optical fibres embedded in composite materials. In 3rd International Conference on Intelligent Materials, pages 209-212. International Society for Optics and Photonics, 1996. 
[44] Hong C.S, Park J.W, Ryu C.Y, and Kang H.K. Signal characteristics of efpi in the delaminated composites. In Optical Fiber Sensors, volume 3746, page 192, 1999.

[45] Hadzic R., John S., and I. Herszberg. Structural integrity analysis of embedded optical fibres in composite structures. Composite structures, 47(1):759-765, 1999.

[46] Lee D.C, Lee J.J, and Yun S.J. The mechanical characteristics of smart composite structures with embedded optical fiber sensors. Composite Structures, 32(14):39-50, 1995.

[47] Jensen D.W, Pascual J., and August J.A. Performance of graphite/bismaleimide laminates with embedded optical fibers. part i. uniaxial tension. Smart Materials and Structures, 1(1):24, 1992.

[48] Jensen D.W, Pascual J., and August J.A. Performance of graphite/bismaleimide laminates with embedded optical fibers.part ii. uniaxial compression. Smart Materials and Structures, 1(1):24, 1992.

[49] Pedrazzani J.R., Klute S.M, Gifford D.K, Sang A.K, and Froggatt M.E. Embedded and surface mounted fiber optic sensors detect manufacturing defects and accumulated damage as a wind turbine blade is cycled to failure. Luna Innovations Inc, 2012.

[50] Torres B., Payá-Zaforteza I., Calderó P.A, and Adam J.M. Analysis of the strain transfer in a new fbg sensor for structural health monitoring. Engineering Structures, 33(2):539-548, 2011.

[51] Pilling M.W, Yates B., Black M.A, and Tattersall P. The thermal conductivity of carbon fibre-reinforced composites. Journal of Materials Science, 14(6):1326$1338,1979$.

[52] Huerta E., Corona J.E, Oliva A.I, Avilés F., and González-Hernández J. Universal testing machine for mechanical properties of thin materials. Revista mexicana de física, 56(4):317-322, 2010.

[53] Oliver W.C and Pharr G.M. Measurement of hardness and elastic modulus by instrumented indentation: Advances in understanding and refinements to methodology. Journal of materials research, 19(01):3-20, 2004.

[54] ASTM Standard. D7136: Standard test method for measuring the damage resistance of a fiber-reinforced polymer matrix composite to a drop-weight impact event. ASTM International: West Conshohocken, 2005. 
[55] ASTM Standard. Standard test method for flexural properties of polymer matrix composite materials. ASTM D7264/ D7264-M. 


\title{
Appendix A \\ Model Parameters and Material \\ Properties
}

\author{
A.1 Data sheet of optical fiber
}


CORNING Corning Incorporated

\section{PI1036}

Ixsued: $1 / 99$

Supersedes: 11/98

ISO 9001 Rejistered

GENERAL

Corning ${ }^{6}$ SMF-28 $8^{\mathrm{m}}$ single-mode fiber is considered the "standard" optical fiber for telephory, cable television, submarine, and private network applications in the transmission of data, voice and/or video services. Coming SMF-28 fiber is manufactured to the most demanding specifications in the industry.

SMF-28 fiber is oplimized for use in the $1310 \mathrm{~nm}$ wavelength region. The information-carrying capacity of the fiber is at its highest in this transmission window, and it is also where dispersion is the lowest. SMF-28 fiber also can be used effectively in the $1550 \mathrm{~nm}$ wavelength region.

Corning's enhanced, dual layer acrylate CPC6 coating provides excellent fiber protection and is easy to work with. CPC6 can be mechanically stripped and has an outside diameter of $245 \mu \mathrm{m}$. CPC6 is optimized for use in many single and multi-fiber cable designs including loose tube, ribbon, slotted core, and tight buffer cables.

SMF-28 fiber is manufactured using the Outside Vapor Deposition (OVD) process, which produces a totally synthetic, ultra-pure fiber. As a result, Corning SMF-28 fiber has consistent geometric properties, high strength and low attenuation. Corning SMF-28 fiber can be counted on to deliver excellent performance and high reliability, reel after reel. Measurement methods comply with ITU recommendations G.650, IEC 60793-1 and Bellcore GR-20-CORE.

\section{FEATURES \& BENEFITS}

- Versatility in $1310 \mathrm{~nm}$ and $1550 \mathrm{~nm}$ applications

- Outstanding geometrical properties for low splice loss and high splice yields.

- OVD manufacturing reliability and product consistency.

- Optimized for use in ribbon, loose tube, and other common cable designs.

\section{OPTICAL SPECIFICATIONS}

\section{- Attenuation}

\begin{tabular}{|c|c|c|}
\hline \multirow{2}{*}{\begin{tabular}{c} 
Uncabled Fiber Attenuation Cells \\
\multirow{2}{*}{$\begin{array}{c}\text { Wavelength } \\
(\mathrm{nm})\end{array}$}
\end{tabular}} & \multicolumn{2}{|c|}{ Attenuation Cells (dB/km) } \\
\cline { 2 - 3 } & Premium* & Standard \\
\hline 1310 & $\leq 0.35$ & $\leq 0.40$ \\
\hline 1550 & $\leq 0.25$ & $\leq 0.30$ \\
\hline
\end{tabular}

Point Discontinuity

No point discontinuity greater than

$0.10 \mathrm{~dB}$ at either $1310 \mathrm{~nm}$ or $1550 \mathrm{~nm}$.

Attenuation at the Water Peak

The attenuation at $1383 \pm 3 \mathrm{~nm}$ does not exceed $2.1 \mathrm{~dB} / \mathrm{km}$.

* Lower attenuation avalabie in fimited quantities. 
OPTICAL SPECIFICATIONS, (continued)

\begin{tabular}{|c|c|c|}
\hline \multicolumn{2}{|c|}{ Attenuation vs Wavelength } \\
\hline $\begin{array}{c}\text { Range } \\
(\mathrm{nm})\end{array}$ & $\begin{array}{c}\text { Ref. } \lambda \\
(\mathrm{nm})\end{array}$ & $\begin{array}{c}\text { Max Increase } \\
\alpha(\mathrm{dB} / \mathrm{km})\end{array}$ \\
\hline $1285-1330$ & 1310 & 0.05 \\
\hline $1525-1575$ & 1550 & 0.05 \\
\hline
\end{tabular}

\begin{tabular}{|c|c|c|c|}
\hline \multicolumn{4}{|c|}{ Attenuation Wrth Bending } \\
$\begin{array}{c}\text { Mandrel } \\
\text { Diameter }(\mathrm{mm})\end{array}$ & $\begin{array}{c}\text { Number } \\
\text { of Turns }\end{array}$ & $\begin{array}{c}\text { Wavelength } \\
(\mathrm{nm})\end{array}$ & $\begin{array}{c}\text { Induced } \\
\text { Attenuation (dB) }\end{array}$ \\
\hline 32 & 1 & 1550 & $\leq 0.50$ \\
\hline 75 & 100 & 1310 & $\leq 0.05$ \\
\hline 75 & 100 & 1550 & $\leq 0.10$ \\
\hline
\end{tabular}

- Cable Cutoff Wavelength $\left(\lambda_{\text {ccf }}\right)$

$\lambda_{\text {cef }}<1260 \mathrm{~nm}$
The attenuation in a given wavelength range does not exceed the attenuation of the reference wavelength $(\lambda)$ by more than the value $\alpha$.

- Dispersion

- Mode-Field Diameter

8.80 to $9.80 \mu \mathrm{m}$ at $1310 \mathrm{~nm}$

9.50 to $11.50 \mu \mathrm{m}$ at $1550 \mathrm{~nm}$

Zero Dispersion Wavelength $\left(\lambda_{0}\right): 1301.5 \mathrm{~nm} \leq \lambda_{\mathrm{o}} \leq 1321.5 \mathrm{~nm}$

Zero Dispersion Slope $\left(\mathrm{S}_{\mathrm{o}}\right): \leq 0.092 \mathrm{ps} /\left(\mathrm{nm}^{2} \bullet \mathrm{km}\right)$

\begin{tabular}{|l|c|}
\hline \multicolumn{2}{|c|}{ Fiber Polarization Mode Dispersion (PMD) } \\
\hline & Value $(\mathrm{ps} / \sqrt{\mathrm{km}})$ \\
\hline PMD Link Value & $\leq 0.1^{\star}$ \\
\hline Maximum Individual Fiber & $\leq 0.2$ \\
\hline
\end{tabular}

*Complies with IEC SC 86AWG1, Method 1, September 1997
The induced attenuation due to fiber wrapped around a mandrel of a specified diameter.

\section{Dispersion Caloulation}

Dispersion $=\mathrm{D}(\lambda):=\frac{\mathrm{S}_{\mathrm{o}}}{4}\left[\lambda-\frac{\lambda_{\mathrm{o}}^{4}}{\lambda^{3}}\right] \mathrm{ps} /(\mathrm{nm} \bullet \mathrm{km}), \quad$ for $1200 \mathrm{~nm} \leq \lambda \leq 1600 \mathrm{~nm} \quad \lambda=$ Operating Wavelength

\section{ENVIRONMENTAL SPECIFICATIONS}

\begin{tabular}{|l|c|c|}
\hline \multirow{2}{*}{ Environmental Test Condition } & \multicolumn{2}{|c|}{$\begin{array}{c}\text { Induced } \\
\text { Attenuation (dB/km) }\end{array}$} \\
\cline { 2 - 3 } & $1310 \mathrm{~nm}$ & $1550 \mathrm{~nm}$ \\
\hline $\begin{array}{l}\text { Temperature Dependence } \\
-60^{\circ} \mathrm{C} \text { to }+85^{\circ} \mathrm{C}^{*}\end{array}$ & $\leq 0.05$ & $\leq 0.05$ \\
\hline $\begin{array}{l}\text { Temperature-Humidity Cycling } \\
-10^{\circ} \mathrm{C} \text { to }+85^{\circ} \mathrm{C}^{*}, \text { up to } 98 \% \mathrm{RH}\end{array}$ & $\leq 0.05$ & $\leq 0.05$ \\
\hline Water Immersion, $23^{\circ} \mathrm{C}$ & $\leq 0.05$ & $\leq 0.05$ \\
\hline Heat Aging, $85^{\circ} \mathrm{C}^{*}$ & $\leq 0.05$ & $\leq 0.05$ \\
\hline
\end{tabular}

Operating Temperature Range

$-60^{\circ} \mathrm{C}$ to $+85^{\circ} \mathrm{C}$

${ }^{\star}$ Reference temperature $=+23^{\circ} \mathrm{C}$

Page 2 of 4 PI1036

The PMD link value is a term used to describe the PMD of concatenated lengths of fiber (also known as the link quadrature average). This value is used to determine a statistical upper limit for system PMD performance.

Individual PMD values may change when cabled. Corning's fiber specification supports emerging network design requirements for a $0.5 \mathrm{psec} / \sqrt{\mathrm{km}}$ maximum PMD. 
DIMEN SIONAL SPECIFICATIONS

Standard Length (km/reel): 2.2 - 25.2

"Longer spliced lengths available at a premium.

Glass Geometry

Fiber Curt: $\geq 4.0 \mathrm{~m}$ radius of curvature

Cladding Diameter: $125.0 \pm 1.0 \mu \mathrm{m}$

Core-Clad Concentricity: $\leq 0.5 \mu \mathrm{m}$

Cladding Non-Circularity: $\leq 1.0 \%$

Defined as: $\quad\left[1-\frac{\text { Min. Cladding Diameter }}{\text { Max. Cladding Diameter }}\right] \times 100$

\section{Coating Geometry}

Coating Diameter: $245 \pm 5 \mu \mathrm{m}$

Coating-Cladding Concentricity $<12 \mu \mathrm{m}$

\section{MECHANICAL SPECIFICATIONS}

Proof Test:

The entire length of fiber is subjected to a tensile proof stress $\geq 100 \mathrm{kpsi}\left(0.7 \mathrm{GN} / \mathrm{m}^{2}\right)^{2}$.

- Higher proof test available at a premium.

\section{PERFORMANCE CHARACTERIZATIONS}

Characterized parameters are typical values.

Core Diameter:

$8.3 \mu \mathrm{m}$

Numerical Aperture:

0.13

NA was measured at the one percent power angie of a one-dimensional far-field scan at $1310 \mathrm{~nm}$.

Zero Dispersion Wavelength $\left(\lambda_{0}\right)$ :

$1312 \mathrm{~nm}$

Zero Dispersion Slope $\left(\mathrm{S}_{0}\right)$ :

$0.090 \mathrm{ps} /\left(\mathrm{nm}^{2} \bullet \mathrm{km}\right)$
Refractive Index Difference:

$0.36 \%$

Effective Group Index of Refraction $\left(\mathrm{N}_{\mathrm{eff}}\right)$ :

1.4675 at $1310 \mathrm{~nm}$

1.4681 at $1550 \mathrm{~nm}$

Fatigue Resistance Parameter $\left(\mathbf{n}_{\mathbf{d}}\right)$ :

20

Coating Strip Force:

Dry: $0.6 \mathrm{lbs} .(2.7 \mathrm{~N})$

Wet, 14 days room temperature: 0.6 Ibs. $(2.7 \mathrm{~N})$ 

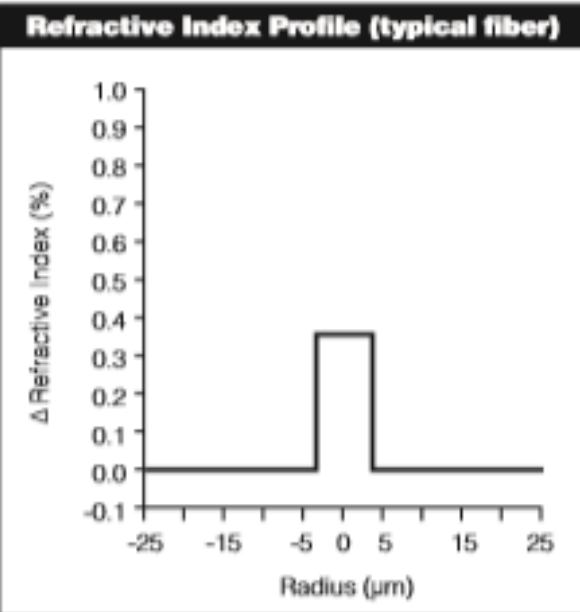

Spectral Attenuation (typleal mber)

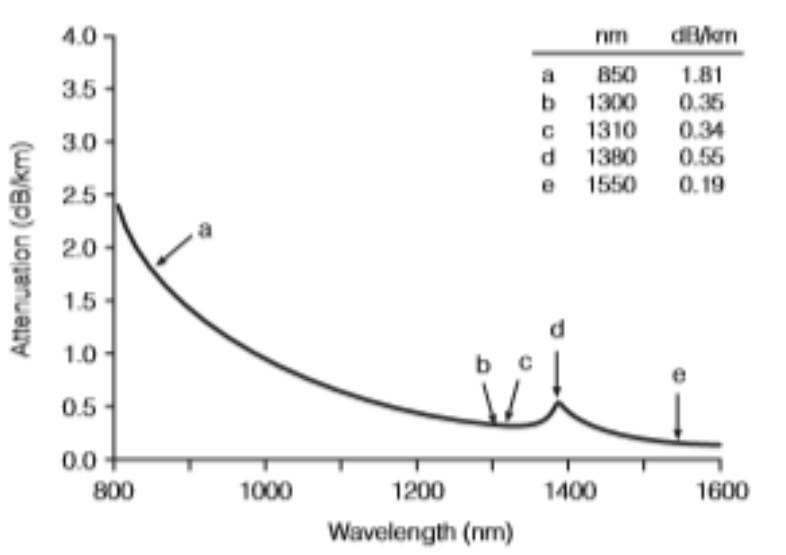

\section{Ordering Information}

To order Corning ${ }^{4}$ SMF-28 $8^{\mathrm{m}}$ optical fiber, contact your sales representative, or call the Telecommunications Products Division Customer Service Department at 910-395-7659 (North America) and +1-607-974-7174 (International). Please specily the following parameters when ordering.

Fiber Type: Corning $^{\circ}$ SMF-28 ${ }^{M}$ single-mode fiber

Coating: CPC6 (245 $\mu \mathrm{m}$ outside diameter)

Fiber Attenuation Cell: $\mathrm{dB} / \mathrm{km}$

Fiber Quantity: kms

Other: (Requested ship date, etc.)

\section{Conitive}

Corning Incorporated

Telecommunications Products Division

Corning, NY 14831 USA

Tel: (910) 395-7659 (North America)

Fax: (910) 395-7286 (North America)

Tel: + 1(607) 974-5354 (International)

Fax: + 1(607) 974-7041 (International)

Email: fibereccorning.com

Internet: www.corningfiber.com 


\section{Appendix B}

\section{Testing parameters}

\section{B.1 Calculation of Young's Modulus Using Com- pliance}

Total compliance $\left(C_{T}\right)$ measured by the crosshead during tensile testing is the sum of the material's compliance $\left(C_{m a t}\right)$ and the machine's compliance $\left(C_{m}\right)$ [52].

$$
C_{T}=C_{m a t}+C_{m}
$$

The load vs displacement curves of stainless steel was plotted using the crosshead and extensometer displacements and can be seen in Figure 3.43. Compliance is the inverse of the slope of the load-displacement curve $[52,53]$. For a test coupon of cross sectional area, $A$ and gage length, $L$, the modulus, $E$ is defined as :

$$
E=\frac{\sigma}{\varepsilon}=\frac{F L}{A \Delta L}
$$

where, $\sigma$ is the stress and $\varepsilon$ is the strain experienced by the material. 


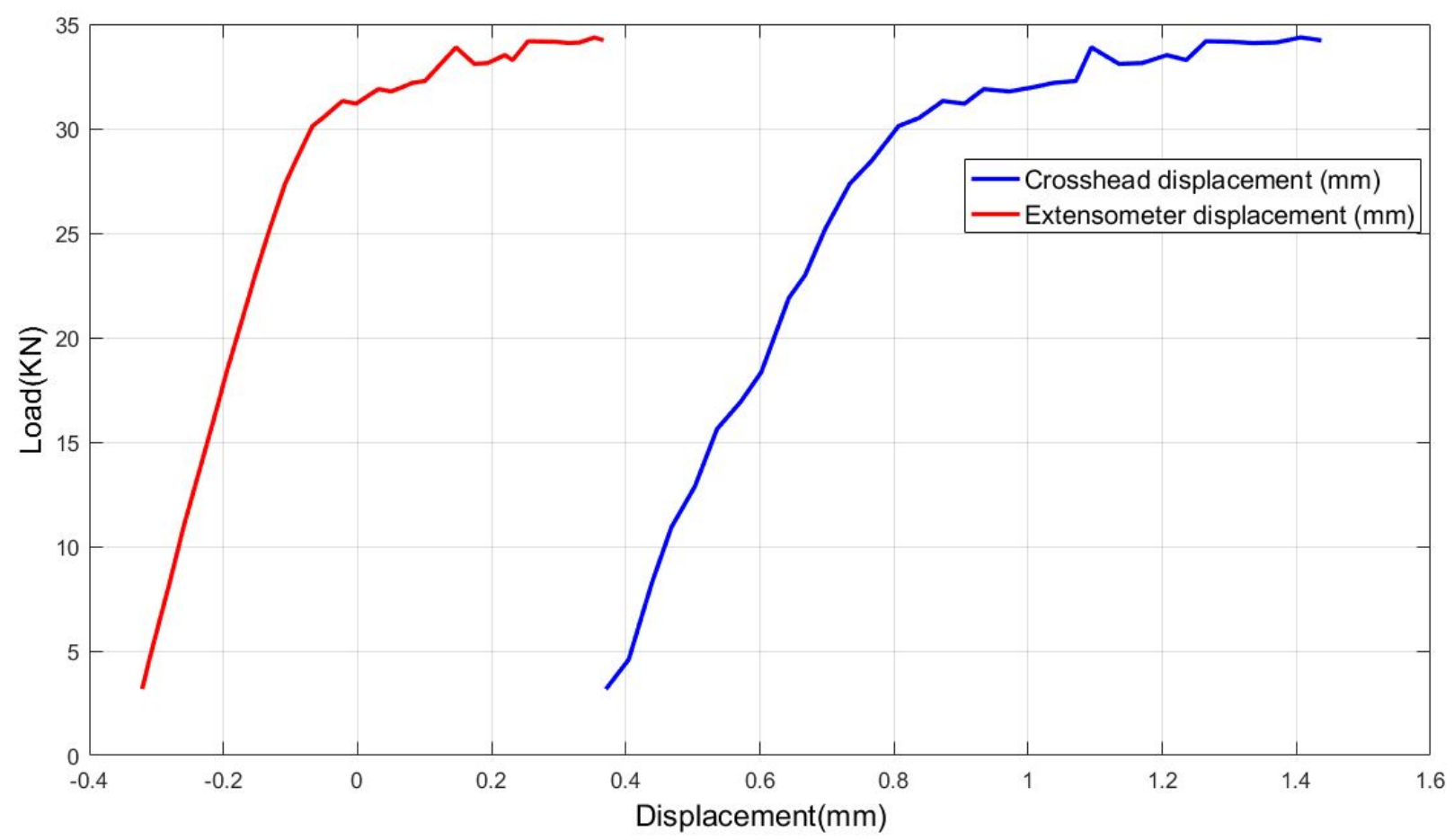

Figure B.1: Load vs displacement for SS304 sample1

From the above expression,

$$
\frac{\Delta L}{F}=\frac{L}{E A}=\text { compliance }
$$

From the first line,

$$
\begin{gathered}
C_{m}=C_{T}-C_{m a t} \\
=\frac{L}{E_{T} A}-\frac{L}{E A} \\
=\frac{E L-E_{T} L}{E E_{T} A}
\end{gathered}
$$




$$
\begin{gathered}
E L-E_{T} L=C_{m} E E_{T} A \\
E-\frac{C_{m} E E_{T} A}{L}=E_{T} \\
E\left(1-\frac{C_{m} E_{T} A}{L}\right)=E_{T} \\
E=\frac{E_{T}}{1-\frac{C_{m} E_{T} A}{L}}
\end{gathered}
$$

This equation is used to calculate modulus of material, $E$ using machine's compliance, $C_{m}$.

\section{B.2 Stress-strain curves}




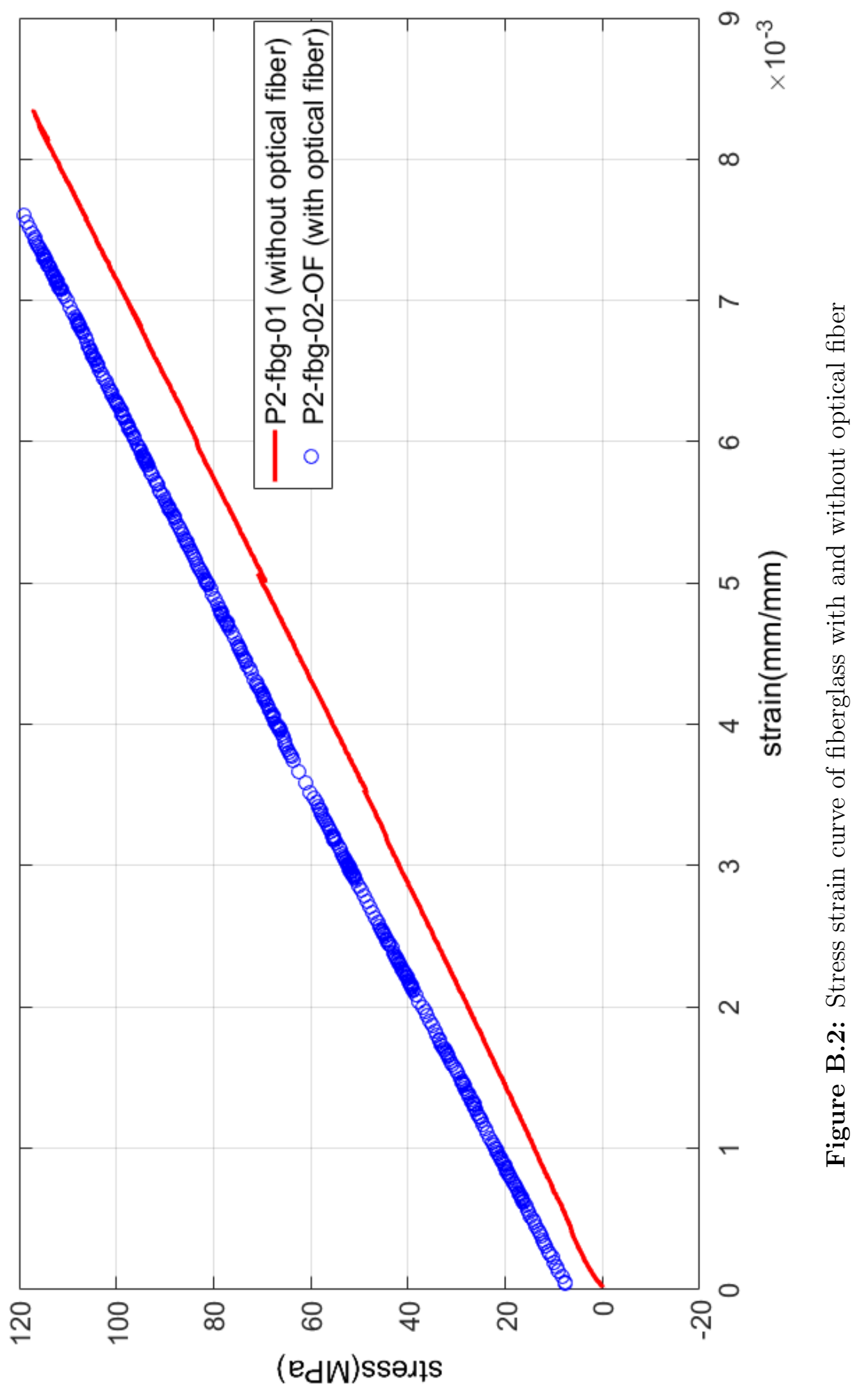




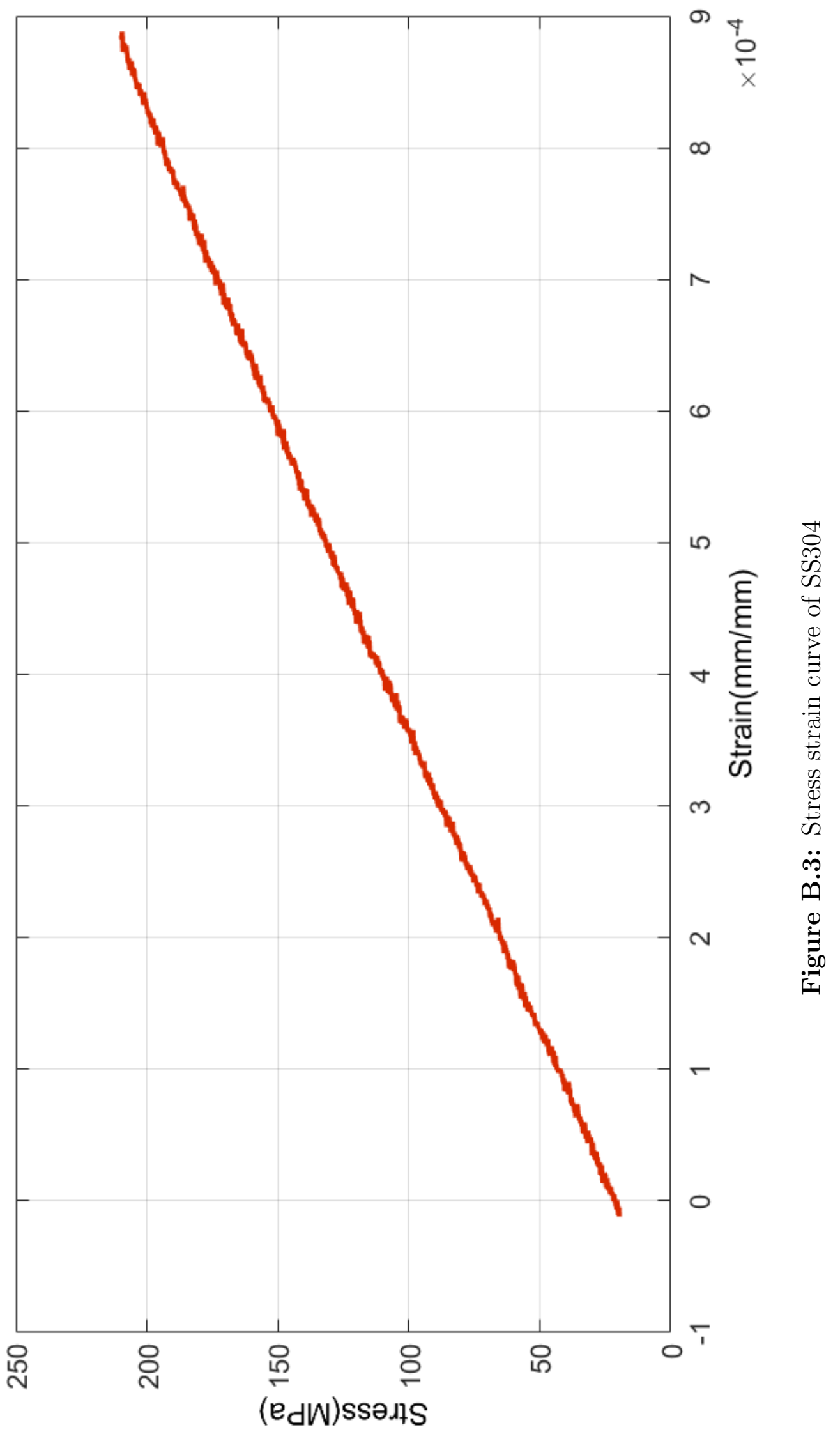




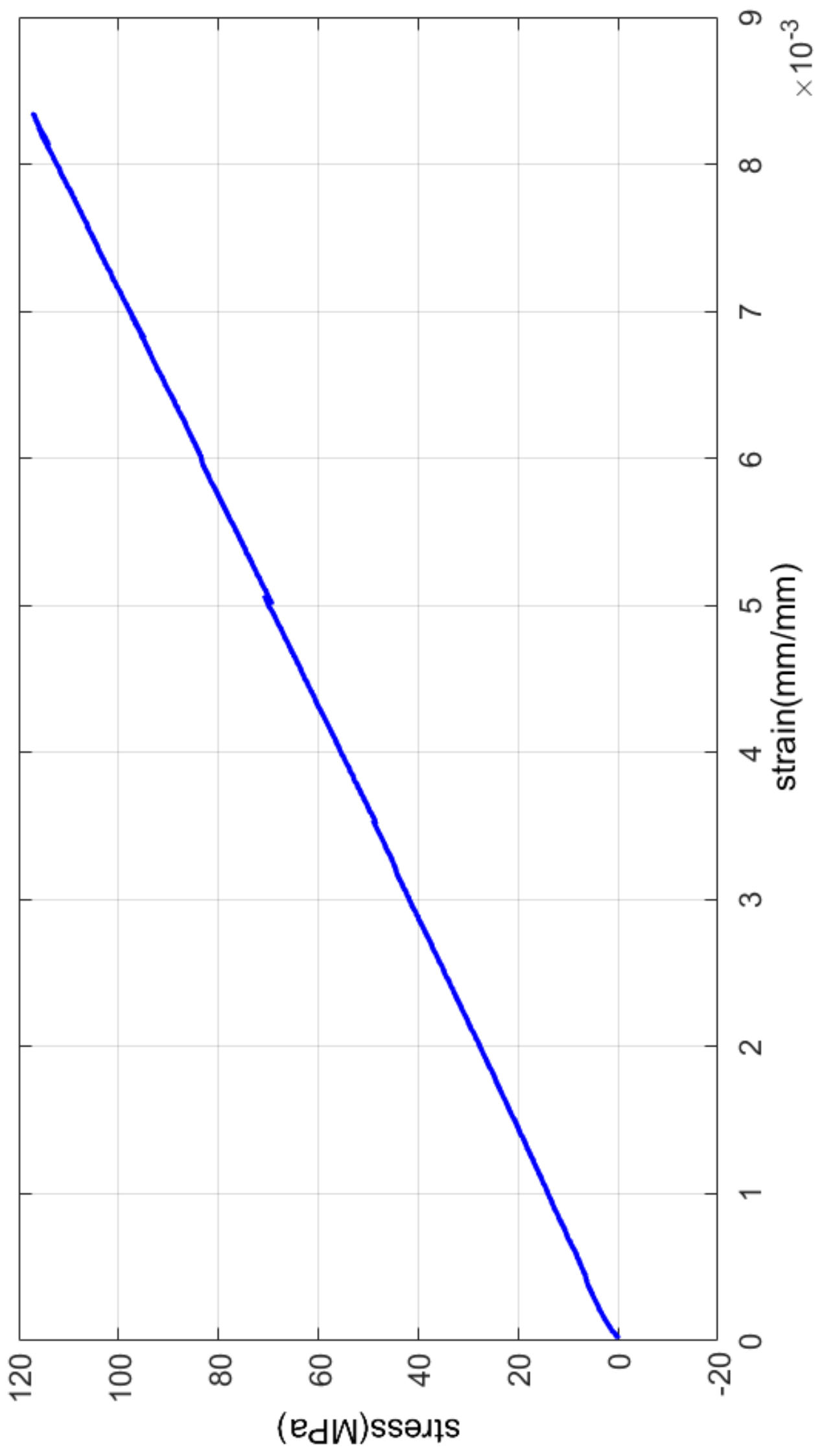

126

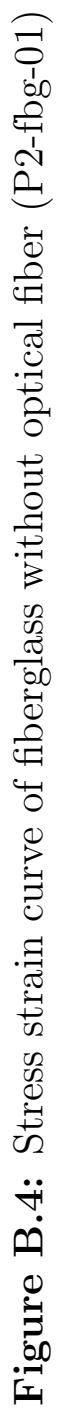




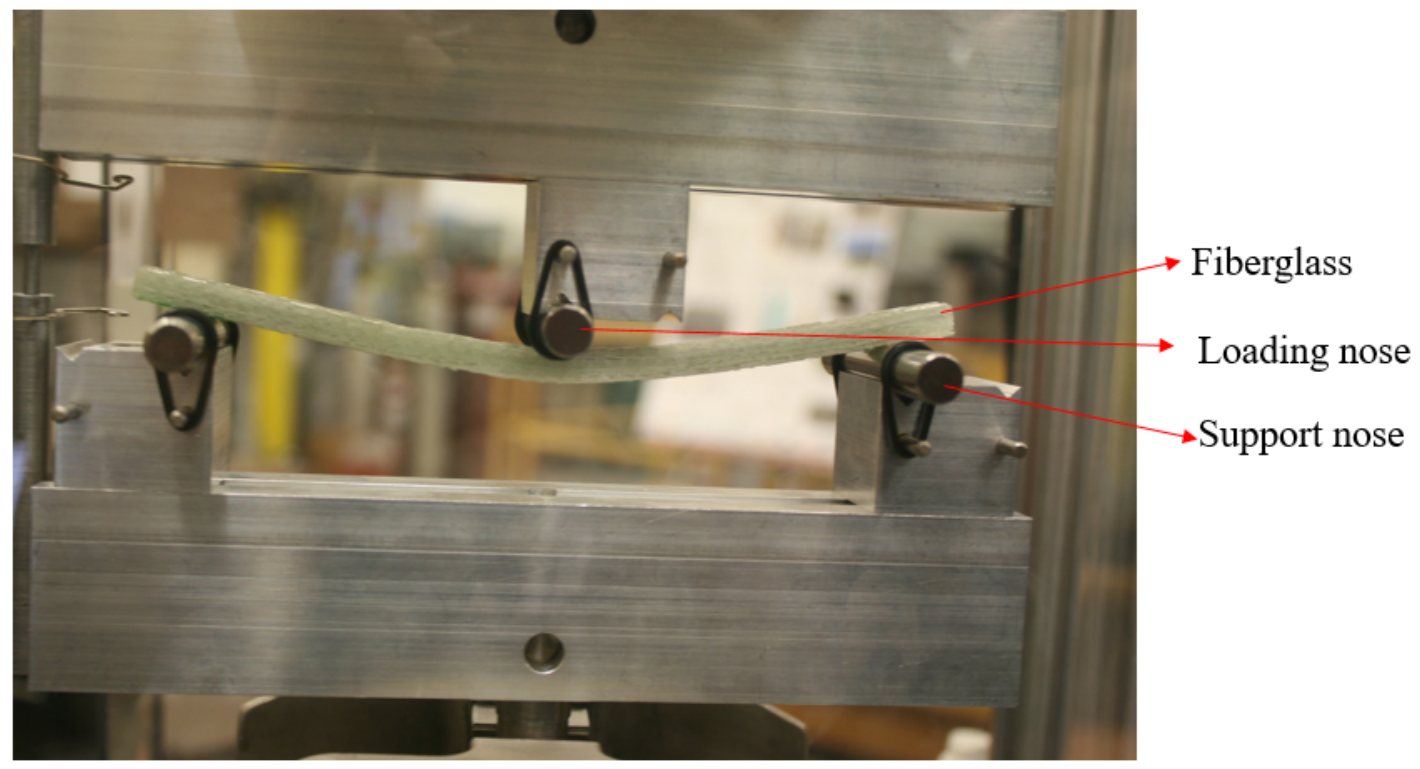

Figure B.5: Flexural test showing failure of fiberglass

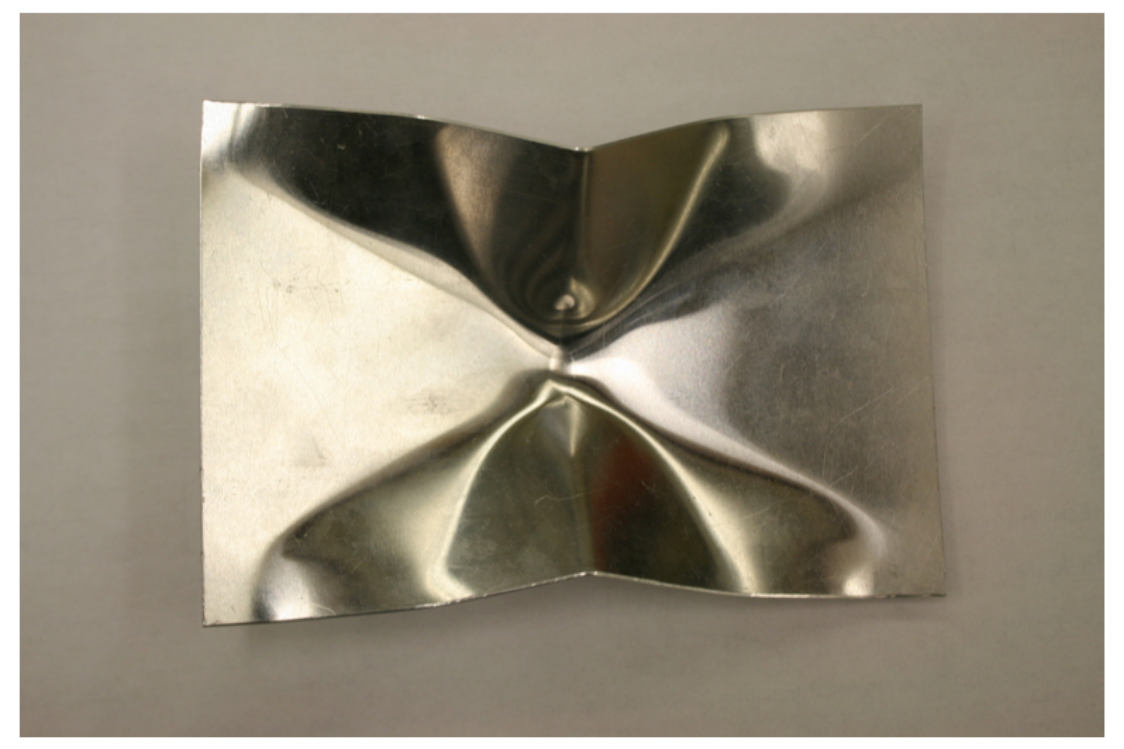

Figure B.6: AA6061 sample (1 mm thick) after impact test 


\section{Appendix $\mathrm{C}$}

\section{Data Sheet of Epoxy Resin}




\section{PT2712 \\ Low Viscosity System for Tough Parts \& Structures}

\section{DESCRIPTION}

PT2712 is a lowviscosity epoxy system designed for the fabrication of parts and structures by the resin infusion method. This system flows extremely well, and produces dense, void-free laminates routinely. The cured properties of this system are very high, so it produces items with good strength and toughness with excellent long-term stability.

Three hardeners areavailable foruse with this resin, which provide a range of workingtimes. The hardeners havegel times of approximately 1 hour, 2 hours and 3 hours, so, by properselection between the three, it is possible to easily infuseany size structure. The three hardeners are identical except for reaction time, so no matter which hardener is chosen, the user can expect the same high performance properties. The mixed viscosity with all three hardeners is just over 300 centipoise, so the material flows very well, even in thin walled areas. It penetrates heavy fabric sections and wets out quickly for further ease of production.

\begin{tabular}{|c|c|c|c|c|c|c|}
\hline & PT2712-A & Part B & Part B1 & Part B2 & Part B3 & $\begin{array}{l}\text { ASTM } \\
\text { Method }\end{array}$ \\
\hline Color & Amber Clear & \multicolumn{4}{|c|}{ Amber } & Visual \\
\hline Viscosity, centipoise & $1000 \mathrm{cps}$ & \multicolumn{3}{|c|}{$25 \mathrm{cps}$} & $60 \mathrm{cps}$ & D2392 \\
\hline Specific Gravity, gms./cc & 1.10 & \multirow{2}{*}{\multicolumn{4}{|c|}{$\begin{array}{l}100: 22 \text { By Weight } \\
4 \text { to } 1 \text { By Volume }\end{array}$}} & D1475 \\
\hline $\begin{array}{ll}\text { Mix Ratio, } & \begin{array}{l}\text { By Weight } \\
\text { By Volume }\end{array}\end{array}$ & & & & & & PTM\&W \\
\hline Pot Life, 4 fl. Oz. Mass @ 77F & & $\begin{array}{l}\sim 1 \text { Hour } \\
\text { (70 min.) }\end{array}$ & $\begin{array}{l}\sim 2 \text { Hours } \\
(122 \mathrm{~min} .)\end{array}$ & $\begin{array}{l}\sim 3 \text { Hours } \\
(175 \mathrm{~min} .)\end{array}$ & $\begin{array}{c}40 \\
\text { minutes }\end{array}$ & D2471 \\
\hline
\end{tabular}

\section{HANDLING and CURING}

The fourhardeners forPT2712 will cure completely at room temperature, if required. In the case of smaller parts and structures made with the faster hardeners B and B3, the material will gel hard ovemight at normal ambienttemperatures. Atthis point in the cure, the bag and ancillary infusion materials can be removed from the laminate and the part can be sanded or trimmed as required. Full cure with these 2 hardeners will be achieved in 4 to 6 days at normal room temperature. Warmer summertemperatures will shorten this cure and a cooler environment will increase cure time.

When using Part B1 or B2, for larger structures, longer time must be given at all cure stages to allow proper curing with this slower reacting hardener. Well over 24 hours at room temperature is required before the structure can be removed and sanded, with the exact time depending upon laminate size and shop environment. Tests with standard laminate samples made with Part B2 hardener have shown that full cured properties are reached in 10 days at $75^{\circ} \mathrm{F}$ for example.

In all instances, a heat cure will shorten the curingtime of PT2712. In situationswhere the laminate can be placed in an oven aftera room temperature gel, curing times of 8 to 10 hours at $180^{\circ} \mathrm{F}$ or 14 to 18 hours at $150^{\circ} \mathrm{F}$ will provide $90 \%$ of full cured properties. When an oven has not been available or practical, due to the size of the structure, for example, structures have been tented with plastic or tarps and then lights or space heaters have been used as the heat source for curing. Also, plywood boxes have been fabricated to enclose the structure for curing in this manner. Experimentation will determine the best method to use for the individual structure and shop conditions.

\section{PACKAGING WEIGHTS}

\begin{tabular}{|c|c|c|c|}
\hline & Gallon Kit & Pail Kit & Drum Kit \\
\hline PT2712 Part A & $9 \mathrm{lb}$. & $36 \mathrm{lb}$. & $500 \mathrm{lb}$. \\
\hline Part B, B1, B2 or B3 & 2 lb. & $8 \mathrm{lb}$. & 111 lb. $(3 @ 37$ lb. \\
\hline
\end{tabular}


PT2712 Infusion Resin System, Page 2

TYPICAL MECHANICAL PROPERTIES

\begin{tabular}{|c|c|c|}
\hline & PT2712 A / B *1 & $\begin{array}{c}\text { ASTM } \\
\text { Method }\end{array}$ \\
\hline $\begin{array}{l}\text { By Weight } \\
\text { By Volume }\end{array}$ & $\begin{array}{c}100: 22 \text { By Weight (All } 4 \text { Hardeners) } \\
4 \text { to } 1 \text { By Volume (All } 4 \text { Hardeners) }\end{array}$ & PTM\&W \\
\hline Pot Life, @ 77॰F & $\begin{array}{l}\text { Part B - } 70 \text { min.; Part B1 - } 122 \text { min.; } \\
\text { Part B2 - } 175 \text { min.; Part B3 - } 40 \text { min. }\end{array}$ & D2471 \\
\hline Color & Light Amber & Visual \\
\hline Mixed Viscosity, centipoise & 320 cps. & D2393 \\
\hline Cured Hardness, Shore D & 86 Shore D & D2240 \\
\hline Specific Gravity, grams, cc & 1.08 & D1475 \\
\hline Tensile Strength, psi & 10,960 psi & \multirow{3}{*}{ D638 } \\
\hline Elongation, $\%$ at Yield & $6.3 \%$ & \\
\hline Tensile modulus, psi & 486,610 psi & \\
\hline Tensile Strength, psi & 41,415 psi & \multirow{3}{*}{ D638 } \\
\hline Elongation, \% at Break & $2.54 \%$ & \\
\hline Tensile modulus, psi & 2,792,062 psi & \\
\hline Flexural Strength, psi & 18,942 psi & \multirow{2}{*}{ D790 } \\
\hline Flexural Modulus, psi & 528,460 psi & \\
\hline Flexural Strength, psi & 54,683 psi & \multirow{2}{*}{ D790 } \\
\hline Flexural Modulus, psi & $2,876,867 \mathrm{psi}$ & \\
\hline Compressive Strength, psi & 15,930 psi & \multirow{2}{*}{ D695 } \\
\hline Compressive Modulus, psi & 491,503 psi & \\
\hline Izod Impact Strength, ft-lbs / in Method A & 1.093 & D256 \\
\hline $\begin{array}{c}\text { Glass Transition Temperature, DMA Tg Onset (E') } \\
\text { Tg Peak }\end{array}$ & $\begin{array}{l}161^{\circ} \mathrm{F} \\
204^{\circ} \mathrm{F}\end{array}$ & D4065 \\
\hline Thermal Coefficient of Expansion, Range: $40^{\circ} \mathrm{C}$ to $60^{\circ} \mathrm{C}$ & $5.42 \times 10^{-5}$ in./in. ${ }^{\circ} F$ & D696 \\
\hline
\end{tabular}

*1: The 4 Hardeners for PT2712 are Functionally Identical Except for Reaction Time, so Cured Properties are The Same for All.

-2: Tensile and Flexural Properties were Determined with a 1/8 inch Laminate Style 7500 Boat \& Tooling Fiberglass Cloth, Resin Content of 40\%.

\section{SAFETY and HANDLING}

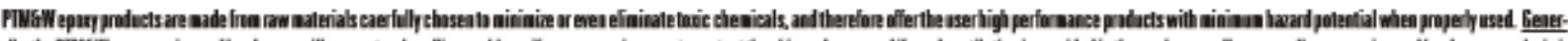

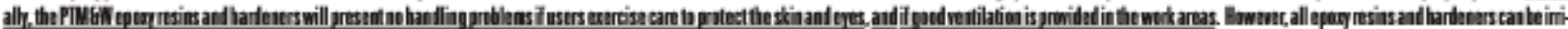

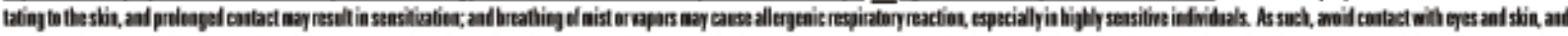

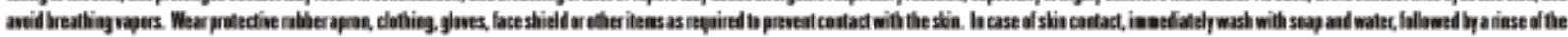

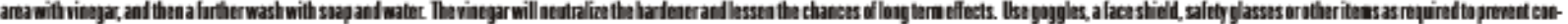

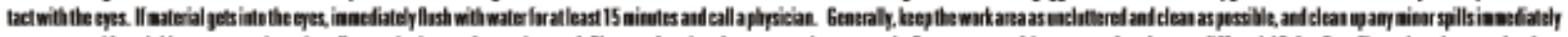

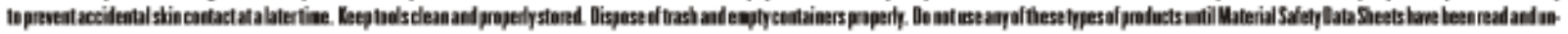
destrai.

PT2712 Bulletin / ZW-41 /031808-C3
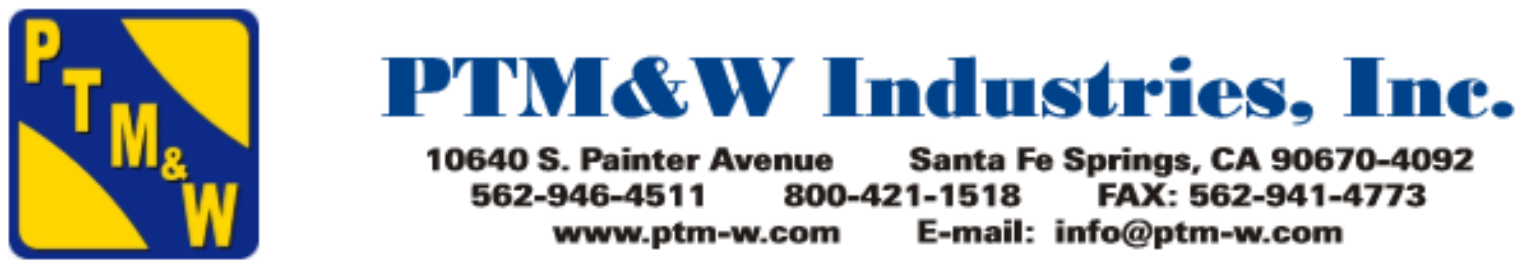

10640 S. Painter Avenue Santa Fe Springs, CA 90670-4092

562-946-4511 800-421-1518 FAX: 562-941-4773

www.ptm-w.com E-mail: info@ptm-w.com 